LOCKHEED MATTIN

ENVIRONMENTAL RESTORATION PROGRAM

\section{RECEIVED}

\author{
MAR 201996
}

OSTI

\section{Toxicological Benchmarks} for Potential Contaminants of Concern for Effects on Soil and Litter Invertebrates and Heterotrophic Process 
This report has been reproduced directly from the best available copy.

Available to DOE and DOE contractors from the Office of Scientific and Technical Information, P.O. Box 62, Oak Ridge, TN 37831; prices available from 615-576-8401 (fax 615-576-2865).

Available to the public from the National Technical Information Service, U.S.

Department of Commerce, 5285 Port Royal Rd., Springfield, VA 22161. 


\title{
Toxicological Benchmarks for Potential Contaminants of Concern for Effects on Soil and Litter Invertebrates and Heterotrophic Process
}

\author{
M.E. Will
}

G. W. Suter II

Date Issued-September 1995

\section{Environmental Restoration Risk Assessment Program} Lockheed Martin Energy Systems, Inc.

Oak Ridge, Tennessee 37831

\section{Prepared for the}

\section{U.S. Department of Energy}

Office of Environmental Management under budget and reporting code EW 20

\section{LOCKHEED MARTIN ENERGY SYSTEMS, INC.}

$$
\text { managing the }
$$

Environmental Management Activities at the

Oak Ridge K-25 Site Paducah Gaseous Diffusion Plant

Oak Ridge Y-12 Plant Portsmouth Gaseous Diffusion Plant

Oak Ridge National Laboratory under contract DE-AC05-84OR21400

for the

U.S. DEPARTMENT OF ENERGY 


\section{PREFACE}

This report presents a standard method for deriving benchmarks for the purpose of "contaminant screening," performed by comparing measured ambient concentrations of chemicals. The work was performed under Work Breakdown Structure 1.4.12.2.3.04.07.02 (Activity Data Sheet 8304). In addition, this report presents sets of data concerning the effects of chemicals in soil on invertebrates and soil microbial processes, benchmarks for chemicals potentially associated with United States Department of Energy sites, and literature describing the experiments from which data were drawn for benchmark derivation.

\section{DISCLAIMER}

This report was prepared as an account of work sponsored by an agency of the United States Government. Neither the United States Government nor any agency thereof, nor any of their employees, makes any warranty, express or implied, or assumes any legal liability or responsibility for the accuracy, completeness, or usefulness of any information, apparatus, product, or process disclosed, or represents that its use would not infringe privately owned rights. Reference herein to any specific commercial product, process, or service by trade name, trademark, manufacturer, or otherwise does not necessarily constitute or imply its endorsement, recommendation, or favoring by the United States Government or any agency thereof. The views and opinions of authors expressed herein do not necessarily state or reflect those of the United States Government or any agency thereof. 


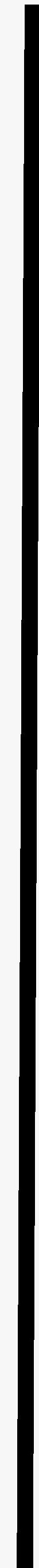




\section{ACKNOWLEDGMENTS}

The authors would like to thank Carla Gunderson and Art Stewart for their helpful reviews of the document. In addition, the authors would like to thank Christopher Evans for conducting part of the literature review. 


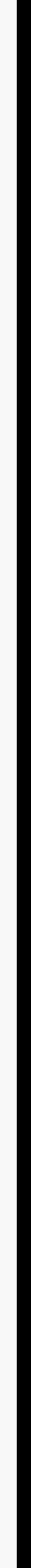




\section{CONTENTS}

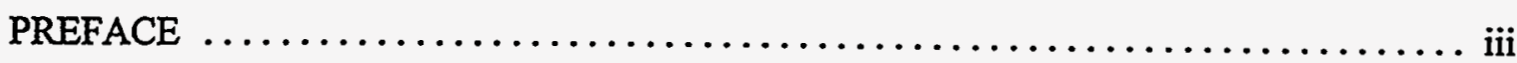

ACKNOWLEDGMENTS $\ldots \ldots \ldots \ldots \ldots \ldots \ldots \ldots \ldots \ldots \ldots \ldots \ldots \ldots \ldots \ldots$



ABBREVIATIONS $\ldots \ldots \ldots \ldots \ldots \ldots \ldots \ldots \ldots \ldots \ldots \ldots \ldots \ldots \ldots \ldots \ldots \ldots \ldots \ldots$

EXECUTTVE SUMMARY $\ldots \ldots \ldots \ldots \ldots \ldots \ldots \ldots \ldots \ldots \ldots \ldots \ldots \ldots \ldots \ldots \ldots \ldots \ldots \ldots$

1. SCREENING BENCHMARKS IN ECOLOGICAI RISK ASSESSMENT $\ldots \ldots \ldots \ldots$ 1-1

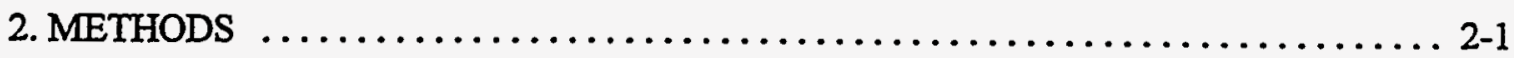

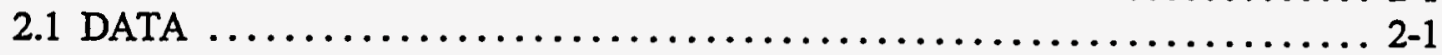

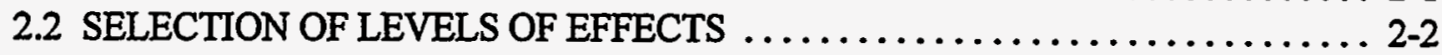

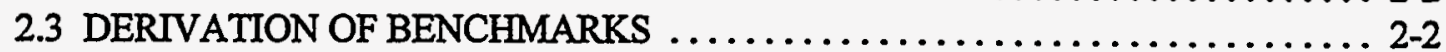



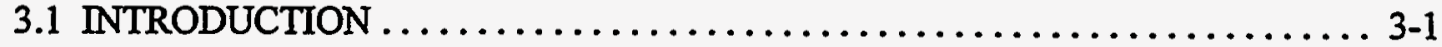

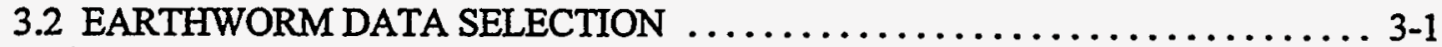

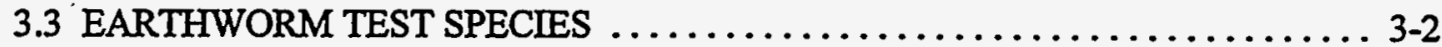

3.4 EARTHWORM DATA AND BENCHMARK DERIVATION $\ldots \ldots \ldots \ldots \ldots \ldots . . \ldots$

3.4.1 Inorganic Compounds ................................ 3-3

3.4 .2 Organic Compounds . .............................. 3-9

4. MICROBIAL HETEROTROPHS AND PROCESSES $\ldots \ldots \ldots \ldots \ldots \ldots \ldots \ldots \ldots \ldots$. 4

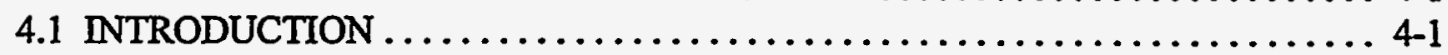



4.3 MICROBE DATA AND BENCHMARK DERIVATION $\ldots \ldots \ldots \ldots \ldots \ldots \ldots \ldots$ 4-2

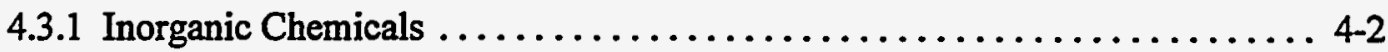

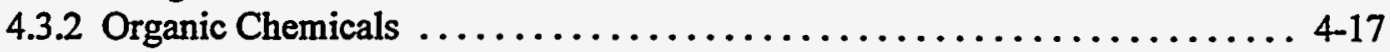

5. INVERTEBRATES OTHER THAN EARTHWORMS AND MICROBIAL

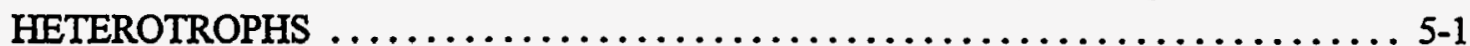

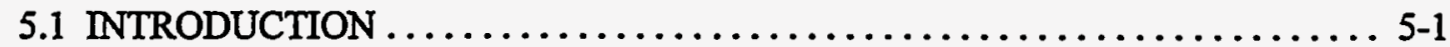

5.2 INVERTEBRATE DATA SELECTION $\ldots \ldots \ldots \ldots \ldots \ldots \ldots \ldots \ldots \ldots \ldots$ 5-1

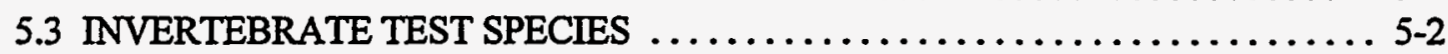

5.4 OTHER INVERTEBRATES LITERATURE REVIEW $\ldots \ldots \ldots \ldots \ldots \ldots \ldots$.

6. RELATIONSHIP BETWEEN SOIL TOXICITY BENCHMARKS AND OTHER ECOTOXICOLOGICAL CRITERIA ......................... 6-1

6.1 COMPARISON OF TOXICITY BENCHMARKS FOR CONTAMINANTS IN SOIL TO CANADIAN ENVIRONMENTAL QUALITY CRITERIA FOR CONTAMINATED SITES $\ldots \ldots \ldots \ldots \ldots \ldots \ldots \ldots \ldots \ldots \ldots \ldots .6 .6 .1$ 
6.2 COMPARISON OF TOXICITY BENCHMARKS FOR CONTAMINANTS IN SOIL TO RIVM (NETHERLANDS) ECOTOXICOLOGICAL INTERVENTION VALUES FOR CONTAMINANTS IN SOILS $\ldots \ldots \ldots \ldots \ldots \ldots \ldots \ldots \ldots \ldots \ldots \ldots \ldots, 6-1$

7. COMPARISON OF TOXICITY BENCHMARKS FOR CONTAMINANTS IN SOIL TO CONCENTRATIONS OF CHEMICALS IN UNPOLLUTED SOILS . ......... 7-1

7.1 COMPARISON TO USGS ELEMENT CONCENTRATIONS IN SOILS AND OTHER SURFICIAL MATERIALS OF THE EASTERN UNITED STATES $\ldots . .7-1$

7.2 COMPARISON TO DOE OAK RIDGE RESERVATION BACKGROUND SOIL CHARACTERIZATION ELEMENT CONCENTRATIONS IN SOILS ....... 7-1

8. RECOMMENDATIONS AND CONCLUSIONS $\ldots \ldots \ldots \ldots \ldots \ldots \ldots \ldots \ldots \ldots$ 8-1

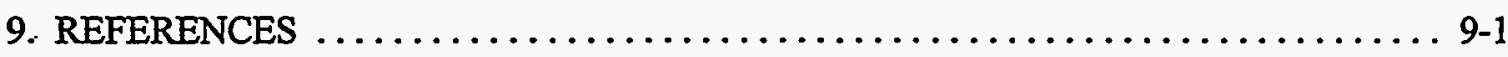




\section{TABLES}

1. Screening benchmark concentrations for the toxicity of chemicals to earthworms ... 2-4

2. Screening benchmark concentrations for the toxicity of chemicals to soil microorganisms

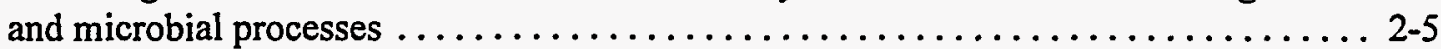

3. Comparison of screening benchmark concentrations for the toxicity to earthworms and soil microbes of chemicals in soil to CCME remediation criteria (RC), RIVM ecotoxicological intervention values (EIV's), arithmetic means of elements in uncontaminated soils of the Oak Ridge Reservation (ORR), and geometric means of elements in soils and surficial materials of the eastern U.S. 
, 


$\begin{array}{ll}\text { CCME } & \text { Canadian Council of Ministers of the Environment } \\ \text { CEC } & \text { Cation Exchange Capacity } \\ \text { CERCLA } & \text { Comprehensive Environmental Response, Compensation, and Liability Act } \\ \text { DOE } & \text { United States Department of Energy } \\ \text { EIV } & \text { Ecotoxicological Intervention Value } \\ \text { EPA } & \text { United States Environmental Protection Agency } \\ \text { ER-L } & \text { Effects Range Low } \\ \text { HCl } & \text { Hydrochloric Acid } \\ \text { LCT } & \text { Lowest Concentration Tested } \\ \text { LOEC } & \text { Lowest Observed Effect Concentration } \\ \text { NOEC } & \text { No Observed Effect Concentration } \\ \text { OECD } & \text { Organization for Economic Cooperation and Development } \\ \text { ORR } & \text { Oak Ridge Reservation } \\ \text { PAH } & \text { Polycyclic Aromatic Hydrocarbon } \\ \text { PCB } & \text { Polychlorinated Biphenyl } \\ \text { RC } & \text { Remediation Criteria } \\ \text { RIVM } & \text { National Institute of Public Health and Environmental Protection } \\ \text { USGS } & \text { United States Geological Survey }\end{array}$





\section{EXECUTIVE SUMMARY}

One of the initial stages in ecological risk assessments for hazardous waste sites is the screening of contaminants to determine which of them are worthy of further consideration as "contaminants of potential concern." This process is termed "contaminant screening." It is performed by comparing measured ambient concentrations of chemicals to benchmark concentrations. Currently, no standard benchmark concentrations exist for assessing contaminants in soil with respect to their toxicity to soil- and litter-dwelling invertebrates, including earthworms, other micro- and macroinvertebrates, or heterotrophic bacteria and fungi. This report presents a standard method for deriving benchmarks for this purpose, sets of data concerning effects of chemicals in soil on invertebrates and soil microbial processes, and benchmarks for chemicals potentially associated with United States Department of Energy sites. In addition, literature describing the experiments from which data were drawn for benchmark derivation. Chemicals that are found in soil at concentrations exceeding both the benchmarks and the background concentration for the soil type should be considered contaminants of potential concern. 



\section{SCREENING BENCHMARKS IN ECOLOGICAL RISK ASSESSMENT}

An important step in ecological risk assessments is screening the chemicals occurring on a site for contaminants of potential concern. Screening may be accomplished by comparing reported ambient concentrations to a set of toxicological benchmarks. Multiple endpoints for assessing risks posed by soil-borne contaminants to organisms directly impacted by them have been established. Benchmarks for toxic effects of contaminants on terrestrial plants are presented in a companion manuscript (Will and Suter, 1994). This report presents benchmarks for soil invertebrates and microbial processes and addresses only chemicals found at United States Department of Energy (DOE) sites. No benchmarks for pesticides are presented.

If a chemical's concentration or reported detection limit exceeds the screening benchmark, additional analysis may be needed to determine the hazards posed by that chemical (i.e., it is a contaminant of potential concern). However, if the chemical's concentration or detection limit falls below the proposed benchmark, the chemical may be ignored during further study unless public concern or ancillary evidence suggest that it should be retained.

Soil benchmarks are based on data provided by toxicity studies in the field or, more commonly, in laboratory settings. The reported toxic concentrations are not all equivalent to concentrations reported from field sites. Most of the soil concentrations of metals reported from waste sites are from extractions with hydrochloric acid $(\mathrm{HCl})$ or other mineral acids which are intended to provide estimates of total concentrations. Similarly, concentrations of organic contaminants in waste site soils are total concentrations derived from rigorous extractions by solvents. In some cases, toxicity tests report contaminant concentrations extracted from soils, but various extractants are used that may not yield total concentrations. More commonly, the concentrations reported are nominal concentrations of a soluble form (i.e., a highly bioavailable form) of the chemical added to soil. We have chosen to use nominal concentrations from the literature to compare to the "total" extracted quantities of a chemical reported for waste sites.

These benchmarks are appropriate for contaminant screening purposes only. An assessor must realize that soil and invertebrate characteristics play a large part in toxicity and incorporate these site-specific considerations in the evaluation of the potential hazards of a chemical. If chemical concentrations reported in soils supporting many earthworms exceed one or more of the benchmarks presented in this report, or if a benchmark is exceeded by background soil concentrations, it is generally safe to assume that the benchmark is a poor measure of risk to earthworms at that site.

After discussing methods, this report presents the results of the literature reviews and benchmark derivation for toxicity to earthworms (Sect. 3), heterotrophic microbes and their processes (Sect. 4), and other invertebrates (Sect. 5). The final sections compare the benchmarks to other criteria and background and draw conclusions concerning the utility of the benchmarks. 


$$
1-2
$$




\section{METHODS}

\subsection{DATA}

References on the toxicity of selected chemicals to soil and litter dwelling invertebrates, microbes, and microbial processes were obtained from searches of bibliographic data bases (BIOSIS, POL TOX I), review articles, and conventional literature searching. The target was reports of toxicity tests of individual chemicals in laboratory, greenhouse, or field settings. Data presented in this report were derived mainly from primary sources. More specific information on the types of effects data available for each group of organisms is given in the appropriate section of this report. The general criteria for inclusion of a study in the data set used to derive toxicity benchmarks follow.

1. Methodology was clearly stated (especially concentrations of applied chemicals) and followed in the experiment.

2. Results were quantified as measures of survivorship, growth, respiration, reproduction, substrate transformation, or enzyme activity.

3. Results were presented in numeric form, or graphical presentations of data were clearly interpretable.

4. An unambiguous reduction existed in the measured parameter within the range of applied concentrations of the chemical of interest.

The data selected for soil benchmarks using these criteria appear in Appendix A through Appendix C. Data were collected in the following categories for analysis:

1. Chemical-The effects of individual chemicals of interest were analyzed. In the case of metals, the metal itself is listed in the "Chemical" field. For organics, the compound is listed in the "Chemical" field.

2. Chemical Form-The form in which the chemical was added to the experimental medium (e.g., soluble salt, organic).

3. Growth Medium-Substrate in which organisms were kept during the experiment. The media included natural and artificial soil, manure, soil/litter microcosms, and other experimental substrates.

4. Cation exchange capacity is the sum of the exchangeable cations that a soil can adsorb, expressed as milliequivalents per $100 \mathrm{~g}$ of soil. Soil organic and inorganic constituents contain negatively charged sites that are the location of important interactions with positively charged ions in soil solution. These interactions affect the toxicity of many contaminants.

5. Organic matter-Soil organic matter is important in reactions of many contaminants in the soil. Percentage organic carbon, if given, was converted to the more frequently cited 
measure of percentage organic matter by the equation (Nelson and Sommers, 1982):

\%organic carbon $\times 2=\%$ organic matter

6. Soil pH-The $\mathrm{pH}$ of the soil exerts control over chemical reactions that affect speciation and bioavailability of chemicals

7. Species-The species of earthworm, other invertebrate, or microorganism is necessary when provided. However, most microbiological experiments were conducted with an undefined, mixed native microflora.

8. Exposure duration-How long the organisms were exposed to the test chemical.

9. NOEC Applied-The no observed effect concentration (NOEC) is defined as the highest applied concentration of the chemical of interest causing a reduction of $20 \%$ or less in a measured response.

10. LOEC Applied-The lowest observed effect concentration (LOEC) is defined as the lowest applied concentration of the chemical of interest causing a greater than $20 \%$ reduction in a measured response. In some cases, the LOEC for the test was the lowest concentration tested $\left(\mathrm{LCT}\right.$ ) or the only concentration reported, as when the $\mathrm{EC}_{50}$ (or $\mathrm{ED}_{50}$ ) was reported.

11. Growth parameter-Response varied with the type of organism and experiment.

12. Percent decrease-Percent decrease in measured parameter compared to control organism.

\subsection{SELECTION OF LEVELS OF EFFECTS}

Twenty percent reduction in growth, reproduction, or activity was used as the threshold for significant effects to be consistent with other screening benchmarks for ecological risk assessment and with current regulatory practice (Suter, 1992). In brief, most regulatory criteria are based on concentrations in toxicity tests that cause effects which are statistically significantly different from controls. On average, these concentrations correspond to greater than $20 \%$ effects. In addition, regulatory actions may be based on comparisons of biological parameters measured on contaminated sites to those from reference sites. Differences between sites generally must be greater than $20 \%$ to be reliably detected in such studies. Therefore, the $20 \%$ effects level is treated as a conservative approximation of the threshold for regulatory concern.

\subsection{DERIVATION OF BENCHMARKS}

Because of the diversity of soils, species, chemical forms, and test procedures, it is impossible to estimate concentrations that would constitute a threshold for toxic effects on the invertebrate communities at particular sites from published toxicity data. This situation is analogous to the problem of deriving benchmarks for sediments. In this report, the method used for deriving soil benchmarks is based on the National Oceanographic and Atmospheric Administration's method for deriving the Effects Range Low (ER-L) (Long and Morgan, 1990) which has been recommended as a sediment screening benchmark by the U.S. Environmental Protection Agency (EPA) Region IV. 
The ER-L is the tenth percentile of the distribution of various toxic effects thresholds for various organisms in sediments.

This approach can be justified by assuming that the toxicity of a chemical in soil is a random variate, the toxicity of contaminated soil at a particular site is drawn from the same distribution, and the assessor should be $90 \%$ certain of protecting organisms growing in the site soil. Any bias in the data set would mitigate against that assumption. In this implementation of the approach, the bias most likely to be significant is the use of soluble salts of metals in the toxicity tests which are likely to be more toxic than the mixture of forms encountered in field soils. That bias would result in conservative benchmark values. Other possible sources of bias include the exclusion of synergistic and antagonistic effects resulting from interactions between chemicals, use of a limited number of test species that may not be representative of those in the field, use of artificial soils that may not be representative of soils in general, and other laboratory test conditions that may not berepresentative of field conditions. The direction and magnitude of these potential biases is unknown.

The toxicity benchmarks were derived by rank ordering the LOEC values and then picking a number that approximated the 10th percentile. As with the ER-Ls, statistical fitting was not used because there was seldom sufficient data and because these benchmarks are to be used as screening values and do not require the consistency and precision of regulatory criteria. If there were 10 or fewer values for a chemical, the lowest LOEC was used. If there were more than 10 values, the 10th percentile LOEC value was used. If the 10th percentile fell between LOEC values, a value was chosen by interpolation. Since these benchmarks are intended to be thresholds for significant effects on growth and production, test endpoints that indicate a high frequency of lethality are not appropriate. Therefore, when a benchmark is based on an $\mathrm{LC}_{50}$ or on some other endpoint that includes a $50 \%$ or greater reduction in survivorship, the value is divided by a factor of 5; this factor is based on the authors' expert judgment. Although no data exist for comparison of lethal and sublethal effects concentrations in tests conducted with the same species and soils, it is assumed that a factor of 5 can be used to approximate the ratio $\mathrm{LC}_{50} / \mathrm{EC}_{20}$.

In all cases, benchmark values were rounded down to one significant figure. This rounding was done for two reasons. First, it is not appropriate to ascribe greater precision to a number than it actually possesses; these benchmarks are very imprecise. Second, the rounding serves to emphasize the fact that the benchmarks are conceptually distinct from the test endpoint values from which they were derived. That is, an LOEC may be a precise estimate of the lowest toxic concentration for a particular plant variety in a particular test system, but when an LOEC is used as a benchmark for all plants in field soils, it is a qualitatively different and much more poorly defined value.

Benchmarks were derived in the previously described manner for earthworms and microbial heterotrophs. Insufficient information was available for establishing benchmarks for other invertebrates, as discussed in the appropriate section of this report. Proposed screening benchmarks for toxic effects of contaminants in soils are presented in Table 1 (earthworms) and Table 2 (microbial populations). 


$$
2-4
$$

Table 1. Screening benchmark concentrations for the toxicity of chemicals to earthworms

\begin{tabular}{lc}
\hline CHEMICAL & SOIL \\
& $(\mathrm{mg} / \mathrm{kg})$ \\
\hline & \\
Arsenic & 60 \\
Cadmium & 20 \\
Chromium & 0.4 \\
Copper & 50 \\
Lead & 500 \\
Mercury & 0.1 \\
Nickel & 200 \\
Selenium & 70 \\
Zinc & 200 \\
\hline & \\
Chloroacetamide & 2 \\
3-chloroaniline & 30 \\
2,4-dichloroaniline & 100 \\
3,4-dichloroaniline & 20 \\
2,4,5-trichloroaniline & 20 \\
2,3,5,6-tetrachloroaniline & 20 \\
Pentachloroaniline & 100 \\
1,2-dichloropropane & 700 \\
Dimethylphthalate. & 200 \\
Fluorene & 30 \\
N-nitrosodiphenylamine & 20 \\
Phenol & 30 \\
4-nitrophenol & 7 \\
3-chlorophenol & 10 \\
3,4-dichlorophenol & 20 \\
2,4,5-trichlorophenol & 9 \\
2,4,6-trichlorophenol & 10 \\
2,3,4,5-tetrachlorophenol & 20 \\
Pentachlorophenol & 4 \\
Chlorobenzene & 40 \\
1,4-dichlorobenzene & 20 \\
1,2,3-trichlorobenzene & 20 \\
1,2,4-trichlorobenzene & 20 \\
1,2,3,4-tetrachlorobenzene & 10 \\
Pentachlorobenzene & 20 \\
Nitrobenzene & 40 \\
\hline & \\
& \\
\hline
\end{tabular}




\section{$2-5$}

Table 2. Screening benchmark concentrations for the toxicity of chemicals to soil microorganisms and microbial processes

\begin{tabular}{lc}
\hline CHEMICAL & SOIL \\
& $(\mathrm{mg} / \mathrm{kg})$ \\
\hline & \\
Aluminum & 600 \\
Arsenic & 100 \\
Barium & 3000 \\
Boron & 20 \\
Cadmium & 20 \\
Chromium & 10 \\
Cobalt & 1000 \\
Copper & 100 \\
Fluorine & 30 \\
Iron & 200 \\
Lanthanum & 50 \\
Lead & 900 \\
Lithium & 10 \\
Manganese & 100 \\
Mercury & 30 \\
Molybdenum & 200 \\
Nickel & 90 \\
Selenium & 100 \\
Silver & 50 \\
Tin & 2000 \\
Titanium & 1000 \\
Tungsten & 400 \\
Vanadium & 20 \\
Zinc & 100 \\
Acrylonitrile & 1000 \\
Carbon tetrachloride & 1000 \\
Cis-1,4-dichloro-2-butene & 1000 \\
Hexachlorobenzene & 1000 \\
Nitrobenzene & 1000 \\
Phenol & 100 \\
Pentachlorophenol & 50 \\
Trans-1,4-dichloro-2-butene & 1000 \\
\hline & \\
& \\
& \\
&
\end{tabular}


This method of deriving screening benchmarks for soil organisms may appear as insufficiently conservative. This impression might result from the fact that the derivation of the benchmark (like the derivation of the ER-L values) implies a significant effect on approximately $10 \%$ of the species. However, the method probably is sufficiently conservative for the following reasons. First, the benchmarks were derived for a community-level assessment endpoint. Given the water, nutrient, or physical limitations of most soil- and litter-dwelling communities, a reduction in survival, growth, or reproduction of $10 \%$ of earthworm species or reduction of the rates of $10 \%$ of microbial processes is likely to be acceptable. Second, the benchmarks derived by these methods have proved to be conservative in practice. In some cases, the benchmarks are lower than background concentrations (Sect. 7). It is believed that this is caused by the fact that the benchmarks are based on toxicity tests that dose growth substrates with soluble salts of metals which are more available than most naturally occurring metals and even metals at many, if not most, waste sites.

The authors have attempted to assign levels of confidence to the benchmarks; these are presented with the appropriate chemicals in Sect. 3. The criteria best reflecting that confidence are as follows:

1. Low Confidence-Benchmarks based on fewer than 10 literature values.

2. Moderate Confidence-Benchmarks based on 10 to 20 literature values.

3. High Confidence-Benchmarks based on more than 20 literature values.

High confidence in a benchmark based on more than 20 reported toxic concentrations may be reduced to moderate if the range of plant, earthworm, or microbial species tested is narrow (i.e., no tree species or only one family of plants was tested). Moderate or high confidence benchmarks were in some instances demoted one level if the value approximating the 10th percentile was the lowest concentration tested and caused a greater than 30\% reduction in the measured growth parameter. These criteria may seem arbitrary, but the result is a confidence classification that fairly reflects the authors' professional judgment.

Any scheme for deriving a set of standard ecotoxicological benchmarks is based on assumptions that may be questioned by readers. The procedure used herein is consistent with current regulatory practice and contains a minimum of assumptions or factors. Readers who care to make other assumptions or add safety factors may make use of the data presented herein to calculate their own benchmarks. 


\section{EARTHWORMS}

\subsection{INTRODUCTION}

Earthworms are probably the most important soil invertebrate in promoting soil fertility (Edwards, 1992). Their feeding and burrowing activities break down organic matter and release nutrients and improve aeration, drainage, and aggregation of soil. Earthworms are also important components of the diets of many higher animals.

Earthworms are known to take up many inorganic and organic soil contaminants. Availability of contaminants for uptake from the soil is controlled by soil characteristics. van Gestel (1992) concludes that, with the exception of extremes in $\mathrm{pH}$, it is not possible to predict metal availability on the basis of soil variables. Availability of contaminants from plant litter in varying degrees of decomposition is also complex and poorly understood. The feeding and burrowing habits of earthworms determine their exposure to chemicals in soil and litter. Geophagus organisms (those taking in large amounts of soil during feeding on well-decomposed organic material) and those living on or near the soil surface may have greater exposure to organic chemicals than worms feeding on litter pulled down into burrows in the subsoil (Curl et al., 1987). Organic contaminants may undergo oxidation by the cytochrome $\mathrm{P}-450$ and other enzyme systems within the earthworm. Earthworms also may bind xenobiotics and their metabolites in unextractable forms (Stenersen, 1992). Physiological response mechanisms to metals are species specific (Tomlin, 1992). Much of the ingested lead, cadmium, and zinc (the three most studied inorganic contaminants) is accumulated in chloragogenous tissue (intestinal wall) of the posterior alimentary canal (Morgan et al., 1993). Little is known about mechanisms of toxicity of chemicals in earthworms.

\subsection{EARTHWORM DATA SELECTION}

Information suitable for calculating screening benchmarks was available for a limited number of metals and a larger number of organic compounds. Toxic effects information on polychlorinated biphenyls (PCBs) is not available and is limited for polycyclic aromatic hydrocarbons (PAHs). The toxicity of many agricultural pesticides has been tested, but as stated previously, they will not be presented herein. Data on which the benchmarks are based are given in Appendix A; benchmarks are given in Table 1.

Only experiments in which earthworms were exposed to soil (natural or artificial mixture of natural components), soil/litter microcosms, or manure were considered for determining benchmark levels of contaminants in soils. The main alternative method is the contact filter paper test in which the organisms are placed on filter paper containing the chemical to be tested for toxicity. Results are presented as $\mathrm{mg}$ chemical per $\mathrm{cm}^{2}$ filter paper and are therefore not comparable to results given as concentrations (mg per kg substrate). The test gives information about skin contact toxicity but not oral ingestion toxicity (Reinecke, 1992). Although uptake through the cuticle is considered an important uptake route for some organic chemicals (Stenersen, 1992), oral ingestion is an important uptake route for metals and organic compounds found in soil and litter. Heimbach (1988) reports that there is little correlation between contact paper test and OECD artificial soil test results. Good correlation between the OECD artificial soil test and field tests are reported for several pesticides (Heimbach, 1992). 
Acute and chronic toxicity are tested for in experiments evaluating the effects of chemicals on earthworms. Mortality is the main endpoint in acute toxicity tests with results reported as the concentration causing death in $50 \%$ of the test population $\left(\mathrm{LC}_{50}\right)$. In the case of organic compounds, most of the literature reports $\mathrm{LC}_{50}$ values.

Change of individual body weight, which may indicate sublethal effects, can also be measured during acute toxicity tests. Endpoints that indicate effects important to population dynamics include cocoon production, cocoon hatching rates, and juvenile survival (Kokta, 1992). It should be noted that several researchers have found a negative correlation between adult body weight and reproduction (Kokta, 1992), and the conclusion is that these characteristics should be investigated together.

\subsection{EARTHWORM TEST SPECIES}

Experiments on the toxicity of chemicals to earthworms have been performed with representatives of three families (Megascolecidae, Eudrilidae, and Lumbricidae) and 12 species representing earthworms from Europe and North America, Africa, India, and Asia.

The most commonly used earthworm, Eisenia fetida, is a nonburrowing organism found in compost piles and other organic-rich environments (Lee, 1985). They belong to the epigeic ecological category of Bouche (1992). Eisenia fetida may be the most prolific of worms with a shorter lifespan than others of the Lumbricidae family. Its natural habitat may be under the bark of fallen trees, and protozoa may be an essential part of its diet (Lee, 1985). Eisenia andrei is considered a sibling species of $E$. fetida by most researchers (Bouche, 1992); however, it has been treated as a subspecies of $E$. fetida by others in the past (van Gestel and $\mathrm{Ma}, 1988$ ). These earthworms are considered ideal for toxicity testing because of the ease with which populations are maintained in the laboratory. The short generation time of $E$. fetida allows investigation of effects of chemicals on reproduction and second generation survival.

Lumbricus rubellus is a shallow-burrowing lumbricid active in the surface and litter horizons of pastures and grasslands (Lee, 1985). It may forage for food, such as dead roots, in the subsurface horizon and dig deep burrows in which to rest during periods of environmental stress. In the litter layer, $L$. rubellus feeds on slightly decomposed plant remains, dung, and bacteria.

The genus Allolobophora is represented in the toxicity literature by three species. Allolobophora chlorotica is a shallow-burrowing lumbricid worm found in permanent pasture and other grasslands (Lee, 1985). It spends most of its life in the topsoil feeding on well-decomposed plant remains (humus). It is considered to be geophagus because it ingests a large quantity of soil during feeding. Allolobophora caliginosa and Apporectodea caliginosa are classified by Dindal (1990) as the same organism. It is similar to $A$. chlorotica in its burrowing and feeding habits and is common in alkaline soils of Egypt (Lee, 1985). No life history information was available on the species $A$. tuberculata.

Octolasium cyaneum is a burrowing lumbricid species that lives in the soil and feeds on dead roots (Lee, 1985). It is common in pasture lands where it creates deep horizontal burrows.

Dendrobaena rubida is an ubiquitous forest litter inhabiting lumbricid (Lee, 1985). It feeds on slightly decomposed leaf litter and does not burrow into the soil. 
The Eudrilidae family is represented by Eudrilus eugeniae. This tropical species from west Africa is now widespread throughout tropical and temperate regions (Neuhauser et al., 1979). It is a common inhabitant of topsoils and prefers habitats with high concentrations of organic matter.

The Megascolecidae family is represented by three organisms for which little information is available. Perionyx excavatus is the Indian subcontinent equivalent of Eisenia fetida, preferring compost heaps and other accumulations of organic material (Lee, 1985). It is known to feed on animal dung. Pheretima posthuma is originally from east and southeast Asia. No life history information was found on Octochaetus pattoni; however, other members of the genus occur in New Zealand (Lee, 1985).

\subsection{EARTHWORM DATA AND BENCHMARK DERIVATION}

\subsubsection{Inorganic Compounds}

Arsenic. Fischer and Koszorus (1992) tested the effects of $68 \mathrm{ppm}$ of arsenic (as potassium arsenate) on growth and reproduction of Eisenia fetida (average initial age of 5 weeks) when added to a combination of peaty marshland soil and horse manure (1:1). Number of survivors and their live mass and number of cocoons produced were measured. The number of cocoons produced per worm showed the highest sensitivity to arsenic with a $56 \%$ reduction at the test concentration.

The benchmark of $60 \mathrm{ppm}$ arsenic is based on this study only. Because of the lack of data, confidence in this benchmark is low.

Cadmium. van Gestel and his colleagues in the Netherlands have established a fairly standard procedure for testing the toxicity of chemicals to earthworms in an artificial soil mixture made up of (by dry weight) $10 \%$ sphagnum peat, $20 \%$ kaolin clay, and $69 \%$ fine sand and $\mathrm{CaCO}_{3}$ to adjust the $\mathrm{pH}$ to approximately 6 (OECD soil) (van Gestel et al., 1992). The work in this citation evaluated the effects of $\mathrm{Cd}$, added to the soil as $\mathrm{CdCl}_{2}$, on growth and reproduction (cocoons/worm/week, percent fertility of cocoons, juveniles/fertile cocoon, juveniles/worm/week) of Eisenia andrei after 21 days. The $C d$ was added in aqueous form and the resultant substrate added to $1 \mathrm{~L}$ glass jars. Approximately $5 \mathrm{~g}$ finely ground cow dung was added to a shallow hole in the middle of the substrate to serve as a food source for the 10 worms. A concentration of $18 \mathrm{ppm} \mathrm{Cd}$ was required to reduce the number of cocoons produced/week and the number of juveniles/worm ( 23 and $22 \%$ ). Growth and reproduction were not affected at $10 \mathrm{ppm} \mathrm{Cd}$. In other experiments by van Gestel et al. (1991a) using the same system but comparing the results from putting the food source in a hole with those from mixing it in with substrate, growth was reduced $44 \%$ by $100 \mathrm{ppm}$ ( $32 \mathrm{ppm}$ had no effect) in the former case and $40 \%$ by $32 \mathrm{ppm}$ (10 ppm had no effect), in the latter. The $\mathrm{EC}_{50}$ for clitella development (indicating sexual maturity) was $108 \mathrm{ppm} \mathrm{Cd}$ for dung placed in a center hole in the substrate, and $27 \mathrm{ppm}$ for dung mixed in with substrate.

Spurgeon et al. (1994) kept adult $E$. fetida in contaminated OECD artificial soil ( $\mathrm{pH}$ 6.3) for 8 weeks to test the effects of $\mathrm{Cd}$ [as $\left.\mathrm{Cd}\left(\mathrm{NO}_{3}\right)_{2}\right]$ on survival and growth of the earthworms. Results were reported as $\mathrm{LC}_{50} \mathrm{~s}$ for mortality and $\mathrm{EC}_{50} \mathrm{~s}$ for effects on cocoon production. After 56 days, the calculated $\mathrm{LC}_{50}$ was greater than $300 \mathrm{ppm} \mathrm{Cd}$. The $\mathrm{EC}_{50}$ for cocoon production was $46.3 \mathrm{ppm}$.

The effects of $C d$ added to horse manure (as $C d$ acetate) on $E$. fetida (initially less than 2 weeks old) was investigated by Malecki et al. (1982). Two growth periods were used, 8 and 20 weeks, and 
survival, weight gain, and cocoon production were measured. The most sensitive parameter was cocoon production. In the 8-week test, the lowest concentration tested, $25 \mathrm{ppm} \mathrm{Cd}$, caused a $52 \%$ decrease in cocoon production. In the 20-week test, the lowest concentration tested, $50 \mathrm{ppm} \mathrm{Cd}$, caused a $24 \%$ decrease in cocoon production.

The previously described system (horse manure) was used by Neuhauser et al. (1984) to look at the effects of $\mathrm{Cd}$ added as various soluble salts on growth and reproduction of $E$. fetida. The authors report their results with pooled data from all forms of a metal. After 6 weeks, both growth (weight) and cocoon production were decreased ( 25 and $100 \%$ ) by $100 \mathrm{ppm} \mathrm{Cd}$, the lowest concentration tested.

Bengtsson et al. (1986) report the effects of Cd on reproduction in the earthworm Dendrobaena rubida when grown in substrate at varying acidity. The metal was added to a 1:2 (volume) combination of sandy soil and well-decomposed cattle dung with a resulting organic carbon of about $6 \%$. After 4 months at $\mathrm{pH} 4.5$, the number of cocoons produced per worm was reduced $62 \%$ by 100 ppm Cd, while $10 \mathrm{ppm}$ had no effect. The percent hatched cocoons, hatchlings/cocoon, and total number of hatchlings were not affected. At $\mathrm{pH} 5.5$, the number of cocoons produced per worm, hatchlings/cocoon, and total number of hatchlings were reduced 78,71 , and $74 \%$, respectively, by $100 \mathrm{ppm} \mathrm{Cd}$, while $10 \mathrm{ppm}$ had no effect. The percent hatched cocoons was not affected. At $\mathrm{pH} 6.5$, the percent hatched cocoons, hatchlings/cocoon, and total number of hatchlings were reduced 47 , 38 , and $30 \%$, respectively, by $100 \mathrm{ppm} \mathrm{Cd}$, while $10 \mathrm{ppm}$ had no effect. The number of cocoons/worm was not affected.

van Gestel and van Dis (1988) conducted a series of experiments in a sandy soil (1.7\% organic matter, CEC $5.5 \mathrm{meq} / 100 \mathrm{~g}$ soil) to investigate the effects of acidity on acute toxicity of $\mathrm{Cd}\left(\mathrm{CdCl}_{2}\right)$ to adult $E$. andrei. The $\mathrm{LC}_{50}$ was between 320 and $560 \mathrm{ppm} \mathrm{Cd}$ after 14 days at $\mathrm{pH} 4.1$ and $>1000$ (no effect) at $\mathrm{pH} 7$. The LC50 concentration in OECD soil, with $10 \%$ organic matter at $\mathrm{pH} 7$, was also $>1000$ (no effect).

Neuhauser et al. (1985) used OECD artificial soil (pH 6) to determine $\mathrm{LC}_{50}$ of Cd (added as Cd nitrate) for adult $E$. fetida. After 14 days, the $\mathrm{LC}_{50}$ was calculated to be $1843 \mathrm{ppm} \mathrm{Cd}$.

In a study examining the effects of soil factors on $\mathrm{Cd}$ toxicity and uptake, $\mathrm{Ma}$ (1982) used a sandy loam soil ( $\mathrm{pH} 7.3,8 \%$ organic matter) spiked with $\mathrm{CdCl}_{2}$ to determine the effects of $\mathrm{Cd}$ on survival of adult Lumbricus rubellus. After 12 weeks, $1000 \mathrm{ppm} \mathrm{Cd}$ caused an $82 \%$ decrease in survival while $150 \mathrm{ppm}$ had no effect.

A benchmark of $20 \mathrm{ppm}$ has been computed for $\mathrm{Cd}$ on the basis of the 16 available concentrations causing toxicity. Confidence in this benchmark is moderate.

Chromium. Abbasi and Soni (1983) worked with a system in which the earthworm Octochaetus pattoni was kept in concrete tanks containing a mixture of soil and animal dung for 60 days to assess the effect of $\mathrm{Cr}(\mathrm{VI})$, added as $\mathrm{K}_{2} \mathrm{Cr}_{2} \mathrm{O}_{7}$, on survival and reproduction. Survival was the most sensitive measure with a $75 \%$ decrease resulting from $2 \mathrm{ppm} \mathrm{Cr}$, the lowest concentration tested. The number of cocoons produced was not diminished until the concentration reached $20 \mathrm{ppm} \mathrm{Cr}$ (highest concentration tested); the number of juveniles produced was not affected.

These same researchers (Soni and Abbasi, 1981) found no survival of Pheretima posthuma after 61 days in a paddy soil to which $10 \mathrm{ppm} \mathrm{Cr}(\mathrm{VI})$ (lowest concentration tested) was added. 
van Gestel et al. (1992), in the system described previously for Cd, also found growth of $E$. andrei to be more sensitive to $\mathrm{Cr}$ than reproduction. In this case, $\mathrm{Cr}$ (III) was added as chromic nitrate to OECD soil. A concentration of $32 \mathrm{ppm} \mathrm{Cr}$ reduced growth by $30 \%$ while cocoons/worm/week, percent fertile cocoons, and juveniles/worm/week were reduced 28,22 , and $51 \%$, respectively, by $100 \mathrm{ppm} \mathrm{Cr}$.

Molnar et al. (1989) examined the effects of $\mathrm{Cr}(\mathrm{III})$ and $\mathrm{Cr}(\mathrm{VI})$ on growth and reproduction of Eisenia fetida in an undefined substrate. Chromium (VI) was added as $\mathrm{K}_{2} \mathrm{Cr}_{2} \mathrm{O}_{7}$ and $\mathrm{Cr}$ (III) as $\mathrm{KCr}\left(\mathrm{SO}_{4}\right)_{2}$. Reproduction after 8 weeks was the measure most sensitive to $\mathrm{Cr}(\mathrm{III})$ with a $55 \%$ decrease in the number of cocoons and hatchlings at $625 \mathrm{ppm} \mathrm{Cr}$ (III). The authors indicate that reproduction was also sensitive to $\mathrm{Cr}(\mathrm{VI})$ but no data were given. After 2 weeks, mass gain of juveniles was decreased $34 \%$ by $2,500 \mathrm{ppm} \mathrm{Cr}$ (III) (625 ppm had no effect) and $43 \%$ by $625 \mathrm{ppm}$ $\mathrm{Cr}$ (VI) (lowest concentration tested). After 4 weeks, mass gain of juveniles was decreased $39 \%$ by $2,500 \mathrm{ppm} \mathrm{Cr}$ (III) (625 ppm had no effect), and Cr(VI) had no effect. Chromium(VI) at $1,250 \mathrm{ppm}$ was ineffective when worms were introduced after the soil had equilibrated for 2 weeks, regardless of the length of exposure.

It is difficult to set a benchmark concentration for toxicity of $\mathrm{Cr}$ to earthworms. Survival may be more sensitive than reproduction to the metal when it is added to the earthworm substrate as a soluble salt. The relative toxicity of $\mathrm{Cr}(\mathrm{III})$ and $\mathrm{Cr}(\mathrm{VI})$ is not clear from these studies. $\mathrm{Cr}(\mathrm{VI})$ ions can pass through cell membranes with much greater ease than $\mathrm{Cr}(\mathrm{III})$ ions. However, it is thought that $\mathrm{Cr}(\mathrm{VI})$ is reduced to $\mathrm{Cr}$ (III) inside the cell (Molnar et al., 1989); this latter may be the final active form. Without a better understanding of $\mathrm{Cr}$ transformations in the soil, transport across earthworm cell membranes, and reactions within the cell, it is difficult to separate the effects of the two different forms.

The $0.4 \mathrm{ppm}$ benchmark for $\mathrm{Cr}$ is based on the work of Abbasi and Soni (1983). A safety factor of 5 was applied to the $2 \mathrm{ppm}$ LOEC because it caused a $75 \%$ reduction in earthworm survival.

Confidence in this benchmark is low because it is based on only five reported concentrations causing toxicity to earthworms.

Copper. Neuhauser et al. (1984) evaluated the effects of soluble forms of copper on growth and reproduction $E$. fetida as described for $C d$. The authors report their results with pooled data from all forms of a metal. After 6 weeks, both growth (weight) and cocoon production were decreased (75 and $85 \%$ ) by $2000 \mathrm{ppm} \mathrm{Cu}$, while $1000 \mathrm{ppm}$ had no effect.

Neuhauser et al. (1985) used the OECD artificial soil (pH 6) to estimate $\mathrm{LC}_{50}$ of $\mathrm{Cu}$ (added as $\mathrm{Cu}$ nitrate) for adult $E$. fetida. After 14 days, the $\mathrm{LC}_{50}$ was $643 \mathrm{ppm} \mathrm{Cu}$.

Spurgeon et al. (1994) kept adult $E$. fetida in contaminated OECD artificial soil ( $\mathrm{pH}$ 6.3) for 8 weeks to test the effects of $\mathrm{Cu}$ (as $\mathrm{Cu}\left(\mathrm{NO}_{3}\right)_{2}$ ) on survival and growth of the earthworms, as described for Cd. After 56 days, the calculated $\mathrm{LC}_{50}$ was $555 \mathrm{ppm}$, and the $\mathrm{EC}$ for cocoon production was $53.3 \mathrm{ppm}$.

The effects of $\mathrm{Cu}$ added to horse manure (as copper acetate) on $E$. fetida (initially less than 2 weeks old) was investigated by Malecki et al. (1982). Two growth periods were used, 8 and 20 weeks, and survival, weight gain, and cocoon production were measured. The most sensitive parameter was cocoon production. In the 8-week test, $500 \mathrm{ppm} \mathrm{Cu}$ caused a $24 \%$ decrease in cocoon 
production, while $300 \mathrm{ppm}$ had no effect. In the 20 -week test, $1000 \mathrm{ppm} \mathrm{Cu}$ caused a $24 \%$ decrease in cocoon production, while $500 \mathrm{ppm}$ had no effect.

Bengtsson et al. (1986) looked at the effects of copper on Dendrobaena rubida at different acidities in the same type of experiments described for Cd. After 4 months at $\mathrm{pH} 4.5$, the number of cocoons produced per worm, hatchlings/cocoon, and total number of hatchlings were reduced 70 , 64 , and $74 \%$, respectively, by $100 \mathrm{ppm} \mathrm{Cu}$, the lowest concentration tested. The percent hatched cocoons was not affected. At pH 5.5, the number of cocoons produced per worm, hatchlings/cocoon, and percent hatched cocoons were reduced 96,100 , and $100 \%$, respectively, by $500 \mathrm{ppm} \mathrm{Cu}$, while $100 \mathrm{ppm}$ had no effect. The total number of hatchlings was not affected. At $\mathrm{pH} 6.5$, the number of cocoons produced per worm, hatchlings/cocoon, and percent hatched cocoons were reduced 90,100 , and $100 \%$, respectively, by $500 \mathrm{ppm} \mathrm{Cu}$, while $100 \mathrm{ppm}$ had no effect. The total number of hatchlings was not affected.

In experiments by van Gestel et al. (1991b) using the same system described previously but with $\mathrm{Cu}\left(\mathrm{CuCl}_{2}\right)$ mixed homogeneously with the OECD substrate, growth of $E$. fetida was reduced $32 \%$ by $100 \mathrm{ppm}$ ( $32 \mathrm{ppm}$ had no effect). The $\mathrm{EC}_{50}$ for clitella development (sexual development) was $>100 \mathrm{ppm} \mathrm{Cu}$.

In a study examining the effects of soil factors on $\mathrm{Cu}$ toxicity and uptake, $\mathrm{Ma}$ (1982) used a sandy loam soil ( $\mathrm{pH} 7.3,8 \%$ organic matter) spiked with $\mathrm{CuCl}_{2}$ to determine the effects of $\mathrm{Cu}$ on survival of adult Lumbricus rubellus. After 12 weeks, $1000 \mathrm{ppm} \mathrm{Cu}$ caused an $82 \%$ decrease in survival while $150 \mathrm{ppm}$ had no effect.

The effect of soil organic carbon on toxicity of $\mathrm{Cu}\left(\mathrm{CuSO}_{4}\right)$ to the earthworm Octolasium cyaneum was evaluated by Streit and Jaggy (1983). They determined the 14-day LC $_{50}$ in a Brown soil, a Rendzina soil, and a peat soil containing $3.2,14$, and $43 \%$ organic carbon, respectively. LC $_{50}$ concentrations were 180,850 , and $2500 \mathrm{ppm}$, respectively.

van Rhee (1975) tested the effects of a single concentration of $\mathrm{Cu}$ added to a polder soil on body weight, number of cocoons produced per week, mortality and sexual development of Allolobophora caliginosa. After 60 days, number of cocoons produced was the only measure affected; it decreased by $27 \%$ in the presence of $110 \mathrm{ppm} \mathrm{Cu}$.

Using the OECD artificial soil (pH 6) and 21-day test procedure, van Gestel et al. (1989) looked at the effects of $\mathrm{Cu}\left(\mathrm{as} \mathrm{CuCl}_{2}\right)$ on reproductive parameters of adult $E$. andrei. After 21 days, cocoon production was decreased $36 \%$ by the addition of $180 \mathrm{ppm} \mathrm{Cu}$ to the substrate, while $120 \mathrm{ppm}$ had no effect. Cocoon hatchability and number of juveniles per cocoon were not affected.

The sublethal effects of $\mathrm{Cu}$ on $L$. rubellus were investigated with respect to mortality, growth, cocoon production, and litter breakdown activity (Ma, 1984). Loamy sand field soil (5.7\% organic matter, $\mathrm{pH} 4.8$ ), with $\mathrm{Cu}$ added as $\mathrm{CuCl}_{2}$, was placed in bags with leaf litter added to the top. In an experiment lasting 6 weeks, the number of cocoons produced was decreased $42 \%$ by $131 \mathrm{ppm}$ $\left(\mathrm{HNO}_{3}: \mathrm{H}_{2} \mathrm{SO}_{4}\right.$ extractable), while $54 \mathrm{ppm}$ had no effect. In another study using this soil with the $\mathrm{pH}$ adjusted to between 4.8 and 7.1, $\mathrm{Ma}$ investigated at the effect of acidity on toxicity of $\mathrm{Cu}\left(\mathrm{CuSO}_{4}\right)$ to $L$. rubellus growth and reproduction. At pH $4.8,148 \mathrm{ppm}$ Cu resulted in a $26 \%$ decrease in production ( $83 \mathrm{ppm}$ had no effect). At $\mathrm{pH} 6$, a $33 \%$ reduction in cocoon production resulted from $278 \mathrm{ppm} \mathrm{Cu}$, while $148 \mathrm{ppm}$ had no effect. In a 6-week experiment using a calcareous sandy loam 
soil (pH 7.3, organic matter 3.4\%), the number of cocoons produced was diminished $41 \%$ in cultures to which $63 \mathrm{ppm} \mathrm{Cu}$ were added as $\mathrm{CuCl}_{2}$ (13 ppm had no effect).

The relative sensitivity of several lumbricid earthworms to $\mathrm{Cu}\left(\mathrm{CuCl}_{2}\right)$ added to a sandy soil $(\mathrm{pH}$ 5 , organic matter $5 \%$ ) was investigated by $\mathrm{Ma}(1988) . \mathrm{EC}_{50} \mathrm{~s}$ for cocoon production of $L$. rubellus, Aporrectodea caliginosa, and Allolobophora chlorotica were 122,68 , and $51 \mathrm{ppm} \mathrm{Cu}$.

The work of Streit and Jaggy (1983) and others shows that the organic carbon content of the soil is a strong determinant of the bioavailability and toxicity of copper. From the studies cited, it appears that low $\mathrm{pH}$ has a compounding effect, with an increase in $\mathrm{Cu}$ availability resulting from more acid conditions. Overall, reproduction is more sensitive than mortality, and there is no consistent evidence that one genus of earthworms is any less tolerant to $\mathrm{Cu}$ under a given set of conditions than another genus.

The benchmark for $\mathrm{Cu}$ was established at $50 \mathrm{ppm}$. Confidence in this benchmark is moderate.

Lead. Bengtsson et al. (1986) examined the effects of lead on Dendrobaena rubida at different acidities in the same type of experiments as those described for $\mathrm{Cd}$. After 4 months at $\mathrm{pH} 4.5$, the number of cocoons produced per worm, hatchlings/cocoon, and percent hatched cocoons were reduced 75,100 , and $100 \%$, respectively, by $500 \mathrm{ppm} \mathrm{Pb}$, while $100 \mathrm{ppm}$ had no effect. At pH 5.5 and $6.5, \mathrm{~Pb}$ had no effect at any level on any of the measures.

Spurgeon et al. (1994) kept adult $E$. fetida in contaminated OECD artificial soil (pH 6.3) for 8 weeks to examine the effects of $\mathrm{Pb}\left(\mathrm{as} \mathrm{Pb}\left(\mathrm{NO}_{3}\right)_{2}\right.$ ) on survival and growth of the earthworms as described for $\mathrm{Cd}$. After 56 days, the calculated $\mathrm{LC}_{50}$ was $3760 \mathrm{ppm}$, and the $\mathrm{Ef}$ for cocoon production was $1940 \mathrm{ppm}$.

The effects of $\mathrm{Pb}$ added to horse manure (as lead acetate) on $E$. fetida was investigated by Malecki et al. (1982), as described above for $\mathrm{Cd}$. The most sensitive parameter was cocoon production. In the 8-week test, $4000 \mathrm{ppm} \mathrm{Pb}$ caused a $50 \%$ decrease in cocoon production, while $2000 \mathrm{ppm}$ had no effect. In the 20 -week test, $5000 \mathrm{ppm} \mathrm{Pb}$ caused a $28 \%$ decrease in cocoon production, while $1000 \mathrm{ppm}$ had no effect.

Neuhauser et al. (1985) used the OECD artificial soil ( $\mathrm{pH} 6$ ) to determine $\mathrm{LC}_{50}$ of $\mathrm{Pb}$ [added as $\left.\mathrm{Pb}\left(\mathrm{NO}_{3}\right)\right]$ for adult $E$. fetida. After 14 days, the $\mathrm{LC}_{50}$ was calculated to be $5941 \mathrm{ppm} \mathrm{Pb}$.

Neuhauser et al. (1984) evaluated the effects of soluble forms of lead on growth and reproduction of $E$. fetida as described for $C d$. The authors report their results with pooled data from all forms of a metal. After 6 weeks, cocoon production was decreased $80 \%$ by $5000 \mathrm{ppm} \mathrm{Pb}$, the lowest concentration tested. Growth was not affected until $40,000 \mathrm{ppm}$ was added to the substrate.

A benchmark of $500 \mathrm{ppm}$ has been established for $\mathrm{Pb}$ based on the work of Bengtsson et al. (1986) which showed inhibition of reproduction at this concentration. Confidence in this benchmark is low because of the limited amount of data.

Mercury. Abbasi and Soni (1983) worked with Octochaetus pattoni in a system described previously for $\mathrm{Cd}$. They assessed the effect of $\mathrm{Hg}(\mathrm{II})$, added as $\mathrm{HgCl}_{2}$, on survival and reproduction. Survival and cocoon production were reduced 65 and $40 \%$ at $0.5 \mathrm{ppm} \mathrm{Hg}$, the lowest concentration tested. The number of juveniles produced was not affected. 
The effect of methyl mercury on survival and segment regeneration of $E$. fetida was investigated by Beyer et al. (1985). Methyl mercury chloride was added to an undefined potting soil in which the earthworms were cultured for 84 days. A concentration of $12.5 \mathrm{ppm} \mathrm{Hg}$ reduced survival by $21 \%$, and the ability to regenerate excised segments was reduced by $69 \%$. Methyl mercury at $2.5 \mathrm{ppm}$ had no effect.

It is not possible to evaluate the relative toxicity of forms of $\mathrm{Hg}$ based on these two studies which used different systems and evaluated two different families of earthworms.

A benchmark of $0.1 \mathrm{ppm}$ was established for $\mathrm{Hg}$ based on the work of Abbasi and Soni (1983). A safety factor of 5 was applied to the $0.5 \mathrm{ppm}$ LOEC because it caused a $65 \%$ reduction in earthworm survival. Confidence in this benchmark is low because of the limited amount of data.

Nickel. The effects of $\mathrm{Ni}$ (added to horse manure as $\mathrm{Ni}$ acetate) on $\mathrm{E}$. fetida were investigated by Malecki et al. (1982), as described for $\mathrm{Cd}$. The most sensitive parameter was cocoon production. In the 8-week test, $300 \mathrm{ppm} \mathrm{Ni}$ caused a $41 \%$ decrease in cocoon production, while $200 \mathrm{ppm}$ had no effect. In the 20 -week test, $200 \mathrm{ppm} \mathrm{Ni}$ caused a $23 \%$ decrease in cocoon production, while $100 \mathrm{ppm}$ had no effect.

Neuhauser et al. (1985) used the OECD artificial soil ( $\mathrm{pH}$ 6) to determine $\mathrm{LC}_{50}$ of Ni (added as Ni nitrate) for adult $E$. fetida. After 14 days, the $\mathrm{LC}_{50}$ was calculated to be $757 \mathrm{ppm} \mathrm{Ni}$.

Neuhauser et al. (1984) evaluated the effects of soluble forms of nickel on growth and reproduction $E$. fetida as described for $C d$. The authors report their results with pooled data from all forms of a metal. After 6 weeks, cocoon production was decreased $33 \%$ by $250 \mathrm{ppm} \mathrm{Ni}$, the lowest concentration tested. Growth was not affected until $500 \mathrm{ppm}$ was added to the substrate.

In a study examining the effects of soil factors on Ni toxicity and uptake, Ma (1982) used a

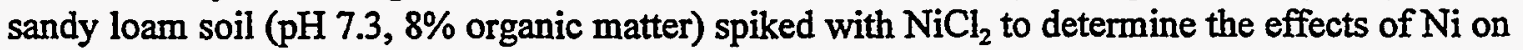
survival of adult Lumbricus rubellus. After 12 weeks, $1000 \mathrm{ppm}$ Cd caused a $31 \%$ decrease in survival while $150 \mathrm{ppm}$ had no effect.

A benchmark of $200 \mathrm{ppm}$ has been established for Ni based on the work of Malecki et al. (1982) which showed inhibition of reproduction at this concentration. Confidence in this benchmark is low because of the limited amount of data.

Selenium. Fischer and Koszorus (1992) tested the effects of $77 \mathrm{ppm}$ of selenium (as sodium arsenite) on growth and reproduction of Eisenia fetida when added to a combination of peaty marshland soil and horse manure (1:1). Number of survivors and their live mass and number of cocoons produced were measured. The number of cocoons produced per worm showed the highest sensitivity to selenium with a $69 \%$ reduction at the test concentration.

The benchmark of $70 \mathrm{ppm}$ is based on this study. Confidence in this benchmark is low.

Zinc. van Gestel et al. (1993) evaluated the effect of zinc added as $\mathrm{ZnCl}_{2}$ to $\mathrm{OECD}$ artificial soil (pH 6.2 ), on the growth and reproduction of $E$. andrei. The numbers of cocoons and juveniles produced were reduced 31 and $42 \%$ by $560 \mathrm{ppm}$, while $320 \mathrm{ppm}$ had no effect. The percent fertile cocoons and number of juveniles per fertile cocoon were not affected until $\mathrm{Zn}$ was added to a concentration of $1000 \mathrm{ppm} \mathrm{Zn}$, and percent growth of individuals increased with increasing $\mathrm{Zn}$ concentration. 
Spurgeon et al. (1994) kept adult $E$. fetida in contaminated OECD artificial soil (pH 6.3) for 8 weeks to test the effects of $\mathrm{Zn}$ (as $\mathrm{Zn}\left(\mathrm{NO}_{3}\right)_{2}$ ) on survival and growth of the earthworms as described for $\mathrm{Cd}$. After 56 days, the calculated $\mathrm{LC}_{50}$ was $745 \mathrm{ppm}$, and the $\mathrm{ES}_{6}$ for cocoon production was $276 \mathrm{ppm}$.

Neuhauser et al. (1985) used the OECD artificial soil ( $\mathrm{pH}$ 6) to determine $\mathrm{LC}_{50}$ of $\mathrm{Zn}$ [added as $\left.\mathrm{Zn}\left(\mathrm{NO}_{3}\right)\right]$ for adult $E$. fetida. After 14 days, the $\mathrm{LC}_{50}$ was calculated to be $662 \mathrm{ppm} \mathrm{Zn}$.

van Rhee (1975) tested the effects of one concentration of $\mathrm{Zn}(1100 \mathrm{ppm})$ added to a polder soil on body weight, number of cocoons produced per week, mortality and sexual development of Allolobophora caliginosa. After 60 days, there was a 53\% loss of body weight and a $22 \%$ increase in mortality; clitellum development and cocoon production were completely inhibited.

Neuhauser et al. (1984) evaluated the effects of soluble forms of zinc on growth and reproduction $E$. fetida as described for $\mathrm{Cd}$. The authors report their results with data pooled from all forms of a metal. After 6 weeks, cocoon production was decreased $50 \%$ by $2500 \mathrm{ppm} \mathrm{Zn}$, while $1000 \mathrm{ppm}$ had no effect. Growth was not affected until $5000 \mathrm{ppm}$ was added to the substrate.

The effects of $\mathrm{Zn}$ added to horse manure (as zinc acetate) on $E$. fetida was investigated by Malecki et al. (1982), as described for $\mathrm{Cd}$. The most sensitive parameter was cocoon production. In the 8-week test, $2000 \mathrm{ppm} \mathrm{Zn}$ caused a $36 \%$ decrease in cocoon production, while $1000 \mathrm{ppm}$ had no effect. In the 20 -week test, $5000 \mathrm{ppm} \mathrm{Zn}$ caused a $53 \%$ decrease in cocoon production, while $2500 \mathrm{ppm}$ had no effect.

The $\mathrm{EC}_{50}$ value of 276 (Spurgeon et al., 1994) was the lowest toxic concentration of the seven reported. Confidence in the benchmark of $200 \mathrm{ppm} \mathrm{Zn}$ is low because of the limited amount of data.

\subsubsection{Organic Compounds}

A small number of research groups have been conducting experiments on the toxicity of organic compounds and pesticides to earthworms. As a result, there are a limited number of experimental designs in use, and data are mainly in the form of $\mathrm{LC}_{50} \mathrm{~s}$. The following review describes the experimental designs of the various groups; the reader is directed to Appendix A for complete data.

Chloroacetamide. van Gestel and van Dis (1988) evaluated the effects of soil pH and organic matter content on toxicity of chloroacetamide to survival of adult $E$. andrei. The $\mathrm{LC}_{50}(14 \mathrm{~d})$ in a sandy soil (1.7\% organic matter) at $\mathrm{pH} 4.1$ and 7 was determined. Clearly, $\mathrm{pH}$ had an effect in this soil with higher $\mathrm{LC}_{50}$ values at $\mathrm{pH} 7$. In the OECD artificial soil (7.7\% organic matter) at $\mathrm{pH} 7$, the $\mathrm{LC}_{50}$ was similar to that in the sandy soil at the same $\mathrm{pH}$. It appears that differences in the organic matter content in this range were not determining the toxicity of this compound.

Heimbach (1984) also used the OECD artificial soil ( $\mathrm{pH} 7$ ) to evaluate the effects of this compound on the survival of $E$. fetida after 28 days. He found an $\mathrm{LC}_{50}$ of $24 \mathrm{ppm}$.

The effect of chloroacetamide on growth and reproduction of $E$. fetida after 56 days of growth in horse manure was assessed by Neuhauser and Callahan (1990). A concentration of $500 \mathrm{ppm}$ had no effect on the earthworms, but 1000 ppm caused $100 \%$ mortality. 
The $\mathrm{LC}_{50}$ value between 10 and 18 (van Gestel and van Dis, 1988) was the lowest toxic concentration of the five reported. A safety factor of 5 was applied to the lower bound on the $\mathrm{LC}_{50}$ to obtain the benchmark of $2 \mathrm{ppm}$ chloroacetamide. Confidence in this benchmark is low because of the limited amount of data.

3-chloroaniline. van Gestel and $\mathrm{Ma}$ (1993) investigated the effects of soil $\mathrm{pH}$ and organic matter content on the toxicity of this compound to two earthworms, E. andrei and L. rubellus. In a sandy soil with $\mathrm{pH} 4.8$ and $3.7 \%$ organic matter, $\mathrm{LC}_{50}$ values were lower for both earthworm species than it was in the OECD artificial soil with pH 5.9 and $8.1 \%$ organic matter. The authors conclude that, with this narrow a range of $\mathrm{pH}$ values, it is likely that the difference in organic matter is responsible for the results.

The $\mathrm{LC}_{50}$ value of 195 (van Gestel and Ma, 1993) was the lowest toxic concentration of the four reported. A safety factor of 5 was applied to this $\mathrm{LC}_{50}$ to obtain the benchmark of $30 \mathrm{ppm} \mathrm{3-}$ chloroaniline. Confidence in this benchmark is low.

2,4-dichloroaniline. van Gestel et al. (1989) used the OECD artificial soil (pH 6) to determine the effects of this compound on growth and reproduction of $E$. andrei. After 21 days, cocoon production was reduced $23 \%$ by $100 \mathrm{ppm}$, while $56 \mathrm{ppm}$ had no effect. Cocoon fertility and number of juveniles per cocoon were not affected by concentrations up to $180 \mathrm{ppm}$, the highest concentration tested.

van Gestel and $\mathrm{Ma}$ (1990) investigated the effects of soil $\mathrm{pH}$ and organic matter content on the toxicity of this compound to two earthworms, $E$. andrei and $L$. rubellus. Two sandy soils had similar $\mathrm{pH}$ values (5.3 and 5.6) but different organic matter levels (3.7 and 6.1\%). The OECD artificial soil had a pH of 5.9 and $8.1 \%$ organic matter. A peaty soil also used had a pH of 4 and organic matter content of $15.6 \%$. The $\mathrm{LC}_{50}$ values for 2-4-dichloroaniline ranged from 145 to $824 \mathrm{ppm}$, with organic matter being the more important determinant of bioavailability of this compound within the narrow $\mathrm{pH}$ range of soils used.

The $100 \mathrm{ppm}$ benchmark is based on the work of van Gestel et al. (1989) which showed inhibition of reproduction at this concentration. This test endpoint is chosen as more appropriate than lethality $\left(\mathrm{LC}_{50}\right)$. Confidence in the benchmark is low because of the few data available.

3,4-dichloroaniline. van Gestel and van Dis (1988) investigated the effects of soil $\mathrm{pH}$ and organic matter content on the toxicity of this compound to $E$. fetida. A sandy soil (1.7\% organic matter) was tested at $\mathrm{pH} 4.1$ and 7. The OECD artificial soil had a $\mathrm{pH}$ of 7 and $7.7 \%$ organic matter. The $\mathrm{LC}_{50}$ values ranged from 140 to $250 \mathrm{ppm}$ increased with increasing organic matter content. No difference related to $\mathrm{pH}$ was seen in the sandy soil.

The $\mathrm{LC}_{50}$ value of 140 (van Gestel and van Dis, 1988) was the lowest toxic concentration of the three reported. A safety factor of 5 was applied to this $\mathrm{LC}_{50}$ to obtain the benchmark of $20 \mathrm{ppm} \mathrm{3,4-}$ dichloroaniline. Confidence in this benchmark is low.

2,4,5-trichloroaniline. van Gestel and Ma (1993) evaluated the effects of this compound on the earthworms $E$. andrei and $L$. rubellus as described for 3-chloroaniline. As was the case for that compound, it is likely that the difference in organic matter is responsible for the results.

The lowest $\mathrm{LC}_{50}$ value of 134 derives from this work. A safety factor of 5 was applied to this $\mathrm{LC}_{50}$ to obtain the benchmark of $20 \mathrm{ppm} 2,4,5$-trichloroaniline. Confidence in this benchmark is low. 
2,3,5,6-tetrachloroaniline. van Gestel and Ma (1993) evaluated the effects of this compound on the earthworms $E$. andrei and L. rubellus as described for 3-chloroaniline. There is not much difference in the results under different $\mathrm{pH}$ and organic matter conditions, and it is not clear that organic matter affecting the bioavailability as in the case of 3-chloroaniline and 2,4,5-trichloroaniline.

The lowest $\mathrm{LC}_{50}$ value of $116 \mathrm{ppm}$ derives from this work. A safety factor of 5 was applied to this $\mathrm{LC}_{50}$ to obtain the benchmark of $20 \mathrm{ppm} \mathrm{2,3,5,6-tetrachloroaniline.} \mathrm{Confidence} \mathrm{in} \mathrm{this}$ benchmark is low.

Pentachloroaniline. van Gestel and Ma (1993) evaluated the effects of this compound on the earthworms $E$. andrei and $L$. rubellus as described previously. There is considerable difference in the $\mathrm{LC}_{50} \mathrm{~s}$ but no discernible pattern was evident based on soil characteristics or species of earthworm tested.

The lowest $\mathrm{LC}_{50}$ value of 825 derives from this work. A safety factor of 5 was applied to this $\mathrm{LC}_{50}$ to obtain the benchmark of $100 \mathrm{ppm}$ pentachloroaniline. Confidence in this benchmark is low.

1,2-dichloropropane. Neuhauser et al. (1986) used the OECD artificial soil (pH 6) to assess the effects of this compound on survival of adults of four earthworms, Perionyx excavatus, Eudrilus eugeniae, Eisenia fetida, and Allolobophora tuberculata. They determined the $\mathrm{LC}_{50}$ after 14 days and found less than two-fold difference in sensitivity among the worms; sensitivity decreased in the order $P$. excavatus $>E$. fetida $>A$. tuberculata $>E$. eugeniae.

Neuhauser and Callahan (1990) investigated the effect of this compound on growth and reproduction of $E$. fetida after 56 days of growth in horse manure. A concentration of $80,800 \mathrm{ppm}$ had no effect on the earthworms, but 92,300 ppm caused $100 \%$ mortality.

The $\mathrm{LC}_{50}$ value of 3880 (Neuhauser et al., 1986) was the lowest toxic concentration of the five reported. A safety factor of 5 was applied to this $\mathrm{LC}_{50}$ to obtain the benchmark of $700 \mathrm{ppm} \mathrm{1,2-}$ dichloropropane. Confidence in this benchmark is low.

Dimethylphthalate. Neuhauser et al. (1986) used the OECD artificial soil (pH 6) to assess the effects of this compound on survival of adults of four species of earthworms, as described previously. The $\mathrm{LC}_{50} \mathrm{~s}$ after 14 days showed a three-fold difference in sensitivity among the worms; sensitivity decreased in the order $P$. excavatus $>E$. eugeniae $>E$. fetida $>A$. tuberculata.

Neuhauser and Callahan (1990) evaluated the effect of this compound on growth and reproduction of $E$. fetida after 56 days of growth in horse manure. A concentration of $47,200 \mathrm{ppm}$ had no effect on the earthworms, but $70,800 \mathrm{ppm}$ caused a $62 \%$ reduction in cocoon production.

The $\mathrm{LC}_{50}$ value of 1064 (Neuhauser et al., 1986) was the lowest toxic concentration of the three reported. A safety factor of 5 was applied to this $\mathrm{LC}_{50}$ to obtain the benchmark of $200 \mathrm{ppm}$ dimethylphthalate. Confidence in this benchmark is low.

Fluorene. Neuhauser et al. (1986) used the OECD artificial soil (pH 6) to assess the effects of this compound on survival of adults of four earthworms, as described previously. The $\mathrm{LC}_{50} \mathrm{~s}$ after 14 days showed little difference in sensitivity among the worms; sensitivity decreased in the order P. excovatus $>$ E. fetida $>$ E. eugeniae $>A$. tuberculata. 
Neuhauser and Callahan (1990) investigated the effect of this compound on growth and reproduction of $E$. fetida after 56 days of growth in horse manure. A concentration of $500 \mathrm{ppm}$ had no effect on the earthworms, but 750 ppm caused a $49 \%$ reduction in cocoon production.

The $\mathrm{LC}_{50}$ value of 170 (Neuhauser et al., 1986) was the lowest toxic concentration of the five reported. A safety factor of 5 was applied to this $\mathrm{LC}_{50}$ to obtain the benchmark of $30 \mathrm{ppm}$ fluorene. Confidence in this benchmark is low.

N-nitrosodiphenylamine. Neuhauser et al. (1986) used the OECD artificial soil (pH 6) to assess the effects of this compound on survival of adults of four earthworms, as described previously. The $\mathrm{LC}_{50} \mathrm{~s}$ after 14 days showed little difference in sensitivity among the worms; sensitivity decreased in the order $E$. eugeniae $>P$. excavatus $>E$. fetida $>A$. tuberculata.

Neuhauser and Callahan (1990) looked at the effect of this compound on growth and reproduction of $E$. fetida after 56 days of growth in horse manure. A concentration of $1400 \mathrm{ppm}$ (lowest concentration tested) caused a $37 \%$ reduction in cocoon production.

The $\mathrm{LC}_{50}$ value of 109 (Neuhauser et al., 1986) was the lowest toxic concentration of the five reported. A safety factor of 5 was applied to this $\mathrm{LC}_{50}$ to obtain the benchmark of $20 \mathrm{ppm}$ $\mathrm{N}$-nitrosodiphenylamine. Confidence in this benchmark is low.

Phenol. Neuhauser et al. (1986) used OECD artificial soil (pH 6) to assess the effects of this compound on survival of adults of four species of earthworms, as described previously. The $\mathrm{LC}_{50} \mathrm{~s}$ after 14 days showed a less than three-fold difference in sensitivity among the worms; sensitivity decreased in the order $E$. eugeniae $>P$. excavatus $>E$. fetida $>A$. tuberculata.

Neuhauser and Callahan (1990) assessed the effect of this compound on growth and reproduction of $E$. fetida after 56 days of growth in horse manure. A concentration of $3900 \mathrm{ppm}$ had no effect on the earthworms, but $4900 \mathrm{ppm}$ caused a $26 \%$ reduction in cocoon production.

The LC $_{50}$ value of 188 (Neuhauser et al., 1986) was the lowest toxic concentration of the five reported. A safety factor of 5 was applied to this $\mathrm{LC}_{50}$ to obtain the benchmark of $30 \mathrm{ppm}$ phenol. Confidence in this benchmark is low.

4-nitrophenol. Neuhauser et al. (1986) used the OECD artificial soil ( $\mathrm{pH}$ 6) to assess the effects of this compound on survival of adults of four species of earthworms, as described previously. The $\mathrm{LC}_{50} \mathrm{~s}$ after 14 days showed little difference in sensitivity among the worms; sensitivity decreased in the order $E$. fetida $>E$. eugeniae $>P$. excavatus $>A$. tuberculata.

Neuhauser and Callahan (1990) looked at the effect of this compound on growth and reproduction of $E$. fetida after 56 days of growth in horse manure. A concentration of $600 \mathrm{ppm}$ (the lowest concentration tested) caused a $39 \%$ reduction in cocoon production.

The LC $_{50}$ value of 38 (Neuhauser et al., 1986) was the lowest toxic concentration of the five reported. A safety factor of 5 was applied to this $\mathrm{LC}_{50}$ to obtain the benchmark of $7 \mathrm{ppm}$ 4-nitrophenol. Confidence in this benchmark is low.

3-chlorophenol. van Gestel and $\mathrm{Ma}$ (1990) investigated the effects of soil pH and organic matter content on the toxicity of this compound to two earthworms, $E$. andrei and L. rubellus. Two sandy 
soils had similar pH values (5.3 and 5.6) but different organic matter levels (3.7 and 6.1\%). The OECD artificial soil had a pH of 5.9 and $8.1 \%$ organic matter. A peaty soil also used had a $\mathrm{pH}$ of 4 and organic matter content of $15.6 \%$. The $\mathrm{LC}_{50}$ values ranged from 75 to $633 \mathrm{ppm}$, with organic matter being the more important determinant of bioavailability of this compound within the narrow $\mathrm{pH}$ range of soils used.

van Gestel and $\mathrm{Ma}$ (1988) looked at the effects of this compound on survival of $L$. rubellus and $E$. andrei in two humic sand soils of differing organic matter content ( 3.7 and $6.1 \%$ ) but similar $\mathrm{pH}$ (5 and 5.6). These investigators found a three-fold difference between the highest and lowest values with no strong trend in relation to earthworm species or soil factors.

The benchmark for this compound has been established at $10 \mathrm{ppm}$. The $\mathrm{LC}_{50}$ of 75 from the work of van Gestel and $\mathrm{Ma}$ (1990) approximates the 10th percentile. A safety factor of 5 was applied to this value to obtain the benchmark. Confidence in this benchmark is low because all 12 values of the data set are $\mathrm{LC}_{50} \mathrm{~s}$.

3,4-dichlorophenol. van Gestel and $\mathrm{Ma}$ (1990) investigated the effects of soil $\mathrm{pH}$ and organic matter content on the toxicity of this compound to two earthworms, $E$. andrei and $L$. rubellus, as described previously. The $L C_{50}$ values ranged from 134 to $680 \mathrm{ppm}$, with a trend of organic matter being more important than $\mathrm{pH}$ as a determinant of bioavailability for this compound.

van Gestel and $\mathrm{Ma}$ (1988) assessed at the effects of this compound on survival of $L$. rubellus and $E$. andrei in two humic sand soils of differing organic matter content but similar with respect to $\mathrm{pH}$, as described previously. There was about a three-fold difference between the highest and lowest values with no strong trend in relation to earthworm species or soil factors.

The benchmark for this compound was established at $20 \mathrm{ppm}$. The $\mathrm{LC}_{50}$ of 134 from the work of van Gestel and $\mathrm{Ma}$ (1990) approximates the 10th percentile. A safety factor of 5 was applied to this value to obtain the benchmark. Confidence in this benchmark is low because all 12 values of the data set are $\mathrm{LC}_{50} \mathrm{~s}$.

2,4,5-trichlorophenol. van Gestel and $\mathrm{Ma}$ (1990) investigated the effects of soil $\mathrm{pH}$ and organic matter content on the toxicity of this compound to two earthworm species, $E$. andrei and $L$. rubellus, as described previously. The $\mathrm{LC}_{50}$ values ranged from 46 to $875 \mathrm{ppm}$, with a trend of organic matter being more important than $\mathrm{pH}$ as a determinant of bioavailability within earthworm type. $E$. andrei appears to be more sensitive than $L$. rubellus to this compound.

van Gestel and $\mathrm{Ma}$ (1988) assessed the effects of this compound on survival of $L$. rubellus and $E$. andrei in two humic sand soils of differing organic matter content but similar $\mathrm{pH}$, as described previously. The $\mathrm{LC}_{50}$ values ranged from 52 to $290 \mathrm{ppm}$, with a trend of organic matter being the more important determinant of bioavailability within earthworm type. $E$. andrei again appears to be more sensitive to this compound than $L$. rubellus.

The benchmark for this compound was established at $9 \mathrm{ppm}$. The $\mathrm{LC}_{50}$ of 46 from the work of van Gestel and $\mathrm{Ma}$ (1990) approximates the 10th percentile. A safety factor of 5 was applied to this value to obtain the benchmark. Confidence in this benchmark is low because all 12 values of the data set are $\mathrm{LC}_{30} \mathrm{~s}$. 
2,4,6-trichlorophenol. Neuhauser et al. (1986) used the OECD artificial soil (pH 6) to assess the effects of this compound on survival of adults of four earthworms, as described previously. The $\mathrm{LC}_{50} \mathrm{~s}$ after 14 days showed little difference in sensitivity among the worms; sensitivity decreased in the order $E$. fetida $>P$. excovatus $>E$. eugeniae $>A$. tuberculata.

Neuhauser and Callahan (1990) assessed the effect of this compound on growth and reproduction of $E$. fetida after 56 days of growth in horse manure. A concentration of $100 \mathrm{ppm}$ (lowest concentration tested) caused a $28 \%$ reduction in cocoon production.

The $\mathrm{LC}_{50}$ value of 58 (Neuhauser et al., 1986) was the lowest toxic concentration of the five reported. A safety factor of 5 was applied to this $\mathrm{LC}_{50}$ to obtain the benchmark of $10 \mathrm{ppm}$ for $2,4,6-$ trichlorophenol. Confidence in this benchmark is low.

2,3,4,5-tetrachlorophenol. van Gestel and $\mathrm{Ma}$ (1990) investigated the effects of soil $\mathrm{pH}$ and organic matter content on the toxicity of this compound to two earthworms, $E$. andrei and $L$. rubellus, as described previously. The $\mathrm{LC}_{50}$ values ranged from 117 to $875 \mathrm{ppm}$, with a trend of organic matter being more important that $\mathrm{pH}$ as a determinant of bioavailability within earthworm species. $E$. andrei appears to be more sensitive than $L$. rubellus to this compound.

van Gestel and Ma (1988) looked at the effects of this compound on survival of $L$. rubellus and $E$. andrei in two humic sand soils of differing organic matter content but similar $\mathrm{pH}$, as described previously. The $\mathrm{LC}_{50}$ values ranged from 116 to $828 \mathrm{ppm}$, with a trend of organic matter being the more important determinant of bioavailability within earthworm type. $E$. andrei again appears to be more sensitive to this compound than $L$. rubellus.

The $\mathrm{LC}_{50}$ value of 116 (van Gestel and $\mathrm{Ma}, 1990$ ) was the lowest toxic concentration of the eight reported. A safety factor of 5 was applied to this $L C_{50}$ to obtain the benchmark of $20 \mathrm{ppm} 2,3,4,5-$ tetrachlorophenol. Confidence in this benchmark is low.

Pentachlorophenol. van Gestel and van Dis (1988) investigated the effects of soil pH and organic matter content on the toxicity of this compound to $E$. fetida. A sandy soil ( $1.7 \%$ organic matter) was tested at $\mathrm{pH} 4.1$ and 7. The OECD artificial soil had a $\mathrm{pH}$ of 7 and $7.7 \%$ organic matter. There was no strong trend related to organic matter, but the highest $\mathrm{LC}_{50}$ occurred in the more acid soil.

van Gestel et al. (1989) used the OECD artificial soil (pH 6) to determine the effects of this compound on the growth and reproduction of $E$. andrei. After 21 days, percent cocoon hatching success was reduced $50 \%$ by $32 \mathrm{ppm}$, while $10 \mathrm{ppm}$ had no effect. Cocoon production and number of juveniles per cocoon were not affected until $100 \mathrm{ppm}$ was added.

Heimbach (1984) used the OECD artificial soil ( $\mathrm{pH} 7$ ) to evaluate the effects of this compound on survival of $E$. fetida after 28 days. He found an $\mathrm{LC}_{50}$ of $87 \mathrm{ppm}$.

van Gestel and Ma (1990) investigated the effects of soil $\mathrm{pH}$ and organic matter content on the toxicity of this compound to two earthworms, $E$. andrei and $L$. rubellus, as described previously. The $\mathrm{LC}_{50}$ values ranged from 83 to $2298 \mathrm{ppm}$, with the highest value occurring in soil with the highest organic matter content for each earthworm species. $E$. andrei appears to be more sensitive than $L$. rubellus to this compound. 
van Gestel and $\mathrm{Ma}$ (1988) investigated the effects of this compound on survival of $L$. rubellus and $E$. andrei in two humic sand soils of differing organic matter content but similar $\mathrm{pH}$, as described previously. The $\mathrm{LC}_{50}$ values ranged from 94 to $1094 \mathrm{ppm}$, with no strong trend related to organic matter. $E$. andrei again appears to be more sensitive to this compound than $L$. rubellus.

The 10th percentile of the data lay between $\mathrm{LC}_{50}$ values of 16 and 29 (van Gestel and van Dis, 1988). A safety factor of 5 was applied to the geometric mean of these two values (21.5) to obtain the benchmark of $4 \mathrm{ppm}$ pentachlorophenol. Confidence in this benchmark is low because all but one of the 17 values in the data set are $\mathrm{LC}_{50} \mathrm{~s}$.

Chlorobenzene. van Gestel et al. (1991b) investigated the effects of soil pH and organic matter content on the toxicity of this compound to two earthworms species, $E$. andrei and $L$. rubellus. In a sandy soil with pH 4.8 and $3.7 \%$ organic matter and OECD artificial soil (pH 5.9 and $8.1 \%$ organic matter), $\mathrm{LC}_{50}$ values were lower for $E$. fetida than for $L$. rubellus. Values ranged from 240 to 1107 ppm.

The LC $_{50}$ value of 240 (van Gestel et al., 1991b) was the lowest toxic concentration of the four reported. A safety factor of 5 was applied to this $\mathrm{LC}_{50}$ to obtain the benchmark of $40 \mathrm{ppm}$ chlorobenzene. Confidence in this benchmark is low.

1,4-dichlorobenzene. van Gestel et al. (1991b) investigated the effects of soil pH and organic matter content on the toxicity of this compound to two earthworms species, $E$. andrei and $L$. rubellus. In a sandy soil with $\mathrm{pH} 4.8$ and $3.7 \%$ organic matter and the OECD artificial soil (pH 5.9 and $8.1 \%$ organic matter), $\mathrm{LC}_{50}$ values were lower in the soil with a lower percentage of organic matter. $\mathrm{LC}_{50}$ values ranged from 128 to $615 \mathrm{ppm}$.

The $\mathrm{LC}_{50}$ value of 128 (van Gestel et al., 1991b) was the lowest toxic concentration of the four reported. A safety factor of 5 was applied to this $\mathrm{LC}_{50}$ to obtain the benchmark of $20 \mathrm{ppm} \mathrm{1,4-}$ dichlorobenzene. Confidence in this benchmark is low.

1,2,3-trichlorobenzene. van Gestel and Ma (1990) investigated the effects of soil $\mathrm{pH}$ and organic matter content on the toxicity of this compound to two earthworms species, $E$. andrei and L. rubellus, as described previously. The $\mathrm{LC}_{50}$ values ranged from 115 to $563 \mathrm{ppm}$, with the highest $\mathrm{LC}_{50}$ occurring in soil with the highest organic matter content. No trend in sensitivity of earthworm species was evident.

The $\mathrm{LC}_{50}$ value of 115 (van Gestel and Ma, 1990) was the lowest toxic concentration of the eight reported. A safety factor of 5 was applied to this $\mathrm{LC}_{50}$ to obtain the benchmark of $20 \mathrm{ppm} \mathrm{1,2,3-}$ trichlorobenzene. Confidence in this benchmark is low because of the limited amount of data.

1,2,4-trichlorobenzene. Neuhauser et al. (1986) used the OECD artificial soil ( $\mathrm{pH}$ 6) to assess the effects of this compound on survival of adults of four earthworms species, as described previously. The $\mathrm{LC}_{50} \mathrm{~s}$ after 14 days showed little difference in sensitivity among the worms; sensitivity decreased in the order $E$. eugeniae $>P$. excavatus $>E$. fetida $>A$. tuberculata.

The $\mathrm{LC}_{50}$ value of $127 \mathrm{ppm}$ (Neuhauser et al., 1986) was the lowest toxic concentration of the four reported. A safety factor of 5 was applied to this $L C_{50}$ to obtain the benchmark of $20 \mathrm{ppm} \mathrm{1,2,4-}$ trichlorobenzene. Confidence in this benchmark is low. 
1,2,3,4-tetrachlorobenzene. van Gestel et al. (1991b) investigated the effects of soil pH and organic matter content on the toxicity of this compound to two earthworms species, $E$. andrei and L. rubellus. In a sandy soil with $\mathrm{pH} 4.8$ and $3.7 \%$ organic matter and the $\mathrm{OECD}$ artificial soil (pH 5.9 and $8.1 \%$ organic matter), $\mathrm{LC}_{50}$ values were lower in the soil with less organic matter. The $\mathrm{LC}_{50}$ values ranged from 75 to $223 \mathrm{ppm}$.

The $\mathrm{LC}_{50}$ value of 75 (van Gestel et al., 1991b) was the lowest toxic concentration of the five reported. A safety factor of 5 was applied to this $\mathrm{LC}_{50}$ to obtain the benchmark of $10 \mathrm{ppm} 1,2,3,4-$ tetrachlorobenzene. Confidence in this benchmark is low.

Pentachlorobenzene. van Gestel et al. (1991a) investigated the effects of soil pH and organic matter content on the toxicity of this compound to two earthworms species, $E$. andrei and $L$. rubellus, as described previously. In a sandy soil and the $\mathrm{OECD}$ artificial soil, $\mathrm{LC}_{50}$ values were lower in the soil with a lower percentage of organic matter. $L_{50}$ values ranged from 72 to $223 \mathrm{ppm}$.

The $\mathrm{LC}_{50}$ value of 115 (van Gestel et al., 1991b) was the lowest toxic concentration of the four reported. A safety factor of 5 was applied to this $\mathrm{LC}_{50}$ to obtain the benchmark of $20 \mathrm{ppm}$ pentachlorobenzene. Confidence in this benchmark is low.

Nitrobenzene. Neuhauser et al. (1986) used the OECD artificial soil ( $\mathrm{pH} 6)$ to assess the effects of this compound on survival of adults of four earthworms species, as described previously. The $\mathrm{LC}_{50} \mathrm{~s}$ after 14 days showed little difference in sensitivity among the worms; sensitivity decreased in the order $E$. eugeniae $>E$. fetida $>P$. excavatus $>A$. tuberculata.

The LC $_{50}$ value of 226 (Neuhauser et al., 1986) was the lowest toxic concentration of the four reported. A safety factor of 5 was applied to this $L_{50}$ to obtain the benchmark of $40 \mathrm{ppm}$ nitrobenzene. Confidence in this benchmark is low. 


\section{MICROBIAL HETEROTROPHS AND PROCESSES}

\subsection{INTRODUCTION}

Soil microorganisms play a critical role in nutrient cycling. As primary consumers of soil organic matter, soil microbes convert nutrients to plant-available forms and serve as a food source for higher trophic levels. The soil microbiota is a heterogeneous collection of highly adaptable organisms exploiting the many micro-niches in the soil. The effect of contaminants may be to change the microbial community structure without overall changes in the functional ability of the community. The authors' assessment endpoint, however, is microflora community functioning. This is measured as effects on $\mathrm{C}$ mineralization, $\mathrm{N}$ transformation, and enzyme activities.

Little information is available on the mechanisms of toxicity of contaminants to soil microorganisms. Some metal ions may inhibit enzyme reactions by complexing with enzyme substrates, combining with the protein active group of the enzyme, or reacting with the enzymesubstrate complex (Juma and Tabatabai, 1977).

As with the others benchmarks, much of the variance is due to the variance in soil characteristics that influence toxicity. These characteristics control bioavailability to all soil-dwelling organisms, with $\mathrm{pH}$ and organic matter content being among those that are very important.

\subsection{MICROBE DATA SELECTION}

Toxic response data were collected for inorganic elements and organic compounds. Measures of effects of soil-borne chemicals on microorganisms include growth, respiration, nitrogen transformation reactions (denitrification, mineralization, and nitrification), $C$ mineralization, $P$ mineralization, cellulolytic activity, oxidation of hydrogen gas, alpha-glucosidase synthesis, and other enzyme activities.

Many enzymes that are produced by plants and microbes can exist and function extracellularly in the soil for varying periods of time, depending on soil micro-environmental factors (Tabatabai, 1982). For this reason, it may not be appropriate to interpret measured effects of chemicals on soil enzyme activities as representing effects on soil microbial populations. Soil enzymes do, however, give valuable information about the functioning of the soil in organic matter degradation. These enzymes include urease which catalyzes the hydrolysis of urea to $\mathrm{CO}_{2}$ and $\mathrm{NH}_{3}$; phosphatases which catalyze the hydrolysis of phospho esters and anhydrides; arylsulfatase which catalyzes the hydrolysis of the arylsulfate ion; amidase, which catalyzes the hydrolysis of acid amides with the release of $\mathrm{NH}_{3}$; amylases, enzymes which catalyze the hydrolysis of starch and glycogen; and dehydrogenases, a group of enzymes which catalyze the dehydrogenation of many organic compounds. Dehydrogenase activity is considered by some to provide an overall estimate of microbial activity. None of these activities is accepted as adequate for characterizing the response of the soil microbial community to toxic stress because of the many soil and microbial factors affecting, them at the micro-environment level. However, it is often the case that benchmarks are based on the effects of a chemical on a single activity (e.g., reduction of phosphatase activity) because of lack of other data. 
Most of the research used to establish benchmarks was conducted in the laboratory with native soil microflora in small samples of soil or soil/litter microcosms. Exposure durations ranged from one and one-half hours to one and one-half years. The chemicals tested were mixed into the soil in the form of salts. Bacteria, actinomycetes, and fungi are included and evaluated together. Tests conducted in culture media are not included because they are not directly relevant to the soil environment.

\subsection{MICROBE DATA AND BENCHMARK DERIVATION}

A short review of the available literature is discussed in the following text. Data are summarized in Appendix B, and benchmarks are given in Table 2.

\subsubsection{Inorganic Chemicals}

Aluminum. The effects of soil characteristics on effects of $\mathrm{Al}$ (as $\mathrm{AlCl}_{3}$ ) on arylsulfatase activity was evaluated by Al-Khafaji and Tabatabai (1979). Soils were chosen with a range in $\mathrm{pH}$, organic matter, and clay contents ( 6.2 to $7.6 ; 5.4$ to $10.6 \% ; 26$ to $34 \%$ ). Air-dried, sieved soil samples were placed in flasks with the test chemical added in solution. The samples were incubated for 90 minutes before microbial activity was stopped and arylsulfatase activity measured. In all soils, a concentration of $675 \mathrm{ppm} \mathrm{Al}$ reduced the enzyme activity between 24 and $43 \%$. The least inhibition occurred in the soil with the highest contents of organic matter and clay.

Juma and Tabatabai (1977) used essentially the same system and three of the same soils to evaluate the effects of several metals on soil acid and alkaline phosphatase activities. Three soils were used to test effects and acid phosphatase activity with $\mathrm{pH}$, organic matter, and clay ranging from 5.8 to $7.8,5.2$ to $11 \%$, and 23 to $30 \%$. Alkaline phosphatase activity was not tested in the most acid soil. For Al in a loam soil ( $\mathrm{pH} 5.8$; percent organic matter 5.2) acid phosphatase activity was reduced, and alkaline phosphatase activity was reduced in another loam soil ( $\mathrm{pH} 7.4$, percent organic matter 11) by a concentration of $675 \mathrm{ppm} \mathrm{Al}$. Aluminum had no effect on the activity of either enzyme in an alkaline soil ( $\mathrm{pH} 7.8$, percent organic matter 7.4).

The benchmark of $600 \mathrm{ppm}$ of $\mathrm{Al}$ was derived from the previously described studies. Confidence in the benchmark is low because of the limited amount and type of data available.

Arsenic. Juma and Tabatabai (1977) used the system described for $\mathrm{Al}$ to evaluate the effects of two forms of As on soil acid and alkaline phosphatase activities. Arsenic (III) had no effect on acid phosphatase activity in any of the three soils. At a concentration of $1875 \mathrm{ppm}$ As (lowest concentration tested), alkaline phosphatase activity was reduced in a loam soil ( $\mathrm{pH} 7.8$; percent organic matter 7.4). Arsenic (V) was more toxic than As(III) to both enzyme complexes. Alkaline and acid phosphatase activities were reduced by as little as $187.5 \mathrm{ppm}$ As(V) (lowest concentration tested) in soils of pH 5.8 to 7.4 and percent organic matter 5.2 to 11 .

Frankenberger and Tabatabai (1981) investigated the effect of As(III) on amidase activity in three soils in shaker flask assays as described previously. After $21 / 2 \mathrm{hrs}$, amidase activity was reduced in all three soils. Activity was almost totally inhibited in the soil with the soils tested with a lowest concentration of $1873 \mathrm{ppm}$. 
The effective concentration of $187 \mathrm{ppm}$ (Frankenberger and Tabatabai, 1981) is the lowest of the eight reported. Confidence in the benchmark of $100 \mathrm{ppm}$ is low because of the limited amount and type of data available.

Barium. The influence of soil characteristics on effects of $\mathrm{Ba}$ on arylsulfatase activity was evaluated by Al-Khafaji and Tabatabai (1979) using methods described for Al. A reduction in activity was measured in only one of the four soils, having the lowest $\mathrm{pH}$ and organic matter content. A $22 \%$ reduction in activity was caused by $3433 \mathrm{ppm} \mathrm{Ba}$ (only concentration tested).

The benchmark of $3000 \mathrm{ppm}$ is based on this study. Confidence in the benchmark is low because of the limited amount of data available.

Boron. The influence of soil characteristics on effects of B on arylsulfatase activity was evaluated by Al-Khafaji and Tabatabai (1979) using methods described for Al. Approximately the same degree of reduction in activity was measured in all soils at $270 \mathrm{ppm}$, and at $27 \mathrm{ppm}$ in a loam $(\mathrm{pH} 6.5$, percent organic matter 5.8) There was no clear relationship between magnitude of reduction in activity and soil $\mathrm{pH}$ and organic matter.

Juma and Tabatabai (1977) used the system described for Al to evaluate the effects of B on soil acid and alkaline phosphatase activities. Acid phosphatase activity was not affected in the soil with the highest $\mathrm{pH}$. It was reduced in the other two soils at a concentration of $270 \mathrm{ppm}$. Alkaline phosphatase activity was not affected by $B$ in the soils tested.

The effective concentration of $27 \mathrm{ppm}$ (Al-Khafaji and Tabatabai, 1979) is the lowest of the six reported. Confidence in the benchmark of $20 \mathrm{ppm}$ is low because of the limited amount and type of data available.

Cadmium. The influence of soil characteristics on effects of $\mathrm{Cd}$ on arylsulfatase activity was evaluated by Al-Khafaji and Tabatabai (1979) using methods described for Al. A reduction in activity was measured in all four soils (23 to $55 \%$ ) at $2810 \mathrm{ppm} \mathrm{Cd}$, with the greatest reduction in the soil with the lowest clay content.

Juma and Tabatabai (1977) used the system described for Al to evaluate the effects of Cd on soil acid and alkaline phosphatase activities. Acid phosphatase activity was reduced in all three of the soils ( 44 to $51 \%$ ) at $2810 \mathrm{ppm}$. Alkaline phosphatase activity was reduced $27 \%$ in the loam soil at a concentration of $281 \mathrm{ppm}$ and $78 \%$ at $2810 \mathrm{ppm}$ in a clay loam soil in which this was the only concentration tested.

Haanstra and Doelman (1991) investigated short- and long-term effects of metals on arylsulfatase activity, urease activity (Doelman and Haanstra, 1986), and total phosphatase activity (Doelman and Haanstra, 1989) by native soil microflora in five soils (sand, sandy loam, silt loam, clay, and sandy peat) of varying characteristics. Soil $\mathrm{pH}$ ranged from 7.7 to 4 , organic matter content from 1.6 to $12.8 \%$, and clay from 2 to $60 \%$. Metals were added as salts to the sieved soils in flasks, and enzyme activity was measured after a 6-week or 18-month study. Results were reported as $\mathrm{EC}_{50}$. In the 6-week incubation study on the effects of $\mathrm{Cd}$, data from the sandy loam soil were not available. Data for the effects on phosphatase activity were also not available for sandy peat. For all three enzyme systems, the highest $\mathrm{EC}_{50} \mathrm{~s}$ were found in the soil with the highest clay content $(9520$, 9779 , and $4460 \mathrm{ppm}$ for arylsulfatase, phosphatase, and urease activities, respectively). The lowest $\mathrm{EC}_{50} \mathrm{~s}$ were $1888 \mathrm{ppm}$ for arylsulfatase, and 840 and $340 \mathrm{ppm}$ in the sand for phosphatase and urease 
activities. In the 18-month study, data from the sandy peat soil were not available for arylsulfatase and phosphatase. The highest $\mathrm{EC}_{50}$ s were $230 \mathrm{ppm}$ in the soil with the highest $\mathrm{pH}$ for phosphatase, $30 \mathrm{ppm} \mathrm{Cd}$ in the sandy loam soil for urease, and $121 \mathrm{ppm}$ in the sand (lowest pH, organic matter, and clay) for arylsulfatase.

The effects of several elements on dehydrogenase activity of the native soil microflora in a composite soil sample from the Rocky Mountain Arsenal was assessed by Rogers and Li (1985). Soil was amended with glucose and alfalfa, with the metal salts added in solution. After 6 days, a concentration of $30 \mathrm{ppm}$ Cd (lowest concentration tested), added as cadmium nitrate, reduced dehydrogenase activity by $47 \%$.

Lighthart and Bond (1976) investigated the effects of $\mathrm{Cd}$ (as $\left.\mathrm{CdCl}_{2}\right)$ added to a small $(600 \mathrm{ml})$ soil and litter microcosm. Soil was homogenized and sieved and the overlying plant litter layer was sieved. The $\mathrm{Cd}(0.006$ or $6.1 \mathrm{ppm} \mathrm{Cd})$ was introduced into the microcosm by injecting an aqueous solution into the soil and litter with a syringe. After 24 days, the native soil and litter microflora exhibited a $43 \%$ reduction in respiration $\left(\mathrm{O}_{2}\right.$ uptake) in microcosms inoculated with $6.1 \mathrm{ppm} \mathrm{Cd}$.

Threshold levels of $\mathrm{Cd}$ (as cadmium acetate) for soil respiration of native microflora in three soils were determined by Reber (1989). The soils ranged in $\mathrm{pH}$ from 5.6 to 7, percent organic matter 1.7 to 2.6, and percent clay 3.2 to 21.3. There was no clear relationship between these soil characteristics and the magnitude of reduction in soil respiration at the concentrations tested. The highest LOEC concentration ( $56.3 \mathrm{ppm}$ ) for Cd was associated with the soil containing the lowest percentage of organic matter and the lowest $\mathrm{pH}$.

Liang and Tabatabai (1977) investigated the effects of various metals on $\mathrm{N}$ mineralization by native soil microflora in four soils varying in $\mathrm{pH}$ from 6 to 7.8 , clay from 23 to $34 \%$, and organic matter content from 6 to $11 \%$. Only one concentration of each metal was tested and was added to the soil as a salt solution. Cadmium reduced $\mathrm{N}$ mineralization in two soils at $562 \mathrm{ppm}$ but no relationship between soil characteristics and effects of $\mathrm{Cd}$ could be discerned.

Bollag and Barabasz (1979) evaluated the effects of several metals on denitrification in autoclaved soil by three species of soil-dwelling Pseudomonas species of bacteria andon denitrification in soil by native soil microflora. The silt loam soil was autoclaved to kill the majority of its microflora, inoculated with individual metals and bacterial populations, and incubated 4 days under anaerobic conditions. The same soil was used to determine the effects of metals on denitrification by the native soil microflora after 21-day incubation under anaerobic conditions. In the autoclaved soil, two of the three Pseudomonas species had reductions in activity at $50 \mathrm{ppm} \mathrm{Cd}$, while the third was more sensitive to the toxic effects of this metal (and $\mathrm{Cu}$ and $\mathrm{Zn}$ ) on denitrification. The native soil population in unautoclaved soil was more tolerant of the $C d$, with reductions in activity at $100 \mathrm{ppm} \mathrm{Cd}$. It is not clear whether this difference is due to changes in the chemical and physical nature of the soil during autoclaving or to other organisms in the natural soil being more tolerant to $\mathrm{Cd}$.

Khan and Frankland (1984) used a dyed cellophane film technique to evaluate the effects of Cd on cellulolytic activity of native soil microflora in a Brown earth soil ( $\mathrm{pH} 4.6)$. The film was encased in nylon mesh, buried in the potted soils containing $\mathrm{Cd}$ added as $\mathrm{CdCl}_{2}$, and allowed to equilibrate for 15 days. After a further 30 days past the equilibrium period, the film was retrieved and analyzed for dye release. A $35 \%$ reduction in percent cellulose decomposition was measured in pots containing $100 \mathrm{ppm} \mathrm{Cd}$, while $50 \mathrm{ppm}$ had no effect. 
Lighthart et al. (1977) evaluated the effects of a number of metals at single concentrations on respiration of native soil microflora in small coniferous forest soil/litter microcosms. Metals in solution form were mixed into the soil and litter which were then layered in the microcosm. Cadmium at $920 \mathrm{ppm}$ reduced respiration $61 \%$.

In a study on the effects of $\mathrm{Cd}$ on $\mathrm{N}$ mineralization and nitrification by native soil microflora in a moderately acid soil, Bewley and Stotzky (1983) found $N$ mineralization to be unaffected by $\mathrm{Cd}$ levels up to $1000 \mathrm{ppm}$, the highest concentration tested. Nitrification was reduced $62 \%$ by 1000 ppm.

The effects of $\mathrm{Cd}$ as $\mathrm{CdCl}_{2}$ on carbon and nitrogen mineralization and nitrogen transformations in alfalfa-amended sieved soil were determined by Suter and Sharples (1984). The silt loam soil had a pH of 4.7. At 3 days, respiration was reduced by $20 \%$ at $500 \mathrm{ppm}$, but at later dates no significant reduction occūrred. Ammonia levels were increased (by as much as a factor of 12) on days 22 to 53 at $50 \mathrm{ppm} \mathrm{Cd}$ and higher. Nitrate levels were reduced by $>21 \%$ on days 25,32 , and 39 at $50 \mathrm{ppm}$ $\mathrm{Cd}$ and higher, but on days 46 and 53 significant effects occurred at only $100 \mathrm{ppm}$ and higher. These results suggest that nitrification is highly sensitive to $C d$ relative to $C$ mineralization and may be chronically reduced at $50 \mathrm{ppm}$.

A benchmark of $20 \mathrm{ppm} \mathrm{Cd}$ was established as the 10th percentile of the 47 reported effective values. Confidence in this benchmark is high because of the relatively large amount of data available for a variety of functional measures.

Chromium. Liang and Tabatabai (1977) investigated the effects of various metals on $N$ mineralization by native soil microflora in four soils, as described for Cd. Chromium(III) at $260 \mathrm{ppm}$ reduced $\mathrm{N}$ mineralization in the soil containing the highest organic matter content. This same soil showed an effect of added $\mathrm{Cu}$.

The effects of $\mathrm{Cr}(\mathrm{III})$ on dehydrogenase activity of the native soil microflora in soil from the Rocky Mountain Arsenal was assessed by Rogers and Li (1985) as described previously for Cd. After 6 days, a concentration of $30 \mathrm{ppm} \mathrm{Cr}$ (the lowest concentration tested) reduced dehydrogenase activity by $54 \%$.

Juma and Tabatabai (1977) used the system described for $\mathrm{Al}$ to evaluate the effect of $\mathrm{Cr}$ on soil acid and alkaline phosphatase activities. Acid and alkaline phosphatase activities were affected at $1635 \mathrm{ppm}$ in all three soils to about the same degree, but greater inhibition of alkaline phosphatase activity occurred in the soil with the greatest content of organic matter and clay.

Ross et al. (1981) evaluated the relative toxicities of forms of $\mathrm{Cr}$ to respiration of native soil microflora in a loam and a sandy loam soil. After 22 days, $\mathrm{Cr}$ (III), tested at only $100 \mathrm{ppm}$, caused reductions in both soils of 41 and $48 \%$. A concentration of $10 \mathrm{ppm}$ (the lowest concentration tested) $\mathrm{Cr}$ (VI) caused reductions in both soils ( 27 and $33 \%$ ). In this experiment, $\mathrm{Cr}(\mathrm{VI})$ was more toxic than $\mathrm{Cr}$ (III) to soil respiration.

Premi and Cornfield $(1969,1969 / 1970)$ investigated the effects of $\mathrm{Cr}$ added to a sandy loam soil on nitrogen transformations by native soil microflora. In a 21-day experiment (1969), nitrification was severely inhibited at $1000 \mathrm{ppm} \mathrm{Cr}$ (added as sulfate salt), but was unaffected at $100 \mathrm{ppm}$. In an 8-week experiment (1969/1970) with sucrose and ammonium nitrate added to the soil, nitrification was not affected by $10,000 \mathrm{ppm} \mathrm{Cr}$, the highest concentration tested. Possible 
reasons for the differences in results for the two sets of experiments are differences in exposure duration and effects of amendments.

Bhuiya and Comfield (1976) investigated the effects of several metals on $N$ mineralization and nitrification by native soil microflora in a sandy soil at different $\mathrm{pH}$ levels. Metals were added to the soil as oxides to achieve a concentration of $1000 \mathrm{ppm}$, and the $\mathrm{pH}$ was adjusted to 7 (or left at the natural $\mathrm{pH} \mathrm{6}$ ) before a 2-month equilibration period. After an additional 6 or 12 weeks past the equilibrium period, $\mathrm{N}$ transformation measures were made. After 6 weeks, both mineralization and nitrification were reduced by $1000 \mathrm{ppm} \mathrm{Cr}$ at $\mathrm{pH} \mathrm{7,} \mathrm{but} \mathrm{not} \mathrm{at} \mathrm{pH}$ 6. After 12 weeks, neither mineralization nor nitrification was affected by $\mathrm{Cr}$ at either $\mathrm{pH}$.

The effects of soil characteristics on toxicity of $\mathrm{Cr}$ to arylsulfatase activity was evaluated by Al-Khafaji and Tabatabai (1979) using methods described for Al. Activity was reduced in all soils at $1300 \mathrm{ppm} \mathrm{Cr}$. Magnitude of reduction was inversely related to soil organic $\mathrm{C}$ content.

Haanstra and Doelman (1991) investigated short- and long-term effects of $\mathrm{Cr}$ on arylsulfatase activity, urease activity (Doelman and Haanstra, 1986), and total phosphatase activity (Doelman and Haanstra, 1989) by native soil microflora in five soils, as described for $\mathrm{Cd}$. In the 6-week incubation study on the effects of $\mathrm{Cr}$, data from the silt loam soil were not available for arylsulfatase activity and not available from the sandy loam soil for urease. The highest $\mathrm{EC}_{50} \mathrm{~s}$ were 3203,5512 , and 4470 $\mathrm{ppm}$, respectively, for arylsulfatase, phosphatase, and urease activities found in different soils. The lowest was $17 \mathrm{ppm}$ in the sand for arylsulfatase and 1170 and $490 \mathrm{ppm}$ in the clay for phosphatase and urease. In an 18-month study, the highest $\mathrm{EC}_{50}$ s were 1798,20020 , and $1110 \mathrm{ppm} \mathrm{Cr}$, respectively, for arylsulfatase, phosphatase, and urease activities found in different soils. The lowest were 12 and $<1 \mathrm{ppm}$ in the clay for arylsulfatase and urease activities and $2692 \mathrm{ppm}$ in the sandy loam for phosphatase activity.

The benchmark for $\mathrm{Cr}$ was established at $10 \mathrm{ppm}$ because the 10 th percentile lies between the $\mathrm{EC}_{50}$ values of 12 and $15 \mathrm{ppm}$ from the work of Haanstra and Doelman (1991). Confidence in this benchmark is high because of the relatively large amount of data available for a variety of functional measures.

Cobalt. Lighthart et al. (1977) evaluated the effects of Co at a single concentration on respiration of native soil microflora in soil/litter microcosms, as described for Cd. Co at $1362 \mathrm{ppm}$ reduced respiration $23 \%$.

The benchmark of $1000 \mathrm{ppm}$ comes from this study. Confidence in the benchmark is low because of the limited amount of data available.

Copper. Liang and Tabatabai (1977) investigated the effects of various metals on $\mathrm{N}$ mineralization by native soil microflora in four soils, as described for Cd. Copper at $320 \mathrm{ppm}$ severely reduced $\mathrm{N}$ mineralization in one soil. This same soil showed an effect of added $\mathrm{Cr}$ (III).

The effects of $\mathrm{Cu}$ on dehydrogenase activity of the native soil microflora in soil from the Rocky Mountain Arsenal was assessed by Rogers and Li (1985) using methods described for Cd. A concentration of $30 \mathrm{ppm} \mathrm{Cu}$ (the lowest concentration tested) $\mathrm{Cu}$ reduced dehydrogenase activity by $28 \%$. 
Bollag and Barabasz (1979) evaluated the effects of $\mathrm{Cu}$ on denitrification by three species of soil-dwelling Pseudomonas species of bacteria in autoclaved soil and by native soil microflora, as described for $\mathrm{Cd}$. In the autoclaved soil, there was a range of sensitivities of the Pseudomonas species to $\mathrm{Cu}$. LOECs ranged from 10 (lowest concentration tested) to $250 \mathrm{ppm}$ (highest concentration tested). The organism most sensitive to the effects of $\mathrm{Cd}$ and $\mathrm{Zn}$ was also more sensitive to the toxic effects of $\mathrm{Cu}$ on denitrification. Denitrification by the native soil population was reduced $44 \%$ by $250 \mathrm{ppm} \mathrm{Cu}$.

The effects of adding $\mathrm{Cu}$, as $\mathrm{CuSO}_{4}$, to a sandy loam adjusted to three $\mathrm{pH}$ levels on $\mathrm{N}$ mineralization during a 21-day incubation was assessed by Quraishi and Comfield (1973). Mineralization was decreased by $1000 \mathrm{ppm} \mathrm{Cu}$ at all three $\mathrm{pH}$ levels $(5.1,5.9$, and 7.3) with inhibitory effect increasing with decreasing $\mathrm{pH}$ from $39 \%$ to $100 \%$.

Premi and Cornfield $(1969,1969 / 1970)$ investigated the effects of several metals added to a sandy loam soil on nitrogen transformations by native soil microflora. In a 21-day experiment (1969), nitrification was severely inhibited at $10,000 \mathrm{ppm} \mathrm{Cu}$, added as $\mathrm{CuSO}_{4}$, but unaffected at $1000 \mathrm{ppm}$. Copper added in carbonate form was ineffective at $10,000 \mathrm{ppm}$ (highest concentration tested), probably because of the increase in soil pH caused by addition of this form. In an 8-week experiment (1969/1970) with sucrose and ammonium nitrate added to the soil, nitrification was decreased at $1000 \mathrm{ppm} \mathrm{Cu}$ but unaffected at $100 \mathrm{ppm}$. Possible reasons for the differences in results between the two experiments are differences in exposure duration and effects of amendments.

Bhuiya and Cornfield (1972) assessed the effects of several metals on C mineralization by native microflora in a sandy soil, with or without added organic matter. Metals were added to the soil as oxides to achieve a concentration of $1000 \mathrm{ppm}$ and a small amount of ground oat straw was added to part of the soil before a 2-month equilibration period. After a further 12 weeks, soil respiration was reduced in the $\mathrm{Cu}$-treated soil with amendment but not in the unamended soil.

The influence of soil characteristics on effects of $\mathrm{Cu}$ on arylsulfatase activity was evaluated by Al-Khafaji and Tabatabai (1979) using methods described previously for Al. In the soil with the highest $\mathrm{pH}$ (7.6), $\mathrm{Cu}$ had no effect. Arylsulfatase activity in the other three soils was reduced by $\mathrm{Cu}$ at a concentration of $1590 \mathrm{ppm}$. Reductions were the least severe in the soil having the highest organic carbon and clay content.

Juma and Tabatabai (1977) used the system described for Al to evaluate the effects of two forms of $\mathrm{Cu}$ on soil acid and alkaline phosphatase activities. Acid phosphatase activity was affected by $\mathrm{Cu}(\mathrm{I})$ and $\mathrm{Cu}(\mathrm{II})$ in all three soils about equally at a concentration of $1590 \mathrm{Cu}$ (lowest concentration tested). The greatest reduction occurred in the soil with the lowest $\mathrm{pH}$ and the lowest contents of organic matter and clay. Alkaline phosphatase activity was more sensitive to $\mathrm{Cu}(\mathrm{I})$ than $\mathrm{Cu}(\mathrm{II})$.

Haanstra and Doelman (1991) investigated short- and long-term effects of $\mathrm{Cu}$ on arylsulfatase activity, urease activity (Doelman and Haanstra, 1986), and total phosphatase activity (Doelman and Haanstra, 1989) for native soil microflora in five soils, as described for Cd. In the 6-week study, data were not available for phosphatase activity in the sandy loam or for urease activity in the silt loam. The highest $\mathrm{EC}_{50} \mathrm{~s}$ for arylsulfatase and phosphatase activities $(14,946$ and $6424 \mathrm{ppm})$ was found in the soil with the highest $\mathrm{pH}$ (silt loam). The highest $\mathrm{EC}_{50}$ for urease activity $(4200 \mathrm{ppm})$ was found in the soil with the greatest content of organic matter and the lowest $\mathrm{pH}$ (sandy peat). The lowest $\mathrm{EC}_{50} \mathrm{~s}$, all found in the sand, were 390,140 , and $260 \mathrm{ppm}$ for arylsulfatase, phosphatase, and urease. In the 18-month incubation study, the highest $\mathrm{EC}_{50}$ were 6996 and $4200 \mathrm{ppm} \mathrm{Cu}$ in the soil with the 
greatest percentage organic matter for arylsulfatase and urease activities and $2773 \mathrm{ppm}$ for phosphatase in the clay soil. Lowest $\mathrm{EC}_{50} \mathrm{~s}$ were 203,170 , and $680 \mathrm{ppm}$ in the sand for arylsulfatase, phosphatase, and urease activities, respectively.

The effects of $\mathrm{Cu}$ (as $\mathrm{CuCl}_{2}$ ) on carbon and nitrogen mineralization and nitrogen transformations in alfalfa-amended sieved soil were determined by Suter and Sharples (1984). The silt loam soil had a pH of 4.7 . At 10 days, respiration was reduced by $24 \%$ at $100 \mathrm{ppm}$, but significant reductions occurred at $500 \mathrm{ppm}$ on days 3 and 14 and at $1000 \mathrm{ppm}$ on all dates. Ammonia concentration was decreased significantly by $58 \%$ on days 4 and 11 at $10 \mathrm{ppm}$, but there was no increase of effects with concentration on those dates, and ammonia concentrations were unchanged or increased at those concentrations on later dates. Ammonia concentrations were significantly increased at 500 and $1000 \mathrm{ppm}$ from day 18 to 53 , and after day 18 there were regular patterns of increasing ammonia at increasing $\mathrm{Cu}$ levels. Nitrate levels were reduced by $21 \%$ on day 4 at a concentration of $10 \mathrm{ppm}$, but not on later dates. On day 11 , nitrate concentrations were significantly reduced to $50-1000 \mathrm{ppm}$ (but increased at $10 \mathrm{ppm}$ ), and on days 18 to 53 , they were significantly reduced only at 500 and $1000 \mathrm{ppm} \mathrm{Cu}$. These results suggest that nitrification is highly sensitive to $\mathrm{Cu}$, relative to $\mathrm{C}$ and $\mathrm{N}$ mineralization. If the chronic response is used as the basis for the benchmark, the threshold for significant effects in this test is $500 \mathrm{ppm} \mathrm{Cu}$.

The benchmark for $\mathrm{Cu}$ has been established at $100 \mathrm{ppm}$. Confidence in this benchmark is high.

Fluoride. The effects of fluoride, added as potassium fluoride to poplar litter, on nitrogen and phosphorus mineralization by native microflora was investigated by van Wensem and Adema (1991). The newly fallen (2 months old) litter was air-dried, cut into small pieces, and rewetted with $\mathrm{KF}$ solutions of varying concentrations. After 9 weeks, $\mathrm{K}$ mineralization was reduced $22 \%$ in litter treated with $32.3 \mathrm{ppm} \mathrm{F}$, the lowest concentration tested. Nitrogen mineralization was reduced $26 \%$ by $100.7 \mathrm{ppm}$, while $32.3 \mathrm{ppm}$ had no effect.

The effects of $F$ on dehydrogenase activity of the native soil microfiora in soil from the Rocky Mountain Arsenal was assessed by Rogers and $\mathrm{Li}$ (1985) as described previously for Cd. A concentration of $5000 \mathrm{ppm} F$ reduced dehydrogenase activity by $30 \%$ ( $3000 \mathrm{ppm}$ had no effect).

The toxic concentration of $32 \mathrm{ppm}$ (van Wensem and Adema, 1991) is the lowest of the two reported. Confidence in the benchmark of $30 \mathrm{ppm}$ is low because of the limited amount and type of data available.

Iron. Liang and Tabatabai (1977) investigated the effects of Fe on $\mathrm{N}$ mineralization by native soil microflora in four soils, as described for Cd. Iron(III) reduced $\mathrm{N}$ mineralization in one soil at 280 ppm. This same soil showed an effect of added Cd.

The influence of soil characteristics on effects of Fe(III) on arylsulfatase activity was evaluated by Al-Khafaji and Tabatabai (1979) as described previously for Al. In the soil with the highest $\mathrm{pH}$ (7.6), Fe(III) had no effect. Activity was reduced in all other soils at $1398 \mathrm{ppm}$ Fe. The magnitude of reduction generally was inversely related to soil $\mathrm{pH}$.

Juma and Tabatabai (1977) used the system described for Al to evaluate the effects of Fe(II) and Fe(III) on soil acid and alkaline phosphatase activities. Iron(II) reduced acid phosphatase activity at $1398 \mathrm{ppm}$ in only the soil with the lowest $\mathrm{pH}$ and organic matter and clay contents. Iron(III) reduced activity to a greater degree in this soil and also in the soil with the second lowest 
$\mathrm{pH}$ (but highest organic matter and clay contents). Iron(II) inhibited alkaline phosphatase activity in one of the soils tested and Fe(II) in the soil in which both forms of $\mathrm{Fe}$ inhibited acid phosphatase activity.

The effective concentration of $280 \mathrm{ppm}$ (Liang and Tabatabai, 1977) is the lowest of the nine reported. Confidence in the benchmark of $200 \mathrm{ppm}$ is low because of the limited amount and type of data available.

Lanthanum. Lighthart et al. (1977) evaluated the effects of $\mathrm{La}$ (as $\mathrm{LaCl}_{2}$ ) at a single concentration on respiration of native soil microflora in soil/litter microcosms, as described for Cd. After 23 days, lanthanum at $57 \mathrm{ppm}$ reduced respiration by $22 \%$.

The benchmark of $50 \mathrm{ppm}$ (Al-Khafaji and Tabatabai, 1979) is based on this work. Confidence in the benchmark is low because of the limited amount of data available.

Lead. Khan and Frankland (1984) used a dyed cellophane film technique to evaluate the effects of

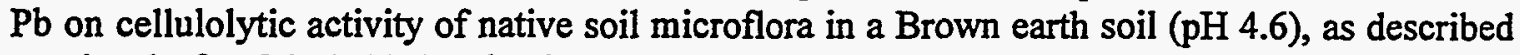
previously for $\mathrm{Cd}$. A $23 \%$ reduction in percent cellulose decomposition was measured in pots containing $1000 \mathrm{ppm} \mathrm{Pb}$, while $500 \mathrm{ppm}$ had no effect.

The mediating influence of clay on effects of lead on soil respiration was assessed by Debosz et al. (1985). The sandy loam soil ( $9 \%$ clay) was amended with glucose and $\mathrm{Pb}$ acetate in solution. After 15 days, respiration was reduced $29 \%$ by $10,000 \mathrm{ppm} \mathrm{Pb}(1000 \mathrm{ppm}$ had no effect). In the same soil amended with either $9 \%$ by weight kaolinite or montmorillonite, $\mathrm{Pb}$ up to $10,000 \mathrm{ppm}$ had no effect.

Cole (1977) assessed the effects of various carbohydrate additions and $\mathrm{Pb}$ compounds on amylase synthesis and activity by native soil microflora in a silt loam soil. Carbohydrates were added to the soil in solution and $\mathrm{Pb}$ in dry salt form. With the addition of glucose and lead acetate, amylase activity was more sensitive than synthesis, with a $74 \%$ reduction at the lowest concentration tested $(2000 \mathrm{ppm})$. With the addition of starch, amylase activity was reduced less by $\mathrm{PbCl}_{2}$ than with lead acetate and lead sulfate. With the addition of lead acetate, amylase activity was more sensitive with the addition of starch than with glucose. Cole also investigated the effect of $\mathrm{Pb}$ acetate on alpha-glucosidase synthesis and bacterial population size. Both were reduced by the addition of 2000 $\mathrm{ppm} \mathrm{Pb}$ (lowest concentration tested).

Liang and Tabatabai (1977) investigated the effects of $\mathrm{Pb}$ on $\mathrm{N}$ mineralization by native soil microflora in four soils, as described for Cd. Lead reduced $\mathrm{N}$ mineralization in one soil at $1035 \mathrm{ppm}$. This same soil showed an effect of added $\mathrm{Cd}$.

Bhuiya and Cornfield (1972) assessed the toxic effects of $\mathrm{Pb}$ on $\mathrm{C}$ mineralization by native microflora in a sandy soil, with or without added organic matter, as described for $\mathrm{Cu}$. After 12 weeks, soil respiration was reduced in the $\mathrm{Pb}$-treated soil without oat straw, but not in the strawamended soil.

Juma and Tabatabai (1977) used the system described for Al to evaluate the effects of two forms of $\mathrm{Pb}$ (acetate and nitrate) to soil acid and alkaline phosphatase activities. The two forms had equal effect on acid phosphatase activity at $5175 \mathrm{ppm}$ and that only in the soil with the lowest $\mathrm{pH}$ and organic matter and clay contents. They had equal effects on alkaline phosphatase activity at this 
concentration in one of the soils tested, and only $\mathrm{Pb}$ acetate was inhibitory in the soil with the highest organic matter and clay contents.

Haanstra and Doelman (1991) investigated short- and long-term effects of $\mathrm{Pb}$ on arylsulfatase activity, urease activity (Doelman and Haanstra, 1986), and total phosphatase activity (Doelman and Haanstra, 1989) by native soil microflora in five soils, as described for Cd. In the 6-week study on the effects of $\mathrm{Pb}$, data from the sandy loam, clay, and sandy peat soils were not available for arylsulfatase, the sand, sandy loam and peat for phosphatase, and the sand for urease. The highest $\mathrm{EC}_{50} \mathrm{~s}$ for arylsulfatase and phosphatase activities $(9138$ and $1168 \mathrm{ppm}$ ) were found in the clay soil. The highest $\mathrm{EC}_{50}$ for urease activity $(7190 \mathrm{ppm})$ was found in the silt loam (highest $\mathrm{pH}$ ). The lowest were 8288,8184 , and $5060 \mathrm{ppm} \mathrm{Pb}$ for arylsulfatase, phosphatase, and urease activities. In the 18month study, data from the sandy peat soil were not available for arylsulfatase and phosphatase and from the clay and sandy loam for phosphatase. The highest $\mathrm{EC}_{50} \mathrm{~s}$ were $12,411 \mathrm{ppm}$ in the soil with the highest clay for arylsulfatase, 78,943 ppm for phosphatase in the sand, and 8130 in the silt loam for urease. The lowest $\mathrm{EC}_{50} \mathrm{~s}$ were 3004,7604 , and $1340 \mathrm{ppm}$, in different soils.

Doelman and Haanstra (1979) evaluated the effects of $\mathrm{Pb}$ on soil respiration and dehydrogenase activity in several soils. After 24 hours, respiration in a sand ( $\mathrm{pH} 5.7$, percent organic matter 3) was reduced by $750 \mathrm{ppm} \mathrm{Pb}$, the lowest concentration tested. Dehydrogenase activity was not affected at this concentration. After 40 months, respiration in this soil was reduced to approximately the same degree at $1500 \mathrm{ppm}$, the lowest concentration tested. Dehydrogenase activity was not evaluated. In another sandy soil, (pH 5.4, percent organic matter 6.7), dehydrogenase activity was severely inhibited by $1500 \mathrm{ppm}$, but not at $750 \mathrm{ppm} \mathrm{Pb}$ after 24 hours. Respiration was not affected at this concentration. In a clay soil, dehydrogenase activity was inhibited by $375 \mathrm{ppm}$, the lowest concentration tested. Respiration was not evaluated.

The benchmark of $900 \mathrm{ppm} \mathrm{Pb}$ is the 10 th percentile of the 36 reported effective values. Confidence in this benchmark is high because of the relatively large amount of data available for a variety of functional measures.

Lithium. Lighthart et al. (1977) evaluated the effects of $\mathrm{Li}$ at a single concentration on respiration of native soil microflora in soil/litter microcosms, as described for $\mathrm{Cd}$. Lithium at $17 \mathrm{ppm}$ reduced respiration $43 \%$.

The effective concentration of $10 \mathrm{ppm}$ was derived from this study. Confidence in the benchmark is low because of the limited amount of data available.

Manganese. Liang and Tabatabai (1977) investigated the effects of Mn on N mineralization by native soil microflora in four soils, as described for Cd. Manganese at $275 \mathrm{ppm}$ reduced $\mathrm{N}$ mineralization in one soil. This same soil showed an effect of added $\mathrm{Cd}$.

Premi and Cornfield (1969) investigated the effects of $\mathrm{Mn}$ added to a sandy loam soil on nitrogen transformations by native soil microflora. In a 21-day experiment, nitrification was severely inhibited at $100 \mathrm{ppm}$, added as sulfate salt, the lowest concentration tested.

Juma and Tabatabai (1977) used the system described for Al to evaluate the effect of Mn on soil acid and alkaline phosphatase activities. Acid phosphatase activity was affected at $1375 \mathrm{ppm}$ only in the soil with the lowest $\mathrm{pH}$ and organic matter and clay contents. Alkaline phosphatase activity was reduced in one of the soils tested by this same concentration. 
The effective concentration of $100 \mathrm{ppm}$ (Premi and Cornfield, 1969) the lowest of the four reported. Confidence in the benchmark of $100 \mathrm{ppm}$ is low because of the limited amount and type of data available.

Mercury. van Fanssen (1973) investigated the effects of an inorganic and an organic mercury compound on $\mathrm{N}$ mineralization and nitrification by native soil microflora in two alkaline soils: a dune sand with $2 \%$ organic matter and a mix of two clay soils with $6 \%$ organic matter. Little information was provided concerning the experimental design. In the clay soil, both $\mathrm{HgCl}_{2}$ and phenylmercury acetate reduced nitrification at $100 \mathrm{ppm} \mathrm{Hg}$ (10 ppm had no effect), but the organic form was more inhibitory than the inorganic form. Mineralization was not affected by the inorganic form but was decreased by phenylmercury acetate. In the dune sand, $\mathrm{HgCl}_{2}$ severely reduced nitrification at $100 \mathrm{ppm}$ (10 ppm had no effect) and phenylmercury acetate reduced nitrification at $10 \mathrm{ppm} \mathrm{Hg}$ (lowest concentration tested). Mineralization was not affected by the organic form but was decreased by $\mathrm{HgCl}_{2}$ at $100 \mathrm{ppm} \mathrm{Hg}$. This work indicates that the relative toxicity of various forms of $\mathrm{Hg}$ can be influenced by soil characteristics.

Landa and Fang (1978) investigated the effects of mercuric chloride (up to $100 \mathrm{ppm} \mathrm{Hg}$ ) on carbon mineralization by native soil microflora in five agricultural topsoils varying in $\mathrm{pH}$ and organic matter content. The magnitude of effects varied greatly among the soils and were not related to those two soil characteristics. Effects ranged from an $87 \%$ reduction at $0.1 \mathrm{ppm}$ (the lowest concentration tested) in one of the soils to no effect at $100 \mathrm{ppm}$ in another soil.

Bremner and Douglas (1971) evaluated the effects of several metals on urease activity in two soils with similar $\mathrm{pH}$, organic matter, and clay content characteristics. Metals were added individually in solution at a concentration of $50 \mathrm{ppm}$, and urease activity was determined after 5 hours. Mercury, added either as the chloride or sulfate salt, decreased urease activity by 36 to $42 \%$ in both soils.

Liang and Tabatabai (1977) investigated the effects of $\mathrm{Hg}$ on $\mathrm{N}$ mineralization by native soil microflora in four soils, as described for Cd. Mercury reduced N mineralization in all soils at 1003 $\mathrm{ppm}$. The greatest magnitude of the toxic effect was seen in the soil having the lowest $\mathrm{pH}$ and organic matter and clay contents.

The influence of soil characteristics on effects of $\mathrm{Hg}$ on arylsulfatase activity was evaluated by Al-Khafaji and Tabatabai (1979) as described previously for Al. In two soils tested with a lowest concentration of $502 \mathrm{ppm}$, arylsulfatase activity was greatly reduced. In the two soils tested with a lowest concentration of $5015 \mathrm{ppm}$, arylsulfatase activity was inhibited almost totally. No clear differences between the soils with regard to effects on toxicity of $\mathrm{Hg}$ could be discerned.

Frankenberger and Tabatabai (1981) investigated the effect of $\mathrm{Hg}$ on amidase activity in three soils in shaker flask assays as described previously. After $21 / 2$ hours, amidase activity was reduced in all three soils at $5015 \mathrm{ppm}$. The greatest reduction occurred in the soil with the lowest $\mathrm{pH}$ and organic matter and clay contents.

Juma and Tabatabai (1977) used the system described for Al to evaluate the effect of $\mathrm{Hg}$ on soil acid and alkaline phosphatase activities. Acid and alkaline phosphatase activities were affected at $5015 \mathrm{ppm}$ in all three soils to about the same degree. 
The benchmark of $30 \mathrm{ppm} \mathrm{Hg}$ is the 10 th percentile of the 27 reported effective values. Confidence in this benchmark is high because of the relatively large amount of data available for a variety of functional measures.

Molybdenum. Liang and Tabatabai (1977) investigated the effects of Mo on $\mathrm{N}$ mineralization by native soil microflora in four soils, as described for $\mathrm{Cd}$. Molybdenum reduced $\mathrm{N}$ mineralization in three of the soils at $480 \mathrm{ppm}$. No toxic effect was seen in the soil having the lowest $\mathrm{pH}$ and organic matter and clay contents. No clear relationship between soil characteristics and magnitude of effects of Mo could be discerned.

The influence of soil characteristics on effects of Mo on arylsulfatase activity was evaluated by Al-Khafaji and Tabatabai (1979) as described previously for Al. In the soil with the highest clay and organic matter contents, Mo had no effect. Activity was severely reduced at $2398 \mathrm{ppm}$ (lowest concentration tested) in the soil with the lowest $\mathrm{pH}$ and organic matter content. It is possible that activity in this soil would have been inhibited to a somewhat lesser degree by $240 \mathrm{ppm} \mathrm{Mo}$, as it was in the two remaining soils.

Juma and Tabatabai (1977) used the system described for Al to evaluate the effect of Mo on soil acid and alkaline phosphatase activities. Acid phosphatase activity in all three soils was reduced at $2398 \mathrm{ppm}$. In the soil with the lowest $\mathrm{pH}$, and organic matter and clay contents, it was also inhibited at $240 \mathrm{ppm} \mathrm{Mo}$. Alkaline phosphatase activity in both soils tested was reduced about the same degree at this concentration.

The benchmark for Mo was established at $200 \mathrm{ppm}$ based on the work of Al-Khafaji and Tabatabai (1979). Confidence in this benchmark is moderate.

Nickel. The effects of $\mathrm{Ni}$, as nickel sulfate, on dehydrogenase activity of the native soil microflora in soil from the Rocky Mountain Arsenal was assessed by Rogers and Li (1985) as described previously for Cd. After 6 days, a concentration of $30 \mathrm{ppm}$ (lowest concentration tested) Ni reduced dehydrogenase activity by $39 \%$.

Babich and Stotzky (1982) evaluated the effects of two forms of $\mathrm{Ni}$ on mycelial growth rate of a number of soil-dwelling fungi inoculated individually into autoclaved sandy loam soil. The concentrations at which growth was reduced ranged from 50 to $750 \mathrm{ppm}$ for $\mathrm{Ni}$ (added in chloride or sulfate form).

Giashuddin and Cornfield assessed the effect of Ni added in oxide (1979) and sulfate (1978) forms on $\mathrm{N}$ and $\mathrm{C}$ mineralization by native soil microflora in a sandy soil. The metal salts were mixed into the soil in dry form. After 42 days incubation, soil respiration (C mineralization) was reduced in soil containing $10 \mathrm{ppm} \mathrm{Ni}$ from $\mathrm{Ni}$ sulfate (lowest concentration tested), and $\mathrm{N}$ mineralization was affected at $100 \mathrm{ppm}$. Soil respiration was reduced in soil containing $50 \mathrm{ppm} \mathrm{Ni}$ from $\mathrm{Ni}$ oxide (lowest concentration tested), and $\mathrm{N}$ mineralization was affected at $1000 \mathrm{ppm}$. Because of the test concentrations used, it is difficult to assess the relative toxicity of these two forms of $\mathrm{Ni}$ to $\mathrm{C}$ mineralization. When the soil $\mathrm{pH}$ was raised to 6.9 (from its normal 5.9), soil respiration was reduced in soil containing $250 \mathrm{ppm} \mathrm{Ni}$ from Ni oxide (lowest concentration tested), and $\mathrm{N}$ mineralization was affected at $1000 \mathrm{ppm}$. The effect of $\mathrm{Ni}$ from $\mathrm{Ni}$ sulfate was not tested at the higher $\mathrm{pH}$. Raising the $\mathrm{pH}$ appeared to affect soil respiration but not $\mathrm{N}$ mineralization. 
Bhuiya and Cornfield (1974) assessed the effects of $\mathrm{Ni}$ on $\mathrm{C}$ mineralization by native microflora in a sandy soil, with or without added organic matter, as described for $\mathrm{Cu}$. After 12 weeks, soil respiration was reduced in the Ni-treated soil with or without oat straw, but to a greater degree in the straw-amended soil.

The influence of soil characteristics on effects of $\mathrm{Ni}$ on arylsulfatase activity was evaluated by Al-Khafaji and Tabatabai (1979) as described previously for Al. In only one soil was the highest concentration tested, $1468 \mathrm{ppm}$, found to reduce arylsulfatase activity. This soil had the lowest $\mathrm{pH}$ and organic matter content of the four soils tested.

Juma and Tabatabai (1977) used the system described for Al to evaluate the effect of $\mathrm{Ni}$ on soil acid and alkaline phosphatase activities. Acid phosphatase activity was not affected at $1468 \mathrm{ppm}$ only in the soil with the highest $\mathrm{pH}$. Alkaline phosphatase activity was reduced in one of the soils tested by this same concentration.

Haanstra and Doelman (1991) investigated short- and long-term effects of $\mathrm{Ni}$ on arylsulfatase activity, urease activity (Doelman and Haanstra, 1986), and total phosphatase activity (Doelman and Haanstra, 1989) by native soil microflora in five soils, as described for Cd. In the 6-week study on the effects of $\mathrm{Ni}$, data from the sandy peat soil were not available for arylsulfatase and phosphatase activities. The highest $\mathrm{EC}_{50} \mathrm{~s}(5659,6516$, and $3380 \mathrm{ppm}$ for arylsulfatase, phosphatase, and urease activities) were found in the soil with the highest clay content. The lowest were 2119,1109 , and 100 $\mathrm{ppm}$, for arylsulfatase, phosphatase, and urease activities found in the sand. In the 18-month study, data from the sandy loam soil were not available for arylsulfatase activity nor from clay and sandy peat for phosphatase activities. The highest $\mathrm{EC}_{50} \mathrm{~s}$ were 8101,8042 , and $2790 \mathrm{ppm} \mathrm{Ni}$ for arylsulfatase, phosphatase, and urease activities in different soils. The lowest $\mathrm{LC}_{50} \mathrm{~S}, 92,769$, and 370 $\mathrm{ppm}$, were found in the sand.

A benchmark of $90 \mathrm{ppm} \mathrm{Ni}$ was established based on the 56 reported effective values. Confidence in this benchmark is high because of the relatively large amount of data available for a variety of functional measures.

Selenium. Lighthart et al. (1977) evaluated the effects of using methods at a single concentration on respiration of native soil microflora in soil/litter microcosms, as described for $\mathrm{Cd}$. Selenium at $484 \mathrm{ppm}$ reduced respiration $43 \%$.

The influence of soil characteristics on effects of Se on arylsulfatase activity was evaluated by Al-Khafaji and Tabatabai (1979) as described previously for Al. In the soil with the lowest clay content, activity was reduced by $198 \mathrm{ppm}$. In the other soils, arylsulfatase activity was reduced by $1975 \mathrm{ppm}$ with the greatest reduction in the soil with the lowest $\mathrm{pH}$ and organic matter content.

Frankenberger and Tabatabai (1981) investigated the effect of Se on amidase activity in three soils in shaker-flask assays as described previously. After $21 / 2$ hours, amidase activity was reduced in only one soil at $1975 \mathrm{ppm}$. This soil had the lowest $\mathrm{pH}$ and organic matter and clay contents of the soils tested.

Juma and Tabatabai (1977) used the system described for Al to evaluate the effect of Se(IV) to soil acid and alkaline phosphatase activities. Acid phosphatase activity in all three soils was reduced at $1975 \mathrm{ppm}$. Alkaline phosphatase activity in both soils tested was reduced about the same degree at this concentration. 


$$
\text { 4-14 }
$$

The effective concentration of $198 \mathrm{ppm}$ (Al-Khafaji and Tabatabai, 1979) is the lowest of the 10 reported. Confidence in the benchmark of $100 \mathrm{ppm}$ is moderate.

Silver. Bremner and Douglas (1971) evaluated the effects of Ag on urease activity in two soils, as described for $\mathrm{Hg}$. After 5 hours, silver, added as either nitrate or sulfate salt, decreased urease activity by 60 to $65 \%$ in both soils.

Liang and Tabatabai (1977) investigated the effects of $\mathrm{Ag}$ on $\mathrm{N}$ mineralization by native soil microflora in four soils, as described for Cd. Silver at $540 \mathrm{ppm}$ reduced $\mathrm{N}$ mineralization in all soils. The greatest magnitude of the inhibitory effect was seen in the soil having the lowest $\mathrm{pH}$ and organic matter and clay contents.

The influence of soil characteristics on effect of $\mathrm{Ag}$ on arylsulfatase activity was evaluated by Al-Khafaji and Tabatabai (1979) as described previously for Al. In two soils tested with a lowest concentration of $270 \mathrm{ppm}$, arylsulfatase activity was greatly reduced. In the two soils tested with a lowest concentration of $2698 \mathrm{ppm}$, arylsulfatase activity was almost totally inhibited.

Frankenberger and Tabatabai (1981) investigated the effect of $\mathrm{Ag}$ on amidase activity in three soils in shaker-flask assays as described previously. After $21 / 2$ hours, amidase activity was severely reduced in all three soils at $2698 \mathrm{ppm}$. The greatest reduction occurred in the soil with the lowest $\mathrm{pH}$ and organic matter and clay contents.

Juma and Tabatabai (1977) used the system described for Al to evaluate the effect of silver on soil acid and alkaline phosphatase activities. Acid phosphatase activity was affected at $2698 \mathrm{ppm}$ only in the soil with the highest $\mathrm{pH}$ (7.8). Alkaline phosphatase activity was reduced $28 \%$ in the loam soil at an Ag concentration of $270 \mathrm{ppm}$ and $93 \%$ at $2698 \mathrm{ppm}$ in a clay loam soil.

A benchmark of $50 \mathrm{ppm} \mathrm{Ag} \mathrm{was} \mathrm{established} \mathrm{based} \mathrm{on} \mathrm{the} 17$ reported effective values. Confidence in this benchmark is moderate.

Tin. The influence of soil characteristics on effect of $\mathrm{Sn}$ on arylsulfatase activity was evaluated by Al-Khafaji and Tabatabai (1979) as described previously for Al. In the soil with the highest pH (7.6), $\mathrm{Sn}$ had no effect. Arylsulfatase activity in the other three soils was reduced by $2968 \mathrm{ppm} \mathrm{Sn}$. The reductions were the least seyere in the soil having the highest organic $\mathrm{C}$ and clay content.

Juma and Tabatabai (1977) used the system described for Al to evaluate the effect of Sn on soil acid and alkaline phosphatase activities. Acid phosphatase activity was affected at $2968 \mathrm{ppm}$ only in the soil with the lowest $\mathrm{pH}$ and organic matter and clay contents. Alkaline phosphatase activity was reduced in both soils tested by this same concentration.

The effective concentration of $2968 \mathrm{ppm}$ (Al-Khafaji and Tabatabai, 1979) is the lowest of the seven reported. Confidence in the benchmark of $2000 \mathrm{ppm}$ is low because of the limited amount and type of data available.

Titanium. The influence of soil characteristics on effect of $\mathrm{Ti}$ (as $\mathrm{TiSO}_{4}$ ) to arylsulfatase activity was evaluated by Al-Khafaji and Tabatabai (1979) as described previously for Al. In two soils tested with a lowest concentration, arylsulfatase activity was reduced by $1198 \mathrm{ppm}$. These two soils had the lowest $\mathrm{pH}$ and organic matter and clay contents of the four tested. 
The effective concentration of $1198 \mathrm{ppm}$ (Al-Khafaji and Tabatabai, 1979) is the lowest of the two reported. Confidence in the benchmark of $1000 \mathrm{ppm}$ is low because of the limited amount and type of data available.

Tungsten. The influence of soil characteristics on effects of tungsten $(\mathrm{W})\left(\mathrm{Na}_{2} \mathrm{WO}_{4}\right)$ on arylsulfatase activity was evaluated by Al-Khafaji and Tabatabai (1979) as described previously for Al. In the soil with the highest clay and organic matter contents, W had no effect. Activity was reduced in all other soils at $4598 \mathrm{ppm}$, with the greatest reduction in the soil with the lowest clay content.

Juma and Tabatabai (1977) used the system described for Al to evaluate the effect of tungsten on soil acid and alkaline phosphatase activities. Acid phosphatase activity in all three soils was reduced at $4598 \mathrm{ppm}$. In the soil with the lowest $\mathrm{pH}$ and organic matter and clay content, it was also inhibited at $460 \mathrm{ppm} \mathrm{W.} \mathrm{Alkaline} \mathrm{phosphatase} \mathrm{activity} \mathrm{in} \mathrm{both} \mathrm{soils} \mathrm{tested} \mathrm{was} \mathrm{reduced} \mathrm{about} \mathrm{the}$ same amount at this concentration.

The effective concentration of $460 \mathrm{ppm}$ (Juma and Tabatabai, 1977) is the lowest of the seven reported. Confidence in the benchmark of $400 \mathrm{ppm}$ is low because of the limited amount and type of data available.

Vanadium. Tyler (1976) evaluated the effect of V, added in a solution of sodium vanadate to fresh needles from a white pine stand, on acid phosphatase activity of the native microflora. After 3 hours of exposure, activity was reduced $40 \%$ by $50 \mathrm{ppm} \mathrm{V}$, while $30 \mathrm{ppm}$ had no effect.

The influence of soil characteristics on effect of $V$ on arylsulfatase activity was evaluated by Al-Khafaji and Tabatabai (1979) as described previously for Al. In two soils tested with a lowest concentration of $127 \mathrm{ppm}$, arylsulfatase activity was reduced with the greatest reduction in the soil with the lowest clay content. In the two soils tested with a lowest concentration of $1273 \mathrm{ppm}$, arylsulfatase activity was severely inhibited.

Juma and Tabatabai (1977) used the system described for Al to evaluate the effect of $\mathrm{V}$ on soil acid and alkaline phosphatase activities. Acid phosphatase activity in all three soils was reduced about the same degree at $1273 \mathrm{ppm}$. In the soil with the lowest $\mathrm{pH}$ and organic matter and clay contents, it was also inhibited at $127.3 \mathrm{ppm} \mathrm{V}$. Alkaline phosphatase activity in both soils tested was reduced about the same degree at $1273 \mathrm{ppm}$. In the soil with the highest organic matter and clay contents, it was also inhibited at $127.3 \mathrm{ppm}$ V.

Lighthart et al. (1977) evaluated the effects of $\mathrm{V}$ at a single concentration on respiration of native soil microflora in soil/litter microcosms, as described for $\mathrm{Cd}$. Vanadium at $23 \mathrm{ppm}$ reduced respiration $21 \%$.

The effective concentration of $23 \mathrm{ppm}$ (Lighthart et al., 1977) is the lowest of the 10 reported. Confidence in the benchmark of $20 \mathrm{ppm}$ is moderate.

Zinc. Wilson (1977) evaluated the effect of $\mathrm{Zn}$, as zinc sulfate solution, on nitrification by native soil microflora in three soils. The soils ranged in $\mathrm{pH}$ from 5.1 to 6.2 , percent organic matter from 1.1 to 2.4 , and percent clay from 2 to 28 . After 49 days, nitrification was severely inhibited in all three soils ( 98 to $100 \%$ ) by $1000 \mathrm{ppm} \mathrm{Zn}$, while $\mathrm{Zn}$ at $100 \mathrm{ppm}$ had no effect. 
Haanstra and Doelman (1991) investigated short- and long-term effects of $\mathrm{Zn}$ on arylsulfatase activity, urease activity (Doelman and Haanstra, 1986), and total phosphatase activity (Doelman and Haanstra, 1989) by native soil microflora in five soils, described for Cd. In the 6-week study on the effects of $\mathrm{Zn}$, data from the sandy peat soil were not available for any of the enzymes. The highest $\mathrm{EC}_{50} \mathrm{~S}$ were 5559,3623 , and $1780 \mathrm{ppm}$ for arylsulfatase, phosphatase, and urease activities, all in the soil with the greatest content of clay. The lowest $\mathrm{EC}_{50} \mathrm{~s}$ of 909,220 , and $420 \mathrm{ppm} \mathrm{Zn}$ were all found in the sand. In the 18-month study, data were not available from the sandy peat for phosphatase or the silt loam for urease. The highest $\mathrm{EC}_{50} \mathrm{~s}$ were 9679,4872 , and $290 \mathrm{ppm} \mathrm{Zn}$ in different soils. The lowest $\mathrm{EC}_{50} \mathrm{~s}$ were 375,170 , and $70 \mathrm{ppm}$ in different soils.

Juma and Tabatabai (1977) used the system described for $\mathrm{Al}$ to evaluate the toxicity of $\mathrm{Zn}$ to soil acid and alkaline phosphatase activities. Acid and alkaline phosphatase activities were affected at $1635 \mathrm{ppm}$ in all three soils to about the same degree, except increased inhibition of alkaline phosphatase activity in the soil with the highest $\mathrm{pH}$.

The influence of soil characteristics on effects of $\mathrm{Zn}$ on arylsulfatase activity was evaluated by Al-Khafaji and Tabatabai (1979) as described previously for Al. A reduction in activity was measured in two soils tested at a concentration of $1635 \mathrm{ppm}$. No clear differences between the soils with regard to influence on effects of $\mathrm{Zn}$ could be discerned.

Bhuiya and Comfield (1974) investigated the effects of $\mathrm{Zn}$ on $\mathrm{N}$ mineralization and nitrification by native soil microflora in a sandy soil at different $\mathrm{pH}$ levels, as described for Cr. After 12 weeks, both mineralization and nitrification were reduced by $1000 \mathrm{ppm} \mathrm{Zn}$ at $\mathrm{pH} 7$, but not at $\mathrm{pH} 6$. After 6 weeks, neither mineralization nor nitrification was affected by $\mathrm{Zn}$ at either $\mathrm{pH}$.

Bhuiya and Cornfield (1974) investigated the effects of $1000 \mathrm{ppm} \mathrm{Zn}$ added as $\mathrm{Zn}$ oxide to a sandy soil at three $\mathrm{pH}$ levels on nitrogen mineralization by native soil microflora. After 42 days, $\mathrm{N}$ mineralization was reduced in the $\mathrm{pH} 7.7$ soil but not in soils at pH 6 and 7 .

The effects of $\mathrm{Zn}$ on dehydrogenase activity of the native soil microflora in soil from the Rocky Mountain Arsenal was assessed by Rogers and $\mathrm{Li}(1985)$ as described previously for $\mathrm{Cd}$. A concentration of $300 \mathrm{ppm} \mathrm{Zn}$ reduced dehydrogenase activity by $30 \% ; \mathrm{Zn}$ at $150 \mathrm{ppm}$ had no effect.

Laskowski et al. (1994) looked at the effects of several metals at low to moderate levels on the respiration rate of acid-mixed forest litter. The fresh litter was treated with solutions of $\mathrm{CdCl}_{2}$ (up to $250 \mathrm{ppm} \mathrm{Cd}$ ), $\mathrm{Pb}\left(\mathrm{NO}_{3}\right)_{2}$ (up to $2500 \mathrm{ppm} \mathrm{Pb}$ ), or $\mathrm{ZnCl}$. Only zinc had an effect at the concentrations tested. A concentration of $1000 \mathrm{ppm} \mathrm{Zn}$ reduced respiration by $26 \% ; \mathrm{Zn}$ at $200 \mathrm{ppm}$ had no effect.

The effect of $\mathrm{Cd}$ and $\mathrm{Zn}$ on respiration of soil microflora in field-collected black oak forest soil/litter microcosms was evaluated by Chaney et al. (1978). The metals, in solutions of chloride salts, were sprinkled over the litter layer of the chamber. After 23 days, Cd at a concentration up to $6 \mathrm{ppm}$ had no effect. Respiration was decreased $21 \%$ by $\mathrm{Zn}$ at $479 \mathrm{ppm} ; \mathrm{Zn}$ at $47 \mathrm{ppm}$ had no effect.

Bollag and Barabasz (1979) evaluated the effects of $\mathrm{Zn}$ on denitrification by three soil-dwelling Pseudomonas (bacteria) in autoclaved soil and by native soil microflora, as described for $\mathrm{Cd}$. In the autoclaved soil, two of the three species had reductions in activity at $250 \mathrm{ppm} \mathrm{Cd}$, while the organism most sensitive to the effects of $\mathrm{Cd}$ and $\mathrm{Cu}$ was also more sensitive to the toxic effects of $\mathrm{Zn}$ on denitrification. Denitrification by the native soil population was reduced $31 \%$ by $250 \mathrm{ppm} \mathrm{Zn}$. 
Lighthart et al. (1977) evaluated the effects of $\mathrm{Zn}$ at a single concentration on respiration of native soil microflora in soil/litter microcosms, as described for $\mathrm{Cd}$. Zinc at $3600 \mathrm{ppm}$ reduced respiration $66 \%$.

Premi and Cornfield $(1969,1969 / 1970)$ investigated the effects of $\mathrm{Zn}$ added to a sandy loam soil on nitrogen transformations by native soil microflora. In a 21-day experiment (1969), nitrification was severely inhibited at $100 \mathrm{ppm} \mathrm{Zn}$, added as sulfate salt, the lowest concentration tested. Zinc added in carbonate form was ineffective at 10,000 ppm (highest concentration tested), probably because of the increase in soil $\mathrm{pH}$ caused by addition of this form. In the 8-week experiment (1969/1970) with sucrose and ammonium nitrate added to the soil, nitrification was decreased only slightly less at $100 \mathrm{ppm} \mathrm{Zn}$ than it was in the 21-day study.

Leita et al. (1995) evaluated the effect of $\mathrm{Zn}\left[\mathrm{Zn}\left(\mathrm{SO}_{4}\right)_{2}\right]$ on microbial biomass of native microflora ina surface soil ( $\mathrm{pH} \mathrm{6,2 \%} \mathrm{organic} \mathrm{carbon,} \mathrm{and} 18 \%$ clay). After $56 \mathrm{~d}$, the $600 \mathrm{ppm}$ single treatment level nitrification reduced biomass $31 \%$.

The benchmark of $100 \mathrm{ppm} \mathrm{Zn}$ is the 10 th percentile of the 47 reported effective values. Confidence in this benchmark is high because of the relatively large amount of data available for a variety of functional response factors.

\subsubsection{Organic Chemicals}

Acrylonitrile. The effects of several organic compounds on respiration of native soil microflora in a sandy loam and a silt loam soil were evaluated by Walton et al. (1989). Both soils were acid (pH 4.9 and 5.3$)$ and low in organic matter (1.4 and 3\%) but differed with respect to amounts of clay (5\% vs and 30\%). Respiration was measured after 6-day exposure to $1000 \mathrm{ppm}$ of each chemical. Chemicals tested at $1000 \mathrm{ppm}$ had no effect and include methyl ethyl ketone, benzene, toluene, pxylene, chlorobenzene, chloroform, and other chlorinated benzenes. Acrylonitrile reduced respiration by $59 \%$ in the sandy loam soil and $41 \%$ in the silt loam. Clay appeared to have an ameliorating influence on the effects of acrylonitrile.

The benchmark of $1000 \mathrm{ppm}$ is based on this work. Confidence in the benchmark is low because of the limited amount and type of data available.

Carbon tetrachloride. The effects of $1000 \mathrm{ppm}$ carbon tetrachloride on respiration of native soil microflora in a sandy loam and a silt loam soil was evaluated by Walton et al. (1989) as described for acrylonitrile. Carbon tetrachloride reduced respiration by $21 \%$ in the sandy loam but did not lower respiration in the silt loam soil. Clay may have had an ameliorating influence on the effects of this compound.

The benchmark of $1000 \mathrm{ppm}$ is based on this work. Confidence in the benchmark is low because of the limited amount and type of data available.

Cis-1,4-dichloro-2-butene. The effects of cis-1,4-dichloro-2-butene on respiration of native soil microflora in a sandy loam and a silt loam soil was evaluated by Walton et al. (1989) as described for acrylonitrile. Cis-1,4-dichloro-2-butene reduced respiration by $48 \%$ in the sandy loam soil and $44 \%$ in the silt loam by $1000 \mathrm{ppm}$. Clay did not appear not to have an ameliorating influence on the effects of this compound. 
The benchmark of $1000 \mathrm{ppm}$ is based on this work. Confidence in the benchmark is low because of the limited amount and type of data available.

Hexachlorobenzene. The effects of $1000 \mathrm{ppm}$ hexachlorobenzene on respiration of native soil microflora in a sandy loam and a silt loam soil was evaluated by Walton et al. (1989) as described for acrylonitrile. Hexachlorobenzene reduced respiration by $37 \%$ in the silt loam but did not lower respiration in the sandy loam soil. Clay did not appear to have an ameliorating effect on the toxicity of this compound.

The benchmark of $1000 \mathrm{ppm}$ is based on this work. Confidence in the benchmark is low because of the limited amount and type of data available.

Nitrobenzene. The effects of $1000 \mathrm{ppm}$ nitrobenzene on respiration of native soil microflora in a sandy loam and a silt loam soil was evaluated by Walton et al. (1989) as described for acrylonitrile. Nitrobenzene reduced respiration by $61 \%$ in the sandy loam soil and by $22 \%$ in the silt loam. Clay appears to have an ameliorating influence on the effect of nitrobenzene.

The benchmark of $1000 \mathrm{ppm}$ is based on this work. Confidence in the benchmark is low because of the limited amount and type of data available.

Pentachlorophenol. van Beelen and Fleuren-Kemila (1993) evaluated the effect of pentachlorophenol (PCP) on mineralization of added acetate by native soil microflora in an acid agricultural soil and an acid dune sand. After 1.8 days, $\mathrm{CO}_{2}$ evolved was reduced $50 \%\left(\mathrm{EC}_{50}\right)$ by 460 $\mathrm{ppm}$ in the agricultural soil (percent organic matter, 10.4; percent clay, 5) and by $1500 \mathrm{ppm}$ in the dune sand (percent organic matter, 1.2; percent clay, 0.4).

van Beelen et al. (1994) evaluated the effect of PCP on mineralization of added acetate by native soil microflora in an alkaline polder agricultural soil ( $\mathrm{pH} 8, \%$ organic matter $1 ; \%$ clay 1 ) and

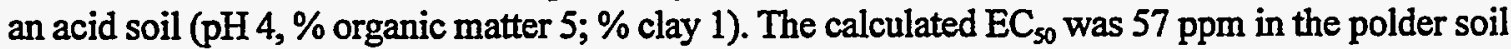
and $1207 \mathrm{ppm}$ in the soil containing a greater amount of organic matter.

The benchmark of $50 \mathrm{ppm}$ for PCP is based on the work of van Beelen et al. (1994). Confidence in the benchmark is low because of the limited amount and type of data available.

Phenol. Effects of phenol on carbon and nitrogen mineralization and nitrogen transformations in alfalfa-amended, sieved soil were determined by Suter and Sharples (1984). The silt loam soil had a pH of 4.7. Carbon dioxide production was increased at $10 \mathrm{ppm}$ and $100 \mathrm{ppm}$ on days 1 and 7 but not on later dates or at higher concentrations. $\mathrm{CO}_{2}$ production was decreased at $1000 \mathrm{ppm}$ phenol on day 1 , but not thereafter, and at $5000 \mathrm{ppm}$ phenol on days 1 through 55 . On all dates (days 7 through 42), ammonia concentrations were significantly increased and nitrate significantly decreased by 1000 and $5000 \mathrm{ppm}$ phenol. At 10 and $100 \mathrm{ppm}$ on day 7 and at $100 \mathrm{ppm}$ on day 42 , but not on intermediate dates, ammonia was significantly increased and nitrate decreased. If the lowest chronic response is used as the basis for the benchmark, the threshold for significant effects in this test is 100 ppm phenol.

The benchmark of $100 \mathrm{ppm}$ is based on this work. Confidence in the benchmark is low because of the limited amount and type of data available. 
Trans-1,4-dichloro-2-butene. The effects of $1000 \mathrm{ppm}$ trans-1,4-dichloro-2-butene on respiration of native soil microflora in a sandy loam and a silt loam soil was evaluated by Walton et al. (1989) as described for acrylonitrile. Trans-1,4-dichloro-2-butene reduced respiration by $44 \%$ in the sandy loam soil and $58 \%$ in the silt loam. Clay did not appear not to have an ameliorating influence on the effect of this compound.

The benchmark of $1000 \mathrm{ppm}$ is based on this work. Confidence in the benchmark is low because of the limited amount and type of data available. 


\section{INVERTEBRATES OTHER THAN EARTHWORMS AND MICROBIAL HETEROTROPHS}

\subsection{INTRODUCTION}

Interest in the toxic effects of soil pollutants on soil and litter dwelling invertebrates other than earthworms and microorganisms stems from concern for negative effects on nutrient cycling and availability and quality of food for animals feeding on soil and litter dwelling invertebrates. In general, the most important route for assimilation of metals by soil invertebrates is through the digestive tract (Beeby, 1991). Assimilation of toxic metals depends on diet and the animal's essential metal demand. In general, invertebrates with a high calcium demand tend to accumulate higher concentrations of toxic metals. The metals are often bound in intracellular granules, structural tissues, and membrane-bound vesicles. There is no clear relationship between the bioconcentration potential of a species and its susceptibility to metal intoxication (van Straalen, 1991).

Toxic effects of metals on invertebrates result in part from their interactions with nutritionally significant metals. van Straalen et al. (1989) suggest that the negative impact of cadmium on mite (Platynothrus peltifer) egg production results from disruption of the role of zinc in reproductive metabolism. Cadmium also blocks the calcium current of Helix neurons (Akaike et al., 1978), possibly leading to tissue damage and reduced reproduction (Russell et al., 1981). The interrelationships between metals, both essential and nonessential, appear to be quite complex and variable among species of invertebrates. Other effects may result from the binding of metals to proteins and enzymes with consequent functional disruption.

\subsection{INVERTEBRATE DATA SELECTION}

The experimental approaches are too diverse, and the data too meager to allow for the establishment of benchmarks for the toxicity of contaminants in soil to soil-dwelling invertebrates other than earthworms. Most experiments evaluating the effects on nematodes are conducted in solution because these organisms inhabit the water films around soil particles and roots. The experiments using Collembola and mites are often conducted by feeding the organisms on algae that were reared on contaminated media. Perhaps the most common method for other organisms is to surface apply a solution, or soluble powder, of the chemical to the organic substrate on which it is to feed during the experiment. At most contaminated sites, soil concentrations are available while soil algae, litter, and pore water concentrations are not. Surface applied chemicals are only appropriate when evaluating sites where deposition of air-borne contaminants onto vegetation and litter is the only route by which these food sources become contaminated. The bioavailability of chemicals introduced to food by these methods is not directly comparable to that of chemicals bound in organic form inside plant material or microflora. Furthermore, it would be difficult to assess the food preferences of these diverse and opportunistic organisms in any specific field situation (Hopkin, 1989) to allow appropriate sampling and analysis.

For the previously described reasons, no benchmarks have been set for these organisms. The information in this part of the document is provided as reference and support material. Experimental data are given in Appendix C. 


\subsection{INVERTEBRATE TEST SPECIES}

The literature on toxicity of chemicals to soil and litter-dwelling invertebrates presents experimental results using microarthropods, macroarthropods, nematodes, and terrestrial gastropods and crustaceans. These organisms represent diverse morphological, physiological, and behavioral groups. The following general information is derived mainly from works edited by Dindal (1990) and Dickinson and Pugh (1974).

Collembola (springtails) are small, wingless microarthropods that live mainly in the soil litter layer. With the mites, springtails make up the majority of the soil litter arthropod fauna. Most soil forms live on partially decomposed vegetation or microflora, especially fungi. The importance of Collembola to soil organic matter breakdown and nutrient cycling results from the comminution of organic matter fragments, feeding on humus and feces in the litter, and on decaying roots. Collembola commonly used as test species are Folsomia candida, Onychiurus armatus, and Orchesella cincta. Folsomia candida is considered well-suited for the study of effects of contaminants on population parameters because it is easy to culture and has a relatively short generation time. This allows the study of individual and population parameters in the same experiment (Crommentuijn et al., 1993).

The Acarina (mites) are a diverse group of arthropods in the suborders Prostigmata, Mesostigmata, Astigmata, and Oribatida. Each suborder contains representatives living in a wide range of habitats. In the soil and litter, mites may be detritivores eating dead plant material, predatory, or fungivores/algivores. Oribatid mites are found in large numbers in organic horizons of soils. They are represented in toxicity tests by Platynothrus peltifer. Like the springtails, mites act to increase the rate of organic matter decomposition by reducing the size of organic matter fragments and feeding on microflora involved in decomposition. Mites, especially oribatids, are considered suitable for the study of effects of contaminants on population parameters because they are easy to culture and have a relatively short generation time (1 per year), although it is longer than that of the Collembola ( 2 per year).

Terrestrial crustaceans are represented in the toxicity literature by woodlice, also known as pill bugs (Isopoda, Porcellio scaber and Oniscus asellus). They are common in deciduous woodland living in the litter layer and on decaying wood. Woodlice are omnivorous, feeding mainly on dead and decaying plants. They increase organic matter decomposition by comminuting the fragments and feeding on microflora involved in primary decomposition. As leaf litter feeders, isopods are considered good candidates for standard organisms in ecotoxicological testing (van Wensem, 1989). Porcellio scaber is common in many countries and is easy to maintain in the laboratory.

The snail Helix aspersa and the slug Arion ater represent terrestrial gastropods. They are generalized feeders (living and dead plant materials) inhabiting the soil surface, the litter layer, and standing vegetation. Their use in ecotoxicological testing stems from their potential importance for accumulation of contaminants in the food chain (Russell et al., 1981).

Nematodes (roundworms) are significantly different from other soil and litter-dwelling organisms discussed herein because they require a continuous water film for survival. They feed on a wide variety of foods although some are specialized parasites. The effects of chemicals on fungivores, bactivores, herbivores, and omnivores/predators have been evaluated. Caenorhabditis elegans used in experiments is a widespread free-living, soil-dwelling nematode. Nematodes have 
been used in ecotoxicological work for a number of reasons. They are abundant, easily retrieved from soil, and reared in the laboratory. Nematodes live in the interstitial water of the soil so experiments can be conducted in water. They may be exposed to higher concentrations of contaminants by this route than earthworms and other invertebrates not constantly in contact with the soil solution. Uptake of chemicals is mainly through the cuticle, and differences in cuticle permeability are thought to be the primary source of variability in response of various nematodes to toxic chemicals (Kammenga et al., 1994).

\subsection{OTHER INVERTEBRATES LITERATURE REVIEW}

Cadmium. Kammenga et al. (1994) compared the acute toxicity of $\mathrm{Cd}\left(\mathrm{CdCl}_{2}\right)$ to seven terrestrial nematode species belonging to different taxonomic and ecological groups. The nematodes were extracted from the surface horizon of an arable soil and a forest floor and identified and selected on the basis of different trophic levels: Rhabditis species and Diplogasteritus species; Cephalobus persegnis, Acrobeloides buetschlii, and Caenorhabditis elegans, bacteria feeders; Aphelenchus avenae, fungus feeder; and Tylenchus elegans, plant feeder. Solutions were mixed to mimic the mineral concentrations of soil solution in a sandy forest surface soil plus $C d$ at different concentrations. $L_{50}$ values were determined after 72 hours. The nematodes $T$. elegans and $A$. avenae had $\mathrm{LC}_{50}$ values of greater than $90 \mathrm{ppm}$ after 96 hours (termination of experiment); that is, they were essentially unaffected by the experimental treatment. Among the bacterial feeders the $\mathrm{LC}_{50}$ ranged from approximately 3 to $60 \mathrm{ppm} C d$ after 72 hours.

The nematode $C$. elegans was used by van Kessel et al. (1989) to test the effects of Cd (as $\mathrm{CdCl}_{2}$ ) on growth (length) and reproduction (number of juveniles per adult) of this soil-dwelling group. Juvenile (J-1) nematodes were cultured for 168 hours in microtiter plates containing solutions with different levels of Cd. Reproduction, the more sensitive parameter, was reduced $36 \%$ by 3.6 ppm.

The influence of $\mathrm{Cd}$ (as $\mathrm{CdCl}_{2}$ ) on life-history characteristics of the collembolan Folsomia candida was investigated by Crommentuijn et al. (1993). One-week old animals were placed on OECD artificial soil (containing, in percent dry weight, 10 sphagnum peat, 20 kaolin clay, 70 quartz sand; $\mathrm{pH}$ 6) containing a series of concentrations of $\mathrm{Cd}$ and fed baker's yeast. Number and weight of adults and number of offspring were determined. A soil concentration ( $\mathrm{HCl}+\mathrm{HNO}_{3}$ extractable) of $326 \mathrm{ppm} \mathrm{Cd}$ reduced the number of offspring produced by $21 \%$ after 42 days. Weight of the individual animals was not affected at this concentration.

Representatives of Collembola and mites were used by van Straalen et al. (1989) to assess the effect of $\mathrm{Cd}$ in diets of soil microarthropods on population growth rates. Three-day old Orchesella cincta (Collembola) were fed green algae containing $\mathrm{Cd}\left(\mathrm{CdSO}_{4}\right)$. A concentration of $15 \mathrm{ppm} \mathrm{Cd}$ caused an approximate $56 \%$ reduction in calculated population growth rate after 61 days, while 4.7 ppm had no effect. Adult mites ( $P$. peltifer) fed the same diet for 84 days experienced a $23 \%$ reduction in population growth rate at a concentration of $9 \mathrm{ppm} \mathrm{Cd}$, while $3 \mathrm{ppm}$ had no effect.

Hopkin and Hames (1994) investigated the effects of $\mathrm{Cd}\left(\right.$ as $\left.\mathrm{CdNO}_{3}\right)$ in food on survival and reproduction of the terrestrial isopod Porcellio scaber. Leaves of field maple (Acer campestre) were sprayed with solutions containing $\mathrm{Cd}$ and placed in plastic containers with juvenile woodlice. After 360 days, the number of surviving isopods and the number of juveniles were determined. The 
number of juveniles produced was decreased $47 \%$ by $10 \mathrm{ppm} \mathrm{Cd}$ (lowest concentration tested) while $50 \mathrm{ppm}$ was required to reduce total survival.

The effects of $\mathrm{Cd}$ on individual weight, new shell growth, and reproductive behavior of the snail Helix aspersa was evaluated by Russell et al. (1981). The diet fed to the sub-adult (4-month- old) snails for 30 days was ground Purina Lab Chow (for rats, mice, and hamsters) with $\mathrm{Cd}$ (as $\mathrm{CdCl}_{2}$ ) added. Snails were raised in plastic containers with sand bottoms. Reproductive activity, as measured by the number of individuals mating or with spermatophores in place, was reduced $28 \%$ by $25 \mathrm{ppm} C d$ while $10 \mathrm{ppm}$ had no effect. New shell growth and weight were not affected at this concentration.

The experimental approaches described in the previous paragraphs are too diverse to allow comparison of results, as discussed in the Introduction. There is agreement between the two studies on the effects of $\mathrm{Cd}$ on nematodes in that approximately $3 \mathrm{ppm}$ in solution is detrimental to the organisms. This number may be useful when soil solution concentration values for $\mathrm{Cd}$ are available.

The one study conducted in soil yielded a toxic concentration of $326 \mathrm{ppm}$, which is higher than the earthworm and microbe benchmarks for soil (Tables 1 and 2).

Copper. The acute toxicity of $\mathrm{Cu}$ to the nematode $C$. elegans in four soils and in solution was evaluated by Donkin and Dusenbery (1993). The soils included two silt loams, a loam, and a clay loam. Adult nematodes were placed in the soil with $\mathrm{Cu}$ added as $\mathrm{CuCl}_{2}$ and native soil organic matter as food. After 24 hours, surviving animals were counted, and an $\mathrm{LC}_{50}$ concentration calculated. Toxicity was also tested in solutions containing $\mathrm{Cu}$. A concentration of $105 \mathrm{ppm} \mathrm{Cu}$ in solution caused $50 \%$ mortality while at least $400 \mathrm{ppm}$ (sandy loam soil) was required in soil. The highest $\mathrm{LC}_{50}(1061 \mathrm{ppm})$ was associated with the highest percentage organic matter in the loam soil.

Parmalee et al. (1993) used a soil microcosm to test the effects of $\mathrm{Cu}$ on survival of nematodes and microarthropods feeding on native soil organic matter. $\mathrm{Cu}$ was added as $\mathrm{CuSO}_{4}$ to the $\mathrm{A}$ horizon of an acid sandy forest soil where native soil nematode and microarthropod populations were exposed for 7 days. There was an average reduction of approximately $70 \%$ in number of individuals of most categories of nematodes (fungivores, bactivores, herbivores, hatchlings) at $400 \mathrm{ppm}$ total $\mathrm{Cu}$, while $185 \mathrm{ppm}$ had no effect. The number of individuals of the omnivores/predators category was reduced $85 \%$ by the lowest concentration of $\mathrm{Cu}$ tested, $72 \mathrm{ppm}$. Total microarthropod numbers were reduced about $50 \%$ by $400 \mathrm{ppm}$. The oribatid and Mesostigmata mites appeared to be more sensitive, and the Collembola population was too small to evaluate.

Hopkin and Hames (1994) investigated the effects of $\mathrm{Cu}$ (as $\mathrm{CuNO}_{3}$ ) in food on survival and reproduction of the terrestrial isopod Porcellio scaber. The experimental design used by the authors is described in the discussion of the effects of $\mathrm{Cd}$ on this animal. After 360 days, the number of surviving isopods and the number of juveniles were determined. The number of juveniles produced was decreased $53 \%$ by $50 \mathrm{ppm} \mathrm{Cu}$ while $100 \mathrm{ppm}$ of $\mathrm{Cu}$ was required to reduce total survival.

The slug, Arion ater, was used as the test organism by Marigomez et al. (1986) to determine the effects of several pollutants on terrestrial mollusks. Slugs collected from the field were reared in plastic boxes and fed a diet of a pulverized mixture of lettuce, apple, carrot, and pumpkin mixed with $\mathrm{CuSO}_{4}$. After 27 days on this diet, the animals experienced a $55 \%$ decrease in growth at 1000 ppm $\mathrm{Cu}$, while $300 \mathrm{ppm}$ had no effect. 
The studies of Donkin and Dusenbery (1993) and Parmalee et al. (1993) taken together show a higher concentration in soil than in solution is required to affect the survival of nematodes. Differences among groups of nematodes in sensitivity to $\mathrm{Cu}$ is shown by Parmalee et al. (1993). The application of soluble form of $\mathrm{Cu}$ to food material by Hopkin and Hames (1994) and Marigomez et al. (1986) show very distinct sensitivities of woodlice and slugs to $\mathrm{Cu}$.

The lowest toxic concentration reported in these two studies (72 ppm Cu) is higher than the benchmarks for earthworms (50 ppm) and microbes (30 ppm).

Iron. The effect of iron on the Collembola Orchesella cincta was investigated by Nottrot et al. (1987). The springtails were grown in plastic dishes and fed green algae (Pleurococcus spp.) containing various concentrations of $\mathrm{Fe}$ for 21 days. Percent growth, feeding activity, and molting were determined. Growth of the springtails was reduced $42 \%$ by a diet of $7533 \mathrm{ppm}$, while 3515 ppm had no effect.

Lead. Bengtsson et al. (1983) evaluated the effects of lead, in the fungus Verticillium bulbillosum, on growth rate of a fungus-feeding collembolan, $O$. armatus. Adult springtails were fed the fungus for 125 days and their lengths were recorded for calculation of growth rate. Lead at $3089 \mathrm{ppm}$ in the fungus caused a $25 \%$ reduction in 0 . armatus growth rate. fungus.

Hopkin and Hames (1994) investigated the effects of $\mathrm{Pb}\left(\right.$ as $\mathrm{PbNO}_{3}$ ) in food on survival and reproduction of the terrestrial isopod Porcellio scaber. The experimental design used by the authors is described in the discussion of the effects of Cd on this animal. After 360 days, the number of surviving isopods and the number of juveniles were determined. Survival and the number of juveniles produced were decreased $100 \%$ by $2000 \mathrm{ppm} \mathrm{Pb}$ while $1000 \mathrm{ppm}$ had no effect.

Beyer and Anderson (1985) also used Porcellio scaber in experiments to determine the effect of $\mathrm{Pb}$, added as $\mathrm{PbO}$ to ground deciduous leaf litter, on several population parameters. The woodlice were reared in plastic containers and fed this diet for 448 days. During this time, the following were measured: lifespan of generation 1, maximum number of individuals in generation 2 , and survival of generation 2 . These parameters were decreased 27,68 , and $84 \%$, respectively, by $12,800 \mathrm{ppm} \mathrm{Pb}$ in the diet, while $6400 \mathrm{ppm}$ had no effect.

The slug, Arion ater, was used as the test organism by Marigomez et al. (1986) to determine the effect of lead on terrestrial mollusks. Field collected slugs were reared in plastic boxes and fed a diet of a pulverized mixture of lettuce, apple, carrot, and pumpkin mixed with $\mathrm{PbNO}_{3}$. After 27 days on this diet, the animals experienced a $51 \%$ decrease in growth at $1000 \mathrm{ppm} \mathrm{Pb}$, while $300 \mathrm{ppm}$ had no effect.

The studies indicate a high tolerance to $\mathrm{Pb}$ in the diets of the tested woodlouse, springtail, and slug species. The discrepancy between the Hopkin and Hames (1994) and Beyer and Anderson (1985) levels of $\mathrm{Pb}$ required to affect the woodlouse may be due to differences in bioavailability of the added $\mathrm{Pb}$ compounds.

Mercury. The slug, Arion ater, was used as the test organism by Marigomez et al. (1986) to determine the effect of mercury (as $\mathrm{HgCl}_{2}$ ) on terrestrial mollusks, as described for $\mathrm{Pb}$. After 27 days on this diet, the animals experienced a $26 \%$ decrease in growth at $1000 \mathrm{ppm} \mathrm{Hg}$, while $\mathrm{Hg}$ at 300 ppm had no effect. 
Zinc. Hopkin and Hames (1994) investigated the effects of $\mathrm{Zn}$ (as $\mathrm{ZnNO}_{3}$ ) in food on survival and reproduction of the terrestrial isopod Porcellio scaber. The experimental design used by the authors is described in the discussion of the effects of Cd on this animal. After 360 days, the number of surviving isopods and number of juveniles were determined. Survival and number of juveniles produced were decreased $100 \%$ by $1000 \mathrm{ppm} \mathrm{Zn}$ while $500 \mathrm{ppm}$ had no effect.

Zinc (as $\mathrm{ZnO}$ ) was added to litter from the $\mathrm{O} 2$ layer under woodlands to evaluate the effects of that metal on Porcellio scaber (Beyer et al., 1984). Adult animals kept in plastic boxes were fed this diet for 56 days before survival was determined. The only concentration tested, $5000 \mathrm{ppm}$, caused a $26 \%$ decrease in survival.

Beyer and Anderson (1985) also used Porcellio scaber in experiments to determine the effect of $\mathrm{Zn}$, added $\mathrm{ZnO}$ to ground deciduous leaf litter, on several population parameters. The woodlice were reared in plastic containers and fed this diet for 448 days. During this time the following were measured: lifespan of generation 1 , maximum number of individuals in generation 2 , and survival of generation 2. The maximum number of individuals in generation 2 and the survival rate for generation 2 were decreased 22 and $27 \%$ by $1600 \mathrm{ppm} \mathrm{Zn}$ in the diet, while $800 \mathrm{ppm}$ had no effect.

The slug, Arion ater, was used as the test organism by Marigomez et al. (1986) to determine the effect of $\mathrm{Zn}$ (as $\mathrm{ZnCl}_{2}$ ) on terrestrial mollusks, as described previously. After 27 days on this diet the animals experienced a $38 \%$ decrease in growth at $10 \mathrm{ppm} \mathrm{Zn}$, the lowest concentration tested.

The experiments evaluating the toxicity of $\mathrm{Zn}$ to the woodlouse Porcellio scaber show a high tolerance to the metal when it is added to the food in soluble form. The work with Arion ater (Marigomez et al., 1986) indicates that this organism is more sensitive than P. scaber to $\mathrm{Zn}$. On the other hand, growth of individual woodlice was not evaluated and may be more sensitive than survival and reproduction.

Benzo(a)pyrene (BaP). The woodlouse $P$. scaber was chosen by van Straalen and Verweij (1991) to determine the effects of this PAH on the soil invertebrate community. Polynuclear aromatic hydrocarbons are strongly sorbed onto soil organic matter which serves as the main food for many of these organisms. Adult woodlice were reared in plastic boxes for 28 days and fed ground poplar leaf litter mixed with benzo(a)pyrene. Growth efficiency was determined as dry weight increase divided by net food consumption (consumption minus defecation). Respiration, food consumption, and food assimilation were also measured. Growth efficiency of the males of the group was reduced $82 \%$ by $125 \mathrm{ppm} \mathrm{BaP}$ in the food, while $25 \mathrm{ppm}$ had no effect. Growth efficiency of the females, respiration, food consumption, and food assimilation were not affected.

Two isopods, Porcellio scaber and Oniscus asellus, were used by van Brummelen and Stuijfzand (1993) to determine the effects of $\mathrm{BaP}$ on litter layer-dwelling soil invertebrates. Weight and length changes and energy reserves were measured in individuals reared in plastic boxes and fed a combination of ground poplar leaves and ground dog food spiked with $\mathrm{BaP}$ for 63 days. Dry weight of $P$. scaber was reduced $30 \%$ with a diet containing $100 \mathrm{ppm} \mathrm{BaP,} \mathrm{while} 32 \mathrm{ppm}$ had no effect. Length and energy reserves (lipids+glycogen+protein) were not affected. Dry weight and length of $O$. asellus were reduced 58 and $48 \%$ with a diet containing $316 \mathrm{ppm} \mathrm{BaP,} \mathrm{while} 100 \mathrm{ppm}$ had no effect. Energy reserves were not affected.

These experiments with woodlice indicate that growth may be affected by $\mathrm{BaP}$ at concentrations of about $100 \mathrm{ppm}$ applied to food. 
p-nitrophenol (PNP). Parmalee et al. (1993) tested the effects of PNP on survival of nematodes and microarthropods in soil microcosms, as described for $\mathrm{Cu}$. There was an average reduction of approximately $55 \%$ in number of individuals of most categories of nematodes (fungivores, herbivores, herbivores/predators, and hatchlings) at $40 \mathrm{ppm}$ total PNP, while $20 \mathrm{ppm}$ had no effect. The number of individuals of the bacterivore category was reduced $40 \%$ by the lowest concentration of PNP tested, $20 \mathrm{ppm}$. Total microarthropod numbers were reduced about $35 \%$ by $176 \mathrm{ppm}$, mainly as the result of reductions in oribatids. P-nitrophenol up to $176 \mathrm{ppm}$ had no effect on numbers of Mesostigmata or unclassified microarthropods, and there were no Collembola were present.

Pentachlorophenol. Kammenga et al. (1994) compared the acute toxicity of PCP in solution culture to seven terrestrial nematode species belonging to different taxonomic and ecological groups. The nematodes and experimental design are the same as described previously for $\mathrm{Cd}$. Aphelenchus avenae, Caenorhabditis elegans, and Acrobeloides beutschlii had $\mathrm{LC}_{50}$ values greater than $9 \mathrm{ppm}$ after 96 hours (that is, experimental concentrations killed fewer than half of the nematodes). $\mathrm{LC}_{50}$ values for the remaining nematodes ranged from approximately 1 to $7 \mathrm{ppm}$ PCP.

Trinitrotoluene (TNT). Parmalee et al. (1993) used a soil microcosm to test the effects of TNT on survival of nematodes and microarthropods in soil microcosms, as described previously for $\mathrm{Cu}$. Trinitrotoluene additions up to $200 \mathrm{ppm}$ had no effect on numbers of nematodes. Total microarthropod numbers were reduced about $58 \%$ by $200 \mathrm{ppm}$, while $100 \mathrm{ppm}$ had no effect. Trinitrotoluene up to $200 \mathrm{ppm}$ had no effect on numbers of Mesostigmata, Collembola, or unclassified microarthropods. 
5-8 


\section{RELATIONSHIP BETWEEN SOIL TOXICITY BENCHMARKS AND OTHER ECOTOXICOLOGICAL CRITERIA}

\subsection{COMPARISON OF TOXICITY BENCHMARKS FOR CONTAMINANTS IN SOIL TO CANADIAN ENVIRONMENTAL QUALITY CRITERIA FOR CONTAMINATED SITES}

The Canadian Council of Ministers of the Environment has developed Environmental Quality Criteria for contaminated sites. These are "numerical limits for contaminants in soil and water intended to maintain, improve, or protect environmental quality and human health at contaminated sites in general" (CCME, 1991). Remediation criteria are presented for comparison to the toxicity benchmarks presented herein because they represent levels considered generally protective of human health and the environment for specified uses of soil (in this case the most conservative use-which is agriculture-has been chosen) without taking into account site-specific conditions. If contaminant concentrations exceed the remediation criteria for a current or future land use, further investigation or remediation is needed. These criteria have an interim status, and their derivation is in the process of refinement. They have been adopted from several Canadian jurisdictions and many lack supporting rationale (CCME, 1991). The remediation criteria are not strictly comparable to the toxicity benchmarks developed herein because they also take into account human health and, presumably, plants and the entire food web dependent upon the soil. New CCME Soil Quality Guidelines are being developed and will be made available in late 1995. A comparison of the toxicity benchmarks presented in this report with the CCME Remediation Criteria is given in Table 3.

For 7 of 18 chemicals, one or both of the soil toxicity benchmarks derived by the method used in this report is lower than the CCME criterion. There is no indication in the source publication as to the level of protection being afforded by the CCME Remediation Criteria. However, because human health is considered in the conservative agriculture land-use scenario, one would expect it to be high. This is seen in the organic chemicals which are known to be toxic to mammals at relatively low levels.

\subsection{COMPARISON OF TOXICITY BENCHMARKS FOR CONTAMINANTS IN SOUL TO RIVM (NETHERLANDS) ECOTOXICOLOGICAL INTERVENTION VALUES FOR CONTAMINANTS IN SOILS}

The Dutch National Institute of Public Health and Environmental Protection (RIVM) developed Ecotoxicological Intervention Values (EIVs) that represent concentrations of contaminants in soil causing $50 \%$ of the species potentially present in an ecosystem to experience adverse effects (van den Berg et al., 1993). The EIVs take into account plants, soil fauna, and microorganisms. The method for deriving the EIVs is described by Denneman and van Gestel in several RIVM publications in Dutch. To take the influence of soil characteristics on the bioavailability of compounds, data were adjusted for organic matter and clay content as described by van den Berg et al. (1993). Risks resulting from biomagnification were included. 


\section{6-2}

Although these EIVs are based on purely "ecological" endpoints, they take into account many more types of organisms than the authors' earthworm and microbe toxicity benchmarks. For metals, benchmarks presented herein are more conservative than the RIVM EIVs in about half of the cases. For organic chemicals, most of benchmarks presented herein for earthworms are in fairly good agreement with the RIVM values. Differences here may stem from the RIVM report of values for undefined compounds of particular classes rather than for particular compounds. 
Table 3. Comparison of screening benchmark concentrations for the toxicity to earthworms and soil microbes of chemicals in soil to CCME remediation criteria (RC), RIVM ecotoxicological intervention values (EIV's), arithmetic means of elements in uncontaminated soils of the Oak Ridge Reservation (ORR), and geometric means of elements in soils and surficial materials of the eastern U.S.

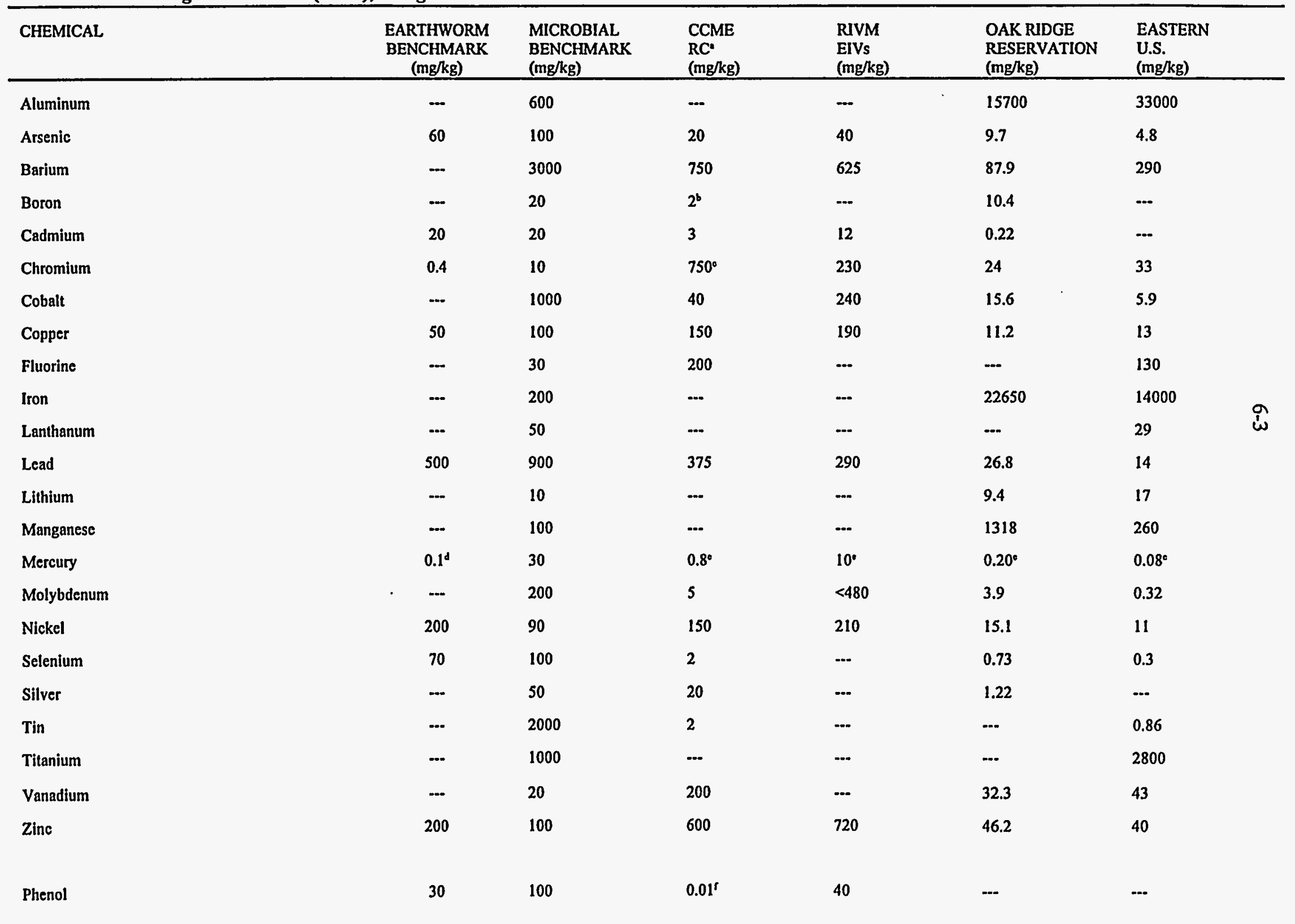


Table 3. (continued)

\begin{tabular}{|c|c|c|c|c|c|c|}
\hline CHEMICAL & $\begin{array}{c}\text { EARTHWORM } \\
\text { BENCHMARK } \\
\text { (mg/kg) }\end{array}$ & $\begin{array}{l}\text { MICROBIAL } \\
\text { BENCHMARK } \\
(\mathrm{mg} / \mathrm{kg})\end{array}$ & $\begin{array}{l}\mathrm{CCME} \\
\mathrm{RC} \\
(\mathrm{mg} / \mathrm{kg})\end{array}$ & $\begin{array}{l}\text { RIVM } \\
\text { EIVs } \\
\text { (mg/kg) }\end{array}$ & $\begin{array}{l}\text { OAK RIDGE } \\
\text { RESERVATION } \\
\text { (mg/kg) }\end{array}$ & $\begin{array}{l}\text { EASTERN } \\
\text { U.S. } \\
(\mathrm{mg} / \mathrm{kg}) \\
\end{array}$ \\
\hline 4-nitrophenol & 7 & $\ldots$ & $0.01^{r}$ & $\ldots$ & ... & $\cdots$ \\
\hline 3-chlorophenol & 10 & -- & $0.05^{8}$ & $10^{i}$ & $\cdots$ & $\cdots$ \\
\hline 3,4-dichlorophenol & 20 & $\cdots$ & 0.058 & $10^{\prime}$ & $\cdots$ & $\cdots$ \\
\hline 2,4,5-trichlorophenol & 9 & $\cdots$ & $0.05 t$ & $10^{1}$ & -.- & $\cdots$ \\
\hline 2,4,6-trichlorophenol & 10 & $\cdots$ & 0.05 & $10^{1}$ & $\cdots$ & $\cdots$ \\
\hline 2,3,4,5-tetrachlorophenol & 20 & $\cdots$ & 0.058 & $10^{1}$ & $\cdots$ & $\cdots$ \\
\hline Pentachlorophenol & 4 & 50 & 0.058 & 5 & -.. & -- \\
\hline Chlorobenzene & 40 & $\cdots$ & 0.1 & 30 & $\cdots$ & --- \\
\hline 1,4,-dichlorobenzene & 20 & $\cdots$ & 0.1 & $30^{\mathrm{J}}$ & -- & $\cdots$ \\
\hline$\cdot 1,2,3$-trichlorobenzene & 20 & $\cdots$ & $0.05^{\mathrm{h}}$ & $30^{\prime}$ & $\cdots$ & -- \\
\hline 1,2,4-trichlorobenzene & 20 & $\cdots$ & $0.05^{\mathrm{h}}$ & $30^{\prime}$ & $\cdots$ & $\cdots$ \\
\hline 1,2,3,4-tetrachlorobenzene & 10 & $\cdots$ & $0.05^{h}$ & $30^{\circ}$ & $\cdots$ & $\cdots$ \\
\hline Pentachlorobenzene & 20 & $\cdots$ & $0.05^{h}$ & 30 & -- & -- \\
\hline Hexachlorobenzene & $\ldots$ & 1000 & 0.05 & 30 & $\ldots$ & $\ldots$ \\
\hline
\end{tabular}

- Agricultural land-use context

- Hot water solubte B

'Total Cr. Criterion for $\mathrm{Cr}$ (VI) is $8 \mathrm{ppm}$

- Combined inorganic and organic forms of tis

'Each unspecified non-chlorinated phenolic compound is not to exceed $0.1 \mathrm{ppm}$

- Each unspecified trit, telta-, and pentichlorinated benzene is not to exceed 0.05 ppm

I Unspecifited chlorinaled phenols 


\section{COMPARISON OF TOXICITY BENCHMARKS FOR CONTAMINANTS IN SOIL TO CONCENTRATIONS OF CHEMICALS IN UNPOLLUTED SOILS}

\subsection{COMPARISON TO USGS ELEMENT CONCENTRATIONS IN SOILS AND OTHER SURFICIAL MATERIALS OF THE EASTERN UNITED STATES}

To place the four sets of critical values into a broader perspective, soil chemical concentrations are presented herein as reported by the United States Geological Survey (USGS) in a survey of soils of the eastern United States (Shacklette and Boerngen, 1984) (Table 3). These samples were collected and analyzed by the USGS to represent, as far as possible, soils that supported native plants and which were altered very little from their natural condition.

It is interesting to compare the levels of elements cited in the literature as toxic against concentrations of those same elements found in natural (i.e., not known to be polluted) soils. This comparison is reasonable in most cases because benchmarks generally were based on nominal soil concentrations (i.e., those added to the soil by the experimenter) as opposed to a measure of either total concentration or of the bioavailable quantity of the element in the soil. Seldom was the background level of the "contaminant" element in the soil measured, the assumption being that very little of the element existed naturally in the soil compared to treatment levels added. This is often, but not always, a reasonable assumption. The USGS compilation contains concentrations of elements derived mainly from strong-acid extractions, although in the case of uranium, neutron activation was used to measure a true total concentration. Values for the eastern United States were used because surficial deposits of the western United States, especially in arid and mountainous regions, may contain unusually high concentrations of naturally-occurring trace elements.

For several of the metals, our toxicity benchmarks were below (Al, $\mathrm{Cr}, \mathrm{F}, \mathrm{Fe}, \mathrm{Mn}, \mathrm{Ti}$, and $\mathrm{V}$ ) or about equal to $(\mathrm{Li})$ the geometric mean for the element in soils and surficial deposits in the eastern United States. The large difference between the USGS soil $\mathrm{Fe}$ and $\mathrm{Al}$ values and the low microbial benchmark based on a quantity of $\mathrm{Fe}$ or $\mathrm{Al}$ added to soil is likely due to the strong extractant used in the USGS study. The form of the element added or some other aspect of the experimental design may account for other low benchmark concentrations as compared to mean levels in soils.

\subsection{COMPARISON TO DOE OAK RIDGE RESERVATION BACKGROUND SOLL CHARACTERIZATION ELEMENT CONCENTRATIONS IN SOILS}

The Background Soil Characterization Project (BSCP) at the ORR was established to determine the background concentrations of organics, metals, and radionuclides in natural soils that are important to environmental restoration projects (Watkins et al., 1993). Soils were sampled, field classified, and analyzed for chemicals using several methods. The data presented in Table 3 show the arithmetic means of elements from 46 sampling sites. The elements were extracted from the soil samples using nitric acid and hydrogen peroxide (EPA, 1986). This standard EPA acid digestion for sediments, sludges, and soils is not explicitly meant to extract total elements from a sample. A comparison with total soil concentrations of elements measured by neutron activation analysis (NAA) shows that for many elements (e.g., $\mathrm{Sb}, \mathrm{As}, \mathrm{Cr}, \mathrm{Co}, \mathrm{Mn}, \mathrm{Si}, \mathrm{V}, \mathrm{Zn}$ ) the $\mathrm{HNO}_{3^{-}}$ 
$\mathrm{H}_{2} \mathrm{O}_{2}$ extraction method was adequate for most of the elements in question (Watkins et al., 1993). Unfortunately, not all elements are amenable to measurement by NAA.

A large discrepancy was found between the BSCP soil $\mathrm{Fe}$ and $\mathrm{Al}$ values and the low soil toxicity benchmarks, based on a quantity of Fe or Al added to soil. At least one of our benchmarks is lower than background soil concentrations in the case of $\mathrm{Cr}, \mathrm{Mn}$, and $\mathrm{V}$, and about equal for $\mathrm{Li}$ and $\mathrm{Hg}$. The form of the element added or some other aspect of the experimental design may account for these differences. 


\section{RECOMMENDATIONS AND CONCLUSIONS}

The values presented in Tables 1 and 2 are intended for use in contaminant screening during the hazard identification (problem formulation) phase of ecological risk assessments. Chemicals with soil concentrations that exceed both the toxicity benchmarks for soil and the background soil concentration for the soil type are contaminants of potential concern. Background soil concentrations have been derived for the ORR and should be generated for other Comprehensive Environmental Response, Compensation and Liability Act (CERCLA) sites as well.

For baseline ecological risk assessments, and other assessments that may lead to regulatory actions, assessors should consult the primary sources of toxicity data and then determine the applicability of the data to their specific site. In addition, assessments should not rely on laboratory toxicity data only. Where toxicity to soil invertebrates is suspected, toxicity tests should be performed with the contaminated soil. In addition, the abundance of earthworms in the soil of a particular site, determined during collection of earthworms for chemical analysis, may provide a rough indication of the likelihood of soil toxicity. 
8-2 


\section{REFERENCES}

Abbasi, S.A., and R. Soni. 1983. Stress-induced enhancement of reproduction in earthworm Octochaetus pattoni exposed to chromium (VI) and mercury (II) - Implications in environmental management, Intern. J. Environ. Stud. 22:43-47.

Akaike, N., K.S. Lee, and A.M. Brown. 1978. The calcium current of Helix neuron, J. Gen. Physiol. 71:509-531.

Al-Khafaji, A.A., and M.A. Tabatabai. 1979. Effects of trace elements on arylsulfatase activity in soils, Soil Sci. 127(3):129-133.

Babich, H., and G. Stotzky. 1982. Toxicity of nickel to microorganisms in soil: Influence of some physicochemical characteristics, Environ. Pollut. 29A:303-315.

Beeby, A. 1991. Toxic metal uptake and essential metal regulation in terrestrial invertebrates: A review, in Metal Ecotoxicology, Concepts \& Applications. M.C. Newman and A.W. McIntosh (eds). Lewis Publishers, Boca Raton. pp. 65-89.

Bengtsson, G., T. Gunnarsson, and S. Rundgren. 1983. Growth changes caused by metal uptake in a population of Onychiurus armatus (Collembola) feeding on metal polluted fungi, OIKOS 40:216-225.

Bengtsson, G., T. Gunnarsson, and S. Rundgren. 1986. Effects of metal pollution on the earthworm Dendrobaena rubida (Sav.) in acidified soils, Water Soil Air Pollut. 28:361-383.

Bewley, R.J.F., and G. Stotzky. 1983. Effects of cadmium and simulated acid rain on ammonification and nitrification in soil, Arch. Environ. Contam. Toxicol. 12:285-291.

Beyer, W.N., and A. Anderson. 1985. Toxicity to woodlice of zinc and lead oxides added to soil litter, Ambio 14(3):173-174.

Beyer, W.N., E. Cromartie, and G.B. Moment. 1985. Accumulation of methylmercury in the earthworm Eisenia foetida, and its effect on regeneration, Bull. Environ. Contam. Toxicol. 35:157-162.

Beyer, W.N., G.W. Miller, and E.J. Cromartie. 1984. Contamination of the O2 soil horizon by zinc smelting and its effect on woodlouse survival, J. Environ. Qual. 13(2):247-251.

Bhuiya, M.R.H., and A.H. Cornfield. 1976. Effect of addition of $\mathrm{Cu}, \mathrm{Cr}, \mathrm{Pb}$ and $\mathrm{Zn}$ on nitrogen mineralisation and nitrification during incubation of sandy soils, Bangladesh J. Biol. Sci. 5(1):18-20.

Bhuiya, M.R.H., and A.H. Cornfield. 1974. Incubation study on effect of $\mathrm{pH}$ on nitrogen mineralisation and nitrification in soils treated with $1000 \mathrm{ppm}$ lead and zinc, as oxides, Environ. Pollut. 7:161-164. 
Bhuiya, M.R.H., and A.H. Cornfield. 1972. Effects of addition of $1000 \mathrm{ppm} \mathrm{Cu}, \mathrm{Ni}, \mathrm{Pb}$ and $\mathrm{Zn}$ on carbon dioxide release during incubation of soil alone and after treatment with straw, Environ. Pollut. 3:173-177.

Bollag, J.-M., and W.Barabasz. 1979. Effect of heavy metals on the denitrification process in soil, J. Environ. Qual. 8(2):196-201.

Bouche, M.B. 1992. Earthworm species and ecotoxicological studies, in Ecotoxicology of Earthworms, P.W. Greig-Smith et al. (eds). Intercept Ltd., U.K. pp. 20-35.

Bremner, J.M., and L.A. Douglas. 1971. Inhibition of urease activity in soils, Soil Biol. Biochem. 3:297-307.

Canadian Council of Ministers of the Environment (CCME). 1991. Interim Canadian Environmental Quality Criteria for Contaminated Sites, CCME EPC-CS34. Winnipeg, Manitoba.

Chaney, W.R., J.M. Kelly, and R.C. Strickland. 1978. Influence of cadmium and zinc on carbon dioxide evolution from litter and soil from a Black Oak forest, J. Environ. Qual. $7(1): 115-119$.

Cole, M.A. 1977. Lead inhibition of enzyme synthesis in soil, Appl. Environ. Microbiol. 33(2):262-268.

Crommentuijn, T., J. Brils, and N.M. van Straaler. 1993. Influence of cadmium on life-history characteristics of Folsomia candida (Willem) in an artificial soil substrate, Ecotoxicol. Environ. Saf. 26:216-227.

Curl, E.A., P.J. Edwards, C. Elliott, and J.P. Leahey. 1987. The conjugation and accumulation of metabolites of cypermethrin by earthworms, Pesticide Sci. 20:207-222.

Debosz, K., H. Babich, and G. Stotzky. 1985. Toxicity of lead to soil respiration: Mediation by clay minerals, humic acids, and compost, Bull. Environ. Contam. Toxicol. 35:517-524.

Dickinson, C.H., and G.J.F. Pugh. (ed). 1974. Biology of Plant Litter Decomposition. Vols I \& 2, Academic Press, New York.

Dindal, D.L. 1990. Soil Biology Guide, John Wiley and Sons, New York.

Doelman, P., and L. Haanstra. 1989. Short- and long-term effects of heavy metals on phosphatase activity in soils: An ecological dose-response model approach, Biol. Fertil. Soils 8:235-241.

Doelman, P., and L. Haanstra. 1986. Short- and long-term effects of heavy metals on urease activity, Biol. Fertil. Soils 2:213-218.

Doelman, P., and L. Haanstra. 1979. Effect of lead on soil respiration and dehydrogenase activity, Soil Biol. Biochem. 11:475-479. 
Donkin, S.G., and D.B. Dusenbery. 1993. A soil toxicity test using the nematode Caenorhabditis elegans and an effective method of recovery, Arch. Environ. Contam. Toxicol. 25:145-151.

Edwards, C.A. 1992. Testing the effects of chemicals on earthworms: The advantages and limitations of field tests, in Ecotoxicology of Earthworms. P.W. Greig-Smith et al. (eds). Intercept Ltd. pp. 75-84.

EPA (United Statees Environmental Protection Agency). 1986. Test Methods for Evaluating Solid Waste. Vol. 1: Laboratory Manual Physical/Chemical Methods, SW 846, Office of Solid Waste and Emergency Response, Washington, D.C.

Fischer, E., and L. Koszorus. 1992. Sublethal effects, accumulation capacities and elimination rates of As, $\mathrm{Hg}$ and $\mathrm{Se}$ in the manure worm, Eisenia fetida (Oligochaeta, Lumbricidae), Pedobiologia 36:172-178.

Frankenberger, W.T., and M.A. Tabatabai. 1981. Amidase activity in soils: IV. Effects of trace elements and pesticides, Soil Sci. Soc. Am. J. 45:1120-1125.

Giashuddin, M., and A.H. Cornfield. 1979. Effects of adding nickel (as oxide) to soil on nitrogen and carbon mineralisation at different $\mathrm{pH}$ values, Environ. Pollut. 19:67-70.

Giashuddin, M., and A.H. Cornfield. 1978. Incubation study on effects of adding varying levels of nickel (as sulphate) on nitrogen mineralisation in soil, Environ. Pollut. 15:231-234.

Haanstra, L., and P. Doelman. 1991. An ecological dose-response model approach to short- and long-term effects of heavy metals on arylsulfatse activity, Biol. Fertil. Soils 11:18-23.

Heimbach, F. 1992. Effects of pesticides on earthworm populations: Comparison of results from laboratory and field tests, in Ecotoxicology of Earthworms, P.W. Greig-Smith et al. (eds), Intercept Ltd., U.K., pp. 100-106.

Heimbach, F. 1988. A comparison of laboratory methods for toxicity testing with earthworms. In Earthworms in Waste and Environmental Management, C.A. Edwards and E.F. Neuhauser (eds), SPB Academic Pub., Netherlands, pp. 329-335.

Heimbach, F. 1984. Correlations between three methods for determining the toxicity of chemicals to earthworms, Pestic Sci. 15:605-611.

Hopkin, S.P. 1989. Ecophysiology of Metals in Terrestrial Invertebrates, Elsevier Applied Science, New York.

Hopkin, S.P. and C.A.C. Hames. 1994. Zinc, among a "cocktail" of metal pollutants, is responsible for the absence of the terrestrial isopod Porcellia scaber from the vicinity of a primary smelting works, Ecotoxicology, 2:68-78.

Juma, N.G., and M.A. Tabatabai. 1977. Effects of trace elements on phosphatase activity in soils, Soil Sci. Soc. Am. J. 41:343-346. 
Kammenga, J.E., C.A.M. van Gestel, and J. Bakker. 1994. Patterns of sensitivity to cadmium and pentachlorophenol (among nematode species from different taxonomic and ecological groups, Arch. Environ. Contam. Toxicol. 27:88-94.

Khan, D.H., and B. Frankland. 1984. Cellulolytic activity and root biomass production in some metal-contaminated soils, Environ. Pollut. 33A:63-74.

Kokta, C. 1992. Measuring effects of chemicals in the laboratory: Effect criteria and endpoints. In Ecotoxicology of Earthworms, P.W. Greig-Smith et al. (eds). Intercept Ltd., U.K. pp. $55-62$.

Landa, E.R., and S.C. Fang. 1978. Effect of mercuric chloride on carbon mineralization in soils, Plant Soil 49:179-183.

Laskowski, R., M. Maryanski, and M. Niklinska. 1994. Effect of heavy metals and mineral nutrients on forest litter respiration rate, Environ. Pollut. 84:97-102.

Lee, K.E. 1985. Earthworms, Their Ecology and Relationships with Soils and Land Use, Academic Press, New York.

Leita, L., M. De Nobili, G. Muhlbachova, C. Mondini, L. Marchiol, and G. Zerbi. 1995. Bioavailability and effects of heavy metals on soil microbial biomass survival during laboratory incubation, Biol. Fertil. Soils 19:103-108.

Liang, C.N., and M.A. Tabatabai. 1977. Effects of trace elements on nitrogen mineralisation in soils, Environ. Pollut. 12:141-147.

Lighthart, B., and H. Bond. 1976. Design and preliminary results from soil/litter microcosms, Intern. J. Environ. Stud. 10:51-58.

Lighthart, B., H. Bond, and M. Ricard. 1977. Trace Elements Research Using Coniferous Forest Soil/Litter Microcosms, USEPA-600/3-77-091.

Long, R. E. and L. G. Morgan. 1990. The potential for biological effects of sediment-sorbed contaminants tested in the national status and trends program, NOAA Technical Memorandum NOS OMA 52.

Ma, W.-C. 1982. The influence of soil properties and worm-related factors on the concentration of heavy metals in earthworms, Pedobiologia 24:109-119.

Ma, W.-C. 1984. Sublethal toxic effects of copper on growth, reproduction and litter breakdown activity in the earthworm Lumbricus rubellus, with observations on the influence of temperature and soil pH, Environ. Pollut. Ser. A 33:207-219.

Ma, W.-C. 1988. Toxicity of copper to lumbricid earthworms in sandy agricultural soils amended with Cu-enriched organic waste materials, Ecol. Bull. 39:53-56.

Malecki, M.R., E.F. Neuhauser, and R.C. Loehr. 1982. The effect of metals on the growth and reproduction of Eisenia foetida (Oligochaeta, Lumbricidae), Pedobiologia 24:129-137. 
Marigomez, J.A., E. Angulo, and V. Saez. 1986. Feeding and growth responses to copper, zinc, mercury, and lead in the terrestrial gastropod Arion ater (Linne), J. Moll. Stud. 52:68-78.

Molnar, L., E. Fischer, and M. Kallay. 1989. Laboratory studies on the effect, uptake and distribution of chromium in Eisenia foetida (Annelida, Oligochaeta), Zool. Anz. 223(1/2):57-66.

Morgan, A.J., J.E. Morgan, M. Turner, C. Winters, and A. Yarwood. 1993. Metal relationships of earthworms. In Ecotoxicology of Metals in Invertebrates, R. Dallinger and P.S. Rainbow (eds). Lewis Publishers, Boca Raton. pp. 333-358.

Nelson, D. W., and L. E. Sommers. 1982. Total carbon, organic carbon, and organic matter, in Methods of Soil Analysis, Part 2, p. 574, ASA/SSSA, Madison, WI.

Neuhauser, E.F. and C.A. Callahan. 1990. Growth and Reproduction of the earthworm Eisenia fetida exposed to sublethal concentrations of organic chemicals, Soil Biol. Biochem. 22(2):175-179.

Neuhauser, F., D.L. Kaplan, and R. Hartenstein. 1979. Life history of the earthworm Eudrilus eugeniae, Rev. Ecol. Biol. Sol. 16:525-534.

Neuhauser, E.F., M.R. Malecki, and R.C. Loehr. 1984. Growth and reproduction of the earthworm Eisenia fetida after exposure to sublethal concentrations of metals, Pedobiologia 27:89-97.

Neuhauser, E.F., R.C. Loehr, D.L. Milligan, and M.R. Malecki. 1985. Toxicity of metals to the earthworm Eisenia fetida, Biol. Fertil. Soils 1:149-152.

Neuhauser, E.F., P.R. Durkin, M.R. Malecki, and M. Anatra. 1986. Comparative toxicity of ten organic chemicals to four earthworm species, Comp. Biochem. Physiol. 83C(1):197-200.

Nottrot, F., E.N.G. Joosse, and N.M. van Straalen. 1987. Sublethal effects of iron and manganese soil pollution on Orchesella cincta (Collembola), Pedobiologia 30:45-53.

Parmalee, R.W., R.S. Wentsel, C.T. Phillips, M. Simini, and R.T. Checkai. 1993. Soil microcosm for testing the effects of chemical pollutants on soil fauna communities and trophic structure, Environ. Toxicol. Chem. 12:1477-1486.

Premi, P.R., and A.H. Cornfield. 1969. Effects of addition of copper, manganese, zinc and chromium compounds on ammonification and nitrification during incubation of soil, Plant Soil 31(2):345-352.

Premi, P.R., and A.H. Cornfield. 1969/1970. Effects of copper, zinc and chromium on immobilization and subsequent re-mobilization of nitrogen during incubation of soil treated with sucrose, Geoderma 3:233-237.

Quraishi, M.S.I., and A.H. Cornfield. 1973. Incubation study of nitrogen mineralisation and nitrification in relation to soil $\mathrm{pH}$ and level of copper addition, Environ. Pollut. 4:159-163. 
Reber, H.H. 1989. Threshold levels of cadmium for soil respiration and growth of spring wheat (Triticum aestivum L.) and difficulties with their determination, Biol. Fertil. Soils 7:152-157.

Reinecke, A.J. 1992. A review of ecotoxicological test methods using earthworms, in Ecotoxicology of Earthworms, P.W. Greig-Smith et al. (eds), Intercept Ltd., U.K., pp. 7-19.

Rogers, J.E., and S.W. Li. 1985. Effect of metals and other inorganic ions on soil microbial activity: Soil dehydrogenase assay as a simple toxicity test, Bull. Environ. Contam. Toxicol. 34:858-865.

Ross, D.S., R.E. Sjogren, and R.J. Bartlett. 1981. Behavior of chromium in soils: IV. Toxicity to microorganisms, J. Environ. Qual. 10(2):145-148.

Russell, L.K., J.I. De Haven, and R.P. Botts. 1981. Toxic effects of cadmium on the garden snail (Helix aspersa), Bull. Environ. Contam. Toxicol. 26:634-640.

Shacklette, H.T., and J.G. Boerngen. 1984. Element Concentrations in Soils and Other Surficial Materials of the Coterminous United States, USGS Prof. Paper 1270, U.S. Government Printing Office, Washington.

Soni, R., and S.A. Abbasi. 1981. Mortality and reproduction in earthworms Pheretima posthuma exposed to chromium (VI), Intern. I Environ. Stud. 17:147-149.

Spurgeon, D.J., S.P. Hopkin, and D.T. Jones. 1994. Effects of cadmium, copper, lead, and zinc on growth, reproduction, and survival of the Earthworm Eisenia fetida (Savigny): Assessing the environmental impact of point-source metal contamination in terrestrial ecosystems, Environ. Pollut. 84:123-130.

Stenersen, J. 1992. Uptake and metabolism of xenobiotics by earthworms, in Ecotoxicology of Earthworms, P.W. Greig-Smith et al. (eds), Intercept Ltd., U.K., pp. 129-138.

Streit, B, and A. Jaggy. 1983. Effect of soil type on copper toxicity and copper uptake in Octolasium cyaneum (Lumbricidae), in New Trends in Soil Biology, Ph. Lebrun et al. (eds), Ottignies-Louvain-la-Neuve, pp. 569-575.

Suter, G. W., II. 1992. Approach and strategy for performing ecological risk assessments for the Department of Energy Oak Ridge Field Office Environmental Restoration Program, ES/ER/TM-33, Oak Ridge National Laboratory, Environmental Science Division.

Suter, G. W., II, and F.E. Sharples. 1984. Examination of a proposed test for effects of toxicants on soil microbial processes, in Toxicity Screening Procedures Using Bacterial Systems, Marcel Dekker, Inc., New York, pp. 327-344.

Tabatabai, M.A. 1982. Soil enzymes, in Methods of Soil Analysis, Part 2. Chemical and Microbiological Properties, ASA/SSSA, Madison, WI., pp. 903-948.

Tomlin, A.D. 1992. Behavior as a source of earthworm susceptibility to ecotoxicants, in Ecotoxicology of Earthworms, P.W. Greig-Smith et al. (eds), Intercept Ltd., U.K., pp. 116-125. 
Tyler, G. 1976. Influence of vanadium on soil phosphatase activity, J. Environ. Qual. 5(2):216-217.

van Beelen, P., and A.K. Fleuren-Kemila. 1993. Toxic effects of pentachlorophenol and other pollutants on the mineralization of acetate in several soils, Ecotoxicol. Environ. Saf. 26:10-17.

van Beelen, P., A.K. Fleuren-Kemila, and C.H.A.M. van Mil. 1994. Stimulatory and toxic effects of acid, pentachlorophenol or zinc on the mineralization of acetate in acid or calcareous soils and subsoils, J. Environ. Sci. Health A29(7):1391-1408.

van Brummelen, T.C., and S.C. Stuijfzand. 1993. Effects of benzo(a)pyrene on survival, growth and energy reserves in terrestrial isopods Oniscus asellus and Porcellio scaber, Sci. Total. Environ. Suppl:921-930.

van den Berg, R., C.A.J. Denneman, and J.M. Roels. 1993. Risk assessment of contaminated soil: Proposal for adjusted, toxicologically based Dutch soil clean-up criteria, in Contaminated Soil '93, F. Arendt, G.J. Annokkee, R. Bosman, and W.J. van den Brink (eds), Kluwer Academic Pub., Netherlands.

van Fanssen, H.G. 1973. Effects of mercury compounds on soil microbes, Plant Soil 38:485-487.

van Gestel, C.A.M. 1992. The influence of soil characteristics on the toxicity of chemicals for earthworms: A review, in Ecotoxicology of Earthworms, P.W. Greig-Smith et al. (eds), Intercept Ltd., U.K., pp. 44-54.

van Gestel, C.A.M. and W.-C. Ma. 1993. Development of QSAR's in soil ecotoxicology: Earthworm toxicity and soil sorption of chlorophenols, chlorobenzenes and dichloroaniline, Water Air Soil Pollut. 69:265-276.

van Gestel, C.A.M. and W.-C. Ma. 1988. Toxicity and bioaccumulation of chlorophenols in earthworms, in relation to bioavailability in soil, Ecotoxicol. Environ. Saf. 15:289-297.

van Gestel, C.A.M. and W.-C. Ma. 1990. An approach to quantitative structure-activity relationships (QSARs) in earthworm toxicity, Chemosphere 21(8):1023-1033.

van Gestel, C.A.M., and W.A. van Dis. 1988. The influence of soil characteristics on the toxicity of four chemicals to the earthworm Eisenia fetida andrei (Oligochaeta), Biol. Fertil. Soils 6:262-265.

van Gestel, C.A.M., W.A. van Dis, E.M. van Breemen, and P.M. Sparenburg. 1989. Development of a standardized reproduction toxicity test with the earthworm species Eisenia fetida andrei using copper, pentachlorophenol, and 2,4-dichloroaniline, Ecotoxicol. Environ. Saf. 18:305-312.

van Gestel, C.A.M., W.A. van Dis, E.M. Dirven-van Breemen, P.M. Sparenburg, and R. Baerselman. 1991a. Influence of cadmium, copper, and pentachlorophenol on growth and sexual development of Eisenia andrei (Oligochaeta; Annelida), Biol. Fertil. Soils 12:117-121. 
van Gestel, C.A.M., W.-C. Ma, and C.E. Smit. 1991b. Development of QSAR's in terrestrial ecotoxicology: Earthworm toxicity and soil sorption of chlorophenols, chlorobenzenes and dichloroaniline, Sci. Total. Environ. 109/110:589-604.

van Gestel, C.A.M., E.M. Dirven-van Breemen, and R. Baerselman. 1993. Accumulation and elimination of cadmium, chromium and zinc and effects on growth and reproduction in Eisenia andrei (Oligochaeta; Annelida), Sci. Total Environ. Suppl.:585-597.

van Gestel, C.A.M., E.M. Dirven-van Breemen, R. Baerselman, H.J.B. Emans, J.A.M. Janssen, R. Postuma, and P.J.M. van Vliet. 1992. Comparison of sublethal and lethal criteria for nine different chemicals in standardized toxicity tests using the earthworm Eisenia andrei, Ecotoxicol. Environ. Saf. 23:206-220.

van Kessel, W.H.M., R.W.B. Zaalberg, and W. Seinen. 1989. Testing environmental pollutants on soil organisms: A simple assay to investigate the toxicity of environmental pollutants on soil organisms, using $\mathrm{CdCl}_{2}$ and nematodes, Ecotoxicol. Environ. Sat. 18:181-190.

van Rhee, J.A. 1975. Copper contamination effects on earthworms by disposal of pig waste in pastures, Progress in Soil Zoology 1975:451-457.

van Straalen, N.M. 1991. Soil and sediment quality criteria derived from invertebrate toxicity data, in Metal Ecotoxicology, Concepts \& Application, M.C. Newman and A.W. McIntosh (eds), Lewis Publishers, Boca Raton, pp. 427-440.

van Straalen, N.M., and R.A. Verweij. 1991. Effects of benzo(a)pyrene on food assimilation and growth efficiency in Porcellio scaber (Isopoda), Bull. Environ. Contam. Toxicol. 46:134-140.

van Straalen, N.M., J.H.M. Schobben, and R.G.M. de Goede. 1989. Population consequences of cadmium toxicity in soil microarthropods, Ecotoxicol. Environ. Saf. 17:190-204.

van Wensem, J. 1989. A terrestrial micro-ecosystem for measuring effects of pollutants on isopodmediated litter decomposition, Hydrobiologia 188/189:507-516.

van Wensem, J., and T. Adema. 1991. Effects of fluoride on soil fauna mediated litter decomposition, Environ. Pollut. 72:239-251.

Walton, B.T., T.A. Anderson, M.S. Hendricks, and S.S. Talmage. 1989. Physiochemical properties as predictors of organic chemical effects on soil microbial respiration, Environ Toxicol Chem 8:53-63.

Watkins, D.R., J.T. Ammons, J.L. Branson, B.B. Burgoa, et al. 1993. Final Report on the Background Soil Characterization Project at the Oak Ridge Reservation, Oak Ridge Tennessee, Vols. 1 and 2, EE/ER/TM-84, Oak Ridge National Laboratory, Environmental Restoration Division.

Will, M. E., and G.W. Suter, II. 1994. Toxicological Benchmarks for Screening Potential Contaminants of Concern for Effects on Terrestrial Plants, ES/ER/TM-85/R1, Oak Ridge National Laboratory, Environmental Science Division. 
Wilson, D.O. 1977. Nitrification in three soils amended with zinc sulfate, Soil Biol. Biochem. 9:277-280. 
9-10 
Appendix A

TOXICITY DATA FOR EARTHWORMS 


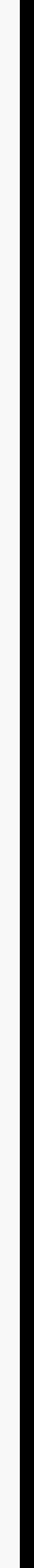


Chemical concentrations are $\mathrm{mg}$ of element $/ \mathrm{kg}$ of growth medium

\%OC - \% organic carbon

\% DEC - \% decrease in measured parameter at LOEC as compared to controls.

OECD soil (\% dry weight): sphagnum peat, 10; kaolin clay, 20; fine sand, 69; CaCO3, 1; pH 6.0

\begin{tabular}{|c|c|c|c|c|c|c|c|c|c|c|c|}
\hline \multicolumn{2}{|c|}{ CHEMICAL / FORM } & $\begin{array}{l}\text { EARTHWORM } \\
\text { SPECIES } \\
\end{array}$ & $\begin{array}{l}\text { GROWTH } \\
\text { MEDIUM } \\
\end{array}$ & pH & $\% O C$ & $\begin{array}{c}\text { EXP } \\
(D)\end{array}$ & $\begin{array}{c}\text { RESPONSE } \\
\text { PARAMETER } \\
\end{array}$ & $\begin{array}{l}\text { NOEC } \\
\text { APPL }\end{array}$ & $\begin{array}{l}\text { LOEC } \\
\text { APPL }\end{array}$ & $\begin{array}{c}\% \\
\text { DEC }\end{array}$ & REFERENCE \\
\hline As & $\mathrm{KH} 2 \mathrm{AsO} 4$ & Eisenia fetida & soil \& manure & & & 56 & cocoons/worm & & 68LCT & 56 & $\begin{array}{l}\text { Fischer \& Koszorus. } \\
1992 .\end{array}$ \\
\hline Cd & $\mathrm{CdCl} 2$ & Eisenia andrei & OECD soil & 6 & 5 & 21 & $\begin{array}{l}\text { cocoons/worm; } \\
\text { juveniles/worm }\end{array}$ & 10 & 18 & 23,22 & $\begin{array}{l}\text { van Gestel, et al. } \\
1992 .\end{array}$ \\
\hline $\mathrm{Cd}$ & $\mathrm{C} 4 \mathrm{H} 6 \mathrm{CdO} 4$ & Eisenia fetida & horse manure & & & 56 & cocoon production & & $25 \mathrm{LCT}$ & 52 & Malecki et al. 1982. \\
\hline $\mathrm{Cd}$ & $\mathrm{CdCl} 2$ & Eisenia andrei & OECD soil & 6 & 5 & 84 & $\begin{array}{l}\text { sexual development } \\
\text { EC50 }\end{array}$ & & 27 & 50 & $\begin{array}{l}\text { van Gestel et al. } \\
\text { 1991a. }\end{array}$ \\
\hline Cd & $\mathrm{CdCl} 2$ & Eisenia andrei & OECD soil & 6 & 5 & 84 & growth & 10 & 32 & 40 & $\begin{array}{l}\text { van Gestel et al. } \\
\text { 1991a. }\end{array}$ \\
\hline $\mathrm{Cd}$ & $\mathrm{Cd}(\mathrm{NO}) 2$ & Eisenia fetida & OECD soil & 6 & & 56 & $\begin{array}{l}\text { cocoon production } \\
\text { EC50 }\end{array}$ & & 46.3 & 50 & $\begin{array}{l}\text { Spurgeon et al. } \\
1994 .\end{array}$ \\
\hline Cd & $\mathrm{C} 4 \mathrm{H} 6 \mathrm{CdO} 4$ & Eisenia fetida & horse manure & & & 140 & cocoon production & & $50 \mathrm{LCT}$ & 24 & Malecki et al. 1982. \\
\hline $\mathrm{Cd}$ & $\begin{array}{l}\text { Soluble } \\
\text { forms }\end{array}$ & Eisenia fetida & horse manure & & & 42 & $\begin{array}{l}\text { growth;cocoon } \\
\text { production }\end{array}$ & & $\begin{array}{r}100 \\
\text { LCT }\end{array}$ & 25,100 & $\begin{array}{l}\text { Neuhauser et al. } \\
1984 .\end{array}$ \\
\hline Cd & $\mathrm{CdCl} 2$ & Eisenia andrei & OECD soil & 6 & 5 & 84 & growth & 32 & 100 & 44 & $\begin{array}{l}\text { van Gestel et al. } \\
\text { 1991a. }\end{array}$ \\
\hline
\end{tabular}


Table A.1 (continued)

\begin{tabular}{|c|c|c|c|c|c|c|c|c|c|c|c|}
\hline \multicolumn{2}{|c|}{ CHEMICAL / FORM } & \multirow{2}{*}{$\begin{array}{c}\begin{array}{c}\text { EARTHWORM } \\
\text { SPECIES }\end{array} \\
\text { Dendrobaena rubida }\end{array}$} & \multirow{2}{*}{$\begin{array}{r}\begin{array}{r}\text { GROWTH } \\
\text { MEDIUM }\end{array} \\
\text { soil \& dung }\end{array}$} & \multirow{2}{*}{$\frac{\mathrm{pH}}{5}$} & \multirow{2}{*}{$\frac{\% O C}{5.7}$} & \multirow{2}{*}{$\begin{array}{l}\operatorname{EXP} \\
(\mathrm{D}) \\
120\end{array}$} & \multirow{2}{*}{$\begin{array}{c}\text { RESPONSE } \\
\text { PARAMETER } \\
\text { cocoons/worm }\end{array}$} & \multirow{2}{*}{$\begin{array}{r}\begin{array}{l}\text { NOEC } \\
\text { APPL }\end{array} \\
10\end{array}$} & \multirow{2}{*}{$\begin{array}{r}\text { LOEC } \\
\text { APPL } \\
100\end{array}$} & \multirow{2}{*}{$\frac{\stackrel{\%}{\mathrm{DEC}}}{62}$} & \multirow{2}{*}{$\begin{array}{l}\text { REFERENCE } \\
\text { Bengtsson et al. } \\
1986 .\end{array}$} \\
\hline Cd & & & & & & & & & & & \\
\hline \multirow{2}{*}{\multicolumn{2}{|c|}{ Cd }} & Dendrobaena rubida & soil \& dung & 6 & 5.7 & 120 & $\begin{array}{l}\text { cocoons/worm; } \\
\text { hatchlings/cocoon }\end{array}$ & 10 & 100 & 78,71 & $\begin{array}{l}\text { Bengtsson et al. } \\
1986 .\end{array}$ \\
\hline & & & & & & & total hatchlings & & & 74 & \\
\hline \multirow{2}{*}{\multicolumn{2}{|c|}{$\mathrm{Cd}$}} & Dendrobaena rubida & soil \& dung & 7 & 5.7 & 120 & $\begin{array}{l}\% \text { cocoon hatching } \\
\text { success }\end{array}$ & 10 & 100 & 47 & $\begin{array}{l}\text { Bengtsson et al. } \\
1986 .\end{array}$ \\
\hline & & & & & & & $\begin{array}{l}\text { hatchlings/coc; total } \\
\text { hatchlings }\end{array}$ & & & 38,30 & $\begin{array}{l}\text { Bengtsson et al. } \\
1986 .\end{array}$ \\
\hline $\mathrm{Cd}$ & $\mathrm{CdCl} 2$ & Eisenia andrei & OECD soil & 6 & 5 & 84 & $\begin{array}{l}\text { sexual development } \\
\text { EC50 }\end{array}$ & & 108 & 50 & $\begin{array}{l}\text { van Gestel et al. } \\
\text { 1991a. }\end{array}$ \\
\hline Cd & $\mathrm{CdCl} 2$ & Eisenia fetida & sandy soil & 4 & 0.9 & 14 & survival LC50 & & 440 & 50 & $\begin{array}{l}\text { van Gestel \& van } \\
\text { Dis. } 1988\end{array}$ \\
\hline $\mathrm{Cd}$ & $\mathrm{CdCl} 2$ & Lumbricus rubellas & sandy loam & 7 & 4 & 84 & survival & 150 & 1000 & 82 & Ma. 1982. \\
\hline $\mathrm{Cd}$ & CdNO3 & Eisenia fetida & OECD soil & 6 & 5 & 14 & survival LC50 & & 1843 & 50 & $\begin{array}{l}\text { Neuhauser et al. } \\
1985\end{array}$ \\
\hline $\mathrm{Cr}$ & $\mathrm{K} 2 \mathrm{Cr} 2 \mathrm{O} 7$ & Octochaetus pattoni & soil \& dung & & & 60 & survival & & $2 \mathrm{LCT}$ & 75 & $\begin{array}{l}\text { Abbasi \& Soni. } \\
1983 .\end{array}$ \\
\hline $\mathrm{Cr}$ & $\mathrm{K} 2 \mathrm{Cr} 2 \mathrm{O} 7$ & Pheretima posthuma & paddy soil & & & 61 & survival & & 10LCT & 100 & $\begin{array}{l}\text { Soni \& Abbasi. } \\
\text { 1981. }\end{array}$ \\
\hline $\mathrm{Cr}$ & $\mathrm{Cr}(\mathrm{NO} 3) 3$ & Eisenia andrei & OECD soil & 6 & 5 & 21 & growth & 10 & 32 & 30 & $\begin{array}{l}\text { van Gestel et al. } \\
1992 .\end{array}$ \\
\hline
\end{tabular}


Table A.1 (continued)

\begin{tabular}{|c|c|c|c|c|c|c|c|c|c|c|c|}
\hline \multicolumn{2}{|c|}{ CHEMICAL / FORM } & \multirow{2}{*}{$\begin{array}{c}\begin{array}{c}\text { EARTHWORM } \\
\text { SPECIES }\end{array} \\
\text { Eisenia fetida }\end{array}$} & \multirow{2}{*}{$\begin{array}{r}\begin{array}{r}\text { GROWTH } \\
\text { MEDIUM }\end{array} \\
\text { soil \& manure }\end{array}$} & \multirow[t]{2}{*}{$\mathrm{pH}$} & \multirow[t]{2}{*}{$\% O C$} & \multirow{2}{*}{$\begin{array}{c}\text { EXP } \\
(\mathrm{D})\end{array}$} & \multirow{2}{*}{$\begin{array}{l}\text { RESPONSE } \\
\text { PARAMETER } \\
\text { number cocoons and } \\
\text { hatchlings }\end{array}$} & \multirow[t]{2}{*}{$\begin{array}{l}\text { NOEC } \\
\text { APPL } \\
\end{array}$} & \multirow{2}{*}{$\begin{array}{r}\text { LOEC } \\
\text { APPL } \\
625 \\
\text { LCT }\end{array}$} & \multirow{2}{*}{$\begin{array}{c}\frac{\%}{\mathrm{DEC}} \\
55\end{array}$} & \multirow{2}{*}{$\begin{array}{r}\text { REFERENCE } \\
\text { Molnar et al. } 1989 .\end{array}$} \\
\hline $\mathrm{Cr}$ & $\mathrm{KCr}(\mathrm{SO} 4) 2$ & & & & & & & & & & \\
\hline $\mathbf{C r}$ & $\mathrm{K} 2 \mathrm{Cr} 2 \mathrm{O}$ & Eisenia fetida & soil \& manure & & & 14 & $\begin{array}{l}\text { weight gain of } \\
\text { juveniles }\end{array}$ & & $\begin{array}{r}625 \\
\mathrm{LCT}\end{array}$ & 43 & Molnar et al. 1989. \\
\hline $\mathrm{Cu}$ & $\mathrm{CuCl} 2$ & $\begin{array}{l}\text { Allolobophora } \\
\text { chlorotica }\end{array}$ & sandy loam & 5 & 2.5 & & cocoon production & & 51 & 50 & Ma. 1988. \\
\hline $\mathrm{Cu}$ & $\mathrm{Cu}(\mathrm{NO} 3) 2$ & Eisenia fetida & OECD soil & 6 & & 56 & $\begin{array}{l}\text { cocoon production } \\
\text { EC50 }\end{array}$ & & 53.3 & 50 & $\begin{array}{l}\text { Spurgeon et al. } \\
1994 .\end{array}$ \\
\hline $\mathrm{Cu}$ & $\mathrm{CuCl} 2$ & Lumbricus rubellus & sandy loam & 7 & 1.7 & 42 & cocoon production & 13 & 63 & 41 & Ma. 1984. \\
\hline $\mathrm{Cu}$ & $\mathrm{CuCl} 2$ & $\begin{array}{l}\text { Apporectodea } \\
\text { caliginosa }\end{array}$ & sandy loam & 5 & 2.5 & & cocoon production & & 68 & 50 & Ma. 1988. \\
\hline $\mathrm{Cu}$ & & Dendrobaena rubida & soil \& dung & 5 & 5.7 & 120 & $\begin{array}{l}\text { cocoons/worm; } \\
\text { hatchlings/cocoon; } \\
\text { total hatchlings }\end{array}$ & & $\begin{array}{r}100 \\
\mathrm{LCT}\end{array}$ & $\begin{array}{l}70 \\
64 \\
74\end{array}$ & $\begin{array}{l}\text { Bengtsson et al. } \\
1986 .\end{array}$ \\
\hline $\mathrm{Cu}$ & $\mathrm{CuCl} 2$ & Eisenia andrei & OECD soil & 6 & 5 & 84 & growth & 32 & 100 & 32 & $\begin{array}{l}\text { van Gestel et al. } \\
\text { 1991a. }\end{array}$ \\
\hline $\mathrm{Cu}$ & & $\begin{array}{l}\text { Allolobophora } \\
\text { caliginosa }\end{array}$ & polder soil & & & 60 & cocoon production & & $\begin{array}{r}110 \\
\mathrm{LCT}\end{array}$ & 27 & van Rhee. 1975. \\
\hline $\mathrm{Cu}$ & $\mathrm{CuCl} 2$ & Lumbricus rubellus & sandy loam & 5 & 2.5 & & cocoon production & & 122 & 50 & Ma. 1988. \\
\hline $\mathrm{Cu}$ & $\mathrm{CuCl} 2$ & Lumbricus rubellus & loamy sand & 5 & 2.9 & 42 & cocoon production & 54 & 131 & 42 & Ma. 1984. \\
\hline $\mathrm{Cu}$ & $\mathrm{CuSO} 4$ & Lumbricus rubellus & loamy sand & 5 & 2.9 & 18 & cocoon production & 83 & 148 & 26 & Ma. 1984. \\
\hline
\end{tabular}


Table A.1 (continued)

\begin{tabular}{|c|c|c|c|c|c|c|c|c|c|c|c|}
\hline \multicolumn{2}{|c|}{ CHEMICAL / FORM } & $\begin{array}{l}\text { EARTHWORM } \\
\text { SPECIES } \\
\end{array}$ & $\begin{array}{l}\text { GROWTH } \\
\text { MEDIUM } \\
\end{array}$ & $\mathrm{pH}$ & $\% O C$ & $\begin{array}{l}\text { EXP } \\
\text { (D) }\end{array}$ & $\begin{array}{c}\text { RESPONSE } \\
\text { PARAMETER } \\
\end{array}$ & $\begin{array}{l}\text { NOEC } \\
\text { APPL } \\
\end{array}$ & $\begin{array}{l}\text { LOEC } \\
\text { APPL } \\
\end{array}$ & $\begin{array}{c}\% \\
\text { DEC } \\
\end{array}$ & REFERENCE \\
\hline $\mathrm{Cu}$ & $\mathrm{CuSO} 4$ & Octolasium cyaneum & Brown soil & & 3 & 14 & survival LC50 & & 180 & 50 & $\begin{array}{l}\text { Streit \& Jaggy. } \\
1983 .\end{array}$ \\
\hline $\mathrm{Cu}$ & $\mathrm{CuCl} 2$ & Eisenia fetida & OECD soil & 6 & 5 & 21 & cocoon production & 120 & 180 & 36 & $\begin{array}{l}\text { van Gestel et al. } \\
1989 .\end{array}$ \\
\hline $\mathrm{Cu}$ & CuSO4 & Lumbricus rubellus & loamy sand & 6 & 2.9 & 18 & cocoon production & 148 & 278 & 33 & Ma. 1984. \\
\hline $\mathrm{Cu}$ & & Dendrobaena rubida & soil \& dung & 6 & 5.7 & 120 & $\begin{array}{l}\text { cocoons/worm; } \\
\text { hatchlings/cocoon; } \\
\text { \% hatching success }\end{array}$ & 100 & 500 & $\begin{array}{r}96 \\
100 \\
100\end{array}$ & $\begin{array}{l}\text { Bengtsson et al. } \\
1986 .\end{array}$ \\
\hline $\mathrm{Cu}$ & & Dendrobaena rubida & soil \& dung & 7 & 5.7 & 120 & $\begin{array}{l}\text { cocoons/worm; } \\
\text { hatchlings/cocoon; } \\
\text { \% hatching success }\end{array}$ & 100 & 500 & $\begin{array}{r}90 \\
100 \\
100\end{array}$ & $\begin{array}{l}\text { Bengtsson et al. } \\
1986 .\end{array}$ \\
\hline $\mathrm{Cu}$ & $\mathrm{C} 4 \mathrm{H}_{6 \mathrm{CuO}} 4$ & Eisenia fetida & horse manure & & & 56 & cocoon production & 300 & 500 & 24 & Malecki et al. 1982 \\
\hline $\mathrm{Cu}$ & CuNO3 & Eisenia fetida & OECD soil & 6 & 5 & 14 & survival LC50 & & 643 & 50 & $\begin{array}{l}\text { Neuhauser et al. } \\
1985 \text {. }\end{array}$ \\
\hline $\mathrm{Cu}$ & CuSO4 & Octolasium cyaneum & Rendzina soil & & 14 & 14 & survival LC50 & & 850 & 50 & $\begin{array}{l}\text { Streit \& Jaggy. } \\
1983 .\end{array}$ \\
\hline $\mathrm{Cu}$ & $\mathrm{C} 4 \mathrm{H} 6 \mathrm{CuO} 4$ & Eisenia fetida & horse manure & & & 140 & cocoon production & 500 & 1000 & 24 & Malecki et al. 1982. \\
\hline $\mathrm{Cu}$ & $\mathrm{CuCl} 2$ & Lumbricus rubellus & sandy loam & 7 & 4 & 84 & survival & 150 & 1000 & 82 & Ma. 1982. \\
\hline $\mathrm{Cu}$ & $\begin{array}{l}\text { Soluble } \\
\text { forms }\end{array}$ & Eisenia fetida & horse manure & & & 42 & $\begin{array}{l}\text { growth;cocoon } \\
\text { production }\end{array}$ & 1000 & 2000 & 27,85 & $\begin{array}{l}\text { Neuhauser et al. } \\
1984 .\end{array}$ \\
\hline $\mathrm{Cu}$ & CuSO4 & Octolasium cyaneum & Peat soil & & 43 & 14 & survival LC50 & & 2500 & 50 & $\begin{array}{l}\text { Streit \& Jaggy. } \\
1983 .\end{array}$ \\
\hline
\end{tabular}


Table A.1 (continued)

\begin{tabular}{|c|c|c|c|c|c|c|c|c|c|c|c|}
\hline \multicolumn{2}{|c|}{ CHEMICAL / FORM } & \multirow{2}{*}{$\begin{array}{c}\begin{array}{c}\text { EARTHWORM } \\
\text { SPECIES }\end{array} \\
\text { Dendrobaena rubida }\end{array}$} & \multirow{2}{*}{$\begin{array}{r}\text { GROWTH } \\
\text { MEDIUM } \\
\text { soil \& dung }\end{array}$} & \multirow{2}{*}{$\frac{\mathrm{pH}}{5}$} & \multirow{2}{*}{$\frac{\% O C}{5.7}$} & \multirow{2}{*}{$\begin{array}{l}\text { EXP } \\
\text { (D) } \\
120\end{array}$} & \multirow{2}{*}{$\begin{array}{l}\text { RESPONSE } \\
\text { PARAMETER } \\
\text { cocoons/worm; } \\
\text { hatchlings/cocoon; } \\
\% \text { hatching success }\end{array}$} & \multirow{2}{*}{$\begin{array}{r}\begin{array}{c}\text { NOEC } \\
\text { APPL }\end{array} \\
100\end{array}$} & \multirow{2}{*}{$\begin{array}{r}\text { LOEC } \\
\text { APPL } \\
500\end{array}$} & \multirow{2}{*}{\begin{tabular}{r}
\multicolumn{1}{c}{$\%$} \\
DEC \\
75 \\
100 \\
100
\end{tabular}} & \multirow{2}{*}{$\begin{array}{l}\text { REFERENCE } \\
\text { Bengtsson et al. } \\
1986 .\end{array}$} \\
\hline $\mathrm{Pb}$ & & & & & & & & & & & \\
\hline $\mathrm{Pb}$ & $\mathrm{Pb}(\mathrm{NO} 3) 2$ & Eisenia fetida & OECD soil & 6 & & 56 & $\begin{array}{l}\text { cocoon production } \\
\text { EC50 }\end{array}$ & & 1940 & 50 & $\begin{array}{l}\text { Spurgeon et al. } \\
1994 .\end{array}$ \\
\hline $\mathrm{Pb}$ & $\mathrm{C} 4 \mathrm{H} 6 \mathrm{O} 4 \mathrm{~Pb}$ & Eisenia fetida & horse manure & & & 56 & cocoon production & 2000 & 4000 & 50 & Malecki et al. 1982. \\
\hline $\mathrm{Pb}$ & $\mathrm{C} 4 \mathrm{H} 6 \mathrm{O} 4 \mathrm{~Pb}$ & Eisenia fetida & horse manure & & & 140 & cocoon production & 1000 & 5000 & 28 & Malecki et al. 1982. \\
\hline $\mathrm{Pb}$ & PbNO3 & Eisenia fetida & OECD soil & 6 & 5 & 14 & survival LC50 & & 5941 & 50 & $\begin{array}{l}\text { Neuhauser et al. } \\
1985 .\end{array}$ \\
\hline $\mathrm{Pb}$ & $\begin{array}{l}\text { Soluble } \\
\text { forms }\end{array}$ & Eisenia fetida & horse manure & & & 42 & cocoon production & & $\begin{array}{l}5000 \\
\text { LCT }\end{array}$ & 80 & $\begin{array}{l}\text { Neuhauser et al. } \\
1984 .\end{array}$ \\
\hline $\mathrm{Hg}$ & $\mathrm{HgCl} 2$ & Octochaetus pattoni & soil \& dung & & & 60 & $\begin{array}{l}\text { survival; cocoon } \\
\text { production }\end{array}$ & & $0.5 \mathrm{LCT}$ & 65,40 & $\begin{array}{l}\text { Abbasi \& Soni. } \\
1983 .\end{array}$ \\
\hline $\mathrm{Hg}$ & $\mathrm{CH} 3 \mathrm{HgCl}$ & Eisenia fetida & polting soil & & & 84 & $\begin{array}{l}\text { survival;segment } \\
\text { regeneration }\end{array}$ & 2.5 & 12.5 & 21,69 & Beyer et al. 1985. \\
\hline $\mathrm{Ni}$ & C4H6NiO4 & Eisenia fetida & horse manure & & & 140 & cocoon production & 100 & 200 & 23 & Malecki et al. 1982. \\
\hline $\mathrm{Ni}$ & $\begin{array}{l}\text { Soluble } \\
\text { forms }\end{array}$ & Eisenia fetida & horse manure & & & 42 & cocoon production & & $\begin{array}{r}250 \\
\mathrm{LCT}\end{array}$ & 33 & $\begin{array}{l}\text { Neuhauser et al. } \\
1984 .\end{array}$ \\
\hline $\mathrm{Ni}$ & $\mathrm{C} 4 \mathrm{H} 6 \mathrm{NiO} 4$ & Eisenia fetida & horse manure & & & 56 & cocoon production & 200 & 300 & 41 & Malecki et al. 1982. \\
\hline $\mathrm{Ni}$ & NiNO3 & Eisenia fetida & OECD soil & 6 & 5 & 14 & survival LC50 & & 757 & 50 & $\begin{array}{l}\text { Neuhauser et al. } \\
1985 .\end{array}$ \\
\hline
\end{tabular}


Table A.1 (continued)

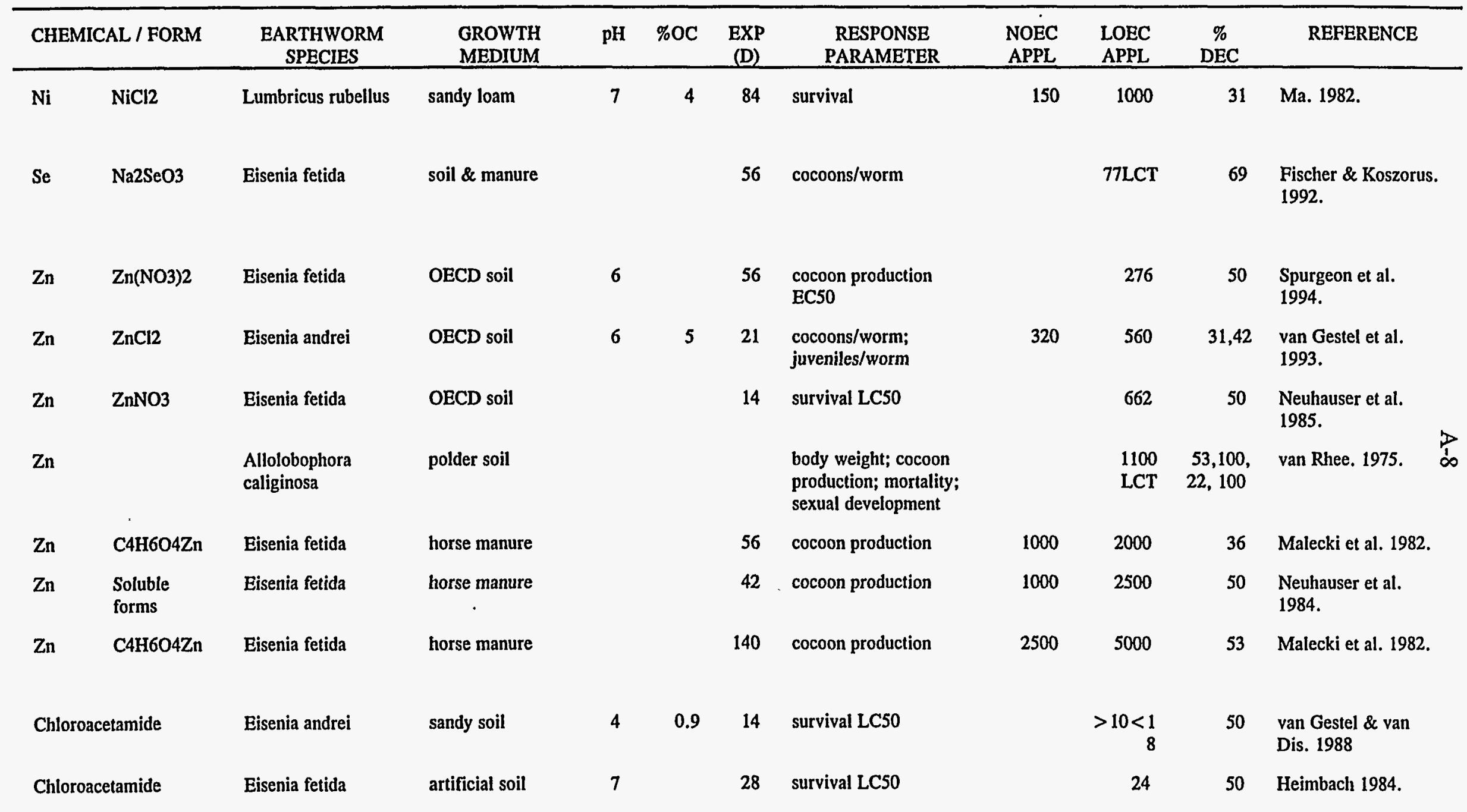


Table A.1 (continued)

\begin{tabular}{|c|c|c|c|c|c|c|c|c|c|c|}
\hline CHEMICAL / FORM & $\begin{array}{c}\text { EARTHWORM } \\
\text { SPECIES } \\
\end{array}$ & $\begin{array}{l}\text { GROWTH } \\
\text { MEDIUM } \\
\end{array}$ & $\mathrm{pH}$ & $\% O C$ & $\begin{array}{l}\text { EXP } \\
\text { (D) }\end{array}$ & $\begin{array}{c}\text { RESPONSE } \\
\text { PARAMETER } \\
\end{array}$ & $\begin{array}{l}\text { NOEC } \\
\text { APPL } \\
\end{array}$ & $\begin{array}{l}\text { LOEC } \\
\text { APPL } \\
\end{array}$ & $\begin{array}{c}\% \\
\text { DEC }\end{array}$ & REFERENCE \\
\hline Chloroacetamide & Eisenia andrei & sandy soil & 7 & 0.9 & 14 & survival LC50 & & $\begin{array}{r}>32<5 \\
6\end{array}$ & 50 & $\begin{array}{l}\text { van Gestel \& van } \\
\text { Dis. } 1988\end{array}$ \\
\hline Chloroacetamide & Eisenia andrei & OECD soil & 7 & 3.9 & 14 & survival LC50 & & 40 & 50 & $\begin{array}{l}\text { van Gestel \& van } \\
\text { Dis. } 1988\end{array}$ \\
\hline Chloroacetamide & Eisenia fetida & horse manure & & & 56 & growth & 500 & 1000 & 100 & $\begin{array}{l}\text { Neuhauser \& } \\
\text { Callahan. } 1990\end{array}$ \\
\hline 3-chloroaniline & Lumbricus rubellus & sandy soil & 5 & 1.9 & 14 & survival LC50 & & 195 & 50 & $\begin{array}{l}\text { van Gestel \& Ma. } \\
1993 .\end{array}$ \\
\hline 3-chloroaniline & Eisenia andrei & sandy soil & 5 & 1.9 & 14 & survival LC50 & & 220 & 50 & $\begin{array}{l}\text { van Gestel \& Ma. } \\
1993 .\end{array}$ \\
\hline 3-chloroaniline & Lumbricus rubellus & OECD soil & 6 & 4 & 14 & survival LC50 & & 332 & 50 & $\begin{array}{l}\text { van Gestel \& Ma. } \\
1993 .\end{array}$ \\
\hline 3-chloroaniline & Eisenia andrei & OECD soil & 6 & 4 & 14 & survival LC50 & & 448 & 50 & $\begin{array}{l}\text { van Gestel \& Ma. } \\
1993 .\end{array}$ \\
\hline 2,4-dichloroaniline & Eisenia andrei & OECD soil & 6 & 5 & 21 & cocoon production & 56 & 100 & 23 & $\begin{array}{l}\text { van Gestel et al. } \\
1989 .\end{array}$ \\
\hline 2,4-dichloroaniline & Eisenia andrei & sandy soil & 5 & 1.9 & 14 & survival LC50 & & 142 & 50 & $\begin{array}{l}\text { van Gestel \& Ma. } \\
1990 .\end{array}$ \\
\hline 2,4-dichloroaniline & Lumbricus rubellus & OECD soil & 6 & 4 & 14 & survival LC50 & & 190 & 50 & $\begin{array}{l}\text { van Gestel \& Ma. } \\
1990 .\end{array}$ \\
\hline
\end{tabular}


Table A.1 (continued)

\begin{tabular}{|c|c|c|c|c|c|c|c|c|c|c|}
\hline CHEMICAL / FORM & $\begin{array}{l}\text { EARTHWORM } \\
\text { SPECIES } \\
\end{array}$ & $\begin{array}{l}\text { GROWTH } \\
\text { MEDIUM } \\
\end{array}$ & $\mathrm{pH}$ & $\% O C$ & $\begin{array}{l}\operatorname{EXP} \\
\text { (D) }\end{array}$ & $\begin{array}{c}\text { RESPONSE } \\
\text { PARAMETER } \\
\end{array}$ & $\begin{array}{l}\text { NOEC } \\
\text { APPL } \\
\end{array}$ & $\begin{array}{l}\text { LOEC } \\
\text { APPL }\end{array}$ & $\begin{array}{c}\% \\
\text { DEC }\end{array}$ & REFERENCE \\
\hline 2,4-dichloroaniline & Lumbricus rubellus & sandy soil & 5 & 1.9 & 14 & survival LC50 & & 201 & 50 & $\begin{array}{l}\text { van Gestel \& Ma. } \\
1990 .\end{array}$ \\
\hline 2,4-dichloroaniline & Eisenia andrei & sandy soil & 6 & 3 & 14 & survival LC50 & & 285 & 50 & $\begin{array}{l}\text { van Gestel \& Ma. } \\
1990 .\end{array}$ \\
\hline 2,4-dichloroaniline & Lumbricus rubellus & sandy soil & 6 & 3 & 14 & survival LC50 & & 304 & 50 & $\begin{array}{l}\text { van Gestel \& Ma. } \\
1990 .\end{array}$ \\
\hline 2,4-dichloroaniline & Eisenia andrei & OECD soil & 6 & 4 & 14 & survival LC50 & & 319 & 50 & $\begin{array}{l}\text { van Gestel \& Ma. } \\
1990 .\end{array}$ \\
\hline 2,4-dichloroaniline & Lumbricus rubellus & peaty soil & 4 & 7.8 & 14 & survival LC50 & & 580 & 50 & $\begin{array}{l}\text { van Gestel \& Ma. } \\
1990 .\end{array}$ \\
\hline 2,4-dichloroaniline & Eisenia andrei & peaty soil & 4 & 7.8 & 14 & survival LC50 & & 824 & 50 & $\begin{array}{l}\text { van Gestel \& Ma. } \\
1990 .\end{array}$ \\
\hline 3,4-dichloroaniline & Eisenia andrei & sandy soil & 7 & 0.9 & 6 & survival LC50 & & 140 & 50 & $\begin{array}{l}\text { van Gestel \& van } \\
\text { Dis. } 1988\end{array}$ \\
\hline 3,4-dichloroaniline & Eisenia andrei & sandy soil & 4 & 0.9 & 6 & survival LC50 & & 140 & 50 & $\begin{array}{l}\text { van Gestel \& van } \\
\text { Dis. } 1988\end{array}$ \\
\hline 3,4-dichloroaniline & Eisenia andrei & OECD soil & 7 & 3.9 & 11 & survival LC50 & & 250 & 50 & $\begin{array}{l}\text { van Gestel \& van } \\
\text { Dis. } 1988\end{array}$ \\
\hline 2,4,5-trichloroaniline & Eisenia andrei & sandy soil & 5 & 1.9 & 14 & survival LC50 & & 134 & 50 & $\begin{array}{l}\text { van Gestel \& Ma. } \\
1993 .\end{array}$ \\
\hline
\end{tabular}


Table A.1 (continued)

\begin{tabular}{|c|c|c|c|c|c|c|c|c|c|c|}
\hline CHEMICAL / FORM & $\begin{array}{c}\text { EARTHWORM } \\
\text { SPECIES } \\
\end{array}$ & $\begin{array}{l}\text { GROWTH } \\
\text { MEDIUM } \\
\end{array}$ & $\mathrm{pH}$ & $\% O C$ & $\begin{array}{l}\text { EXP } \\
(D)\end{array}$ & $\begin{array}{c}\text { RESPONSE } \\
\text { PARAMETER } \\
\end{array}$ & $\begin{array}{l}\text { NOEC } \\
\text { APPL } \\
\end{array}$ & $\begin{array}{l}\text { LOEC } \\
\text { APPL } \\
\end{array}$ & $\begin{array}{c}\% \\
\text { DEC }\end{array}$ & REFERENCE \\
\hline 2,4,5-trichloroaniline & Lumbricus rubellus & sandy soil & 5 & 1.9 & 14 & survival LC50 & & 174 & 50 & $\begin{array}{l}\text { van Gestel \& Ma. } \\
1993 .\end{array}$ \\
\hline 2,4,5-trichloroaniline & Lumbricus rubellus & OECD soil & 6 & 4 & 14 & survival LC50 & & 213 & 50 & $\begin{array}{l}\text { van Gestel \& Ma. } \\
1993 .\end{array}$ \\
\hline 2,4,5-trichloroaniline & Eisenia andrei & OECD soil & 6 & 4 & 14 & survival LC50 & & 233 & 50 & $\begin{array}{l}\text { van Gestel \& Ma. } \\
1993 .\end{array}$ \\
\hline $\begin{array}{l}2,3,5,6 \text {-tetrachloro- } \\
\text { aniline }\end{array}$ & Eisenia andrei & sandy soil & 5 & 1.9 & 14 & survival LC50 & & 116 & 50 & $\begin{array}{l}\text { van Gestel \& Ma. } \\
1993 .\end{array}$ \\
\hline $\begin{array}{l}2,3,5,6 \text {-tetrachloro- } \\
\text { aniline }\end{array}$ & Eisenia andrei & OECD soil & 6 & 4 & 14 & survival LC50 & & 133 & 50 & $\begin{array}{l}\text { van Gestel \& Ma. } \\
1993 .\end{array}$ \\
\hline $\begin{array}{l}2,3,5,6 \text {-tetrachloro- } \\
\text { aniline }\end{array}$ & Lumbricus rubellus & sandy soil & 5 & 1.9 & 14 & survival LC50 & & 159 & 50 & $\begin{array}{l}\text { van Gestel \& Ma. } \\
1993 .\end{array}$ \\
\hline $\begin{array}{l}2,3,5,6 \text {-tetrachloro- } \\
\text { aniline }\end{array}$ & Lumbricus rubellus & OECD soil & 6 & 4 & 14 & survival LC50 & & 179 & 50 & $\begin{array}{l}\text { van Gestel \& Ma. } \\
1993 .\end{array}$ \\
\hline Pentachloroaniline & Lumbricus rubellus & OECD soil & 6 & 4 & 14 & survival LC50 & & 825 & 50 & $\begin{array}{l}\text { van Gestel \& Ma. } \\
1993 .\end{array}$ \\
\hline Pentachloroaniline & Lumbricus rubellus & sandy soil & 5 & 1.9 & 14 & survival LC50 & & 825 & 50 & $\begin{array}{l}\text { van Gestel \& Ma. } \\
1993 .\end{array}$ \\
\hline Pentachloroaniline & Eisenia andrei & sandy soil & 5 & 1.9 & 14 & survival LC50 & & 1014 & 50 & $\begin{array}{l}\text { van Gestel \& Ma. } \\
1993 .\end{array}$ \\
\hline
\end{tabular}


Table A.1 (continued)

\begin{tabular}{|c|c|c|c|c|c|c|c|c|c|c|}
\hline CHEMICAL / FORM & $\begin{array}{c}\text { EARTHWORM } \\
\text { SPECIES } \\
\end{array}$ & $\begin{array}{l}\text { GROWTH } \\
\text { MEDIUM } \\
\end{array}$ & $\mathrm{pH}$ & $\% O C$ & $\begin{array}{l}\text { EXP } \\
\text { (D) }\end{array}$ & $\begin{array}{c}\text { RESPONSE } \\
\text { PARAMETER } \\
\end{array}$ & $\begin{array}{l}\text { NOEC } \\
\text { APPL } \\
\end{array}$ & $\begin{array}{l}\text { LOEC } \\
\text { APPL } \\
\end{array}$ & $\begin{array}{c}\% \\
\text { DEC }\end{array}$ & REFERENCE \\
\hline Pentachloroaniline & Eisenia andrei & OECD soil & 6 & 4 & 14 & survival LC50 & & $>3200$ & 50 & $\begin{array}{l}\text { van Gestel \& Ma. } \\
1993 .\end{array}$ \\
\hline 1,2-dichloropropane & Perionyx excavatus & OECD soil & 6 & 5 & 14 & survival LC50 & & 3880 & 50 & $\begin{array}{l}\text { Neuhauser et al. } \\
1986 .\end{array}$ \\
\hline 1,2-dichloropropane & Eisenia fetida & OECD soil & 6 & 5 & 14 & survival LC50 & & 4240 & 50 & $\begin{array}{l}\text { Neuhauser et al. } \\
1986 .\end{array}$ \\
\hline 1,2-dichloropropane & $\begin{array}{l}\text { Allolobophora } \\
\text { tuberculata }\end{array}$ & OECD soil & 6 & 5 & 14 & survival LC50 & & 4272 & 50 & $\begin{array}{l}\text { Neuhauser et al. } \\
1986 .\end{array}$ \\
\hline 1,2-dichloropropane & Eudrilus eugeniae & OECD soil & 6 & 5 & 14 & survival LC50 & & 5300 & 50 & $\begin{array}{l}\text { Neuhauser et al. } \\
1986 .\end{array}$ \\
\hline 1,2-dichloropropane & Eisenia fetida & horse manure & & & 56 & growth & 80800 & 92300 & death & $\begin{array}{l}\text { Neuhauser \& } \\
\text { Callahan. } 1990\end{array}$ \\
\hline Dimethylphthalate & Perionyx excavatus & OECD soil & 6 & 5 & 14 & survival LC50 & & 1064 & 50 & $\begin{array}{l}\text { Neuhauser et al. } \\
1986 .\end{array}$ \\
\hline Dimethylphthalate & Eudrilus eugeniae & OECD soil & 6 & 5 & 14 & survival LC50 & & 2000 & 50 & $\begin{array}{l}\text { Neuhauser et al. } \\
1986 .\end{array}$ \\
\hline Dimethylphthalate & Eisenia fetida & OECD soil & 6 & 5 & 14 & survival LC50 & & 3160 & 50 & $\begin{array}{l}\text { Neuhauser et al. } \\
1986 .\end{array}$ \\
\hline Dimethylphthalate & $\begin{array}{l}\text { Allolobophora } \\
\text { tuberculata }\end{array}$ & OECD soil & 6 & 5 & 14 & survival LC50 & & 3335 & 50 & $\begin{array}{l}\text { Neuhauser et al. } \\
1986 .\end{array}$ \\
\hline
\end{tabular}


Table A.1 (continued)

\begin{tabular}{|c|c|c|c|c|c|c|c|c|c|c|}
\hline CHEMICAL / FORM & $\begin{array}{l}\text { EARTHWORM } \\
\text { SPECIES }\end{array}$ & $\begin{array}{l}\text { GROWTH } \\
\text { MEDIUM }\end{array}$ & $\mathrm{pH}$ & \%OC & $\begin{array}{l}\text { EXP } \\
\text { (D) }\end{array}$ & $\begin{array}{c}\text { RESPONSE } \\
\text { PARAMETER } \\
\end{array}$ & $\begin{array}{l}\text { NOEC } \\
\text { APPL }\end{array}$ & $\begin{array}{l}\text { LOEC } \\
\text { APPL } \\
\end{array}$ & $\begin{array}{c}\% \\
\text { DEC }\end{array}$ & REFERENCE \\
\hline Dimethylphthalate & Eisenia fetida & horse manure & & & 56 & cocoon production & 4720 & 70800 & 62 & $\begin{array}{l}\text { Neuhauser \& } \\
\text { Callahan. } 1990\end{array}$ \\
\hline Fluorene & Perionyx excavatus & OECD soil & 6 & 5 & 14 & survival LC50 & & 170 & 50 & $\begin{array}{l}\text { Neuhauser et al. } \\
1986 .\end{array}$ \\
\hline Fluorene & Eisenia fetida & OECD soil & 6 & 5 & 14 & survival LC50 & & 173 & 50 & $\begin{array}{l}\text { Neuhauser et al. } \\
1986 .\end{array}$ \\
\hline Fluorene & Eudrilus eugeniae & OECD soil & 6 & 5 & 14 & survival LC50 & & 197 & 50 & $\begin{array}{l}\text { Neuhauser et al. } \\
1986 .\end{array}$ \\
\hline Fluorene & $\begin{array}{l}\text { Allolobophora } \\
\text { tuberculata }\end{array}$ & OECD soil & 6 & 5 & 14 & survival LC50 & & 206 & 50 & $\begin{array}{l}\text { Neuhauser et al. } \\
1986 .\end{array}$ \\
\hline Fluorene & Eisenia fetida & horse manure & & & 56 & cocoon production & 500 & 750 & 49 & $\begin{array}{l}\text { Neuhauser \& } \\
\text { Callahan. } 1990\end{array}$ \\
\hline $\mathrm{N}$-nitrosodiphenylamine & Eudrilus eugeniae & OECD soil & 6 & 5 & 14 & survival LC50 & & 109 & 50 & $\begin{array}{l}\text { Neuhauser et al. } \\
1986 .\end{array}$ \\
\hline $\mathrm{N}$-nitrosodiphenylamine & Perionyx excavatus & OECD soil & 6 & 5 & 14 & survival LC50 & & 128 & 50 & $\begin{array}{l}\text { Neuhauser et al. } \\
1986 .\end{array}$ \\
\hline N-nitrosodiphenylamine & Eisenia fetida & OECD soil & 6 & 5 & 14 & survival LC50 & & 151 & 50 & $\begin{array}{l}\text { Neuhauser et al. } \\
1986 .\end{array}$ \\
\hline $\mathrm{N}$-nitrosodiphenylamine & $\begin{array}{l}\text { Allolobophora } \\
\text { tuberculata }\end{array}$ & OECD soil & 6 & 5 & 14 & survival LC50 & & 155 & 50 & $\begin{array}{l}\text { Neuhauser et al. } \\
1986 .\end{array}$ \\
\hline
\end{tabular}


Table A.1 (continued)

\begin{tabular}{|c|c|c|c|c|c|c|c|c|c|c|}
\hline CHEMICAL / FORM & $\begin{array}{c}\text { EARTHWORM } \\
\text { SPECIES } \\
\end{array}$ & $\begin{array}{l}\text { GROWTH } \\
\text { MEDIUM } \\
\end{array}$ & $\mathrm{pH}$ & $\% O C$ & $\begin{array}{l}\operatorname{EXP} \\
(D)\end{array}$ & $\begin{array}{c}\text { RESPONSE } \\
\text { PARAMETER } \\
\end{array}$ & $\begin{array}{l}\text { NOEC } \\
\text { APPL }\end{array}$ & $\begin{array}{l}\text { LOEC } \\
\text { APPL } \\
\end{array}$ & $\begin{array}{c}\% \\
\text { DEC }\end{array}$ & REFERENCE \\
\hline $\mathrm{N}$-nitrosodiphenylamine & Eisenia fetida & horse manure & & & 56 & cocoon production & & $\begin{array}{l}1400 \\
\text { LCT }\end{array}$ & 37 & $\begin{array}{l}\text { Neuhauser \& } \\
\text { Callahan. } 1990\end{array}$ \\
\hline Phenol & Eudrilus eugeniae & OECD soil & 6 & 5 & 14 & survival LC50 & & 188 & 50 & $\begin{array}{l}\text { Neuhauser et al. } \\
1986 .\end{array}$ \\
\hline Phenol & Perionyx excavatus & OECD soil & 6 & 5 & 14 & survival LC50 & & 258 & 50 & $\begin{array}{l}\text { Neuhauser et al. } \\
1986 .\end{array}$ \\
\hline Phenol & Eisenia fetida & OECD soil & 6 & 5 & 14 & survival LC50 & & 401 & 50 & $\begin{array}{l}\text { Neuhauser et al. } \\
1986 .\end{array}$ \\
\hline Phenol & $\begin{array}{l}\text { Allolobophora } \\
\text { tuberculata }\end{array}$ & OECD soil & 6 & 5 & 14 & survival LC50 & & 450 & 50 & $\begin{array}{l}\text { Neuhauser et al. } \\
1986 .\end{array}$ \\
\hline Phenol & Eisenia fetida & horse manure & & & 56 & cocoon production & 3900 & 4900 & 26 & $\begin{array}{l}\text { Neuhauser \& } \\
\text { Callahan. } 1990\end{array}$ \\
\hline 4-nitrophenol & Eisenia fetida & OECD soil & 6 & 5 & 14 & survival LC50 & & 38 & 50 & $\begin{array}{l}\text { Neuhauser et al. } \\
1986 .\end{array}$ \\
\hline 4-nitrophenol & Eudrilus eugeniae & OECD soil & 6 & 5 & 14 & survival LC50 & & 40 & 50 & $\begin{array}{l}\text { Neuhauser et al. } \\
1986 .\end{array}$ \\
\hline 4-nitrophenol & Periony $x$ excavatus & OECD soil & 6 & 5 & 14 & survival LC50 & & 44 & 50 & $\begin{array}{l}\text { Neuhauser et al. } \\
1986 .\end{array}$ \\
\hline 4-nitrophenol & $\begin{array}{l}\text { Allolobophora } \\
\text { tuberculata }\end{array}$ & OECD soil & 6 & 5 & 14 & survival LC50 & & 56 & 50 & $\begin{array}{l}\text { Neuhauser et al. } \\
1986 .\end{array}$ \\
\hline
\end{tabular}


Table A.1 (continued)

\begin{tabular}{|c|c|c|c|c|c|c|c|c|c|c|}
\hline CHEMICAL / FORM & $\begin{array}{c}\text { EARTHWORM } \\
\text { SPECIES }\end{array}$ & $\begin{array}{l}\text { GROWTH } \\
\text { MEDIUM } \\
\end{array}$ & $\mathrm{pH}$ & $\% O C$ & $\begin{array}{l}\text { EXP } \\
\text { (D) }\end{array}$ & $\begin{array}{c}\text { RESPONSE } \\
\text { PARAMETER } \\
\end{array}$ & $\begin{array}{l}\text { NOEC } \\
\text { APPL }\end{array}$ & $\begin{array}{l}\text { LOEC } \\
\text { APPL } \\
\end{array}$ & $\begin{array}{c}\% \\
\text { DEC } \\
\end{array}$ & REFERENCE \\
\hline 4-nitrophenol & Eisenia fetida & horse manure & & & 56 & cocoon production & & $\begin{array}{r}600 \\
\text { LCT }\end{array}$ & 39 & $\begin{array}{l}\text { Neuhauser \& } \\
\text { Callahan. } 1990\end{array}$ \\
\hline 3-chlorophenol & Eisenia andrei & sandy soil & 5 & 1.9 & 14 & survival LC50 & & 75 & 50 & $\begin{array}{l}\text { van Gestel \& Ma. } \\
1990 .\end{array}$ \\
\hline 3-chlorophenol & Eisenia andrei & humic sand & 5 & 1.9 & 14 & survival LC50 & & 78 & 50 & $\begin{array}{l}\text { van Gestel \& Ma. } \\
1988 .\end{array}$ \\
\hline 3-chlorophenol & Eisenia andrei & OECD soil & 6 & 4 & 14 & survival LC50 & & 130 & 50 & $\begin{array}{l}\text { van Gestel \& Ma. } \\
1990 .\end{array}$ \\
\hline 3-chlorophenol & Eisenia andrei & sandy soil & 6 & 3 & 14 & survival LC50 & & 134 & 50 & $\begin{array}{l}\text { van Gestel \& Ma. } \\
1990 .\end{array}$ \\
\hline 3-chlorophenol & Eisenia andrei & humic sand & 6 & 3 & 14 & survival LC50 & & 140 & 50 & $\begin{array}{l}\text { van Gestel \& Ma. } \\
1988 .\end{array}$ \\
\hline 3-chlorophenol & Lumbricus rubellus & humic sand & 5 & 1.9 & 14 & survival LC50 & & 150 & 50 & $\begin{array}{l}\text { van Gestel \& Ma. } \\
1988 .\end{array}$ \\
\hline 3-chlorophenol & Lumbricus rubellus & sandy soil & 5 & 1.9 & 14 & survival LC50 & & 150 & 50 & $\begin{array}{l}\text { van Gestel \& Ma. } \\
1990 .\end{array}$ \\
\hline 3-chlorophenol & Lumbricus rubellus & OECD soil & 6 & 4 & 14 & survival LC50 & & $247^{\prime}$ & 50 & $\begin{array}{l}\text { van Gestel \& Ma. } \\
1990 .\end{array}$ \\
\hline 3-chlorophenol & Lumbricus rubellus & humic sand & 6 & 3 & 14 & survival LC50 & & 296 & 50 & $\begin{array}{l}\text { van Gestel \& Ma. } \\
1988 .\end{array}$ \\
\hline 3-chlorophenol & Lumbricus rubellus & sandy soil & 6 & 3 & 14 & survival LC50 & & 342 & 50 & $\begin{array}{l}\text { van Gestel \& Ma. } \\
1990 .\end{array}$ \\
\hline
\end{tabular}


Table A.1 (continued)

\begin{tabular}{|c|c|c|c|c|c|c|c|c|c|c|}
\hline CHEMICAL / FORM & $\begin{array}{c}\text { EARTHWORM } \\
\text { SPECIES } \\
\end{array}$ & $\begin{array}{l}\text { GROWTH } \\
\text { MEDIUM } \\
\end{array}$ & $\mathrm{pH}$ & $\% O C$ & $\begin{array}{r}\operatorname{EXP} \\
(\mathrm{D}) \\
\end{array}$ & $\begin{array}{c}\text { RESPONSE } \\
\text { PARAMETER } \\
\end{array}$ & $\begin{array}{l}\text { NOEC } \\
\text { APPL } \\
\end{array}$ & $\begin{array}{l}\text { LOEC } \\
\text { APPL } \\
\end{array}$ & $\begin{array}{c}\% \\
\mathrm{DEC} \\
\end{array}$ & REFERENCE \\
\hline 3-chlorophenol & Eisenia andrei & peaty soil & 4 & 7.8 & 14 & survival LC50 & & 423 & 50 & $\begin{array}{l}\text { van Gestel \& Ma. } \\
1990 .\end{array}$ \\
\hline 3-chlorophenol & Lumbricus rubellus & peaty soil & 4 & 7.8 & 14 & survival LC50 & & 633 & 50 & $\begin{array}{l}\text { van Gestel \& Ma. } \\
1990 .\end{array}$ \\
\hline 3,4-dichlorophenol & Eisenia andrei & sandy soil & 5 & 1.9 & 14 & survival LC50 & & 134 & 50 & $\begin{array}{l}\text { van Gestel \& Ma. } \\
1990 .\end{array}$ \\
\hline 3,4-dichlorophenol & Eisenia andrei & humic sand & 5 & 1.9 & 14 & survival LC50 & & 140 & 50 & $\begin{array}{l}\text { van Gestel \& Ma. } \\
1988 .\end{array}$ \\
\hline 3,4-dichlorophenol & Eisenia andrei & OECD soil & 6 & 4 & 14 & survival LC50 & & 172 & 50 & $\begin{array}{l}\text { van Gestel \& Ma. } \\
1990 .\end{array}$ \\
\hline 3,4-dichlorophenol & Eisenia andrei & sandy soil & 6 & 3 & 14 & survival LC50 & & 240 & 50 & $\begin{array}{l}\text { van Gestel \& Ma. } \\
1990 .\end{array}$ \\
\hline 3,4-dichlorophenol & Eisenia andrei & humic sand & 6 & 3 & 14 & survival LC50 & & 250 & 50 & $\begin{array}{l}\text { van Gestel \& Ma. } \\
1988 .\end{array}$ \\
\hline 3,4-dichlorophenol & Lumbricus rubellus & humic sand & 5 & 1.9 & 14 & survival LC50 & & 303 & 50 & $\begin{array}{l}\text { van Gestel \& Ma. } \\
1988 .\end{array}$ \\
\hline 3,4-dichlorophenol & Lumbricus rubellus & OECD soil & 6 & 4 & 14 & survival LC50 & & 322 & 50 & $\begin{array}{l}\text { van Gestel \& Ma. } \\
1990 .\end{array}$ \\
\hline 3,4-dichlorophenol & Lumbricus rubellus & sandy soil & 5 & 1.9 & 14 & survival LC50 & & 352 & 50 & $\begin{array}{l}\text { van Gestel \& Ma. } \\
1990 .\end{array}$ \\
\hline 3,4-dichlorophenol & Eisenia andrei & peaty soil & 4 & 7.8 & 14 & survival LC50 & & 423 & 50 & $\begin{array}{l}\text { van Gestel \& Ma. } \\
1990 .\end{array}$ \\
\hline
\end{tabular}


Table A.1 (continued)

\begin{tabular}{|c|c|c|c|c|c|c|c|c|c|c|}
\hline CHEMICAL / FORM & $\begin{array}{l}\text { EARTHWORM } \\
\text { SPECIES } \\
\end{array}$ & $\begin{array}{l}\text { GROWTH } \\
\text { MEDIUM } \\
\end{array}$ & $\mathrm{pH}$ & $\% O C$ & $\begin{array}{l}\text { EXP } \\
\text { (D) } \\
\end{array}$ & $\begin{array}{c}\text { RESPONSE } \\
\text { PARAMETER } \\
\end{array}$ & $\begin{array}{l}\text { NOEC } \\
\text { APPL } \\
\end{array}$ & $\begin{array}{l}\text { LOEC } \\
\text { APPL } \\
\end{array}$ & $\begin{array}{c}\% \\
\text { DEC } \\
\end{array}$ & REFERENCE \\
\hline 3,4-dichlorophenol & Lumbricus rubellus & sandy soil & 6 & 3 & 14 & survival LC50 & & 486 & 50 & $\begin{array}{l}\text { van Gestel \& Ma. } \\
1990 .\end{array}$ \\
\hline 3,4-dichlorophenol & Lumbricus rubellus & humic sand & 6 & 3 & 14 & survival LC50 & & 486 & 50 & $\begin{array}{l}\text { van Gestel \& Ma. } \\
1988 .\end{array}$ \\
\hline 3,4-dichlorophenol & Lumbricus rubellus & peaty soil & 4 & 7.8 & 14 & survival LC50 & & 680 & 50 & $\begin{array}{l}\text { van Gestel \& Ma. } \\
1990 .\end{array}$ \\
\hline 2,4,5-trichlorophenol & Eisenia andrei & sandy soil & 5 & 1.9 & 14 & survival LC50 & & 46 & 50 & $\begin{array}{l}\text { van Gestel \& Ma. } \\
1990 .\end{array}$ \\
\hline 2,4,5-trichlorophenol & Eisenia andrei & humic sand & 5 & 1.9 & 14 & survival LC50 & & 52 & 50 & $\begin{array}{l}\text { van Gestel \& Ma. } \\
1988 .\end{array}$ \\
\hline 2,4,5-trichlorophenol & Eisenia andrei & OECD soil & 6 & 4 & 14 & survival LC50 & & 63 & 50 & $\begin{array}{l}\text { van Gestel \& Ma. } \\
1990 .\end{array}$ \\
\hline 2,4,5-trichlorophenol & Eisenia andrei & sandy soil & 6 & 3 & 14 & survival LC50 & & 76 & 50 & $\begin{array}{l}\text { van Gestel \& Ma. } \\
1990 .\end{array}$ \\
\hline 2,4,5-trichlorophenol & Eisenia andrei & humic sand & 6 & 3 & 14 & survival LC50 & & 90 & 50 & $\begin{array}{l}\text { van Gestel \& Ma. } \\
1988 .\end{array}$ \\
\hline 2,4,5-trichlorophenol & Eisenia andrei & peaty soil & 4 & 7.8 & 14 & survival LC50 & & 164 & 50 & $\begin{array}{l}\text { van Gestel \& Ma. } \\
1990 .\end{array}$ \\
\hline 2,4,5-trichlorophenol & Lumbricus rubellus & humic sand & 5 & 1.9 & 14 & survival LC50 & & 201 & 50 & $\begin{array}{l}\text { van Gestel \& Ma. } \\
1988 .\end{array}$ \\
\hline 2,4,5-trichlorophenol & Lumbricus rubellus & sandy soil & 5 & 1.9 & 14 & survival LC50 & & 235 & 50 & $\begin{array}{l}\text { van Gestel \& Ma. } \\
1990 .\end{array}$ \\
\hline
\end{tabular}


Table A.1 (continued)

\begin{tabular}{|c|c|c|c|c|c|c|c|c|c|c|}
\hline CHEMICAL / FORM & $\begin{array}{c}\text { EARTHWORM } \\
\text { SPECIES } \\
\end{array}$ & $\begin{array}{l}\text { GROWTH } \\
\text { MEDIUM } \\
\end{array}$ & $\mathrm{pH}$ & $\% O C$ & $\begin{array}{c}\operatorname{Exp} \\
\text { (D) }\end{array}$ & $\begin{array}{c}\text { RESPONSE } \\
\text { PARAMETER } \\
\end{array}$ & $\begin{array}{l}\text { NOEC } \\
\text { APPL } \\
\end{array}$ & $\begin{array}{l}\text { LOEC } \\
\text { APPL } \\
\end{array}$ & $\begin{array}{c}\% \\
\mathrm{DEC} \\
\end{array}$ & REFERENCE \\
\hline 2,4,5-trichlorophenol & Lumbricus rubellus & humic sand & 6 & 3 & 14 & survival LC50 & & 290 & 50 & $\begin{array}{l}\text { van Gestel \& Ma. } \\
1988 .\end{array}$ \\
\hline 2,4,5-trichlorophenol & Lumbricus rubellus & sandy soil & 6 & 3 & 14 & survival LC50 & & 316 & 50 & $\begin{array}{l}\text { van Gestel \& Ma. } \\
1990 .\end{array}$ \\
\hline 2,4,5-trichlorophenol & Lumbricus rubellus & OECD soil & 6 & 4 & 14 & survival LC50 & & 362 & 50 & $\begin{array}{l}\text { van Gestel \& Ma. } \\
1990 .\end{array}$ \\
\hline 2,4,5-trichlorophenol & Lumbricus rubellus & peaty soil & 4 & 7.8 & 14 & survival LC50 & & 875 & 50 & $\begin{array}{l}\text { van Gestel \& Ma. } \\
1990 .\end{array}$ \\
\hline 2,4,6-trichlorophenol & Eisenia fetida & OECD soil & 6 & 5 & 14 & survival LC50 & & 58 & 50 & $\begin{array}{l}\text { Neuhauser et al. } \\
1986 .\end{array}$ \\
\hline 2,4,6-trichlorophenol & Perionyx excavatus & OECD soil & 6 & 5 & 14 & survival LC50 & & 78 & 50 & $\begin{array}{l}\text { Neuhauser et al. } \\
1986 .\end{array}$ \\
\hline 2,4,6-trichlorophenol & Eudrilus eugeniae & OECD soil & 6 & 5 & 14 & survival LC50 & & 85 & 50 & $\begin{array}{l}\text { Neuhauser et al. } \\
1986 .\end{array}$ \\
\hline 2,4,6-trichlorophenol & Eisenia fetida & horse manure & & & 56 & cocoon production & & $\begin{array}{r}100 \\
\text { LCT }\end{array}$ & 28 & $\begin{array}{l}\text { Neuhauser \& } \\
\text { Callahan. } 1990\end{array}$ \\
\hline 2,4,6-trichlorophenol & $\begin{array}{l}\text { Allolobophora } \\
\text { tuberculata }\end{array}$ & OECD soil & 6 & 5 & 14 & survival LC50 & & 108 & 50 & $\begin{array}{l}\text { Neuhauser et al. } \\
1986 .\end{array}$ \\
\hline $\begin{array}{l}2,3,4,5 \text {-tetrachloro- } \\
\text { phenol }\end{array}$ & Eisenia andrei & humic sand & 5 & 1.9 & 14 & survival LC50 & & 116 & 50 & $\begin{array}{l}\text { van Gestel \& Ma. } \\
1988 .\end{array}$ \\
\hline
\end{tabular}


Table A.1 (continued)

\begin{tabular}{|c|c|c|c|c|c|c|c|c|c|c|}
\hline CHEMICAL / FORM & $\begin{array}{c}\text { EARTHWORM } \\
\text { SPECIES }\end{array}$ & $\begin{array}{l}\text { GROWTH } \\
\text { MEDIUM } \\
\end{array}$ & $\mathrm{pH}$ & $\% O C$ & $\begin{array}{c}\text { EXP } \\
(\mathrm{D}) \\
\end{array}$ & $\begin{array}{c}\text { RESPONSE } \\
\text { PARAMETER } \\
\end{array}$ & $\begin{array}{l}\text { NOEC } \\
\text { APPL } \\
\end{array}$ & $\begin{array}{l}\text { LOEC } \\
\text { APPL } \\
\end{array}$ & $\begin{array}{c}\% \\
\text { DEC }\end{array}$ & REFERENCE \\
\hline $\begin{array}{l}2,3,4,5 \text {-tetrachloro- } \\
\text { phenol }\end{array}$ & Eisenia andrei & sandy soil & 5 & 1.9 & 14 & survival LC50 & & 117 & 50 & $\begin{array}{l}\text { van Gestel \& Ma. } \\
1990 .\end{array}$ \\
\hline $\begin{array}{l}2,3,4,5 \text {-tetrachloro- } \\
\text { phenol }\end{array}$ & Eisenia andrei & sandy soil & 6 & 3 & 14 & survival LC50 & & 166 & 50 & $\begin{array}{l}\text { van Gestel \& Ma. } \\
1990 .\end{array}$ \\
\hline $\begin{array}{l}\text { 2,3,4,5-tetrachloro- } \\
\text { phenol }\end{array}$ & Eisenia andrei & humic sand & 6 & 3 & 14 & survival LC50 & & 176 & 50 & $\begin{array}{l}\text { van Gestel \& Ma. } \\
1988 .\end{array}$ \\
\hline $\begin{array}{l}2,3,4,5 \text {-tetrachloro- } \\
\text { phenol }\end{array}$ & Lumbricus rubellus & humic sand & 5 & 1.9 & 14 & survival LC50 & & 514 & 50 & $\begin{array}{l}\text { van Gestel \& Ma. } \\
1988 .\end{array}$ \\
\hline $\begin{array}{l}\text { 2,3,4,5-tetrachloro- } \\
\text { phenol }\end{array}$ & Lumbricus rubellus & sandy soil & 5 & 1.9 & 14 & survival LC50 & & 515 & 50 & $\begin{array}{l}\text { van Gestel \& Ma. } \\
1990 .\end{array}$ \\
\hline $\begin{array}{l}2,3,4,5 \text {-tetrachloro- } \\
\text { phenol }\end{array}$ & Lumbricus rubellus & humic sand & 6 & 3 & 14 & survival LC50 & & 828 & 50 & $\begin{array}{l}\text { van Gestel \& Ma. } \\
1988 .\end{array}$ \\
\hline $\begin{array}{l}\text { 2,3,4,5-tetrachloro- } \\
\text { phenol }\end{array}$ & Lumbricus rubellus & sandy soil & 6 & 3 & 14 & survival LC50 & & 875 & 50 & $\begin{array}{l}\text { van Gestel \& Ma. } \\
1990 .\end{array}$ \\
\hline Pentachlorophenol & Eisenia andrei & sandy soil & 7 & 0.9 & 14 & survival LC50 & & 16 & 50 & $\begin{array}{l}\text { van Gestel \& van } \\
\text { Dis. } 1988\end{array}$ \\
\hline Pentachlorophenol & Eisenia andrei & OECD soil & 7 & 3.9 & 14 & survival LC50 & & 29 & 50 & $\begin{array}{l}\text { van Gestel \& van } \\
\text { Dis. } 1988\end{array}$ \\
\hline Pentachlorophenol & Eisenia andrei & OECD soil & 6 & 5 & 21 & $\begin{array}{l}\% \text { cocoon hatch } \\
\text { success }\end{array}$ & 10 & 32 & 50 & $\begin{array}{l}\text { van Gestel et al. } \\
1989 .\end{array}$ \\
\hline Pentachlorophenol & Eisenia andrei & sandy soil & 4 & 0.9 & 14 & survival LC50 & & 52 & 50 & $\begin{array}{l}\text { van Gestel \& van } \\
\text { Dis. } 1988\end{array}$ \\
\hline
\end{tabular}


Table A.1 (continued)

\begin{tabular}{|c|c|c|c|c|c|c|c|c|c|c|}
\hline CHEMICAL / FORM & $\begin{array}{c}\text { EARTHWORM } \\
\text { SPECIES } \\
\end{array}$ & $\begin{array}{l}\text { GROWTH } \\
\text { MEDIUM } \\
\end{array}$ & $\mathrm{pH}$ & $\% O C$ & $\begin{array}{l}\text { EXP } \\
\text { (D) }\end{array}$ & $\begin{array}{c}\text { RESPONSE } \\
\text { PARAMETER } \\
\end{array}$ & $\begin{array}{l}\text { NOEC } \\
\text { APPL } \\
\end{array}$ & $\begin{array}{l}\text { LOEC } \\
\text { APPL } \\
\end{array}$ & $\begin{array}{c}\% \\
\text { DEC }\end{array}$ & REFERENCE \\
\hline Pentachlorophenol & Eisenia andrei & OECD soil & 6 & 4 & 14 & survival LC50 & & 83 & 50 & $\begin{array}{l}\text { van Gestel \& Ma. } \\
1990 .\end{array}$ \\
\hline Pentachlorophenol & Eisenia andrei & sandy soil & 5 & 1.9 & 14 & survival LC50 & & 84 & 50 & $\begin{array}{l}\text { van Gestel \& Ma. } \\
1990 .\end{array}$ \\
\hline Pentachlorophenol & Eisenia fetida & artificial soil & 7 & & 28 & survival LC50 & & 87 & 50 & Heimbach 1984. \\
\hline Pentachlorophenol & Eisenia andrei & humic sand & 5 & 1.9 & 14 & survival LC50 & & 94 & 50 & $\begin{array}{l}\text { van Gestel \& Ma. } \\
1988 .\end{array}$ \\
\hline Pentachlorophenol & Eisenia andrei & sandy soil & 6 & 3 & 14 & survival LC50 & & 142 & 50 & $\begin{array}{l}\text { van Gestel \& Ma. } \\
1990 .\end{array}$ \\
\hline Pentachlorophenol & Eisenia andrei & humic sand & 6 & 3 & 14 & survival LC50 & & 143 & 50 & $\begin{array}{l}\text { van Gestel \& Ma. } \\
1988 .\end{array}$ \\
\hline Pentachlorophenol & Lumbricus rubellus & OECD soil & 6 & 4 & 14 & survival LC50 & & 362 & 50 & $\begin{array}{l}\text { van Gestel \& Ma. } \\
1990 .\end{array}$ \\
\hline Pentachlorophenol & Eisenia andrei & peaty soil & 4 & 7.8 & 14 & survival LC50 & & 502 & 50 & $\begin{array}{l}\text { van Gestel \& Ma. } \\
1990 .\end{array}$ \\
\hline Pentachlorophenol & Lumbricus rubellus & humic sand & 6 & 3 & 14 & survival LC50 & & 883 & 50 & $\begin{array}{l}\text { van Gestel \& Ma. } \\
1988 .\end{array}$ \\
\hline Pentachlorophenol & Lumbricus rubellus & sandy soil & 6 & 3 & 14 & survival LC50 & & 1013 & 50 & $\begin{array}{l}\text { van Gestel \& Ma. } \\
1990 .\end{array}$ \\
\hline Pentachlorophenol & Lumbricus rubellus & humic sand & 5 & 1.9 & 14 & survival LC50 & & 1094 & 50 & $\begin{array}{l}\text { van Gestel \& Ma. } \\
1988 .\end{array}$ \\
\hline Pentachlorophenol & Lumbricus rubellus & sandy soil & 5 & 1.9 & 14 & survival LC50 & & 1206 & 50 & $\begin{array}{l}\text { van Gestel \& Ma. } \\
1990 .\end{array}$ \\
\hline
\end{tabular}


Table A.1 (continued)




Table A.1 (continued)

\begin{tabular}{|c|c|c|c|c|c|c|c|c|c|c|}
\hline CHEMICAL / FORM & $\begin{array}{c}\text { EARTHWORM } \\
\text { SPECIES } \\
\end{array}$ & $\begin{array}{l}\text { GROWTH } \\
\text { MEDIUM } \\
\end{array}$ & $\mathrm{pH}$ & $\% O C$ & $\begin{array}{l}\text { EXP } \\
(D)\end{array}$ & $\begin{array}{c}\text { RESPONSE } \\
\text { PARAMETER } \\
\end{array}$ & $\begin{array}{l}\text { NOECC } \\
\text { APPL } \\
\end{array}$ & $\begin{array}{l}\text { LOEC } \\
\text { APPL } \\
\end{array}$ & $\begin{array}{c}\% \\
\text { DEC } \\
\end{array}$ & REFERENCE \\
\hline 1,2,3-trichlorobenzene & Eisenia andrei & OECD soil & 6 & 4 & 14 & survival LC50 & & 133 & 50 & $\begin{array}{l}\text { van Gestel \& Ma. } \\
1990 .\end{array}$ \\
\hline 1,2,3-trichlorobenzene & Eisenia andrei & sandy soil & 5 & 1.9 & 14 & survival LC50 & & 134 & 50 & $\begin{array}{l}\text { van Gestel \& Ma. } \\
1990 .\end{array}$ \\
\hline 1,2,3-trichlorobenzene & Lumbricus rubellus & OECD soil & 6 & 4 & 14 & survival LC50 & & 195 & 50 & $\begin{array}{l}\text { van Gestel \& Ma. } \\
1990 .\end{array}$ \\
\hline 1,2,3-trichlorobenzene & Lumbricus rubellus & sandy soil & 6 & 3 & 14 & survival LC50 & & 200 & 50 & $\begin{array}{l}\text { van Gestel \& Ma. } \\
1990 .\end{array}$ \\
\hline 1,2,3-trichlorobenzene & Eisenia andrei & sandy soil & 6 & 3 & 14 & survival LC50 & & 240 & 50 & $\begin{array}{l}\text { van Gestel \& Ma. } \\
1990 .\end{array}$ \\
\hline 1,2,3-trichlorobenzene & Eisenia andrei & peaty soil & 4 & 7.8 & 14 & survival LC50 & & 547 & 50 & $\begin{array}{l}\text { van Gestel \& Ma. } \\
1990 .\end{array}$ \\
\hline 1,2,3-trichlorobenzene & Lumbricus rubellus & peaty soil & 4 & 7.8 & 14 & survival LC50 & & 563 & 50 & $\begin{array}{l}\text { van Gestel \& Ma. } \\
1990 .\end{array}$ \\
\hline 1,2,4-trichlorobenzene & Eudrilus eugeniae & OECD soil & 6 & 5 & 14 & survival LC50 & & 127 & 50 & $\begin{array}{l}\text { Neuhauser et al. } \\
1986 .\end{array}$ \\
\hline 1,2,4-trichlorobenzene & Perionyx excavatus & OECD soil & 6 & 5 & 14 & survival LC50 & & 180 & 50 & $\begin{array}{l}\text { Neuhauser et al. } \\
1986 .\end{array}$ \\
\hline 1,2,4-trichlorobenzene & Eisenia fetida & OECD soil & 6 & 5 & 14 & survival LC50 & & 197 & 50 & $\begin{array}{l}\text { Neuhauser et al. } \\
1986 .\end{array}$ \\
\hline 1,2,4-trichlorobenzene & $\begin{array}{l}\text { Allolobophora } \\
\text { tuberculata }\end{array}$ & OECD soil & 6 & 5 & 14 & survival LC50 & & 251 & 50 & $\begin{array}{l}\text { Neuhauser et al. } \\
1986 .\end{array}$ \\
\hline
\end{tabular}


Table A.1 (continued)

\begin{tabular}{|c|c|c|c|c|c|c|c|c|c|c|}
\hline CHEMICAL / FORM & $\begin{array}{c}\text { EARTHWORM } \\
\text { SPECIES } \\
\end{array}$ & $\begin{array}{l}\text { GROWTH } \\
\text { MEDIUM } \\
\end{array}$ & $\mathrm{pH}$ & \%OC & $\begin{array}{l}\text { EXP } \\
(D) \\
\end{array}$ & $\begin{array}{c}\text { RESPONSE } \\
\text { PARAMETER } \\
\end{array}$ & $\begin{array}{l}\text { NOEC } \\
\text { APPL } \\
\end{array}$ & $\begin{array}{l}\text { LOEC } \\
\text { APPL } \\
\end{array}$ & $\begin{array}{c}\% \\
\text { DEC } \\
\end{array}$ & REFERENCE \\
\hline $\begin{array}{l}1,2,3,4-\text { tetrachloro- } \\
\text { benzene }\end{array}$ & Eisenia fetida & sandy soil & 5 & 1.8 & 14 & survival LC50 & & 75 & 50 & $\begin{array}{l}\text { van Gestel et al. } \\
\text { 1991b. }\end{array}$ \\
\hline $\begin{array}{l}1,2,3,4 \text {-tetrachloro- } \\
\text { benzene }\end{array}$ & Lumbricus rubellus & sandy soil & 5 & 1.8 & 14 & survival LC50 & & 112 & 50 & $\begin{array}{l}\text { van Gestel et al. } \\
1991 b .\end{array}$ \\
\hline $\begin{array}{l}1,2,3,4-\text { tetrachloro- } \\
\text { benzene }\end{array}$ & Lumbricus rubellus & OECD soil & 6 & 4 & 14 & survival LC50 & & 201 & 50 & $\begin{array}{l}\text { van Gestel et al. } \\
1991 b .\end{array}$ \\
\hline $\begin{array}{l}\text { 1,2,3,4-tetrachloro- } \\
\text { benzene }\end{array}$ & Eisenia fetida & OECD soil & 6 & 4 & 14 & survival LC50 & & 223 & 50 & $\begin{array}{l}\text { van Gestel et al. } \\
1991 \mathrm{~b} .\end{array}$ \\
\hline Pentachlorobenzene & Lumbricus rubellus & sandy soil & 5 & 1.8 & 14 & survival LC50 & & 115 & 50 & $\begin{array}{l}\text { van Gestel et al. } \\
\text { 1991b. }\end{array}$ \\
\hline Pentachlorobenzene & Eisenia fetida & sandy soil & 5 & 1.8 & 14 & survival LC50 & & 134 & 50 & $\begin{array}{l}\text { van Gestel et al. } \\
\text { 1991b. }\end{array}$ \\
\hline Pentachlorobenzene & Lumbricus rubellus & OECD soil & 6 & 4 & 14 & survival LC50 & & 201 & 50 & $\begin{array}{l}\text { van Gestel et al. } \\
1991 b .\end{array}$ \\
\hline Pentachlorobenzene & Eisenia fetida & OECD soil & 6 & 4 & 14 & survival LC50 & & 238 & 50 & $\begin{array}{l}\text { van Gestel et al. } \\
\text { 1991b. }\end{array}$ \\
\hline Nitrobenzene & Eudrilus eugeniae & OECD soil & 6 & 5 & 14 & survival LC50 & & 226 & 50 & $\begin{array}{l}\text { Neuhauser et al. } \\
1986 .\end{array}$ \\
\hline Nitrobenzene & Eisenia fetida & OECD soil & 6 & 5 & 14 & survival LC50 & & 319 & 50 & $\begin{array}{l}\text { Neuhauser et al. } \\
1986 .\end{array}$ \\
\hline
\end{tabular}


Table A.1 (continued)

\begin{tabular}{|c|c|c|c|c|c|c|c|c|c|c|}
\hline CHEMICAL / FORM & $\begin{array}{l}\text { EARTHWORM } \\
\text { SPECIES } \\
\end{array}$ & $\begin{array}{l}\text { GROWTH } \\
\text { MEDIUM } \\
\end{array}$ & $\mathrm{pH}$ & $\% O C$ & $\begin{array}{l}\text { EXP } \\
\text { (D) }\end{array}$ & $\begin{array}{c}\text { RESPONSE } \\
\text { PARAMETER } \\
\end{array}$ & $\begin{array}{l}\text { NOEC } \\
\text { APPL }\end{array}$ & $\begin{array}{l}\text { LOEC } \\
\text { APPL } \\
\end{array}$ & $\begin{array}{c}\% \\
\text { DEC } \\
\end{array}$ & REFERENCE \\
\hline Nitrobenzene & Perionyx excavatus & OECD soil & 6 & 5 & 14 & survival LC50 & & 343 & 50 & $\begin{array}{l}\text { Neuhauser et al. } \\
1986 .\end{array}$ \\
\hline Nitrobenzene & $\begin{array}{l}\text { Allolobophora } \\
\text { tuberculata }\end{array}$ & OECD soil & 6 & 5 & 14 & survival LC50 & & 362 & 50 & $\begin{array}{l}\text { Neuhauser et al. } \\
1986 .\end{array}$ \\
\hline
\end{tabular}


Appendix B

TOXICITY DATA FOR MICROORGANISMS 
Chemical concentrations are $\mathrm{mg}$ of element $/ \mathrm{kg}$ of growth medium

\% DEC - \% decrease in measured parameter at LOEC as compared to controls.

EXP DUR (D) - exposure duration in days

GROWTH MEDIUM: Montmorill $=$ mont $=$ montmorillonite clay;

$\mathrm{Kaol}=$ kaolinite clay

\%OC - \% organic carbon in growth medium

$\mathrm{CEC}=$ cation exchange capacity of growth medium (milliequivalents $/ 100 \mathrm{~g}$ )

* denotes phenylmercury acetate

\begin{tabular}{|c|c|c|c|c|c|c|c|c|c|c|c|}
\hline CHEMICAL & $\begin{array}{c}\text { CHEMICAL } \\
\text { FORM }\end{array}$ & ORGANISMS & $\begin{array}{l}\text { GROWTH } \\
\text { MEDIUM } \\
\end{array}$ & $\mathrm{pH}$ & $\% \mathrm{OC}$ & $\begin{array}{l}\text { EXP } \\
\text { (D) }\end{array}$ & $\begin{array}{c}\text { RESPONSE } \\
\text { PARAMETER } \\
\end{array}$ & NOEC & LOEC & $\begin{array}{c}\% \\
\text { DEC }\end{array}$ & REFERENCE \\
\hline Aluminum & $\mathrm{AlCl} 3$ & native soil microflora & clay loam & 6 & 2.7 & 0.1 & Arylsulfatase activity & & $\begin{array}{r}675 \\
\text { LCT }\end{array}$ & 43 & $\begin{array}{l}\text { Al-Khafaji \& } \\
\text { Tabatabai. } 1979 .\end{array}$ \\
\hline Aluminum & $\mathrm{AlCl} 3$ & native soil microflora & loam & 7 & 5.3 & 0.1 & Arylsulfatase activity & & $\begin{array}{r}675 \\
\text { LCT }\end{array}$ & 24 & $\begin{array}{l}\text { Al-Khafaji \& } \\
\text { Tabatabai. } 1979 .\end{array}$ \\
\hline Aluminum & $\mathrm{AlCl} 3$ & native soil microflora & loam & 7 & 2.9 & 0.1 & Arylsulfatase activity & 67.5 & 675 & 34 & $\begin{array}{l}\text { Al-Khafaji \& } \\
\text { Tabatabai. } 1979 .\end{array}$ \\
\hline Aluminum & $\mathrm{AlCl} 3$ & native soil microflora & clay loam & 8 & 3.2 & 0.1 & Arylsulfatase activity & 67.5 & 675 & 42 & $\begin{array}{l}\text { Al-Khafaji \& } \\
\text { Tabatabai. } 1979 .\end{array}$ \\
\hline Aluminum & $\mathrm{AlCl} 3$ & native soil microflora & loam & 6 & 2.6 & 0.1 & $\begin{array}{l}\text { Acid phosphatase } \\
\text { activity }\end{array}$ & 67.5 & 675 & 34 & $\begin{array}{l}\text { Juma \& Tabatabai. } \\
1977 .\end{array}$ \\
\hline Aluminum & $\mathrm{AlCl}$ & native soil microflora & loam & 7 & 5.5 & 0.1 & $\begin{array}{l}\text { Alkaline phosphatase } \\
\text { activity }\end{array}$ & 67.5 & 675 & 25 & $\begin{array}{l}\text { Juma \& Tabatabai. } \\
1977 .\end{array}$ \\
\hline
\end{tabular}


Table B.1 (continued)

\begin{tabular}{|c|c|c|c|c|c|c|c|c|c|c|c|}
\hline CHEMICAL & $\begin{array}{c}\text { CHEMICAL } \\
\text { FORM } \\
\end{array}$ & ORGANISMS & $\begin{array}{l}\text { GROWTH } \\
\text { MEDIUM } \\
\end{array}$ & $\mathrm{pH}$ & $\% O C$ & $\begin{array}{l}\text { EXP } \\
(D) \\
\end{array}$ & $\begin{array}{c}\text { RESPONSE } \\
\text { PARAMETER } \\
\end{array}$ & NOEC & LOEC & $\begin{array}{c}\% \\
\mathrm{DEC} \\
\end{array}$ & REFERENCE \\
\hline Arsenic & $\mathrm{NaAsO} 2$ & native soil microflora & $\begin{array}{l}\text { surface } \\
\text { soil }\end{array}$ & 6 & 2.6 & 0.1 & Amidase activity & & $\begin{array}{r}187.3 \\
\text { LCT }\end{array}$ & 32 & $\begin{array}{l}\text { Frankenberger \& } \\
\text { Tabatabai. } 1981\end{array}$ \\
\hline Arsenic & $\mathrm{Na} 2 \mathrm{HAsO} 4$ & native soil microflora & loam & 6 & 2.6 & 0.1 & $\begin{array}{l}\text { Acid phosphatase } \\
\text { activity }\end{array}$ & & $\begin{array}{r}187.3 \\
\text { LCT }\end{array}$ & 33 & $\begin{array}{l}\text { Juma \& Tabatabai. } \\
1977 .\end{array}$ \\
\hline Arsenic & $\mathrm{Na} 2 \mathrm{HAsO} 4$ & native soil microflora & loam & 7 & 5.5 & 0.1 & $\begin{array}{l}\text { Alkaline phosphatase } \\
\text { activity }\end{array}$ & & $\begin{array}{r}187.3 \\
\text { LCT }\end{array}$ & 32 & $\begin{array}{l}\text { Juma \& Tabatabai. } \\
1977 .\end{array}$ \\
\hline Arsenic & $\mathrm{NaAsO} 2$ & native soil microflora & clay loam & 8 & 3.2 & 0.1 & Amidase activity & & $\begin{array}{l}1873 \\
\mathrm{LCT}\end{array}$ & 98 & $\begin{array}{l}\text { Frankenberger\& } \\
\text { Tabatabai. } 1981\end{array}$ \\
\hline Arsenic & $\mathrm{NaAsO} 2$ & native soil microflora & loam & 7 & 4.7 & 0.1 & Amidase activity & & $\begin{array}{l}1873 \\
\text { LCT }\end{array}$ & 97 & $\begin{array}{l}\text { Frankenberger\& } \\
\text { Tabatabai. } 1981\end{array}$ \\
\hline Arsenic & $\mathrm{NaAsO} 2$ & native soil microflora & clay loam & 8 & 3.7 & 0.1 & $\begin{array}{l}\text { Alkaline phosphatase } \\
\text { activity }\end{array}$ & & $\begin{array}{l}1875 \\
\mathrm{LCT}\end{array}$ & 35 & $\begin{array}{l}\text { Juma \& Tabatabai. } \\
1977 .\end{array}$ \\
\hline Arsenic & $\mathrm{Na2HAsO4}$ & native soil microflora & clay loam & 8 & 3.7 & 0.1 & $\begin{array}{l}\text { Alkaline \& } \\
\text { acid phosphatase } \\
\text { activities }\end{array}$ & & $\begin{array}{l}1875 \\
\mathrm{LCT}\end{array}$ & $\begin{array}{l}75 \\
39\end{array}$ & $\begin{array}{l}\text { Juma \& Tabatabai. } \\
1977 .\end{array}$ \\
\hline Arsenic & $\mathrm{Na2HAsO4}$ & native soil microflora & loam & 7 & 5.5 & 0.1 & $\begin{array}{l}\text { Acid phosphatase } \\
\text { activity }\end{array}$ & & $\begin{array}{l}1875 \\
\text { LCT }\end{array}$ & 62 & $\begin{array}{l}\text { Juma \& Tabatabai. } \\
1977 .\end{array}$ \\
\hline Barium & $\mathrm{BaCl} 2$ & native soil microflora & clay loam & 6 & 2.7 & 0.1 & Arylsulfatase activity & & $\begin{array}{l}3433 \\
\mathrm{LCT}\end{array}$ & 24 & $\begin{array}{l}\text { Al-Khafaji \& } \\
\text { Tabatabai. } 1979 .\end{array}$ \\
\hline Boron & $\mathrm{Na} 2 \mathrm{~B} 4 \mathrm{O} 7$ & native soil microflora & loam & 7 & 2.9 & 0.1 & Arylsulfatase activity & & $\begin{array}{r}27 \\
\text { LCT }\end{array}$ & 31 & $\begin{array}{l}\text { Al-Khafaji \& } \\
\text { Tabatabai. } 1979 .\end{array}$ \\
\hline
\end{tabular}


Table B.1 (continued)

\begin{tabular}{|c|c|c|c|c|c|c|c|c|c|c|c|}
\hline CHEMICAL & $\begin{array}{l}\text { CHEMICAL } \\
\text { FORM } \\
\end{array}$ & ORGANISMS & $\begin{array}{l}\text { GROWTH } \\
\text { MEDIUM } \\
\end{array}$ & $\mathrm{pH}$ & \%OC & $\begin{array}{l}\text { EXP } \\
\text { (D) }\end{array}$ & $\begin{array}{c}\text { RESPONSE } \\
\text { PARAMETER } \\
\end{array}$ & NOEC & LOEC & $\begin{array}{c}\% \\
\mathrm{DEC} \\
\end{array}$ & REFERENCE \\
\hline Boron & $\mathrm{Na} 2 \mathrm{~B} 4 \mathrm{O} 7$ & native soil microflora & loam & 7 & 5.5 & 0.1 & $\begin{array}{l}\text { Acid phosphatase } \\
\text { activity }\end{array}$ & & $\begin{array}{r}270 \\
\text { LCT }\end{array}$ & 22 & $\begin{array}{l}\text { Juma \& Tabatabai. } \\
1977 .\end{array}$ \\
\hline Boron & $\mathrm{Na} 2 \mathrm{~B} 407$ & native soil microflora & clay loam & 6 & 2.7 & 0.1 & Arylsulfatase activity & & $\begin{array}{r}270 \\
\text { LCT }\end{array}$ & 70 & $\begin{array}{l}\text { Al-Khafaji \& } \\
\text { Tabatabai. } 1979 .\end{array}$ \\
\hline Boron & $\mathrm{Na} 2 \mathrm{~B} 4 \mathrm{O} 7$ & native soil microflora & loam & 7 & 5.3 & 0.1 & Arylsulfatase activity & & $\begin{array}{r}270 \\
\text { LCT }\end{array}$ & 60 & $\begin{array}{l}\text { Al-Khafaji \& } \\
\text { Tabatabai. } 1979 .\end{array}$ \\
\hline Boron & $\mathrm{Na} 2 \mathrm{~B} 4 \mathrm{O} 7$ & native soil microflora & clay loam & 8 & 3.2 & 0.1 & Arylsulfatase activity & 27 & 270 & 65 & $\begin{array}{l}\text { Al-Khafaji \& } \\
\text { Tabatabai. } 1979 .\end{array}$ \\
\hline Boron & $\mathrm{Na} 2 \mathrm{~B} 4 \mathrm{O} 7$ & native soil microflora & loam & 6 & 2.6 & 0.1 & $\begin{array}{l}\text { Acid phosphatase } \\
\text { activity }\end{array}$ & 27 & 270 & 33 & $\begin{array}{l}\text { Juma \& Tabatabai. } \\
1977 .\end{array}$ \\
\hline Cadmium & $\mathrm{CdCl} 2$ & native soil microflora & $\begin{array}{l}\text { soil/litter } \\
\text { microcosm }\end{array}$ & & & 24 & Respiration & .006 & 6.1 & 43 & $\begin{array}{l}\text { Lighthart \& Bond. } \\
1976 .\end{array}$ \\
\hline Cadmium & $\mathrm{Cd}(\mathrm{NO}) 2$ & Pseudomonas sp. & silt loam & 7 & 2 & 4 & Denitrification & & $\begin{array}{r}10 \\
\mathrm{LCT}\end{array}$ & 23 & $\begin{array}{l}\text { Bollag \& Barabasz. } \\
1979 .\end{array}$ \\
\hline Cadmium & $\mathrm{C} 4 \mathrm{H} 6 \mathrm{CdO} 4$ & native soil microflora & phaeosem & 7 & 1 & 84 & Respiration & 7 & 14 & 22 & Reber. 1989. \\
\hline Cadmium & $\mathrm{C} 4 \mathrm{H} 6 \mathrm{CdO} 4$ & native soil microflora & $\begin{array}{l}\text { sandy } \\
\text { hortisol }\end{array}$ & 7 & 1.5 & 84 & Respiration & 7 & 14 & 23 & Reber. 1989. \\
\hline Cadmium & $\mathrm{CdCl} 2$ & native soil microflora & $\begin{array}{l}\text { sandy } \\
\text { loam }\end{array}$ & 6 & 3 & 548 & Urease activity & & $\begin{array}{r}30 \\
\text { ED50 }\end{array}$ & 50 & $\begin{array}{l}\text { Doelman \& } \\
\text { Haanstra. } 1986 .\end{array}$ \\
\hline Cadmium & CdNO4 & native soil microflora & $\begin{array}{l}\text { surface } \\
\text { soil }\end{array}$ & & 1.3 & 1 & Dehydrogenase activity & & $\begin{array}{r}30 \\
\mathrm{LCT}\end{array}$ & 47 & Rogers \& Li. 1985. \\
\hline
\end{tabular}


Table B.1 (continued)

\begin{tabular}{|c|c|c|c|c|c|c|c|c|c|c|c|}
\hline CHEMICAL & $\begin{array}{c}\text { CHEMICAL } \\
\text { FORM } \\
\end{array}$ & ORGANISMS & $\begin{array}{l}\text { GROWTH } \\
\text { MEDIUM } \\
\end{array}$ & pH & $\% O C$ & $\begin{array}{l}\text { EXP } \\
\text { (D) }\end{array}$ & $\begin{array}{c}\text { RESPONSE } \\
\text { PARAMETER } \\
\end{array}$ & NOEC & LOEC & $\begin{array}{c}\% \\
\text { DEC }\end{array}$ & REFERENCE \\
\hline Cadmium & $\mathrm{Cd}(\mathrm{NO} 3) 2$ & $\begin{array}{l}\text { Pseudomonas } \\
\text { denitrificans }\end{array}$ & silt loam & 7 & 2 & 4 & Denitrification & 10 & 50 & 22 & $\begin{array}{l}\text { Bollag \& Barabasz. } \\
1979 .\end{array}$ \\
\hline Cadmium & $\mathrm{Cd}(\mathrm{NO} 3) 2$ & $\begin{array}{l}\text { Pseudomonas } \\
\text { aeruginosa }\end{array}$ & silt loam & 7 & 2 & 4 & Denitrification & 10 & 50 & 25 & $\begin{array}{l}\text { Bollag \& Barabasz. } \\
\text { 1979. }\end{array}$ \\
\hline Cadmium & $\mathrm{CdCl} 2$ & native soil microflora & silt loam & 5 & & & Nitrification & & 50 & $>20$ & $\begin{array}{l}\text { Suter and Sharples. } \\
1984 .\end{array}$ \\
\hline Cadmium & C4H6CdO4 & native soil microflora & $\begin{array}{l}\text { acid } \\
\text { cambisol }\end{array}$ & 6 & 1 & 84 & Respiration & 28 & 56 & 23 & Reber. 1989. \\
\hline Cadmium & $\mathrm{CdCl} 2$ & native soil microflora & $\begin{array}{l}\text { brown } \\
\text { earth }\end{array}$ & 5 & & 30 & Cellulolytic activity & 50 & 100 & 35 & $\begin{array}{l}\text { Khan \& Frankland. } \\
\text { 1984. }\end{array}$ \\
\hline Cadmium & $\mathrm{Cd}(\mathrm{NO} 3) 2$ & native soil microflora & silt loam & 7 & 2 & 21 & Denitrification & 50 & 100 & 27 & $\begin{array}{l}\text { Bollag \& Barabasz. } \\
1979 .\end{array}$ \\
\hline Cadmium & $\mathrm{CdCl} 2$ & native soil microflora & sandy soil & 7 & 1 & 548 & Urease activity & & $\begin{array}{r}120 \\
\text { ED50 }\end{array}$ & 50 & $\begin{array}{l}\text { Doelman \& } \\
\text { Haanstra. } 1986 .\end{array}$ \\
\hline Cadmium & $\mathrm{CdCl} 2$ & native soil microflora & sandy soil & 7 & 1 & 548 & Arylsulfatase activity & & $\begin{array}{r}121 \\
\text { ED50 }\end{array}$ & 50 & $\begin{array}{l}\text { Haanstra \& } \\
\text { Doelman. } 1991 .\end{array}$ \\
\hline Cadmium & $\mathrm{CdCl} 2$ & native soil microflora & silty loam & 8 & 1 & 548 & Arylsulfatase activity & & $\begin{array}{r}137 \\
\text { ED50 }\end{array}$ & 50 & $\begin{array}{l}\text { Haanstra \& } \\
\text { Doelman. } 1991 .\end{array}$ \\
\hline Cadmium & $\mathrm{CaCl} 2$ & native soil microflora & silty loam & 8 & 1 & 548 & Phosphatase activity & & $\begin{array}{r}230 \\
\text { ED50 }\end{array}$ & 50 & $\begin{array}{l}\text { Doelman \& } \\
\text { Haanstra. } 1989 .\end{array}$ \\
\hline Cadmium & $\mathrm{CdSO} 4$ & native soil microflora & loam & 7 & 5.5 & 0.1 & $\begin{array}{l}\text { Alkaline phosphatase } \\
\text { activity }\end{array}$ & & $\begin{array}{r}281 \\
\text { LCT }\end{array}$ & 27 & $\begin{array}{l}\text { Juma \& Tabatabai. } \\
1977 .\end{array}$ \\
\hline Cadmium & $\mathrm{CdCl} 2$ & native soil microflora & sandy soil & 7 & 1 & 548 & Phosphatase activity & & $\begin{array}{r}330 \\
\text { ED50 }\end{array}$ & 50 & $\begin{array}{l}\text { Doelman \& } \\
\text { Haanstra. } 1989 .\end{array}$ \\
\hline
\end{tabular}


Table B.1 (continued)

\begin{tabular}{|c|c|c|c|c|c|c|c|c|c|c|c|}
\hline CHEMICAL & $\begin{array}{c}\text { CHEMICAL } \\
\text { FORM } \\
\end{array}$ & ORGANISMS & $\begin{array}{l}\text { GROWTH } \\
\text { MEDIUM } \\
\end{array}$ & $\mathrm{pH}$ & $\% O C$ & $\begin{array}{l}\text { EXP } \\
\text { (D) }\end{array}$ & $\begin{array}{c}\text { RESPONSE } \\
\text { PARAMETER } \\
\end{array}$ & NOEC & LOEC & $\begin{array}{c}\% \\
\text { DEC }\end{array}$ & REFERENCE \\
\hline Cadmium & $\mathrm{CdCl} 2$ & native soil microflora & sandy soil & 7 & 1 & 42 & Urease activity & & $\begin{array}{r}340 \\
\text { EDS0 }\end{array}$ & 50 & $\begin{array}{l}\text { Doelman \& } \\
\text { Haanstra. } 1986 .\end{array}$ \\
\hline Cadmium & $\mathrm{CdCl} 2$ & native soil microflora & sandy peat & 4 & 6.5 & 548 & Urease activity & & $\begin{array}{r}490 \\
\text { ED50 }\end{array}$ & 50 & $\begin{array}{l}\text { Doelman \& } \\
\text { Haanstra. } 1986 .\end{array}$ \\
\hline Cadmium & $\mathrm{CdCl} 2$ & native soil microflora & silty loam & 8 & 1 & 548 & Urease activity & & $\begin{array}{r}520 \\
\text { ED50 }\end{array}$ & 50 & $\begin{array}{l}\text { Doelman \& } \\
\text { Haanstra. } 1986 .\end{array}$ \\
\hline Cadmium & $\mathrm{CdCl} 2$ & native soil microflora & clay & 8 & 1.5 & 548 & Urease activity & & $\begin{array}{r}520 \\
\text { ED50 }\end{array}$ & 50 & $\begin{array}{l}\text { Doelman \& } \\
\text { Haanstra. } 1986 .\end{array}$ \\
\hline Cadmium & $\mathrm{CdSO} 4$ & Native soil microflora & silty clay & 7 & 3 & 20 & $\mathrm{~N}$ mineralization & & $\begin{array}{r}562 \\
\mathrm{LCT}\end{array}$ & 27 & $\begin{array}{l}\text { Liang \& Tabatabai. } \\
1977 .\end{array}$ \\
\hline Cadmium & $\mathrm{CdSO} 4$ & native soil microflora & clay loam & 8 & 4 & 20 & $\mathrm{~N}$ mineralization & & $\begin{array}{r}562 \\
\mathrm{LCT}\end{array}$ & 39 & $\begin{array}{l}\text { Liang \& Tabatabai. } \\
1977 .\end{array}$ \\
\hline Cadmium & $\mathrm{CdCl} 2$ & native soil microflora & sandy soil & 7 & 1 & 42 & Phosphatase activity & & $\begin{array}{r}840 \\
\text { ED50 }\end{array}$ & 50 & $\begin{array}{l}\text { Doelman \& } \\
\text { Haanstra. } 1989 .\end{array}$ \\
\hline Cadmium & $\mathrm{CdCl} 2$ & native soil microflora & $\begin{array}{l}\text { soil/litter } \\
\text { microcosm }\end{array}$ & & & & Respiration & & $\begin{array}{r}920 \\
\mathrm{LCT}\end{array}$ & 61 & $\begin{array}{l}\text { Lighthart et al. } \\
1977 .\end{array}$ \\
\hline Cadmium & $\mathrm{CdCl} 2$ & native soil microflora & silty loam & 8 & 1 & 42 & Urease activity & & $\begin{array}{r}970 \\
\text { ED50 }\end{array}$ & 50 & $\begin{array}{l}\text { Doelman \& } \\
\text { Haanstra. } 1986 .\end{array}$ \\
\hline Cadmium & $\mathrm{CdSO} 4$ & native soil microflora & $\begin{array}{l}\text { surface } \\
\text { soil }\end{array}$ & 6 & 2.9 & 35 & Nitrification & 500 & 1000 & 62 & $\begin{array}{l}\text { Bewley \& Stotzky. } \\
1983 .\end{array}$ \\
\hline Cadmium & $\mathrm{CdCl} 2$ & native soil microflora & clay & 8 & 1.5 & 548 & Arylsulfatase activity & & $\begin{array}{r}1016 \\
\text { ED50 }\end{array}$ & 50 & $\begin{array}{l}\text { Haanstra \& } \\
\text { Doelman. } 1991 .\end{array}$ \\
\hline Cadmium & $\mathrm{CdCl} 2$ & native soil microflora & $\begin{array}{l}\text { sandy } \\
\text { loam }\end{array}$ & 6 & 3 & 548 & Arylsulfatase activity & & $\begin{array}{r}1798 \\
\text { EDS0 }\end{array}$ & 50 & $\begin{array}{l}\text { Haanstra \& } \\
\text { Doelman. } 1991 .\end{array}$ \\
\hline
\end{tabular}


Table B.1 (continued)

\begin{tabular}{|c|c|c|c|c|c|c|c|c|c|c|c|}
\hline CHEMICAL & $\begin{array}{l}\text { CHEMICAL } \\
\text { FORM } \\
\end{array}$ & ORGANISMS & $\begin{array}{l}\text { GROWTH } \\
\text { MEDIUM } \\
\end{array}$ & $\mathrm{pH}$ & $\% O C$ & $\begin{array}{c}\operatorname{EXP} \\
(\mathrm{D}) \\
\end{array}$ & $\begin{array}{c}\text { RESPONSE } \\
\text { PARAMETER }\end{array}$ & NOEC & LOEC & $\begin{array}{c}\% \\
\mathrm{DEC} \\
\end{array}$ & REFERENCE \\
\hline Cadmium & $\mathrm{CdCl} 2$ & native soil microflora & silt loam & 8 & 1 & 42 & Arylsulfatase activity & & $\begin{array}{r}1888 \\
\text { ED50 }\end{array}$ & 50 & $\begin{array}{l}\text { Haanstra \& } \\
\text { Doelman. } 1991 .\end{array}$ \\
\hline Cadmium & $\mathrm{CdCl} 2$ & native soil microflora & sandy soil & 7 & 1 & 42 & Arylsulfatase activity & & $\begin{array}{r}2214 \\
\text { ED50 }\end{array}$ & 50 & $\begin{array}{l}\text { Haanstra \& } \\
\text { Doelman. } 1991 .\end{array}$ \\
\hline Cadmium & $\mathrm{CdSO} 4$ & native soil microflora & clay loam & 8 & 3.7 & 0.1 & $\begin{array}{l}\text { Alkaline \& } \\
\text { acid phosphatase } \\
\text { activities }\end{array}$ & & $\begin{array}{l}2810 \\
\text { LCT }\end{array}$ & $\begin{array}{r}78 \\
51\end{array}$ & $\begin{array}{l}\text { Juma \& Tabatabai. } \\
1977 .\end{array}$ \\
\hline Cadmium & $\mathrm{CdSO} 4$ & native soil microflora & loam & $\cdot 7$ & 5.5 & 0.1 & $\begin{array}{l}\text { Acid phosphatase } \\
\text { activity }\end{array}$ & & $\begin{array}{l}2810 \\
\text { LCT }\end{array}$ & 48 & $\begin{array}{l}\text { Juma \& Tabatabai. } \\
1977 .\end{array}$ \\
\hline Cadmium & $\mathrm{CdSO} 4$ & native soil microflora & clay loam & 6 & 2.7 & 0.1 & Arylsulfatase activity & & $\begin{array}{l}2810 \\
\mathrm{LCT}\end{array}$ & 27 & $\begin{array}{l}\text { Al-Khafaji \& } \\
\text { Tabatabai. } 1979 .\end{array}$ \\
\hline Cadmium & CdSO4 & native soil microflora & loam & 7 & 5.3 & 0.1 & Arylsulfatase activity & & $\begin{array}{l}2810 \\
\text { LCT }\end{array}$ & 42 & $\begin{array}{l}\text { Al-Khafaji \& } \\
\text { Tabatabai. } 1979 .\end{array}$ \\
\hline Cadmium & CdSO4 & native soil microflora & loam & 6 & 2.6 & 0.1 & $\begin{array}{l}\text { Acid phosphatase } \\
\text { activity }\end{array}$ & 281 & 2810 & 44 & $\begin{array}{l}\text { Juma \& Tabatabai. } \\
1977 .\end{array}$ \\
\hline Cadmium & $\mathrm{CdSO} 4$ & native soil microflora & loam & 7 & 2.9 & 0.1 & Arylsulfatase activity & 281 & 2810 & 55 & $\begin{array}{l}\text { Al-Khafaji \& } \\
\text { Tabatabai. } 1979 .\end{array}$ \\
\hline Cadmium & CdSO4 & native soil microflora & clay loam & 8 & 3.2 & 0.1 & Arylsulfatase activity & 281 & 2810 & 23 & $\begin{array}{l}\text { Al-Khafaji \& } \\
\text { Tabatabai. } 1979 .\end{array}$ \\
\hline Cadmium & $\mathrm{CdCl} 2$ & native soil microflora & sandy peat & 4 & 6.5 & 42 & Arylsulfatase activity & & $\begin{array}{r}3192 \\
\text { ED50 }\end{array}$ & 50 & $\begin{array}{l}\text { Haanstra \& } \\
\text { Doelman. } 1991 .\end{array}$ \\
\hline Cadmium & $\mathrm{CdCl} 2$ & native soil microflora & sandy peat & 4 & 6.5 & 42 & Urease activity & & $\begin{array}{r}3260 \\
\text { ED50 }\end{array}$ & 50 & $\begin{array}{l}\text { Doelman \& } \\
\text { Haanstra. } 1986 .\end{array}$ \\
\hline
\end{tabular}


Table B.1 (continued)

\begin{tabular}{|c|c|c|c|c|c|c|c|c|c|c|c|}
\hline CHEMICAL & $\begin{array}{c}\text { CHEMICAL } \\
\text { FORM } \\
\end{array}$ & ORGANISMS & $\begin{array}{l}\text { GROWTH } \\
\text { MEDIUM } \\
\end{array}$ & $\mathrm{pH}$ & $\% O C$ & $\begin{array}{l}\text { EXP } \\
\text { (D) }\end{array}$ & $\begin{array}{c}\text { RESPONSE } \\
\text { PARAMETER }\end{array}$ & NOEC & LOEC & $\begin{array}{c}\% \\
\text { DEC }\end{array}$ & REFERENCE \\
\hline Cadmium & $\mathrm{CdCl} 2$ & native soil microflora & clay & 8 & 1.5 & 42 & Urease activity & & $\begin{array}{r}4460 \\
\text { ED50 }\end{array}$ & 50 & $\begin{array}{l}\text { Doelman \& } \\
\text { Haanstra. } 1986 .\end{array}$ \\
\hline Cadmium & $\mathrm{CdCl} 2$ & Native soil microflora & clay & 8 & 1.5 & 548 & Phosphatase activity & & $\begin{array}{r}5305 \\
\text { ED50 }\end{array}$ & 50 & $\begin{array}{l}\text { Doelman \& } \\
\text { Haanstra. } 1989 .\end{array}$ \\
\hline Cadmium & $\mathrm{CdCl} 2$ & Native soil microflora & Silty loam & 8 & 1 & 42 & Phosphatase activity & & $\begin{array}{r}5485 \\
\text { ED50 }\end{array}$ & 50 & $\begin{array}{l}\text { Doelman \& } \\
\text { Haanstra. } 1989 .\end{array}$ \\
\hline Cadmium & $\mathrm{CdCl} 2$ & native soil microflora & clay & 8 & 1.5 & 42 & Arylsulfatase activity & & $\begin{array}{r}9520 \\
\text { ED50 }\end{array}$ & 50 & $\begin{array}{l}\text { Haanstra \& } \\
\text { Doelman. } 1991 .\end{array}$ \\
\hline Cadmium & $\mathrm{CdCl} 2$ & Native soil microflora & clay & 8 & 1.5 & 42 & Phosphatase activity & & $\begin{array}{r}9779 \\
\text { ED50 }\end{array}$ & 50 & $\begin{array}{l}\text { Doelman \& } \\
\text { Haanstra. } 1989 .\end{array}$ \\
\hline Cadmium & $\mathrm{CdCl} 2$ & native soil microflora & $\begin{array}{l}\text { sandy } \\
\text { loam }\end{array}$ & 6 & 3 & 548 & Phosphatase activity & & $\begin{array}{r}9869 \\
\text { ED50 }\end{array}$ & 50 & $\begin{array}{l}\text { Doelman \& } \\
\text { Haanstra. } 1989 .\end{array}$ \\
\hline Chromium & $\mathrm{CrCl} 3$ & native soil microfora & $\begin{array}{l}\text { sandy } \\
\text { loam }\end{array}$ & 6 & 3 & 548 & Urease activity & & $\begin{array}{r}<1 \\
\text { ED50 }\end{array}$ & 50 & $\begin{array}{l}\text { Doelman \& } \\
\text { Haanstra. } 1986 .\end{array}$ \\
\hline Chromium & $\mathrm{K} 2 \mathrm{Cr} 2 \mathrm{O} 7$ & native soil microflora & $\begin{array}{l}\text { sandy } \\
\text { loam }\end{array}$ & 6 & & 22 & Respiration & & $\begin{array}{r}10 \\
\mathrm{LCT}\end{array}$ & 33 & Ross et al. 1981. \\
\hline Chromium & $\mathrm{K} 2 \mathrm{Cr} 2 \mathrm{O} 7$ & native soil microflora & loam & 6 & & 22 & Respiration & & $\begin{array}{r}10 \\
\text { LCT }\end{array}$ & 27 & Ross et al. 1981. \\
\hline Chromium & $\mathrm{CrCl3}$ & native soil microflora & $\begin{array}{l}\text { sandy } \\
\text { loam }\end{array}$ & 6 & 3 & 548 & Arylsulfatase activity & & $\begin{array}{r}12 \\
\text { EDS0 }\end{array}$ & 50 & $\begin{array}{l}\text { Haanstra \& } \\
\text { Doelman. } 1991 .\end{array}$ \\
\hline Chromium & $\mathrm{CrCl} 3$ & native soil microflora & sandy soil & 7 & 1 & 42 & Arylsulfatase activity & & $\begin{array}{r}17 \\
\text { ED50 }\end{array}$ & 50 & $\begin{array}{l}\text { Haanstra \& } \\
\text { Doelman. } 1991 .\end{array}$ \\
\hline
\end{tabular}


Table B.1 (continued)

\begin{tabular}{|c|c|c|c|c|c|c|c|c|c|c|c|}
\hline CHEMICAL & $\begin{array}{c}\text { CHEMICAL } \\
\text { FORM }\end{array}$ & ORGANISMS & $\begin{array}{l}\text { GROWTH } \\
\text { MEDIUM } \\
\end{array}$ & $\mathrm{pH}$ & $\% O C$ & $\begin{array}{l}\text { EXP } \\
\text { (D) }\end{array}$ & $\begin{array}{c}\text { RESPONSE } \\
\text { PARAMETER } \\
\end{array}$ & NOEC & LOEC & $\begin{array}{c}\% \\
\text { DEC }\end{array}$ & REFERENCE \\
\hline Chromium & $\mathrm{CrSO} 4$ & native soil microflora & $\begin{array}{l}\text { surface } \\
\text { soil }\end{array}$ & & 1.3 & 1 & Dehydrogenase activity & & $\begin{array}{r}30 \\
\text { LCT }\end{array}$ & 54 & Rogers \& Li. 1985. \\
\hline Chromium & $\mathrm{CrCl} 3$ & native soil microflora & $\begin{array}{l}\text { sandy } \\
\text { loam }\end{array}$ & 6 & & 22 & Respiration & * & $\begin{array}{r}100 \\
\text { LCT }\end{array}$ & 48 & Ross et al. 1981. \\
\hline Chromium & $\mathrm{CrCl} 3$ & native soil microflora & loam & 6 & & 22 & Respiration & & $\begin{array}{r}100 \\
\text { LCT }\end{array}$ & 41 & Ross et al. 1981. \\
\hline Chromium & $\mathrm{CrCl} 3$ & native soil microflora & sandy soil & 7 & 1 & 548 & Arylsulfatase activity & & $\begin{array}{r}203 \\
\text { ED50 }\end{array}$ & 50 & $\begin{array}{l}\text { Haanstra \& } \\
\text { Doelman. 1991. }\end{array}$ \\
\hline Chromium & $\mathrm{CrCl} 3$ & native soil microflora & loam & 6 & 3 & 20 & $\mathrm{~N}$ mineralization & & $\begin{array}{r}260 \\
\text { LCT }\end{array}$ & 20 & $\begin{array}{l}\text { Liang \& Tabatabai. } \\
1977 .\end{array}$ \\
\hline Chromium & $\mathrm{CrCl} 3$ & native soil microflora & $\begin{array}{l}\text { silty clay } \\
\text { loam }\end{array}$ & 7 & 6 & 20 & $\mathrm{~N}$ mineralization & & $\begin{array}{r}260 \\
\mathrm{LCT}\end{array}$ & 24 & $\begin{array}{l}\text { Liang \& Tabatabai. } \\
1977 .\end{array}$ \\
\hline Chromium & $\mathrm{CrCl} 3$ & native soil microflora & clay & 8 & 1.5 & 42 & Arylsulfatase activity & & $\begin{array}{r}281 \\
\text { ED50 }\end{array}$ & 50 & $\begin{array}{l}\text { Haanstra \& } \\
\text { Doelman. } 1991 .\end{array}$ \\
\hline Chromium & $\mathrm{CrCl} 3$ & native soil microflora & $\begin{array}{l}\text { sandy } \\
\text { loam }\end{array}$ & 6 & 3 & 42 & Arylsulfatase activity & & $\begin{array}{r}309 \\
\text { ED50 }\end{array}$ & 50 & $\begin{array}{l}\text { Haanstra \& } \\
\text { Doelman. } 1991 .\end{array}$ \\
\hline Chromium & $\mathrm{CrCl} 3$ & native soil microflora & silty loam & 8 & 1 & 548 & Arylsulfatase activity & & $\begin{array}{r}411 \\
\text { EDSO }\end{array}$ & 50 & $\begin{array}{l}\text { Haanstra \& } \\
\text { Doelman. } 1991 .\end{array}$ \\
\hline Chromium & $\mathrm{CrCl} 3$ & native soil microflora & clay & 8 & 1.5 & 548 & Urease activity & & $\begin{array}{r}420 \\
\text { ED50 }\end{array}$ & 50 & $\begin{array}{l}\text { Doelman \& } \\
\text { Haanstra. } 1986 .\end{array}$ \\
\hline Chromium & $\mathrm{CrCl} 3$ & native soil microflora & clay & 8 & 1.5 & 42 & Urease activity & & $\begin{array}{r}490 \\
\text { ED50 }\end{array}$ & 50 & $\begin{array}{l}\text { Doelman \& } \\
\text { Haanstra. } 1986 .\end{array}$ \\
\hline Chromium & $\mathrm{CrCl3}$ & native soil microflora & clay & 8 & 1.5 & 548 & Arylsulfatase activity & & $\begin{array}{r}575 \\
\text { ED50 }\end{array}$ & 50 & $\begin{array}{l}\text { Haanstra \& } \\
\text { Doelman. } 1991 .\end{array}$ \\
\hline
\end{tabular}


Table B.1 (continued)

\begin{tabular}{|c|c|c|c|c|c|c|c|c|c|c|c|}
\hline CHEMICAL & $\begin{array}{c}\text { CHEMICAL } \\
\text { FORM } \\
\end{array}$ & ORGANISMS & $\begin{array}{l}\text { GROWTH } \\
\text { MEDIUM } \\
\end{array}$ & $\mathrm{pH}$ & \%OC & $\begin{array}{l}\text { EXP } \\
\text { (D) }\end{array}$ & $\begin{array}{c}\text { RESPONSE } \\
\text { PARAMETER } \\
\end{array}$ & NOEC & LOEC & $\begin{array}{c}\% \\
\text { DEC } \\
\end{array}$ & REFERENCE \\
\hline Chromium & $\mathrm{CrCl} 3$ & native soil microflora & sandy soil & 7 & 1 & 548 & Urease activity & & $\begin{array}{r}630 \\
\text { ED50 }\end{array}$ & 50 & $\begin{array}{l}\text { Doelman \& } \\
\text { Haanstra. } 1986 .\end{array}$ \\
\hline Chromium & $\mathrm{CrO}$ & native soil microflora & sandy soil & 7 & & 42 & $\begin{array}{l}N \text { mineralization \& } \\
\text { nitrification }\end{array}$ & & $\begin{array}{l}1000 \\
\mathrm{LCT}\end{array}$ & $\begin{array}{r}22 \\
24\end{array}$ & $\begin{array}{l}\text { Bhuiya \& } \\
\text { Cornfield. } 1976 .\end{array}$ \\
\hline Chromium & CuSO4 & native soil microflora & $\begin{array}{l}\text { sandy } \\
\text { loam }\end{array}$ & 7 & 2 & 21 & Nitrification & 100 & 1000 & 67 & $\begin{array}{l}\text { Premi \& Cornfield. } \\
1969 .\end{array}$ \\
\hline Chromium & $\mathrm{CrCl} 3$ & native soil microflora & silty loam & 8 & 1 & 548 & Urease activity & & $\begin{array}{r}1110 \\
\text { ED50 }\end{array}$ & 50 & $\begin{array}{l}\text { Doelman \& } \\
\text { Haanstra. } 1986 .\end{array}$ \\
\hline Chromium & $\mathrm{CrCl} 3$ & native soil microflora & clay & 8 & 1.5 & 42 & Phosphatase activity & & $\begin{array}{r}1170 \\
\text { ED50 }\end{array}$ & 50 & $\begin{array}{l}\text { Doelman \& } \\
\text { Haanstra. } 1989 .\end{array}$ \\
\hline Chromium & $\mathrm{CrCl} 3$ & native soil microflora & clay loam & 6 & 2.7 & 0.1 & Arylsulfatase activity & & $\begin{array}{l}1300 \\
\text { LCT }\end{array}$ & 54 & $\begin{array}{l}\text { Al-Khafaji \& } \\
\text { Tabatabai. } 1979 .\end{array}$ \\
\hline Chromium & $\mathrm{CrCl} 3$ & native soil microflora & loam & 7 & 5.3 & 0.1 & Arylsulfatase activity & & $\begin{array}{l}1300 \\
\mathrm{LCT}\end{array}$ & 32 & $\begin{array}{l}\text { Al-Khafaji \& } \\
\text { Tabatabai. } 1979 .\end{array}$ \\
\hline Chromium & $\mathrm{CrCl} 3$ & native soil microflora & clay loam & 8 & 3.7 & 0.1 & $\begin{array}{l}\text { Alkaline \& } \\
\text { acid phosphatase } \\
\text { activity }\end{array}$ & & $\begin{array}{l}1300 \\
\text { LCT }\end{array}$ & $\begin{array}{r}27 \\
25\end{array}$ & $\begin{array}{l}\text { Juma \& Tabatabai. } \\
1977 .\end{array}$ \\
\hline Chromium & $\mathrm{CrCl} 3$ & native soil microflora & loam & 7 & 5.5 & 0.1 & $\begin{array}{l}\text { Acid phosphatase } \\
\text { activity }\end{array}$ & & $\begin{array}{l}1300 \\
\text { LCT }\end{array}$ & 27 & $\begin{array}{l}\text { Juma \& Tabatabai. } \\
1977 .\end{array}$ \\
\hline Chromium & $\mathrm{CrCl} 3$ & native soil microflora & loam & 7 & 2.9 & 0.1 & Arylsulfatase activity & 130 & 1300 & 43 & $\begin{array}{l}\text { Al-Khafaji \& } \\
\text { Tabatabai. } 1979 .\end{array}$ \\
\hline Chromium & $\mathrm{CrCl3}$ & native soil microflora & clay loam & 8 & 3.2 & 0.1 & Arylsulfatase activity & 130 & 1300 & 35 & $\begin{array}{l}\text { Al-Khafaji \& } \\
\text { Tabatabai. } 1979 .\end{array}$ \\
\hline
\end{tabular}


Table B.1 (continued)

\begin{tabular}{|c|c|c|c|c|c|c|c|c|c|c|c|}
\hline CHEMICAL & $\begin{array}{l}\text { CHEMICAL } \\
\text { FORM } \\
\end{array}$ & ORGANISMS & $\begin{array}{l}\text { GROWTH } \\
\text { MEDIUM } \\
\end{array}$ & $\mathrm{pH}$ & $\% O C$ & $\begin{array}{l}\text { EXP } \\
\text { (D) } \\
\end{array}$ & $\begin{array}{c}\text { RESPONSE } \\
\text { PARAMETER } \\
\end{array}$ & NÖEC & LOEC & $\begin{array}{c}\% \\
\text { DEC } \\
\end{array}$ & REFERENCE \\
\hline Chromium & $\mathrm{CrCl} 3$ & native soil microflora & loam & 6 & 2.6 & 0.1 & $\begin{array}{l}\text { Acid phosphatase } \\
\text { activity }\end{array}$ & 130 & 1300 & 30 & $\begin{array}{l}\text { Juma \& Tabatabai. } \\
1977 .\end{array}$ \\
\hline Chromium & $\mathrm{CrCl} 3$ & native soil microflora & loam & 7 & 5.5 & 0.1 & $\begin{array}{l}\text { Alkaline phosphatase } \\
\text { activity }\end{array}$ & 130 & 1300 & 39 & $\begin{array}{l}\text { Juma \& Tabatabai. } \\
1977 .\end{array}$ \\
\hline Chromium & $\mathrm{CrCl} 3$ & native soil microflora & sandy peat & 4 & 6.5 & 42 & Urease activity & & $\begin{array}{r}1360 \\
\text { ED50 }\end{array}$ & 50 & $\begin{array}{l}\text { Doelman \& } \\
\text { Haanstra. } 1986 .\end{array}$ \\
\hline Chromium & $\mathrm{CrCl} 3$ & native soil microflora & clay & 8 & 1.5 & 548 & Phosphatase activity & & $\begin{array}{r}2652 \\
\text { ED50 }\end{array}$ & 50 & $\begin{array}{l}\text { Doelman \& } \\
\text { Haanstra. } 1989 .\end{array}$ \\
\hline Chromium & $\mathrm{CrCl} 3$ & native soil microflora & $\begin{array}{l}\text { sandy } \\
\text { loam }\end{array}$ & 6 & 3 & 548 & Phosphatase activity & & $\begin{array}{r}2792 \\
\text { ED50 }\end{array}$ & 50 & $\begin{array}{l}\text { Doelman \& } \\
\text { Haanstra. } 1989 .\end{array}$ \\
\hline Chromium & $\mathrm{CrCl3}$ & native soil microflora & sandy peat & 4 & 6.5 & 548 & Arylsulfatase activity & & $\begin{array}{r}3203 \\
\text { ED50 }\end{array}$ & 50 & $\begin{array}{l}\text { Haanstra \& } \\
\text { Doelman. } 1991 .\end{array}$ \\
\hline Chromium & $\mathrm{CrCl3}$ & native soil microflora & sandy soil & 7 & 1 & 42 & Phosphatase activity & & $\begin{array}{r}3208 \\
\text { ED50 }\end{array}$ & 50 & $\begin{array}{l}\text { Doelman \& } \\
\text { Haanstra. } 1989 .\end{array}$ \\
\hline Chromium & $\mathrm{CrCl} 3$ & native soil microflora & sandy peat & 4 & 6.5 & 42 & Phosphatase activity & & $\begin{array}{r}3208 \\
\text { EDS0 }\end{array}$ & 50 & $\begin{array}{l}\text { Doelman \& } \\
\text { Haanstra. } 1989 .\end{array}$ \\
\hline Chromium & $\mathrm{CrCl} 3$ & native soil microflora & silty loam & 8 & 1 & 42 & Phosphatase activity & & $\begin{array}{r}3728 \\
\text { ED50 }\end{array}$ & 50 & $\begin{array}{l}\text { Doelman \& } \\
\text { Haanstra. } 1989 .\end{array}$ \\
\hline Chromium & $\mathrm{CrCl} 3$ & native soil microflora & sandy soil & 7 & 1 & 42 & Urease activity & & $\begin{array}{r}3970 \\
\text { ED50 }\end{array}$ & 50 & $\begin{array}{l}\text { Doelman \& } \\
\text { Haanstra. } 1986 .\end{array}$ \\
\hline Chromium & $\mathrm{CrCl} 3$ & native soil microflora & silty loam & 8 & 1 & 548 & Phosphatase activity & & $\begin{array}{r}4139 \\
\text { ED50 }\end{array}$ & 50 & $\begin{array}{l}\text { Doelman \& } \\
\text { Haanstra. } 1989 .\end{array}$ \\
\hline Chromium & $\mathrm{CrCl} 3$ & native soil microflora & silty loam & 8 & 1 & 42 & Urease activity & & $\begin{array}{r}4470 \\
\text { ED50 }\end{array}$ & 50 & $\begin{array}{l}\text { Doelman \& } \\
\text { Haanstra. } 1986 .\end{array}$ \\
\hline
\end{tabular}


Table B.1 (continued)

\begin{tabular}{|c|c|c|c|c|c|c|c|c|c|c|c|}
\hline CHEMICAL & $\begin{array}{c}\text { CHEMICAL } \\
\text { FORM } \\
\end{array}$ & ORGANISMS & $\begin{array}{l}\text { GROWTH } \\
\text { MEDIUM } \\
\end{array}$ & pH & $\% O C$ & $\begin{array}{c}\operatorname{EXP} \\
(\mathrm{D}) \\
\end{array}$ & $\begin{array}{c}\text { RESPONSE } \\
\text { PARAMETER } \\
\end{array}$ & NOEC & LOEC & $\begin{array}{c}\% \\
\text { DEC }\end{array}$ & REFERENCE \\
\hline Chromium & $\mathrm{CrCl} 3$ & native soil microflora & $\begin{array}{l}\text { sandy } \\
\text { loam }\end{array}$ & 6 & 3 & 42 & Phosphatase activity & & $\begin{array}{r}5512 \\
\text { ED50 }\end{array}$ & 50 & $\begin{array}{l}\text { Doelman \& } \\
\text { Haanstra. } 1989 .\end{array}$ \\
\hline Chromium & $\mathrm{CrCl3}$ & native soil microflora & sandy peat & 4 & 6.5 & 42 & Arylsulfatase activity & & $\begin{array}{r}5928 \\
\text { ED50 }\end{array}$ & 50 & $\begin{array}{l}\text { Haanstra \& } \\
\text { Doelman. } 1991 .\end{array}$ \\
\hline Chromium & $\mathrm{CrCl} 3$ & native soil microflora & sandy soil & 7 & 1 & 548 & Phosphatase activity & & $\begin{array}{l}20020 \\
\text { ED50 }\end{array}$ & 50 & $\begin{array}{l}\text { Doelman \& } \\
\text { Haanstra. } 1989 .\end{array}$ \\
\hline Cobalt & $\mathrm{CoCl} 2$ & native soil microflora & $\begin{array}{l}\text { soil/litter } \\
\text { microcosm }\end{array}$ & & & & Respiration & & $\begin{array}{l}1362 \\
\text { LCT }\end{array}$ & 23 & $\begin{array}{l}\text { Lighthart et al. } \\
1977 .\end{array}$ \\
\hline Copper & $\mathrm{Cu}(\mathrm{NO} 3) 2$ & Pseudomonas sp. & silt loam & 7 & 2 & 4 & Denitrification & & $\begin{array}{r}10 \\
\mathrm{LCT}\end{array}$ & 53 & $\begin{array}{l}\text { Bollag \& Barabasz. } \\
1979 .\end{array}$ \\
\hline Copper & CuSO4 & native soil microflora & $\begin{array}{l}\text { surface } \\
\text { soil }\end{array}$ & & 1.3 & 1 & Dehydrogenase activity & & $\begin{array}{r}30 \\
\text { LCT }\end{array}$ & 28 & Rogers \& Li. 1985. \\
\hline Copper & $\mathrm{Cu}(\mathrm{NO} 3) 2$ & $\begin{array}{l}\text { Pseudomonas } \\
\text { aeruginosa }\end{array}$ & silt loam & 7 & 2 & 4 & Denitrification & 10 & 50 & 43 & $\begin{array}{l}\text { Bollag \& Barabasz. } \\
1979 .\end{array}$ \\
\hline Copper & CuSO4 & native soil microflora & $\begin{array}{l}\text { sandy } \\
\text { loam }\end{array}$ & 5 & 2 & 21 & $\mathbf{N}$ mineralization & & $\begin{array}{l}100 \\
\text { LCT }\end{array}$ & 20 & $\begin{array}{l}\text { Quraishi \& } \\
\text { Cornfield. } 1973 .\end{array}$ \\
\hline Copper & $\mathrm{CuCl} 2$ & native soil microflora & sandy soil & 7 & 1 & 42 & Phosphatase activity & & $\begin{array}{r}140 \\
\text { EDS0 }\end{array}$ & 50 & $\begin{array}{l}\text { Doelman \& } \\
\text { Haanstra. } 1989 .\end{array}$ \\
\hline Copper & $\mathrm{CuCl} 2$ & native soil microflora & sandy soil & 7 & 1 & 548 & Phosphatase activity & & $\begin{array}{r}170 \\
\text { ED50 }\end{array}$ & 50 & $\begin{array}{l}\text { Doelman \& } \\
\text { Haanstra. } 1989 .\end{array}$ \\
\hline
\end{tabular}


Table B.1 (continued)

\begin{tabular}{|c|c|c|c|c|c|c|c|c|c|c|c|}
\hline CHEMICAL & $\begin{array}{c}\text { CHEMICAL } \\
\text { FORM } \\
\end{array}$ & ORGANISMS & $\begin{array}{l}\text { GROWTH } \\
\text { MEDIUM } \\
\end{array}$ & pH & \%OC & $\begin{array}{r}\text { EXP } \\
(D) \\
\end{array}$ & $\begin{array}{c}\text { RESPONSE } \\
\text { PARAMETER } \\
\end{array}$ & NOEC & LOEC & $\begin{array}{c}\% \\
\text { DEC } \\
\end{array}$ & REFERENCE \\
\hline Copper & $\mathrm{Cu}(\mathrm{NO} 3) 2$ & native soil microflora & silt loam & 7 & 2 & 21 & Denitrification & 100 & 250 & 44 & $\begin{array}{l}\text { Bollag \& Barabasz. } \\
1979 .\end{array}$ \\
\hline Copper & $\mathrm{Cu}(\mathrm{NO} 3) 2$ & $\begin{array}{l}\text { Pseudomonas } \\
\text { denitrificans }\end{array}$ & silt loam & 7 & 2 & 4 & Denitrification & 100 & 250 & 22 & $\begin{array}{l}\text { Bollag \& Barabasz. } \\
1979 .\end{array}$ \\
\hline Copper & $\mathrm{CuCl} 2$ & native soil microflora & sandy soil & 7 & 1 & 42 & Urease activity & & $\begin{array}{r}260 \\
\text { ED50 }\end{array}$ & 50 & $\begin{array}{l}\text { Doelman \& } \\
\text { Haanstra. } 1986 .\end{array}$ \\
\hline Copper & $\mathrm{CuCl} 2$ & native soil microflora & sandy soil & 7 & 1 & 548 & Arylsulfatase activity & & $\begin{array}{r}287 \\
\text { ED50 }\end{array}$ & 50 & $\begin{array}{l}\text { Haanstra \& } \\
\text { Doelman. } 1991 .\end{array}$ \\
\hline Copper & CuSO4 & native soil microflora & $\begin{array}{l}\text { silty clay } \\
\text { loam }\end{array}$ & 7 & 6 & 20 & $\mathrm{~N}$ mineralization & & $\begin{array}{r}320 \\
\mathrm{LCT}\end{array}$ & 82 & $\begin{array}{l}\text { Liang \& Tabatabai. } \\
1977 .\end{array}$ \\
\hline Copper & $\mathrm{CuCl} 2$ & native soil microflora & sandy soil & 7 & 1 & 42 & Arylsulfatase activity & & $\begin{array}{r}391 \\
\text { ED50 }\end{array}$ & 50 & $\begin{array}{l}\text { Haanstra \& } \\
\text { Doelman. } 1991 .\end{array}$ \\
\hline Copper & $\mathrm{CuCl} 2$ & native soil microflora & silt loam & 5 & & & Nitrification & & 500 & $>2$ & $\begin{array}{l}\text { Suter and Sharples. } \\
1984 .\end{array}$ \\
\hline Copper & $\mathrm{CuCl} 2$ & native soil microflora & $\begin{array}{l}\text { sandy } \\
\text { loam }\end{array}$ & 6 & 3 & 548 & Arylsulfatase activity & & $\begin{array}{r}548 \\
\text { ED50 }\end{array}$ & 50 & $\begin{array}{l}\text { Haanstra \& } \\
\text { Doelman. } 1991 .\end{array}$ \\
\hline Copper & $\mathrm{CuCl} 2$ & native soil microflora & $\begin{array}{l}\text { sandy } \\
\text { loam }\end{array}$ & 6 & 3 & 42 & Urease activity & & $\begin{array}{r}570 \\
\text { ED50 }\end{array}$ & 50 & $\begin{array}{l}\text { Doelman \& } \\
\text { Haanstra. } 1986 .\end{array}$ \\
\hline Copper & $\mathrm{CuCl} 2$ & native soil microflora & sandy soil & 7 & 1 & 548 & Urease activity & & $\begin{array}{r}680 \\
\text { ED50 }\end{array}$ & 50 & $\begin{array}{l}\text { Doelman \& } \\
\text { Haanstra. } 1986 .\end{array}$ \\
\hline Copper & $\mathrm{CuCl} 2$ & native soil microflora & silty loam & 8 & 1 & 548 & Phosphatase activity & & $\begin{array}{r}744 \\
\text { ED50 }\end{array}$ & 50 & $\begin{array}{l}\text { Doelman \& } \\
\text { Haanstra. } 1989 .\end{array}$ \\
\hline Copper & $\mathrm{CuCl} 2$ & native soil microflora & silty loam & 8 & 1 & 548 & Arylsulfatase activity & & $\begin{array}{r}763 \\
\text { ED50 }\end{array}$ & 50 & $\begin{array}{l}\text { Haanstra \& } \\
\text { Doelman. } 1991 .\end{array}$ \\
\hline
\end{tabular}


Table B.1 (continued)

\begin{tabular}{|c|c|c|c|c|c|c|c|c|c|c|c|}
\hline CHEMICAL & $\begin{array}{c}\text { CHEMICAL } \\
\text { FORM }\end{array}$ & ORGANISMS & $\begin{array}{l}\text { GROWTH } \\
\text { MEDIUM } \\
\end{array}$ & $\mathrm{pH}$ & $\% \mathrm{OC}$ & $\begin{array}{l}\operatorname{EXP} \\
(D)\end{array}$ & $\begin{array}{c}\text { RESPONSE } \\
\text { PARAMETER } \\
\end{array}$ & NOEC & LOEC & $\begin{array}{c}\% \\
\text { DEC }\end{array}$ & REFERENCE \\
\hline Copper & $\mathrm{CuCl} 2$ & native soil microflora & $\begin{array}{l}\text { sandy } \\
\text { loam }\end{array}$ & 6 & 3 & 42 & Arylsulfatase activity & & $\begin{array}{r}967 \\
\text { ED50 }\end{array}$ & 50 & $\begin{array}{l}\text { Haanstra \& } \\
\text { Doelman. } 1991 .\end{array}$ \\
\hline Copper & $\mathrm{CuO}$ & native soil microflora & sandy soil & 6 & 2 & 84 & $\mathrm{C}$ mineralization & & $\begin{array}{l}1000 \\
\text { LCT }\end{array}$ & 33 & $\begin{array}{l}\text { Bhuiya \& } \\
\text { Cornfield. } 1972 .\end{array}$ \\
\hline Copper & $\mathrm{CuSO} 4$ & native soil microflora & $\begin{array}{l}\text { sandy } \\
\text { loam }\end{array}$ & 8 & 2 & 56 & Nitrification & 100 & 1000 & 38 & $\begin{array}{l}\text { Premi \& Cornfield. } \\
\text { 1969/1970. }\end{array}$ \\
\hline Copper & $\mathrm{CuSO} 4$ & native soil microflora & $\begin{array}{l}\text { sandy } \\
\text { loam }\end{array}$ & 6 & 2 & 21 & $\mathrm{~N}$ mineralization & 100 & 1000 & 75 & $\begin{array}{l}\text { Quraishi \& } \\
\text { Cornfield. } 1973 .\end{array}$ \\
\hline Copper & $\mathrm{CuSO} 4$ & native soil microflora & $\begin{array}{l}\text { sandy } \\
\text { loam }\end{array}$ & 5 & 2 & 21 & $\mathrm{~N}$ mineralization & 100 & 1000 & 100 & $\begin{array}{l}\text { Quraishi \& } \\
\text { Cornfield. } 1973 .\end{array}$ \\
\hline Copper & CuSO4 & native soil microflora & $\begin{array}{l}\text { sandy } \\
\text { loam }\end{array}$ & 7 & 2 & 21 & $\mathrm{~N}$ mineralization & 100 & 1000 & 39 & $\begin{array}{l}\text { Quraishi \& } \\
\text { Cornfield. } 1973 .\end{array}$ \\
\hline Copper & $\mathrm{CuCl} 2$ & native soil microflora & clay & 8 & 1.5 & 548 & Urease activity & & $\begin{array}{r}1080 \\
\text { ED50 }\end{array}$ & 50 & $\begin{array}{l}\text { Doelman \& } \\
\text { Haanstra. } 1986 .\end{array}$ \\
\hline Copper & $\mathrm{CuCl} 2$ & native soil microflora & clay & 8 & 1.5 & 42 & Urease activity & & $\begin{array}{r}1370 \\
\text { ED\$̧0 }\end{array}$ & 50 & $\begin{array}{l}\text { Doelman \& } \\
\text { Haanstra. } 1986 .\end{array}$ \\
\hline Copper & $\mathrm{CuSO} 4$ & native soil microflora & clay loam & 6 & 2.7 & 0.1 & Arylsulfatase activity & & $\begin{array}{l}1590 \\
\text { LCT }\end{array}$ & 22 & $\begin{array}{l}\text { Al-Khafaji \& } \\
\text { Tabatabai. } 1979 .\end{array}$ \\
\hline Copper & $\mathrm{CuCl} 2$ & native soil microflora & loam & 7 & 5.5 & 0.1 & $\begin{array}{l}\text { Acid phosphatase } \\
\text { activity }\end{array}$ & & $\begin{array}{l}1590 \\
\text { LCT }\end{array}$ & 43 & $\begin{array}{l}\text { Juma \& Tabatabai. } \\
\text { 1977. }\end{array}$ \\
\hline Copper & $\mathrm{CuSO} 4$ & native soil microflora & loam & 7 & 5.5 & 0.1 & $\begin{array}{l}\text { Acid phosphatase } \\
\text { activity }\end{array}$ & & $\begin{array}{l}1590 \\
\text { LCT }\end{array}$ & 36 & $\begin{array}{l}\text { Juma \& Tabatabai. } \\
\text { 1977. }\end{array}$ \\
\hline
\end{tabular}


Table B.1 (continued)

\begin{tabular}{|c|c|c|c|c|c|c|c|c|c|c|c|}
\hline CHEMICAL & $\begin{array}{c}\text { CHEMICAL } \\
\text { FORM } \\
\end{array}$ & ORGANISMS & $\begin{array}{l}\text { GROWTH } \\
\text { MEDIUM }\end{array}$ & $\mathrm{pH}$ & $\% O C$ & $\begin{array}{l}\text { EXP } \\
\text { (D) }\end{array}$ & $\begin{array}{c}\text { RESPONSE } \\
\text { PARAMETER } \\
\end{array}$ & NOEC & LOEC & $\begin{array}{c}\% \\
\text { DEC }\end{array}$ & REFERENCE \\
\hline Copper & $\mathrm{CuCl} 2$ & native soil microflora & clay loam & 8 & 3.7 & 0.1 & $\begin{array}{l}\text { Alkaline \& } \\
\text { acid phosphatase } \\
\text { activity }\end{array}$ & & $\begin{array}{l}1590 \\
\text { LCT }\end{array}$ & $\begin{array}{r}30, \\
28\end{array}$ & $\begin{array}{l}\text { Juma \& Tabatabai. } \\
1977 .\end{array}$ \\
\hline Copper & CuSO4 & native soil microflora & clay loam & 8 & 3.7 & 0.1 & $\begin{array}{l}\text { Acid phosphatase } \\
\text { activity }\end{array}$ & & $\begin{array}{l}1590 \\
\text { LCT }\end{array}$ & 26 & $\begin{array}{l}\text { Juma \& Tabatabai. } \\
\text { 1977. }\end{array}$ \\
\hline Copper & CuSO4 & native soil microflora & clay loam & 8 & 3.2 & 0.1 & Arylsulfatase activity & 159 & 1590 & 26 & $\begin{array}{l}\text { Al-Khafaji \& } \\
\text { Tabatabai. } 1979 .\end{array}$ \\
\hline Copper & $\mathrm{CuSO} 4$ & native soil microflora & loam & 7 & 2.9 & 0.1 & Arylsulfatase activity & 159 & 1590 & 32 & $\begin{array}{l}\text { Al-Khafaji \& } \\
\text { Tabatabai. } 1979 .\end{array}$ \\
\hline Copper & $\mathrm{CuCl} 2$ & native soil microflora & loam & 6 & 2.6 & 0.1 & $\begin{array}{l}\text { Acid phosphatase } \\
\text { activity }\end{array}$ & 159 & 1590 & 51 & $\begin{array}{l}\text { Juma \& Tabatabai. } \\
1977 .\end{array}$ \\
\hline Copper & $\mathrm{CuSO} 4$ & native soil microflora & loam & 6 & 2.6 & 0.1 & $\begin{array}{l}\text { Acid phosphatase } \\
\text { activity }\end{array}$ & 159 & 1590 & 44 & $\begin{array}{l}\text { Juma \& Tabatabai. } \\
1977 .\end{array}$ \\
\hline Copper & $\mathrm{CuCl} 2$ & native soil microflora & loam & 7 & 5.5 & 0.1 & $\begin{array}{l}\text { Alkaline phosphatase } \\
\text { activity }\end{array}$ & 159 & 1590 & 32 & $\begin{array}{l}\text { Juma \& Tabatabai. } \\
1977 .\end{array}$ \\
\hline Copper & $\mathrm{CuSO} 4$ & native soil microflora & loam & 7 & 5.5 & 0.1 & $\begin{array}{l}\text { Alkaline phosphatase } \\
\text { activity }\end{array}$ & 159 & 1590 & 23 & $\begin{array}{l}\text { Juma \& Tabatabai. } \\
1977 .\end{array}$ \\
\hline Copper & $\mathrm{CuCl} 2$ & native soil microflora & $\begin{array}{l}\text { sandy } \\
\text { loam }\end{array}$ & 6 & 3 & 548 & Phosphatase activity & & $\begin{array}{r}1895 \\
\text { ED50 }\end{array}$ & 50 & $\begin{array}{l}\text { Doelman \& } \\
\text { Haanstra. } 1989 .\end{array}$ \\
\hline Copper & $\mathrm{CuCl} 2$ & native soil microflora & sandy peat & 4 & 6.5 & 548 & Urease activity & & $\begin{array}{r}1970 \\
\text { ED50 }\end{array}$ & 50 & $\begin{array}{l}\text { Doelman \& } \\
\text { Haanstra. } 1986 .\end{array}$ \\
\hline Copper & $\mathrm{CuCl} 2$ & native soil microflora & silty loam & 8 & 1 & 548 & Urease activity & & $\begin{array}{r}1990 \\
\text { ED50 }\end{array}$ & 50 & $\begin{array}{l}\text { Doelman \& } \\
\text { Haanstra. } 1986 .\end{array}$ \\
\hline
\end{tabular}


Table B.1 (continued)

\begin{tabular}{|c|c|c|c|c|c|c|c|c|c|c|c|}
\hline CHEMICAL & $\begin{array}{c}\text { CHEMICAL } \\
\text { FORM }\end{array}$ & ORGANISMS & $\begin{array}{l}\text { GROWTH } \\
\text { MEDIUM }\end{array}$ & $\mathrm{pH}$ & \%OC & $\begin{array}{l}\operatorname{EXP} \\
\text { (D) }\end{array}$ & $\begin{array}{c}\text { RESPONSE } \\
\text { PARAMETER }\end{array}$ & NOEC & LOEC & $\begin{array}{c}\% \\
\text { DEC }\end{array}$ & REFERENCE \\
\hline Copper & $\mathrm{CuCl} 2$ & native soil microflora & sandy peat & 4 & 6.5 & 548 & Phosphatase activity & & $\begin{array}{r}2442 \\
\text { ED50 }\end{array}$ & 50 & $\begin{array}{l}\text { Doelman \& } \\
\text { Haanstra. } 1989 .\end{array}$ \\
\hline Copper & $\mathrm{CuCl} 2$ & native soil microflora & sandy peat & 4 & 6.5 & 42 & Phosphatase activity & & $\begin{array}{r}2639 \\
\text { ED50 }\end{array}$ & 50 & $\begin{array}{l}\text { Doelman \& } \\
\text { Haanstra. } 1989 .\end{array}$ \\
\hline Copper & $\mathrm{CuCl} 2$ & native soil microflora & clay & 8 & 1.5 & 42 & Phosphatase activity & & $\begin{array}{r}2722 \\
\text { ED50 }\end{array}$ & 50 & $\begin{array}{l}\text { Doelman \& } \\
\text { Haanstra. } 1989 .\end{array}$ \\
\hline Copper & $\mathrm{CuCl} 2$ & native soil microflora & clay & 8 & 1.5 & 42 & Arylsulfatase activity & & $\begin{array}{r}2722 \\
\text { ED50 }\end{array}$ & so & $\begin{array}{l}\text { Haanstra \& } \\
\text { Doelman. } 1991 .\end{array}$ \\
\hline Copper & $\mathrm{CuCl} 2$ & native soil microflora & clay & 8 & 1.5 & 548 & Phosphatase activity & & $\begin{array}{r}2754 \\
\text { ED50 }\end{array}$ & 50 & $\begin{array}{l}\text { Doelman \& } \\
\text { Haanstra. } 1989 .\end{array}$ \\
\hline Copper & $\mathrm{CuCl} 2$ & native soil microflora & sandy peat & 4 & 6.5 & 42 & Urease activity & & $\begin{array}{r}4200 \\
\text { ED50 }\end{array}$ & 50 & $\begin{array}{l}\text { Doelman \& } \\
\text { Haanstra. } 1986 .\end{array}$ \\
\hline Copper & $\mathrm{CuCl} 2$ & native soil microflora & clay & 8 & 1.5 & 548 & Arylsulfatase activity & & $\begin{array}{r}4853 \\
\text { ED50 }\end{array}$ & 50 & $\begin{array}{l}\text { Haanstra \& } \\
\text { Doelman. } 1991 .\end{array}$ \\
\hline Copper & $\mathrm{CuCl} 2$ & native soil microflora & silty loam & 8 & 1 & 42 & Phosphatase activity & & $\begin{array}{r}6424 \\
\text { ED50 }\end{array}$ & 50 & $\begin{array}{l}\text { Doelman \& } \\
\text { Haanstra. } 1989 .\end{array}$ \\
\hline Copper & $\mathrm{CuCl} 2$ & native soil microflora & sandy peat & 4 & 6.5 & 548 & Arylsulfatase activity & & $\begin{array}{r}6996 \\
\text { ED50 }\end{array}$ & 50 & $\begin{array}{l}\text { Haanstra \& } \\
\text { Doelman. } 1991 .\end{array}$ \\
\hline Copper & $\mathrm{CuCl} 2$ & native soil microflora & sandy peat & 4 & 6.5 & 42 & Arylsulfatase activity & & $\begin{array}{r}8904 \\
\text { ED50 }\end{array}$ & 50 & $\begin{array}{l}\text { Haanstra \& } \\
\text { Doelman. } 1991 .\end{array}$ \\
\hline Copper & $\mathrm{CuSO} 4$ & native soil microflora & $\begin{array}{l}\text { sandy } \\
\text { loam }\end{array}$ & 7 & 2 & 21 & Nitrification & 1000 & 10000 & 75 & $\begin{array}{l}\text { Premi \& Cornfield. } \\
1969 .\end{array}$ \\
\hline Copper & $\mathrm{CuCl} 2$ & native soil microflora & silty loam & 8 & 1 & 42 & Arylsulfatase activity & & $\begin{array}{l}14946 \\
\text { ED50 }\end{array}$ & 50 & $\begin{array}{l}\text { Haanstra \& } \\
\text { Doelman. } 1991 .\end{array}$ \\
\hline
\end{tabular}


Table B.1 (continued)

\begin{tabular}{|c|c|c|c|c|c|c|c|c|c|c|c|}
\hline CHEMICAL & $\begin{array}{c}\text { CHEMICAL } \\
\text { FORM }\end{array}$ & ORGANISMS & $\begin{array}{l}\text { GROWTH } \\
\text { MEDIUM }\end{array}$ & $\mathrm{pH}$ & $\% O C$ & $\begin{array}{l}\operatorname{EXP} \\
(\mathrm{D})\end{array}$ & $\begin{array}{c}\text { RESPONSE } \\
\text { PARAMETER } \\
\end{array}$ & NOEC & LOEC & $\begin{array}{c}\% \\
\text { DEC }\end{array}$ & REFERENCE \\
\hline Fluoride & $\mathrm{KF}$ & native soil microflora & leaf litter & & & 63 & P mineralization & & $\begin{array}{r}32 \\
\text { LCT }\end{array}$ & 22 & $\begin{array}{l}\text { van Wensem \& } \\
\text { Adema. } 1991 .\end{array}$ \\
\hline Fluoride & $\mathrm{NaF}$ & native soil microflora & $\begin{array}{l}\text { surface } \\
\text { soil }\end{array}$ & & 1.3 & 1 & Dehydrogenase activity & 3000 & 5000 & 30 & Rogers \& Li. 1985. \\
\hline Iron & $\mathrm{FeCl3}$ & native soil microflora & clay loam & 8 & 4 & 20 & $\mathrm{~N}$ mineralization & & $\begin{array}{r}280 \\
\text { LCT }\end{array}$ & 22 & $\begin{array}{l}\text { Liang \& Tabatabai. } \\
1977 .\end{array}$ \\
\hline Iron & $\mathrm{FeCl} 3$ & native soil microflora & clay loam & 6 & 2.7 & 0.1 & Arylsulfatase activity & & $\begin{array}{l}1398 \\
\text { LCT }\end{array}$ & 59 & $\begin{array}{l}\text { Al-Khafaji \& } \\
\text { Tabatabai. } 1979 .\end{array}$ \\
\hline Iron & $\mathrm{FeCl3}$ & native soil microflora & loam & 7 & 5.3 & 0.1 & Arylsulfatase activity & & $\begin{array}{l}1398 \\
\text { LCT }\end{array}$ & 23 & $\begin{array}{l}\text { Al-Khafaji \& } \\
\text { Tabatabai. } 1979 .\end{array}$ \\
\hline Iron & FeSO4 & native soil microflora & clay loam & 8 & 3.7 & 0.1 & $\begin{array}{l}\text { Alkaline phosphatase } \\
\text { activity }\end{array}$ & & $\begin{array}{l}1398 \\
\text { LCT }\end{array}$ & 22 & $\begin{array}{l}\text { Juma \& Tabatabai. } \\
\text { 1977. }\end{array}$ \\
\hline Iron & $\mathrm{FeCl} 2$ & native soil microflora & loam & 7 & 5.5 & 0.1 & $\begin{array}{l}\text { Acid phosphatase } \\
\text { activity }\end{array}$ & & $\begin{array}{l}1398 \\
\text { LCT }\end{array}$ & 26 & $\begin{array}{l}\text { Juma \& Tabatabai. } \\
1977 .\end{array}$ \\
\hline Iron & $\mathrm{FeCl3}$ & native soil microflora & loam & 7 & 2.9 & 0.1 & Arylsulfatase activity & 139.8 & 1398 & 45 & $\begin{array}{l}\text { Al-Khafaji \& } \\
\text { Tabatabai. } 1979 .\end{array}$ \\
\hline Iron & $\mathrm{FeSO} 4$ & native soil microflora & loam & 6 & 2.6 & 0.1 & $\begin{array}{l}\text { Acid phosphatase } \\
\text { activity }\end{array}$ & 139.8 & 1398 & 27 & $\begin{array}{l}\text { Juma \& Tabatabai. } \\
1977 .\end{array}$ \\
\hline Iron & $\mathrm{FeCl} 2$ & native soil microflora & loam & 6 & 2.6 & 0.1 & $\begin{array}{l}\text { Acid phosphatase } \\
\text { activity }\end{array}$ & 139.8 & 1398 & 40 & $\begin{array}{l}\text { Juma \& Tabatabai. } \\
1977 .\end{array}$ \\
\hline
\end{tabular}


Table B.1 (continued)

\begin{tabular}{|c|c|c|c|c|c|c|c|c|c|c|c|}
\hline CHEMICAL & $\begin{array}{c}\text { CHEMICAL } \\
\text { FORM } \\
\end{array}$ & ORGANISMS & $\begin{array}{l}\text { GROWTH } \\
\text { MEDIUM } \\
\end{array}$ & $\mathrm{pH}$ & $\% O C$ & $\begin{array}{c}\operatorname{EXP} \\
(\mathrm{D}) \\
\end{array}$ & $\begin{array}{c}\text { RESPONSE } \\
\text { PARAMETER }\end{array}$ & NOEC & LOEC & $\begin{array}{c}\% \\
\text { DEC }\end{array}$ & REFERENCE \\
\hline Iron & $\mathrm{FeCl} 2$ & native soil microflora & loam & 7 & 5.5 & 0.1 & $\begin{array}{l}\text { Alkaline phosphatase } \\
\text { activity }\end{array}$ & 139.8 & 1398 & 32 & $\begin{array}{l}\text { Juma \& Tabatabai. } \\
1977 .\end{array}$ \\
\hline Lanthanum & $\mathrm{LaCl} 3$ & native soil microflora & $\begin{array}{l}\text { soil/litter } \\
\text { microcosm }\end{array}$ & & & & Respiration & & $\begin{array}{r}57 \\
\text { LCT }\end{array}$ & 22 & $\begin{array}{l}\text { Lighthart et al. } \\
1977 .\end{array}$ \\
\hline Lead & $\mathrm{PbCl} 2$ & native soil microflora & clay & 8 & 1.5 & 1 & Dehydrogenase activity & & $\begin{array}{r}375 \\
\mathrm{LCT}\end{array}$ & 29 & $\begin{array}{l}\text { Doelman \& } \\
\text { Haanstra. } 1979 .\end{array}$ \\
\hline Lead & $\mathrm{PbCl} 2$ & native soil microflora & sandy soil & 6 & 1.5 & 1 & Respiration & 375 & 750 & 35 & $\begin{array}{l}\text { Doelman \& } \\
\text { Haanstra. } 1979 .\end{array}$ \\
\hline Lead & $\mathrm{PbC} 4 \mathrm{H} 6 \mathrm{O} 4$ & native soil microflora & silt loam & & & 2 & Amylase activity & 450 & 900 & 31 & Cole. 1977. \\
\hline Lead & $\mathrm{PbCl} 2$ & native soil microflora & silt loam & & & 2 & Amylase activity & 450 & 900 & 21 & Cole. 1977. \\
\hline Lead & $\mathrm{PbO}$ & native soil microflora & sandy soil & 6 & 2 & 84 & $\mathrm{C}$ mineralization & & $\begin{array}{l}1000 \\
\mathrm{LCT}\end{array}$ & 22 & $\begin{array}{l}\text { Bhuiya \& } \\
\text { Cornfield. } 1972 .\end{array}$ \\
\hline Lead & $\mathrm{PbCl} 2$ & native soil microflora & $\begin{array}{l}\text { brown } \\
\text { earth }\end{array}$ & 5 & & 30 & Cellulolytic activity & 500 & 1000 & 23 & $\begin{array}{l}\text { Khan \& Frankland. } \\
1984 .\end{array}$ \\
\hline Lead & $\mathrm{PbC4H604}$ & native soil microflora & clay loam & 8 & 4 & 20 & $\mathrm{~N}$ mineralization & & $\begin{array}{l}1035 \\
\mathrm{LCT}\end{array}$ & 28 & $\begin{array}{l}\text { Liang \& Tabatabai. } \\
1977 .\end{array}$ \\
\hline Lead & $\mathrm{PbCl} 2$ & native soil microflora & clay & 8 & 1.5 & 548 & Urease activity & & $\begin{array}{r}1340 \\
\text { ED50 }\end{array}$ & 50 & $\begin{array}{l}\text { Doelman \& } \\
\text { Haanstra. } 1986 .\end{array}$ \\
\hline Lead & $\mathrm{PbCl} 2$ & native soil microflora & sandy soil & 6 & 1.5 & 1217 & Respiration & & $\begin{array}{l}1500 \\
\text { LCT }\end{array}$ & 30 & $\begin{array}{l}\text { Doelman \& } \\
\text { Haanstra. } 1979 .\end{array}$ \\
\hline
\end{tabular}


Table B.1 (continued)

\begin{tabular}{|c|c|c|c|c|c|c|c|c|c|c|c|}
\hline CHEMICAL & $\begin{array}{c}\text { CHEMICAL } \\
\text { FORM } \\
\end{array}$ & ORGANISMS & $\begin{array}{l}\text { GROWTH } \\
\text { MEDIUM } \\
\end{array}$ & $\mathrm{pH}$ & $\% O C$ & $\begin{array}{l}\text { EXP } \\
\text { (D) }\end{array}$ & $\begin{array}{c}\text { RESPONSE } \\
\text { PARAMETER } \\
\end{array}$ & NOEC & LOEC & $\begin{array}{c}\% \\
\text { DEC }\end{array}$ & REFERENCE \\
\hline Lead & $\mathrm{PbCl} 2$ & native soil microflora & sandy soil & 5 & 3 & 1 & Dehydrogenase activity & 750 & 1500 & 78 & $\begin{array}{l}\text { Doelman \& } \\
\text { Haanstra. } 1979 .\end{array}$ \\
\hline Lead & $\mathrm{PbCl} 2$ & native soil microflora & sandy soil & 7 & 1 & 548 & Urease activity & & $\begin{array}{r}1590 \\
\mathrm{ED} 50\end{array}$ & 50 & $\begin{array}{l}\text { Doelman \& } \\
\text { Haanstra. } 1986 .\end{array}$ \\
\hline Lead & $\mathrm{PbS}$ & native soil microflora & silt loam & & & 2 & Amylase activity & 900 & 1800 & 58 & Cole. 1977. \\
\hline Lead & $\mathrm{PbC} 4 \mathrm{H} 6 \mathrm{O} 4$ & native soil microflora & silt loam & & & 4 & $\begin{array}{l}\text { alpha-glucosidase } \\
\text { synthesis }\end{array}$ & & $\begin{array}{l}2000 \\
\text { LCT }\end{array}$ & 38 & Cole. 1977. \\
\hline Lead & $\mathrm{PbC4H6O4}$ & native soil microflora & silt loam & & . & 2 & Amylase activity & & $\begin{array}{l}2000 \\
\text { LCT }\end{array}$ & 74 & Cole. 1977. \\
\hline Lead & $\mathrm{PbC4H6O4}$ & native soil microflora & silt loam & & & 5 & Bacterial population size & & $\begin{array}{l}2000 \\
\mathrm{LCT}\end{array}$ & 37 & Cole. 1977. \\
\hline Lead & $\mathrm{PbCl} 2$ & native soil microflora & $\begin{array}{l}\text { sandy } \\
\text { loam }\end{array}$ & 6 & 3 & 548 & Urease activity & & $\begin{array}{r}2870 \\
\text { ED50 }\end{array}$ & 50 & $\begin{array}{l}\text { Doelman \& } \\
\text { Haanstra. } 1986 .\end{array}$ \\
\hline Lead & $\mathrm{PbCl} 2$ & native soil microflora & $\begin{array}{l}\text { sandy } \\
\text { loam }\end{array}$ & 6 & 3 & 548 & Arylsulfatase activity & & $\begin{array}{r}3004 \\
\text { ED50 }\end{array}$ & 50 & $\begin{array}{l}\text { Haanstra \& } \\
\text { Doelman. } 1991 .\end{array}$ \\
\hline Lead & $\mathrm{PbCl} 2$ & native soil microflora & silty loam & 8 & 1 & 548 & Arylsulfatase activity & & $\begin{array}{r}4538 \\
\text { ED50 }\end{array}$ & 50 & $\begin{array}{l}\text { Haanstra \& } \\
\text { Doelman. } 1991 .\end{array}$ \\
\hline Lead & $\mathrm{PbCl} 2$ & native soil microflora & $\begin{array}{l}\text { sandy } \\
\text { loam }\end{array}$ & 6 & 3 & 42 & Urease activity & & $\begin{array}{r}5060 \\
\text { ED50 }\end{array}$ & 50 & $\begin{array}{l}\text { Doelman \& } \\
\text { Haanstra. } 1986 .\end{array}$ \\
\hline Lead & $\mathrm{PbC4H6O4}$ & native soil microflora & clay loam & 8 & 3.7 & 0.1 & $\begin{array}{l}\text { Alkaline phosphatase } \\
\text { activity }\end{array}$ & & $\begin{array}{l}5175 \\
\mathrm{LCT}\end{array}$ & 33 & $\begin{array}{l}\text { Juma \& Tabatabai. } \\
1977 .\end{array}$ \\
\hline Lead & PbNO3 & native soil microflora & clay loam & 8 & 3.7 & 0.1 & $\begin{array}{l}\text { Alkaline phosphatase } \\
\text { activity }\end{array}$ & & $\begin{array}{l}5175 \\
\text { LCT }\end{array}$ & 38 & $\begin{array}{l}\text { Juma \& Tabatabai. } \\
1977 .\end{array}$ \\
\hline
\end{tabular}


Table B.1 (continued)

\begin{tabular}{|c|c|c|c|c|c|c|c|c|c|c|c|}
\hline CHEMICAL & $\begin{array}{c}\text { CHEMICAL } \\
\text { FORM } \\
\end{array}$ & ORGANISMS & $\begin{array}{l}\text { GROWTH } \\
\text { MEDIUM } \\
\end{array}$ & $\mathrm{pH}$ & \%OC & $\begin{array}{c}\text { EXP } \\
\text { (D) }\end{array}$ & $\begin{array}{c}\text { RESPONSE } \\
\text { PARAMETER } \\
\end{array}$ & NOEC & LOEC & $\begin{array}{c}\% \\
\text { DEC }\end{array}$ & REFERENCE \\
\hline Lead & $\mathrm{PbNO} 3$ & native soil microflora & loam & 6 & 2.6 & 0.1 & $\begin{array}{l}\text { Acid phosphatase } \\
\text { activity }\end{array}$ & 517.5 & 5175 & 26 & $\begin{array}{l}\text { Juma \& Tabatabai. } \\
1977 .\end{array}$ \\
\hline Lead & $\mathrm{PbC} 4 \mathrm{H} 6 \mathrm{O} 4$ & native soil microflora & loam & 6 & 2.6 & 0.1 & $\begin{array}{l}\text { Acid phosphatase } \\
\text { activity }\end{array}$ & 517.5 & 5175 & 24 & $\begin{array}{l}\text { Juma \& Tabatabai. } \\
1977 .\end{array}$ \\
\hline Lead & $\mathrm{PbC} 4 \mathrm{H} 604$ & native soil microflora & loam & 7 & 5.5 & 0.1 & $\begin{array}{l}\text { Alkaline phosphatase } \\
\text { activity }\end{array}$ & 517.5 & 5175 & 21 & $\begin{array}{l}\text { Juma \& Tabatabai. } \\
1977 .\end{array}$ \\
\hline Lead & $\mathrm{PbCl} 2$ & native soil microflora & clay & 8 & 1.5 & 42 & Urease activity & & $\begin{array}{r}5730 \\
\mathrm{ED} 50\end{array}$ & 50 & $\begin{array}{l}\text { Doelman \& } \\
\text { Haanstra. } 1986 .\end{array}$ \\
\hline Lead & $\mathrm{PbCl} 2$ & native soil microflora & sandy peat & 4 & 6.5 & 42 & Urease activity & & $\begin{array}{r}6230 \\
\text { ED50 }\end{array}$ & 50 & $\begin{array}{l}\text { Doelman \& } \\
\text { Haanstra. } 1986 .\end{array}$ \\
\hline Lead & $\mathrm{PbCl} 2$ & native soil microflora & sandy peat & 4 & 6.5 & 548 & Urease activity & & $\begin{array}{r}7050 \\
\text { ED50 }\end{array}$ & 50 & $\begin{array}{l}\text { Doelman \& } \\
\text { Haanstra. } 1986 .\end{array}$ \\
\hline Lead & $\mathrm{PbCl} 2$ & native soil microflora & silty loam & 8 & 1 & 548 & Phosphatase activity & & $\begin{array}{r}7604 \\
\text { ED50 }\end{array}$ & 50 & $\begin{array}{l}\text { Doelman \& } \\
\text { Haanstra. } 1989 .\end{array}$ \\
\hline Lead & $\mathrm{PbCl} 2$ & native soil microflora & silty loam & 8 & 1 & 42 & Urease activity & & $\begin{array}{r}7190 \\
\text { ED50 }\end{array}$ & 50 & $\begin{array}{l}\text { Doelman \& } \\
\text { Haanstra. } 1986 .\end{array}$ \\
\hline Lead & $\mathrm{PbCl} 2$ & native soil microflora & silty loam & 8 & 1 & 548 & Urease activity & & $\begin{array}{r}8130 \\
\text { ED50 }\end{array}$ & 50 & $\begin{array}{l}\text { Doelman \& } \\
\text { Haanstra. } 1986 .\end{array}$ \\
\hline Lead & $\mathrm{PbCl} 2$ & native soil microflora & sandy soil & 7 & 1 & 42 & Arylsulfatase activity & & $\begin{array}{r}8288 \\
\text { ED50 }\end{array}$ & 50 & $\begin{array}{l}\text { Haanstra \& } \\
\text { Doelman. } 1991 .\end{array}$ \\
\hline Lead & $\mathrm{PbCl} 2$ & native soil microflora & sandy soil & 7 & 1 & 548 & Arylsulfatase activity & & $\begin{array}{r}8785 \\
\text { ED50 }\end{array}$ & 50 & $\begin{array}{l}\text { Haanstra \& } \\
\text { Doelman. } 1991 .\end{array}$ \\
\hline Lead & $\mathrm{PbCl} 2$ & native soil microflora & silty loam & 8 & 1 & 42 & Arylsulfatase activity & & $\begin{array}{r}9138 \\
\text { ED50 }\end{array}$ & 50 & $\begin{array}{l}\text { Haanstra \& } \\
\text { Doelman. } 1991 .\end{array}$ \\
\hline
\end{tabular}


Table B.1 (continued)

\begin{tabular}{|c|c|c|c|c|c|c|c|c|c|c|c|}
\hline CHEMICAL & $\begin{array}{c}\text { CHEMICAL } \\
\text { FORM } \\
\end{array}$ & ORGANISMS & $\begin{array}{l}\text { GROWTH } \\
\text { MEDIUM } \\
\end{array}$ & $\mathrm{pH}$ & $\% O C$ & $\begin{array}{l}\text { EXP } \\
\text { (D) }\end{array}$ & $\begin{array}{c}\text { RESPONSE } \\
\text { PARAMETER } \\
\end{array}$ & NOEC & LOEC & $\begin{array}{c}\% \\
\mathrm{DEC} \\
\end{array}$ & REFERENCE \\
\hline Lead & $\mathrm{Pb}(\mathrm{NO}) 2$ & native soil microflora & $\begin{array}{l}\text { sandy } \\
\text { loam }\end{array}$ & 5 & & 15 & Respiration & 1000 & 10000 & 29 & Debosz et al. 1985. \\
\hline Lead & $\mathrm{PbCl} 2$ & native soil microflora & clay & 8 & 1.5 & 42 & Phosphatase activity & & $\begin{array}{l}11168 \\
\text { ED50 }\end{array}$ & 50 & $\begin{array}{l}\text { Doelman \& } \\
\text { Haanstra. } 1989 .\end{array}$ \\
\hline Lead & $\mathrm{PbCl} 2$ & native soil microflora & clay & 8 & 1.5 & 548 & Arylsulfatase activity & & $\begin{array}{l}12411 \\
\text { ED50 }\end{array}$ & 50 & $\begin{array}{l}\text { Haanstra \& } \\
\text { Doelman. } 1991 .\end{array}$ \\
\hline Lead & $\mathrm{PbCl} 2$ & native soil microflora & sandy soil & 7 & 1 & 548 & Phosphatase activity & & $\begin{array}{l}78943 \\
\text { ED50 }\end{array}$ & 50 & $\begin{array}{l}\text { Doelman \& } \\
\text { Haanstra. } 1989 .\end{array}$ \\
\hline Lithium & $\mathrm{LiCl}$ & native soil microflora & $\begin{array}{l}\text { soil/litter } \\
\text { microcosm }\end{array}$ & & & & Respiration & & $\begin{array}{r}17 \\
\mathrm{LCT}\end{array}$ & 43 & $\begin{array}{l}\text { Lighthart et al. } \\
1977 .\end{array}$ \\
\hline Manganese & $\mathrm{MnSO4}$ & native soil microflora & $\begin{array}{l}\text { sandy } \\
\text { loam }\end{array}$ & 7 & 2 & 21 & Nitrification & & $\begin{array}{r}100 \\
\text { LCT }\end{array}$ & 67 & $\begin{array}{l}\text { Premi \& Cornfield. } \\
1969 .\end{array}$ \\
\hline Manganese & $\mathrm{MnCl} 2$ & native soil microflora & clay loam & 8 & 4 & 20 & $\mathrm{~N}$ mineralization & & $\begin{array}{r}275 \\
\mathrm{LCT}\end{array}$ & 26 & $\begin{array}{l}\text { Liang \& Tabatabai. } \\
1977 .\end{array}$ \\
\hline Manganese & $\mathrm{MnCl} 2$ & native soil microflora & clay loam & 8 & 3.7 & 0.1 & $\begin{array}{l}\text { Alkaline phosphatase } \\
\text { activity }\end{array}$ & & $\begin{array}{l}1375 \\
\mathrm{LCT}\end{array}$ & 25 & $\begin{array}{l}\text { Juma \& Tabatabai. } \\
1977 .\end{array}$ \\
\hline Manganese & $\mathrm{MnCl} 2$ & native soil microflora & loam & 6 & 2.6 & 0.1 & $\begin{array}{l}\text { Acid phosphatase } \\
\text { activity }\end{array}$ & 137.5 & 1375 & 62 & $\begin{array}{l}\text { Juma \& Tabatabai. } \\
1977 .\end{array}$ \\
\hline Mercury & $\mathrm{HgCl} 2$ & native soil microflora & clay loam & 8 & 2 & 28 & $\mathrm{C}$ mineralization & & $\begin{array}{r}0.1 \\
\mathrm{LCT}\end{array}$ & 87 & $\begin{array}{l}\text { Landa \& Fang. } \\
1978 .\end{array}$ \\
\hline
\end{tabular}


Table B.1 (continued)

\begin{tabular}{|c|c|c|c|c|c|c|c|c|c|c|c|}
\hline CHEMICAL & $\begin{array}{c}\text { CHEMICAL } \\
\text { FORM } \\
\end{array}$ & ORGANISMS & $\begin{array}{l}\text { GROWTH } \\
\text { MEDIUM } \\
\end{array}$ & $\mathrm{pH}$ & $\% O C$ & $\begin{array}{l}\text { EXP } \\
(D) \\
\end{array}$ & $\begin{array}{c}\text { RESPONSE } \\
\text { PARAMETER } \\
\end{array}$ & NOEC & LOEC & $\begin{array}{c}\% \\
\text { DEC } \\
\end{array}$ & REFERENCE \\
\hline Mercury & PMA* & native soil microflora & dune sand & 8 & 1 & & Nitrification & & $\begin{array}{r}10 \\
\mathrm{LCT}\end{array}$ & 57 & van Faassen. 1973. \\
\hline Mercury & $\mathrm{HgCl} 2$ & native soil microflora & clay loam & 7 & 3 & 0.2 & urease activity & & $\begin{array}{r}50 \\
\mathrm{LCT}\end{array}$ & 38 & $\begin{array}{l}\text { Bremner \& } \\
\text { Douglas. } 1971 .\end{array}$ \\
\hline Mercury & $\mathrm{HgSO} 4$ & native soil microflora & clay loam & 7 & 3 & 0.2 & urease activity & & $\begin{array}{r}50 \\
\mathrm{LCT}\end{array}$ & 36 & $\begin{array}{l}\text { Bremner \& } \\
\text { Douglas. } 1971 .\end{array}$ \\
\hline Mercury & $\mathrm{HgCl} 2$ & native soil microflora & $\begin{array}{l}\text { silty clay } \\
\text { loam }\end{array}$ & 7 & 2.2 & 0.2 & urease activity & & $\begin{array}{r}50 \\
\text { LCT }\end{array}$ & 42 & $\begin{array}{l}\text { Bremner \& } \\
\text { Douglas. } 1971 .\end{array}$ \\
\hline Mercury & $\mathrm{HgSO} 4$ & native soil microflora & $\begin{array}{l}\text { silty clay } \\
\text { loam }\end{array}$ & 7 & 2.2 & 0.2 & urease activity & & $\begin{array}{r}50 \\
\mathrm{LCT}\end{array}$ & 46 & $\begin{array}{l}\text { Bremner \& } \\
\text { Douglas. } 1971 .\end{array}$ \\
\hline Mercury & $\mathrm{HgCl} 2$ & native soil microflora & clay loam & 8 & 2 & 28 & $\mathrm{C}$ mineralization & 10 & 100 & 45 & $\begin{array}{l}\text { Landa \& Fang. } \\
1978 .\end{array}$ \\
\hline Mercury & $\mathrm{HgCl} 2$ & native soil microflora & silty clay & 7 & 7 & 28 & $\mathrm{C}$ mineralization & 10 & 100 & 28 & $\begin{array}{l}\text { Landa \& Fang. } \\
1978 .\end{array}$ \\
\hline Mercury & $\mathrm{HgCl} 2$ & native soil microflora & clay & 8 & 3 & & Nitrification & 10 & 100 & 40 & van Faassen. 1973. \\
\hline Mercury & PMA* & native soil microflora & clay & 8 & 3 & & $\begin{array}{l}\text { Nitrification \& } \\
\text { ammonification }\end{array}$ & 10 & 100 & $\begin{array}{r}94 \\
42\end{array}$ & van Faassen. 1973. \\
\hline Mercury & $\mathrm{HgCl} 2$ & native soil microflora & dune sand & 8 & 1 & & $\begin{array}{l}\text { Nitrification \& } \\
\text { ammonification }\end{array}$ & 10 & 100 & $\begin{array}{r}95 \\
34\end{array}$ & van Faassen. 1973. \\
\hline Mercury & $\mathrm{HgCl} 2$ & native soil microflora & loam & 7 & 2.9 & 0.1 & Arylsulfatase activity & & $\begin{array}{r}501.5 \\
\text { LCT }\end{array}$ & 39 & $\begin{array}{l}\text { Al-Khafaji \& } \\
\text { Tabatabai. } 1979 .\end{array}$ \\
\hline Mercury & $\mathrm{HgCl} 2$ & native soil microflora & clay loam & 8 & 3.2 & 0.1 & Arylsulfatase activity & & $\begin{array}{r}501.5 \\
\text { LCT }\end{array}$ & 34 & $\begin{array}{l}\text { Al-Khafaji \& } \\
\text { Tabatabai. } 1979 .\end{array}$ \\
\hline
\end{tabular}


Table B.1 (continued)

\begin{tabular}{|c|c|c|c|c|c|c|c|c|c|c|c|}
\hline CHEMICAL & $\begin{array}{c}\text { CHEMICAL } \\
\text { FORM } \\
\end{array}$ & ORGANISMS & $\begin{array}{l}\text { GROWTH } \\
\text { MEDIUM } \\
\end{array}$ & pH & \%OC & $\begin{array}{l}\operatorname{EXP} \\
\text { (D) } \\
\end{array}$ & $\begin{array}{c}\text { RESPONSE } \\
\text { PARAMETER } \\
\end{array}$ & NOEC & LOEC & $\begin{array}{c}\% \\
\text { DEC } \\
\end{array}$ & REFERENCE \\
\hline Mercury & $\mathrm{HgCl} 2$ & native soil microflora & clay loam & 8 & 3.2 & 0.1 & Arylsulfatase activity & & $\begin{array}{r}501.5 \\
\text { LCT }\end{array}$ & 34 & $\begin{array}{l}\text { Al-Khafaji \& } \\
\text { Tabatabai. } 1979 .\end{array}$ \\
\hline Mercury & $\mathrm{HgCl} 2$ & native soil microflora & loam & 6 & 3 & 20 & $\mathbf{N}$ mineralization & & $\begin{array}{l}1003 \\
\text { LCT }\end{array}$ & 73 & $\begin{array}{l}\text { Liang \& Tabatabai. } \\
1977 .\end{array}$ \\
\hline Mercury & $\mathrm{HgCl} 2$ & native soil microflora & silty clay & 7 & 3 & 20 & $\mathrm{~N}$ mineralization & & $\begin{array}{l}1003 \\
\mathrm{LCT}\end{array}$ & 39 & $\begin{array}{l}\text { Liang \& Tabatabai. } \\
1977 .\end{array}$ \\
\hline Mercury & $\mathrm{HgCl} 2$ & native soil microflora & clay loam & 8 & 4 & 20 & $\mathrm{~N}$ mineralization & & $\begin{array}{l}1003 \\
\text { LCT }\end{array}$ & 35 & $\begin{array}{l}\text { Liang \& Tabatabai. } \\
1977 .\end{array}$ \\
\hline Mercury & $\mathrm{HgCl} 2$ & native soil microflora & $\begin{array}{l}\text { silty clay } \\
\text { loam }\end{array}$ & 7 & 6 & 20 & $\mathbf{N}$ mineralization & & $\begin{array}{l}1003 \\
\mathrm{LCT}\end{array}$ & 32 & $\begin{array}{l}\text { Liang \& Tabatabai. } \\
1977 .\end{array}$ \\
\hline Mercury & $\mathrm{HgCl} 2$ & native soil microflora & clay loam & 8 & 3.2 & 0.1 & Amidase activity & & $\begin{array}{l}5015 \\
\text { LCT }\end{array}$ & 30 & $\begin{array}{l}\text { Frankenberger\& } \\
\text { Tabatabai. } 1981\end{array}$ \\
\hline Mercury & $\mathrm{HgCl} 2$ & native soil microflora & loam & 7 & 4.7 & 0.1 & Amidase activity & & $\begin{array}{l}5015 \\
\text { LCT }\end{array}$ & 27 & $\begin{array}{l}\text { Frankenberger\& } \\
\text { Tabatabai. } 1981\end{array}$ \\
\hline Mercury & $\mathrm{HgCl} 2$ & native soil microflora & clay loam & 6 & 2.7 & 0.1 & Arylsulfatase activity & & $\begin{array}{l}5015 \\
\text { LCT }\end{array}$ & 96 & $\begin{array}{l}\text { Al-Khafaji \& } \\
\text { Tabatabai. } 1979 .\end{array}$ \\
\hline Mercury & $\mathrm{HgCl} 2$ & native soil microflora & loam & 7 & 5.3 & 0.1 & Arylsulfatase activity & & $\begin{array}{l}5015 \\
\mathrm{LCT}\end{array}$ & 86 & $\begin{array}{l}\text { Al-Khafaji \& } \\
\text { Tabatabai. } 1979 .\end{array}$ \\
\hline Mercury & $\mathrm{HgCl} 2$ & native soil microflora & clay loam & 8 & 3.7 & 0.1 & $\begin{array}{l}\text { Alkaline \& } \\
\text { acid phosphatase } \\
\text { activities }\end{array}$ & & $\begin{array}{l}5015 \\
\text { LCT }\end{array}$ & $\begin{array}{r}53 \\
52\end{array}$ & $\begin{array}{l}\text { Juma \& Tabatabai. } \\
1977 .\end{array}$ \\
\hline Mercury & $\mathrm{HgCl} 2$ & native soil microflora & loam & 7 & 5.5 & 0.1 & $\begin{array}{l}\text { Acid phosphatase } \\
\text { activity }\end{array}$ & & $\begin{array}{l}5015 \\
\text { LCT }\end{array}$ & 53 & $\begin{array}{l}\text { Juma \& Tabatabai. } \\
1977 .\end{array}$ \\
\hline
\end{tabular}


Table B.1 (continued)

\begin{tabular}{|c|c|c|c|c|c|c|c|c|c|c|c|}
\hline CHEMICAL & $\begin{array}{c}\text { CHEMICAL } \\
\text { FORM } \\
\end{array}$ & ORGANISMS & $\begin{array}{l}\text { GROWTH } \\
\text { MEDIUM } \\
\end{array}$ & pH & $\% O C$ & $\begin{array}{l}\text { EXP } \\
\text { (D) }\end{array}$ & $\begin{array}{l}\text { RESPONSE } \\
\text { PARAMETER }\end{array}$ & NOEC & LOEC & $\begin{array}{c}\% \\
\text { DEC } \\
\end{array}$ & REFERENCE \\
\hline Mercury & $\mathrm{HgCl} 2$ & native soil microflora & $\begin{array}{l}\text { surface } \\
\text { soil }\end{array}$ & 6 & 2.6 & 0.1 & Amidase activity & 501.5 & 5015 & 46 & $\begin{array}{l}\text { Frankenberger\& } \\
\text { Tabatabai. } 1981\end{array}$ \\
\hline Mercury & $\mathrm{HgCl} 2$ & native soil microflora & loam & 6 & 2.6 & 0.1 & $\begin{array}{l}\text { Acid phosphatase } \\
\text { activity }\end{array}$ & 501.5 & 5015 & 63 & $\begin{array}{l}\text { Juma \& Tabatabai. } \\
1977 .\end{array}$ \\
\hline Mercury & $\mathrm{HgCl} 2$ & native soil microflora & loam & 7 & 5.5 & 0.1 & $\begin{array}{l}\text { Alkaline phosphatase } \\
\text { activity }\end{array}$ & 501.5 & 5015 & 41 & $\begin{array}{l}\text { Juma \& Tabatabai. } \\
1977 .\end{array}$ \\
\hline Molybdenum & $\mathrm{H} 2 \mathrm{MoO} 4$ & native soil microflora & loam & 7 & 2.9 & 0.1 & Arylsulfatase activity & & $\begin{array}{r}239.8 \\
\text { LCT }\end{array}$ & 40 & $\begin{array}{l}\text { Al-Khafaji \& } \\
\text { Tabatabai. } 1979 .\end{array}$ \\
\hline Molybdenum & $\mathrm{H} 2 \mathrm{MoO} 4$ & native soil microflora & clay loam & 8 & 3.2 & 0.1 & Arylsulfatase activity & & $\begin{array}{r}239.8 \\
\text { LCT }\end{array}$ & 26 & $\begin{array}{l}\text { Al-Khafaji \& } \\
\text { Tabatabai. } 1979 .\end{array}$ \\
\hline Molybdenum & $\mathrm{H} 2 \mathrm{MoO} 4$ & native soil microflora & loam & 6 & 2.6 & 0.1 & $\begin{array}{l}\text { Acid phosphatase } \\
\text { activity }\end{array}$ & & $\begin{array}{r}239.8 \\
\text { LCT }\end{array}$ & 69 & $\begin{array}{l}\text { Juma \& Tabatabai. } \\
1977 .\end{array}$ \\
\hline Molybdenum & $\mathrm{H} 2 \mathrm{MoO} 4$ & native soil microflora & silty clay & 7 & 2 & 20 & $\mathrm{~N}$ mineralization & & $\begin{array}{r}480 \\
\mathrm{LCT}\end{array}$ & 22 & $\begin{array}{l}\text { Liang \& Tabatabai. } \\
1977 .\end{array}$ \\
\hline Molybdenum & $\mathrm{H} 2 \mathrm{MoO} 4$ & native soil microflora & clay loam & 8 & 4 & 20 & $\mathrm{~N}$ mineralization & & $\begin{array}{r}480 \\
\text { LCT }\end{array}$ & 22 & $\begin{array}{l}\text { Liang \& Tabatabai. } \\
1977 .\end{array}$ \\
\hline Molybdenum & $\mathrm{H} 2 \mathrm{MoO} 4$ & native soil microflora & $\begin{array}{l}\text { silty clay } \\
\text { loam }\end{array}$ & 7 & 6 & 20 & $\mathrm{~N}$ mineralization & & $\begin{array}{r}480 \\
\mathrm{LCT}\end{array}$ & 54 & $\begin{array}{l}\text { Liang \& Tabatabai. } \\
1977 .\end{array}$ \\
\hline Molybdenum & H2MoO4 & native soil microflora & clay loam & 6 & 2.7 & 0.1 & Arylsulfatase activity & & $\begin{array}{l}2398 \\
\mathrm{LCT}\end{array}$ & 63 & $\begin{array}{l}\text { Al-Khafaji \& } \\
\text { Tabatabai. } 1979 .\end{array}$ \\
\hline Molybdenum & $\mathrm{H} 2 \mathrm{MoO} 4$ & native soil microflora & clay loam & 8 & 3.7 & 0.1 & $\begin{array}{l}\text { Alkaline \& acid phosphatase } \\
\text { activities }\end{array}$ & & $\begin{array}{l}2398 \\
\mathrm{LCT}\end{array}$ & $\begin{array}{r}25 \\
41\end{array}$ & $\begin{array}{l}\text { Juma \& Tabatabai. } \\
1977 .\end{array}$ \\
\hline
\end{tabular}


Table B.1 (continued)

\begin{tabular}{|c|c|c|c|c|c|c|c|c|c|c|c|}
\hline CHEMICAL & $\begin{array}{c}\text { CHEMICAL } \\
\text { FORM }\end{array}$ & ORGANISMS & $\begin{array}{l}\text { GROWTH } \\
\text { MEDIUM } \\
\end{array}$ & $\mathrm{pH}$ & $\% \mathrm{OC}$ & $\begin{array}{l}\text { EXP } \\
\text { (D) }\end{array}$ & $\begin{array}{c}\text { RESPONSE } \\
\text { PARAMETER } \\
\end{array}$ & NOEC & LOEC & $\begin{array}{c}\% \\
\text { DEC } \\
\end{array}$ & REFERENCE \\
\hline Molybdenum & $\mathrm{H} 2 \mathrm{MoO} 4$ & native soil microflora & loam & 7 & 5.5 & 0.1 & $\begin{array}{l}\text { Acid phosphatase } \\
\text { activity }\end{array}$ & & $\begin{array}{l}2398 \\
\text { LCT }\end{array}$ & 68 & $\begin{array}{l}\text { Juma \& Tabatabai. } \\
1977 .\end{array}$ \\
\hline Molybdenum & $\mathrm{H} 2 \mathrm{MoO} 4$ & native soil microflora & loam & 7 & 5.5 & 0.1 & $\begin{array}{l}\text { Alkaline phosphatase } \\
\text { activity }\end{array}$ & 239.8 & 2398 & 22 & $\begin{array}{l}\text { Juma \& Tabatabai. } \\
1977 .\end{array}$ \\
\hline Nickel & NiSO4 & native soil microflora & sand & 6 & 2 & 42 & Respiration & & $\begin{array}{r}10 \\
\text { LCT }\end{array}$ & 22 & $\begin{array}{l}\text { Giashuddin \& } \\
\text { Cornfield. } 1979 .\end{array}$ \\
\hline Nickel & NiSO4 & native soil microflora & $\begin{array}{l}\text { surface } \\
\text { soil }\end{array}$ & & 1.3 & 1 & Dehydrogenase activity & & $\begin{array}{r}30 \\
\text { LCT }\end{array}$ & 39 & Rogers \& Li. 1985. \\
\hline Nickel & $\mathrm{NiO}$ & native soil microflora & sand & 6 & 2 & 42 & Respiration & & $\begin{array}{r}50 \\
\mathrm{LCT}\end{array}$ & 22 & $\begin{array}{l}\text { Giashuddin \& } \\
\text { Cornfield. } 1979 .\end{array}$ \\
\hline Nickel & $\mathrm{NiCl} 2$ & Aspergillus clavatus & $\begin{array}{l}\text { sandy } \\
\text { loam }\end{array}$ & 5 & 3 & 7 & Growth rate & 10 & 50 & 36 & $\begin{array}{l}\text { Babich \& Stotzky. } \\
1982 .\end{array}$ \\
\hline Nickel & $\mathrm{NiCl} 2$ & native soil microflora & silt loam & 8 & 1.2 & 548 & Arylsulfatase activity & & $\begin{array}{r}92 \\
\text { ED50 }\end{array}$ & 50 & $\begin{array}{l}\text { Haanstra \& } \\
\text { Doelman. } 1991 .\end{array}$ \\
\hline Nickel & $\mathrm{NiCl} 2$ & native soil microflora & sand & 7 & 0.8 & 548 & Arylsulfatase activity & & $\begin{array}{r}99 \\
\text { ED50 }\end{array}$ & 50 & $\begin{array}{l}\text { Haanstra \& } \\
\text { Doelman. } 1991 .\end{array}$ \\
\hline Nickel & NiSO4 & $\begin{array}{l}\text { Agrobacteerium } \\
\text { radiobacter }\end{array}$ & $\begin{array}{l}\text { sandy } \\
\text { loam }\end{array}$ & 5 & 3 & 7 & Growth & & $\begin{array}{r}250 \\
\text { LCT }\end{array}$ & 98 & $\begin{array}{l}\text { Babich \& Stotzky. } \\
1982 .\end{array}$ \\
\hline Nickel & NiSO4 & Proteus vulgaris & $\begin{array}{l}\text { sandy } \\
\text { loam }\end{array}$ & 5 & 3 & 7 & Growth & & $\begin{array}{r}250 \\
\mathrm{LCT}\end{array}$ & 54 & $\begin{array}{l}\text { Babich \& Stotzky. } \\
1982 .\end{array}$ \\
\hline Nickel & NiSO4 & Bacillus megaterium & $\begin{array}{l}\text { sandy } \\
\text { loam }\end{array}$ & 5 & 3 & 7 & Growth & & $\begin{array}{r}250 \\
\text { LCT }\end{array}$ & 100 & $\begin{array}{l}\text { Babich \& Stotzky. } \\
1982 .\end{array}$ \\
\hline
\end{tabular}


Table B.1 (continued)

\begin{tabular}{|c|c|c|c|c|c|c|c|c|c|c|c|}
\hline CHEMICAL & $\begin{array}{c}\text { CHEMICAL } \\
\text { FORM } \\
\end{array}$ & ORGANISMS & $\begin{array}{l}\text { GROWTH } \\
\text { MEDIUM } \\
\end{array}$ & $\mathrm{pH}$ & $\% O C$ & $\begin{array}{c}\operatorname{EXP} \\
\text { (D) }\end{array}$ & $\begin{array}{c}\text { RESPONSE } \\
\text { PARAMETER } \\
\end{array}$ & NOEC & LOEC & $\begin{array}{c}\% \\
\text { DEC } \\
\end{array}$ & REFERENCE \\
\hline Nickel & $\mathrm{NiSO} 4$ & Cryptococcus terreus & $\begin{array}{l}\text { sandy } \\
\text { loam }\end{array}$ & 5 & 3 & 7 & Growth & & $\begin{array}{r}250 \\
\mathrm{LCT}\end{array}$ & 73 & $\begin{array}{l}\text { Babich \& Stotzky. } \\
1982 .\end{array}$ \\
\hline Nickel & $\mathrm{NiSO} 4$ & Torulopsis glabrata & $\begin{array}{l}\text { sandy } \\
\text { loam }\end{array}$ & 5 & 3 & 7 & Growth & & $\begin{array}{r}250 \\
\mathrm{LCT}\end{array}$ & 84 & $\begin{array}{l}\text { Babich \& Stotzky. } \\
1982 .\end{array}$ \\
\hline Nickel & $\mathrm{NiO}$ & native soil microflora & sand & 7 & 2 & 42 & Respiration & 50 & 250 & 33 & $\begin{array}{l}\text { Giashuddin \& } \\
\text { Cornfield. } 1979 .\end{array}$ \\
\hline Nickel & $\mathrm{NiCl} 2$ & Aspergillus flavus & $\begin{array}{l}\text { sandy } \\
\text { loam }\end{array}$ & 5 & 3 & 7 & Growth rate & 100 & 250 & 30 & $\begin{array}{l}\text { Babich \& Stotzky. } \\
1982 .\end{array}$ \\
\hline Nickel & $\mathrm{NiCl} 2$ & $\begin{array}{l}\text { Penicillium } \\
\text { vermiculatum }\end{array}$ & $\begin{array}{l}\text { sandy } \\
\text { loam }\end{array}$ & 5 & 3 & 7 & Growth rate & 100 & 250 & 41 & $\begin{array}{l}\text { Babich \& Stotzky. } \\
1982 .\end{array}$ \\
\hline Nickel & $\mathrm{NiCl} 2$ & Aspergillus flavipes & $\begin{array}{l}\text { sandy } \\
\text { loam }\end{array}$ & 5 & 3 & 7 & Growth rate & 250 & 500 & 98 & $\begin{array}{l}\text { Babich \& Stotzky. } \\
1982 .\end{array}$ \\
\hline Nickel & $\mathrm{NiCl} 2$ & Aspergillus niger & $\begin{array}{l}\text { sandy } \\
\text { loam }\end{array}$ & 5 & 3 & 7 & Growth rate & 250 & 500 & 42 & $\begin{array}{l}\text { Babich \& Stotzky. } \\
1982 .\end{array}$ \\
\hline Nickel & $\mathrm{NiCl} 2$ & Rhizopus stolonifer & $\begin{array}{l}\text { sandy } \\
\text { loam }\end{array}$ & 5 & 3 & 7 & Growth rate & 250 & 500 & 84 & $\begin{array}{l}\text { Babich \& Stotzky. } \\
1982 .\end{array}$ \\
\hline Nickel & $\mathrm{NiCl} 2$ & Gliocladium sp. & $\begin{array}{l}\text { sandy } \\
\text { loam }\end{array}$ & 5 & 3 & 7 & Growth rate & 250 & 500 & 23 & $\begin{array}{l}\text { Babich \& Stotzky. } \\
1982 .\end{array}$ \\
\hline Nickel & $\mathrm{NiSO} 4$ & Serratia marcescens & $\begin{array}{l}\text { sandy } \\
\text { loam }\end{array}$ & 5 & 3 & 7 & Growth & 250 & 500 & 87 & $\begin{array}{l}\text { Babich \& Stotzky. } \\
1982 .\end{array}$ \\
\hline Nickel & $\mathrm{NiSO} 4$ & Nocardia rhodochrous & $\begin{array}{l}\text { sandy } \\
\text { loam }\end{array}$ & 5 & 3 & 7 & Growth & 250 & 500 & 25 & $\begin{array}{l}\text { Babich \& Stotzky. } \\
1982 .\end{array}$ \\
\hline
\end{tabular}


Table B.1 (continued)

\begin{tabular}{|c|c|c|c|c|c|c|c|c|c|c|c|}
\hline CHEMICAL & $\begin{array}{c}\text { CHEMICAL } \\
\text { FORM } \\
\end{array}$ & ORGANISMS & $\begin{array}{l}\text { GROWTH } \\
\text { MEDIUM } \\
\end{array}$ & $\mathrm{pH}$ & $\% O C$ & $\begin{array}{l}\operatorname{EXP} \\
\text { (D) }\end{array}$ & $\begin{array}{c}\text { RESPONSE } \\
\text { PARAMETER }\end{array}$ & NOEC & LOEC & $\begin{array}{c}\% \\
\text { DEC }\end{array}$ & REFERENCE \\
\hline Nickel & $\mathrm{NiSO} 4$ & Aspergillus flavipes & $\begin{array}{l}\text { sandy } \\
\text { loam }+ \\
\text { montmorill }\end{array}$ & 6 & 2.5 & 7 & Growth & & $\begin{array}{r}750 \\
\text { LCT }\end{array}$ & 44 & $\begin{array}{l}\text { Babich \& Stotzky. } \\
1982 .\end{array}$ \\
\hline Nickel & $\mathrm{NiSO} 4$ & Aspergillus clavatus & $\begin{array}{l}\text { sandy } \\
\text { loam }+ \\
\text { mont }\end{array}$ & 6 & 2.5 & 7 & Growth & & $\begin{array}{r}750 \\
\text { LCT }\end{array}$ & 31 & $\begin{array}{l}\text { Babich \& Stotzky. } \\
1982 .\end{array}$ \\
\hline Nickel & $\mathrm{NiSO} 4$ & $\begin{array}{l}\text { Penicillium } \\
\text { vermiculatum }\end{array}$ & $\begin{array}{l}\text { sandy } \\
\text { loam }+ \\
\text { mont }\end{array}$ & 6 & 2.5 & 7 & Growth & & $\begin{array}{r}750 \\
\text { LCT }\end{array}$ & 27 & $\begin{array}{l}\text { Babich \& Stotzky. } \\
1982 .\end{array}$ \\
\hline Nickel & $\mathrm{NiSO} 4$ & Trichoderma viride & $\begin{array}{l}\text { sandy } \\
\text { loam }+ \\
\text { mont }\end{array}$ & 6 & 2.5 & 7 & Growth & & $\begin{array}{r}750 \\
\text { LCT }\end{array}$ & 40 & $\begin{array}{l}\text { Babich \& Stotzky. } \\
1982 .\end{array}$ \\
\hline Nickel & $\mathrm{NiSO} 4$ & Aspergillus flavipes & $\begin{array}{l}\text { sandy } \\
\text { loam+ } \\
\text { kaol }\end{array}$ & 6 & 2.5 & 7 & Growth & & $\begin{array}{r}750 \\
\text { LCT }\end{array}$ & 64 & $\begin{array}{l}\text { Babich \& Stotzky. } \\
1982 .\end{array}$ \\
\hline Nickel & $\mathrm{NiSO} 4$ & Aspergillus clavatus & $\begin{array}{l}\text { sandy } \\
\text { loam+ } \\
\text { kaol }\end{array}$ & 6 & 2.5 & 7 & Growth & & $\begin{array}{r}750 \\
\text { LCT }\end{array}$ & 64 & $\begin{array}{l}\text { Babich \& Stotzky. } \\
1982 .\end{array}$ \\
\hline Nickel & $\mathrm{NiSO} 4$ & Rhizopus stolonifer & $\begin{array}{l}\text { sandy } \\
\text { loam }+ \\
\text { kaol }\end{array}$ & 6 & 2.5 & 7 & Growth & & $\begin{array}{r}750 \\
\text { LCT }\end{array}$ & 54 & $\begin{array}{l}\text { Babich \& Stotzky. } \\
1982 .\end{array}$ \\
\hline Nickel & $\mathrm{NiSO} 4$ & $\begin{array}{l}\text { Penicillium } \\
\text { vermiculatum }\end{array}$ & $\begin{array}{l}\text { sandy } \\
\text { loam }+ \\
\text { kaol }\end{array}$ & 6 & 2.5 & 7 & Growth & & $\begin{array}{r}750 \\
\text { LCT }\end{array}$ & 89 & $\begin{array}{l}\text { Babich \& Stotzky. } \\
1982 .\end{array}$ \\
\hline
\end{tabular}


Table B.1 (continued)

\begin{tabular}{|c|c|c|c|c|c|c|c|c|c|c|c|}
\hline CHEMICAL & $\begin{array}{c}\text { CHEMICAL } \\
\text { FORM } \\
\end{array}$ & ORGANISMS & $\begin{array}{l}\text { GROWTH } \\
\text { MEDIUM } \\
\end{array}$ & $\mathrm{pH}$ & $\% O C$ & $\begin{array}{l}\text { EXP } \\
\text { (D) }\end{array}$ & $\begin{array}{c}\text { RESPONSE } \\
\text { PARAMETER } \\
\end{array}$ & NOEC & LOEC & $\begin{array}{c}\% \\
\mathrm{DEC}\end{array}$ & REFERENCE \\
\hline Nickel & $\mathrm{NiSO} 4$ & Trichoderma viride & $\begin{array}{l}\text { sandy } \\
\text { loam + } \\
\text { kaol }\end{array}$ & 6 & 2.5 & 7 & Growth & & $\begin{array}{r}750 \\
\text { LCT }\end{array}$ & 73 & $\begin{array}{l}\text { Babich \& Stotzky. } \\
\text { 1982. }\end{array}$ \\
\hline Nickel & $\mathrm{NiSO} 4$ & Aspergillus flavipes & $\begin{array}{l}\text { sandy } \\
\text { loam }\end{array}$ & 5 & 3 & 7 & Growth rate & & $\begin{array}{r}750 \\
\mathrm{LCT}\end{array}$ & 93 & $\begin{array}{l}\text { Babich \& Stotzky. } \\
1982 .\end{array}$ \\
\hline Nickel & $\mathrm{NiSO} 4$ & Aspergillus clavatus & $\begin{array}{l}\text { sandy } \\
\text { loam }\end{array}$ & 5 & 3 & 7 & Growth rate & & $\begin{array}{r}750 \\
\text { LCT }\end{array}$ & 84 & $\begin{array}{l}\text { Babich \& Stotzky. } \\
1982 .\end{array}$ \\
\hline Nickel & NiSO4 & Rhizopus stolonifer & $\begin{array}{l}\text { sandy } \\
\text { loam }\end{array}$ & 5 & 3 & 7 & Growth rate & & $\begin{array}{r}750 \\
\mathrm{LCT}\end{array}$ & 78 & $\begin{array}{l}\text { Babich \& Stotzky. } \\
1982 .\end{array}$ \\
\hline Nickel & $\mathrm{NiSO} 4$ & $\begin{array}{l}\text { Penicillium } \\
\text { vermiculatum }\end{array}$ & $\begin{array}{l}\text { sandy } \\
\text { loam }\end{array}$ & 5 & 3 & 7 & Growth rate & & $\begin{array}{r}750 \\
\mathrm{LCT}\end{array}$ & 82 & $\begin{array}{l}\text { Babich \& Stotzky. } \\
1982 .\end{array}$ \\
\hline Nickel & $\mathrm{NiSO} 4$ & Trichoderma viride & $\begin{array}{l}\text { sandy } \\
\text { loam }\end{array}$ & 5 & 3 & 7 & Growth rate & & $\begin{array}{r}750 \\
\mathrm{LCT}\end{array}$ & 85 & $\begin{array}{l}\text { Babich \& Stotzky. } \\
1982 .\end{array}$ \\
\hline Nickel & NiSO4 & Gliocladium sp. & $\begin{array}{l}\text { sandy } \\
\text { loam }\end{array}$ & 5 & 3 & 7 & Growth rate & & $\begin{array}{r}750 \\
\text { LCT }\end{array}$ & 52 & $\begin{array}{l}\text { Babich \& Stotzky. } \\
1982 .\end{array}$ \\
\hline Nickel & $\mathrm{NiSO} 4$ & Bacillus cereus & $\begin{array}{l}\text { sandy } \\
\text { loam }\end{array}$ & 5 & 3 & 7 & Growth & 500 & 750 & 32 & $\begin{array}{l}\text { Babich \& Stotzky. } \\
1982 .\end{array}$ \\
\hline Nickel & $\mathrm{NiSO} 4$ & Rhodotorula rubra & $\begin{array}{l}\text { sandy } \\
\text { loam }\end{array}$ & 5 & 3 & 7 & Growth & 500 & 750 & 29 & $\begin{array}{l}\text { Babich \& Stotzky. } \\
1982 .\end{array}$ \\
\hline Nickel & $\mathrm{NiCl} 2$ & Trichoderma viride & $\begin{array}{l}\text { sandy } \\
\text { loam }\end{array}$ & 5 & 3 & 7 & Growth rate & 500 & 750 & 85 & $\begin{array}{l}\text { Babich \& Stotzky. } \\
1982 .\end{array}$ \\
\hline Nickel & $\mathrm{NiCl} 2$ & native soil microflora & sand & 7 & 0.8 & 548 & Phosphatase activity & & $\begin{array}{r}769 \\
\text { ED50 }\end{array}$ & 50 & $\begin{array}{l}\text { Doelman \& } \\
\text { Haanstra. } 1989 .\end{array}$ \\
\hline
\end{tabular}


Table B.1 (continued)

\begin{tabular}{|c|c|c|c|c|c|c|c|c|c|c|c|}
\hline CHEMICAL & $\begin{array}{c}\text { CHEMICAL } \\
\text { FORM } \\
\end{array}$ & ORGANISMS & $\begin{array}{l}\text { GROWTH } \\
\text { MEDIUM } \\
\end{array}$ & $\mathrm{pH}$ & $\% O C$ & $\begin{array}{l}\operatorname{EXP} \\
\text { (D) }\end{array}$ & $\begin{array}{c}\text { RESPONSE } \\
\text { PARAMETER } \\
\end{array}$ & NOEC & LOEC & $\begin{array}{c}\% \\
\text { DEC }\end{array}$ & REFERENCE \\
\hline Nickel & NiSO4 & Bacillus megaterium & $\begin{array}{l}\text { sandy } \\
\text { loam }\end{array}$ & 8 & 1 & & Growth & 750 & 1000 & 22 & $\begin{array}{l}\text { Babich \& Stotzky. } \\
1982 .\end{array}$ \\
\hline Nickel & $\mathrm{NiSO} 4$ & Cryptococcus terreus & $\begin{array}{l}\text { sandy } \\
\text { loam }\end{array}$ & 8 & 1 & & Growth & 750 & 1000 & 21 & $\begin{array}{l}\text { Babich \& Stotzky. } \\
1982 .\end{array}$ \\
\hline Nickel & $\mathrm{NiCl} 2$ & native soil microflora & sand & 7 & 0.8 & 42 & Phosphatase activity & & $\begin{array}{r}1109 \\
\text { ED50 }\end{array}$ & 50 & $\begin{array}{l}\text { Doelman \& } \\
\text { Haanstra. } 1989 .\end{array}$ \\
\hline Nickel & $\mathrm{NiCl} 2$ & native soil microflora & clay loam & 6 & 2.7 & 0.1 & Arylsulfatase activity & & $\begin{array}{l}1468 \\
\text { LCT }\end{array}$ & 26 & $\begin{array}{l}\text { Al-Khafaji \& } \\
\text { Tabatabai. } 1979 .\end{array}$ \\
\hline Nickel & $\mathrm{NiCl} 2$ & native soil microflora & clay loam & 8 & 3.7 & 0.1 & $\begin{array}{l}\text { Alkaline phosphatase } \\
\text { activity }\end{array}$ & & $\begin{array}{l}1468 \\
\text { LCT }\end{array}$ & 22 & $\begin{array}{l}\text { Juma \& Tabatabai. } \\
1977 .\end{array}$ \\
\hline Nickel & $\mathrm{NiCl} 2$ & native soil microflora & loam & 7 & 5.5 & 0.1 & $\begin{array}{l}\text { Acid phosphatase } \\
\text { activity }\end{array}$ & & $\begin{array}{l}1468 \\
\text { LCT }\end{array}$ & 21 & $\begin{array}{l}\text { Juma \& Tabatabai. } \\
1977 .\end{array}$ \\
\hline Nickel & $\mathrm{NiCl} 2$ & native soil microflora & loam & 6 & 2.6 & 0.1 & $\begin{array}{l}\text { Acid phosphatase } \\
\text { activity }\end{array}$ & 146.8 & 1468 & 23 & $\begin{array}{l}\text { Juma \& Tabatabai. } \\
1977 .\end{array}$ \\
\hline Nickel & $\mathrm{NiCl} 2$ & native soil microflora & sand & 7 & 0.8 & 42 & Arylsulfatase activity & & $\begin{array}{r}2119 \\
\text { ED50 }\end{array}$ & 50 & $\begin{array}{l}\text { Haanstra \& } \\
\text { Doelman. } 1991 .\end{array}$ \\
\hline Nickel & $\mathrm{NiCl} 2$ & native soil microflora & silt loam & 8 & 1.2 & 548 & Phosphatase activity & & $\begin{array}{r}2131 \\
\text { ED50 }\end{array}$ & 50 & $\begin{array}{l}\text { Doelman \& } \\
\text { Haanstra. } 1989 .\end{array}$ \\
\hline Nickel & $\mathrm{NiCl} 2$ & native soil microflora & $\begin{array}{l}\text { sandy } \\
\text { loam }\end{array}$ & 6 & 2.8 & 42 & Arylsulfatase activity & & $\begin{array}{r}2348 \\
\text { ED50 }\end{array}$ & 50 & $\begin{array}{l}\text { Haanstra \& } \\
\text { Doelman. } 1991 .\end{array}$ \\
\hline Nickel & $\mathrm{NiCl} 2$ & native soil microflora & clay & 8 & 1.6 & 548 & Arylsulfatase activity & & $\begin{array}{r}2436 \\
\text { ED50 }\end{array}$ & 50 & $\begin{array}{l}\text { Haanstra \& } \\
\text { Doelman. } 1991 .\end{array}$ \\
\hline Nickel & $\mathrm{NiCl} 2$ & native soil microflora & silt loam & 8 & 1.2 & 42 & Phosphatase activity & & $\begin{array}{r}4232 \\
\text { ED50 }\end{array}$ & 50 & $\begin{array}{l}\text { Doelman \& } \\
\text { Haanstra. } 1989 .\end{array}$ \\
\hline
\end{tabular}


Table B.1 (continued)

\begin{tabular}{|c|c|c|c|c|c|c|c|c|c|c|c|}
\hline CHEMICAL & $\begin{array}{c}\text { CHEMICAL } \\
\text { FORM } \\
\end{array}$ & ORGANISMS & $\begin{array}{l}\text { GROWTH } \\
\text { MEDIUM } \\
\end{array}$ & $\mathrm{pH}$ & $\% O C$ & $\begin{array}{l}\operatorname{EXP} \\
\text { (D) }\end{array}$ & $\begin{array}{c}\text { RESPONSE } \\
\text { PARAMETER } \\
\end{array}$ & NOEC & LOEC & $\begin{array}{c}\% \\
\text { DEC }\end{array}$ & REFERENCE \\
\hline Nickel & $\mathrm{NiCl} 2$ & native soil microflora & silt loam & 8 & 1.2 & 42 & Arylsulfatase activity & & $\begin{array}{r}5400 \\
\text { ED50 }\end{array}$ & 50 & $\begin{array}{l}\text { Haanstra \& } \\
\text { Doelman. } 1991 .\end{array}$ \\
\hline Nickel & $\mathrm{NiCl} 2$ & native soil microflora & $\begin{array}{l}\text { sandy } \\
\text { loam }\end{array}$ & 6 & 2.8 & 42 & Phosphatase activity & & $\begin{array}{r}5688 \\
\text { ED50 }\end{array}$ & 50 & $\begin{array}{l}\text { Doelman \& } \\
\text { Haanstra. } 1989 .\end{array}$ \\
\hline Nickel & $\mathrm{NiCl} 2$ & native soil microflora & clay & 8 & 1.6 & 42 & Phosphatase activity & & $\begin{array}{r}6516 \\
\text { ED50 }\end{array}$ & 50 & $\begin{array}{l}\text { Doelman \& } \\
\text { Haanstra. } 1989 .\end{array}$ \\
\hline Nickel & $\mathrm{NiCl} 2$ & native soil microflora & $\begin{array}{l}\text { sandy } \\
\text { loam }\end{array}$ & 6 & 2.8 & 548 & Phosphatase activity & & $\begin{array}{r}8042 \\
\text { ED50 }\end{array}$ & 50 & $\begin{array}{l}\text { Doelman \& } \\
\text { Haanstra. } 1989 .\end{array}$ \\
\hline Nickel & $\mathrm{NiCl} 2$ & native soil microflora & sandy peat & 4 & 6.4 & 548 & Arylsulfatase activity & & $\begin{array}{r}8101 \\
\text { ED50 }\end{array}$ & 50 & $\begin{array}{l}\text { Haanstra \& } \\
\text { Doelman. } 1991 .\end{array}$ \\
\hline Selenium & $\mathrm{H} 2 \mathrm{SeO} 3$ & native soil microflora & loam & 7 & 2.9 & 0.1 & Arylsulfatase activity & & $\begin{array}{r}197.5 \\
\text { LCT }\end{array}$ & 21 & $\begin{array}{l}\text { Al-Khafaji \& } \\
\text { Tabatabai. } 1979 .\end{array}$ \\
\hline Selenium & $\mathrm{SeO} 2$ & native soil microflora & $\begin{array}{l}\text { soil/litter } \\
\text { microcosm }\end{array}$ & & & & Respiration & & $\begin{array}{r}484 \\
\text { LCT }\end{array}$ & 43 & $\begin{array}{l}\text { Lighthart et al. } \\
1977 .\end{array}$ \\
\hline Selenium & $\mathrm{H} 2 \mathrm{SeO} 3$ & native soil microflora & clay loam & 6 & 2.7 & 0.1 & Arylsulfatase activity & & $\begin{array}{l}1975 \\
\mathrm{LCT}\end{array}$ & 32 & $\begin{array}{l}\text { Al-Khafaji \& } \\
\text { Tabatabai. } 1979 .\end{array}$ \\
\hline Selenium & $\mathrm{H} 2 \mathrm{SeO} 3$ & native soil microflora & loam & 7 & 5.3 & 0.1 & Arylsulfatase activity & & $\begin{array}{l}1975 \\
\text { LCT }\end{array}$ & 26 & $\begin{array}{l}\text { Al-Khafaji \& } \\
\text { Tabatabai. } 1979 .\end{array}$ \\
\hline Selenium & $\mathrm{H} 2 \mathrm{SeO} 3$ & native soil microflora & clay loam & 8 & 3.7 & 0.1 & $\begin{array}{l}\text { Alkaline \& } \\
\text { acid phosphatase } \\
\text { activities }\end{array}$ & & $\begin{array}{l}1975 \\
\mathrm{LCT}\end{array}$ & $\begin{array}{r}30 \\
39\end{array}$ & $\begin{array}{l}\text { Juma \& Tabatabai. } \\
1977 .\end{array}$ \\
\hline Selenium & $\mathrm{H} 2 \mathrm{SeO} 3$ & native soil microflora & loam & 7 & 5.5 & 0.1 & $\begin{array}{l}\text { Acid phosphatase } \\
\text { activity }\end{array}$ & & $\begin{array}{l}1975 \\
\mathrm{LCT}\end{array}$ & 34 & $\begin{array}{l}\text { Juma \& Tabatabai. } \\
1977 .\end{array}$ \\
\hline
\end{tabular}


Table B.1 (continued)

\begin{tabular}{|c|c|c|c|c|c|c|c|c|c|c|c|}
\hline CHEMICAL & $\begin{array}{c}\text { CHEMICAL } \\
\text { FORM } \\
\end{array}$ & ORGANISMS & $\begin{array}{l}\text { GROWTH } \\
\text { MEDIUM } \\
\end{array}$ & $\mathrm{pH}$ & $\% O C$ & $\begin{array}{c}\operatorname{EXP} \\
\text { (D) }\end{array}$ & $\begin{array}{c}\text { RESPONSE } \\
\text { PARAMETER } \\
\end{array}$ & NOEC & LOEC & $\begin{array}{c}\% \\
\text { DEC }\end{array}$ & REFERENCE \\
\hline Selenium & $\mathrm{H} 2 \mathrm{SeO} 3$ & native soil microflora & $\begin{array}{l}\text { surface } \\
\text { soil }\end{array}$ & 6 & 2.6 & 0.1 & Amidase activity & 197.5 & 1975 & 27 & $\begin{array}{l}\text { Frankenberger\& } \\
\text { Tabatabai. } 1981\end{array}$ \\
\hline Selenium & $\mathrm{H} 2 \mathrm{SeO} 3$ & native soil microflora & clay loam & 8 & 3.2 & 0.1 & Arylsulfatase activity & 197.5 & 1975 & 26 & $\begin{array}{l}\text { Al-Khafaji \& } \\
\text { Tabatabai. } 1979 .\end{array}$ \\
\hline Selenium & $\mathrm{H} 2 \mathrm{SeO} 3$ & native soil microflora & loam & 6 & 2.6 & 0.1 & $\begin{array}{l}\text { Acid phosphatase } \\
\text { activity }\end{array}$ & 197.5 & 1975 & 24 & $\begin{array}{l}\text { Juma \& Tabatabai. } \\
1977 .\end{array}$ \\
\hline Selenium & $\mathrm{H} 2 \mathrm{SeO} 3$ & native soil microflora & loam & 7 & 5.5 & 0.1 & $\begin{array}{l}\text { Alkaline phosphatase } \\
\text { activity }\end{array}$ & 197.5 & 1975 & 35 & $\begin{array}{l}\text { Juma \& Tabatabai. } \\
\text { 1977. }\end{array}$ \\
\hline Silver & $\mathrm{AgSO} 4$ & native soil microflora & clay loam & 7 & 3 & 0.2 & urease activity & & $\begin{array}{r}50 \\
\text { LCT }\end{array}$ & 61 & $\begin{array}{l}\text { Bremner \& } \\
\text { Douglas. } 1971 .\end{array}$ \\
\hline Silver & AgNO3 & native soil microflora & $\begin{array}{l}\text { silty clay } \\
\text { loam }\end{array}$ & 7 & 2.2 & 0.2 & urease activity & & $\begin{array}{r}50 \\
\mathrm{LCT}\end{array}$ & 65 & $\begin{array}{l}\text { Bremner \& } \\
\text { Douglas. } 1971 .\end{array}$ \\
\hline Silver & $\mathrm{AgSO} 4$ & native soil microflora & & 7 & 2.2 & 0.2 & urease activity & & $\begin{array}{r}50 \\
\text { LCT }\end{array}$ & 63 & $\begin{array}{l}\text { Bremner \& } \\
\text { Douglas. } 1971 .\end{array}$ \\
\hline Silver & AgNO3 & native soil microflora & clay loam & 7 & 3 & 0.2 & urease activity & & $\begin{array}{r}50 \\
\text { LCT }\end{array}$ & 60 & $\begin{array}{l}\text { Bremner \& } \\
\text { Douglas. } 1971 .\end{array}$ \\
\hline Silver & $\mathrm{AgSO} 4$ & native soil microflora & loam & 7 & 2.9 & 0.1 & Arylsulfatase activity & & $\begin{array}{r}269.8 \\
\text { LCT }\end{array}$ & 53 & $\begin{array}{l}\text { Al-Khafaji \& } \\
\text { Tabatabai. } 1979 .\end{array}$ \\
\hline Silver & $\mathrm{AgSO} 4$ & native soil microflora & clay loam & 8 & 3.2 & 0.1 & Arylsulfatase activity & & $\begin{aligned} 269.8 \\
\text { LCT }\end{aligned}$ & 80 & $\begin{array}{l}\text { Al-Khafaji \& } \\
\text { Tabatabai. } 1979 .\end{array}$ \\
\hline Silver & $\mathrm{AgSO} 4$ & native soil microflora & loam & 6 & 3 & 20 & $\mathrm{~N}$ mineralization & & $\begin{array}{r}540 \\
\text { LCT }\end{array}$ & 73 & $\begin{array}{l}\text { Liang \& Tabatabai. } \\
1977 .\end{array}$ \\
\hline
\end{tabular}


Table B.1 (continued)

\begin{tabular}{|c|c|c|c|c|c|c|c|c|c|c|c|}
\hline CHEMICAL & $\begin{array}{c}\text { CHEMICAL } \\
\text { FORM } \\
\end{array}$ & ORGANISMS & $\begin{array}{l}\text { GROWTH } \\
\text { MEDIUM } \\
\end{array}$ & pH & $\% O C$ & $\begin{array}{l}\operatorname{Exp} \\
\text { (D) }\end{array}$ & $\begin{array}{c}\text { RESPONSE } \\
\text { PARAMETER } \\
\end{array}$ & NOEEC & LOEC & $\begin{array}{c}\% \\
\text { DEC } \\
\end{array}$ & REFERENCE \\
\hline Silver & $\mathrm{AgSO} 4$ & native soil microflora & silty clay & 7 & 3 & 20 & $\mathrm{~N}$ mineralization & & $\begin{array}{r}540 \\
\mathrm{LCT}\end{array}$ & 41 & $\begin{array}{l}\text { Liang \& Tabatabai. } \\
1977 .\end{array}$ \\
\hline Silver & $\mathrm{AgSO} 4$ & native soil microflora & clay loam & 8 & 4 & 20 & $\mathrm{~N}$ mineralization & & $\begin{array}{r}540 \\
\text { LCT }\end{array}$ & 59 & $\begin{array}{l}\text { Liang \& Tabatabai. } \\
1977 .\end{array}$ \\
\hline Silver & $\mathrm{AgSO} 4$ & native soil microflora & $\begin{array}{l}\text { silty clay } \\
\text { loam }\end{array}$ & 7 & 6 & 20 & $\mathrm{~N}$ mineralization & & $\begin{array}{r}540 \\
\text { LCT }\end{array}$ & 52 & $\begin{array}{l}\text { Liang \& Tabatabai. } \\
1977 .\end{array}$ \\
\hline Silver & $\mathrm{AgSO} 4$ & native soil microflora & loam & 7 & 4.7 & 0.1 & Amidase activity & & $\begin{array}{l}2698 \\
\text { LCT }\end{array}$ & 50 & $\begin{array}{l}\text { Frankenberger\& } \\
\text { Tabatabai. } 1981\end{array}$ \\
\hline Silver & AgSO4 & native soil microflora & clay loam & 8 & 3.2 & 0.1 & Amidase activity & & $\begin{array}{l}2698 \\
\text { LCT }\end{array}$ & 53 & $\begin{array}{l}\text { Frankenberger\& } \\
\text { Tabatabai. } 1981\end{array}$ \\
\hline Silver & $\mathrm{AgSO} 4$ & native soil microflora & clay loam & 6 & 2.7 & 0.1 & Arylsulfatase activity & & $\begin{array}{l}2698 \\
\text { LCT }\end{array}$ & 94 & $\begin{array}{l}\text { Al-Khafaji \& } \\
\text { Tabatabai. } 1979 .\end{array}$ \\
\hline Silver & $\mathrm{AgSO} 4$ & native soil microflora & loam & 7 & 5.3 & 0.1 & Arylsulfatase activity & & $\begin{array}{l}2698 \\
\mathrm{LCT}\end{array}$ & 95 & $\begin{array}{l}\text { Al-Khafaji \& } \\
\text { Tabatabai. } 1979 .\end{array}$ \\
\hline Silver & $\mathrm{AgSO} 4$ & native soil microflora & clay loam & 8 & 3.7 & 0.1 & $\begin{array}{l}\text { Alkaline \& } \\
\text { acid phosphatase } \\
\text { activities }\end{array}$ & & $\begin{array}{l}2698 \\
\text { LCT }\end{array}$ & $\begin{array}{r}93 \\
38\end{array}$ & $\begin{array}{l}\text { Juma \& Tabatabai. } \\
1977 .\end{array}$ \\
\hline Silver & $\mathrm{AgSO} 4$ & native soil microflora & loam & 7 & 5.5 & 0.1 & $\begin{array}{l}\text { Alkaline phosphatase } \\
\text { activity }\end{array}$ & & $\begin{array}{l}2698 \\
\text { LCT }\end{array}$ & 28 & $\begin{array}{l}\text { Juma \& Tabatabai. } \\
1977 .\end{array}$ \\
\hline Silver & $\mathrm{AgSO} 4$ & native soil microflora & $\begin{array}{l}\text { surface } \\
\text { soil }\end{array}$ & 6 & 2.6 & 0.1 & Amidase activity & 269.8 & 2698 & 62 & $\begin{array}{l}\text { Frankenberger\& } \\
\text { Tabatabai. } 1981\end{array}$ \\
\hline Tin & $\mathrm{SnCl} 2$ & native soil microflora & clay loam & 6 & 2.7 & 0.1 & Arylsulfatase activity & & $\begin{array}{l}2968 \\
\text { LCT }\end{array}$ & 60 & $\begin{array}{l}\text { Al-Khafaji \& } \\
\text { Tabatabai. } 1979 .\end{array}$ \\
\hline
\end{tabular}


Table B.1 (continued)

\begin{tabular}{|c|c|c|c|c|c|c|c|c|c|c|c|}
\hline CHEMICAL & $\begin{array}{c}\text { CHEMICAL } \\
\text { FORM } \\
\end{array}$ & ORGANISMS & $\begin{array}{l}\text { GROWTH } \\
\text { MEDIUM } \\
\end{array}$ & $\mathrm{pH}$ & $\% O C$ & $\begin{array}{l}\operatorname{EXP} \\
(\mathrm{D}) \\
\end{array}$ & $\begin{array}{c}\text { RESPONSE } \\
\text { PARAMETER } \\
\end{array}$ & NOEC & LOEC & $\begin{array}{c}\% \\
\text { DEC } \\
\end{array}$ & REFERENCE \\
\hline Tin & $\mathrm{SnCl} 2$ & native soil microflora & loam & 7 & 5.3 & 0.1 & Arylsulfatase activity & & $\begin{array}{l}2968 \\
\text { LCT }\end{array}$ & 32 & $\begin{array}{l}\text { Al-Khafaji \& } \\
\text { Tabatabai. } 1979 .\end{array}$ \\
\hline Tin & $\mathrm{SnCl} 2$ & native soil microflora & clay loam & 8 & 3.7 & 0.1 & $\begin{array}{l}\text { Alkaline phosphatase } \\
\text { activity }\end{array}$ & & $\begin{array}{l}2968 \\
\text { LCT }\end{array}$ & 25 & $\begin{array}{l}\text { Juma \& Tabatabai. } \\
1977 .\end{array}$ \\
\hline Tin & $\mathrm{SnCl} 2$ & native soil microflora & loam & 7 & 5.5 & 0.1 & $\begin{array}{l}\text { Acid phosphatase } \\
\text { activity }\end{array}$ & & $\begin{array}{l}2968 \\
\text { LCT }\end{array}$ & 21 & $\begin{array}{l}\text { Juma \& Tabatabai. } \\
1977 .\end{array}$ \\
\hline Tin & $\mathrm{SnCl} 2$ & native soil microflora & loam & 7 & 2.9 & 0.1 & Arylsulfatase activity & 296.8 & 2968 & 45 & $\begin{array}{l}\text { Al-Khafaji \& } \\
\text { Tabatabai. } 1979 .\end{array}$ \\
\hline Tin & $\mathrm{SnCl} 2$ & native soil microflora & loam & 6 & 2.6 & 0.1 & $\begin{array}{l}\text { Acid phosphatase } \\
\text { activity }\end{array}$ & 296.8 & 2968 & 41 & $\begin{array}{l}\text { Juma \& Tabatabai. } \\
1977 .\end{array}$ \\
\hline Tin & $\mathrm{SnCl} 2$ & native soil microflora & loam & 7 & 5.5 & 0.1 & $\begin{array}{l}\text { Alkaline phosphatase } \\
\text { activity }\end{array}$ & 296.8 & 2968 & 38 & $\begin{array}{l}\text { Juma \& Tabatabai. } \\
1977 .\end{array}$ \\
\hline Titanium & TiSO4 & native soil microflora & clay loam & 6 & 2.7 & 0.1 & Arylsulfatase activity & & $\begin{array}{l}1198 \\
\text { LCT }\end{array}$ & 33 & $\begin{array}{l}\text { Al-Khafaji \& } \\
\text { Tabatabai. } 1979 .\end{array}$ \\
\hline Titanium & TiSO4 & native soil microflora & loam & 7 & 2.9 & 0.1 & Arylsulfatase activity & 119.8 & 1198 & 31 & $\begin{array}{l}\text { Al-Khafaji \& } \\
\text { Tabatabai. } 1979 .\end{array}$ \\
\hline Tungsten & Na2WO4 & native soil microflora & loam & 6 & 2.6 & 0.1 & $\begin{array}{l}\text { Acid phosphatase } \\
\text { activity }\end{array}$ & & $\begin{array}{r}459.8 \\
\text { LCT }\end{array}$ & 75 & $\begin{array}{l}\text { Juma \& Tabatabai. } \\
1977 .\end{array}$ \\
\hline Tungsten & Na2WO4 & native soil microflora & clay loam & 6 & 2.7 & 0.1 & Arylsulfatase activity & & $\begin{array}{l}4598 \\
\text { LCT }\end{array}$ & 23 & $\begin{array}{l}\text { Al-Khafaji \& } \\
\text { Tabatabai. } 1979 .\end{array}$ \\
\hline
\end{tabular}


Table B.1 (continued)

\begin{tabular}{|c|c|c|c|c|c|c|c|c|c|c|c|}
\hline CHEMICAL & $\begin{array}{c}\text { CHEMICAL } \\
\text { FORM } \\
\end{array}$ & ORGANISMS & $\begin{array}{l}\text { GROWTH } \\
\text { MEDIUM } \\
\end{array}$ & $\mathrm{pH}$ & $\% O C$ & $\begin{array}{l}\text { EXP } \\
(\mathrm{D}) \\
\end{array}$ & $\begin{array}{c}\text { RESPONSE } \\
\text { PARAMETER }\end{array}$ & NOEC & LOEC & $\begin{array}{c}\% \\
\text { DEC }\end{array}$ & REFERENCE \\
\hline Tungsten & $\mathrm{Na} 2 \mathrm{WO} 4$ & native soil microflora & clay loam & 8 & 3.7 & 0.1 & $\begin{array}{l}\text { Alkaline \& } \\
\text { acid phosphatase } \\
\text { activities }\end{array}$ & & $\begin{array}{l}4598 \\
\text { LCT }\end{array}$ & $\begin{array}{r}29 \\
45\end{array}$ & $\begin{array}{l}\text { Juma \& Tabatabai. } \\
1977 .\end{array}$ \\
\hline Tungsten & Na2WO4 & native soil microflora & loam & 7 & 5.5 & 0.1 & $\begin{array}{l}\text { Acid phosphatase } \\
\text { activity }\end{array}$ & & $\begin{array}{l}4598 \\
\text { LCT }\end{array}$ & 69 & $\begin{array}{l}\text { Juma \& Tabatabai. } \\
1977 .\end{array}$ \\
\hline Tungsten & Na2WO4 & native soil microflora & loam & 7 & 2.9 & 0.1 & Arylsulfatase activity & 459.8 & 4598 & 38 & $\begin{array}{l}\text { Al-Khafaji \& } \\
\text { Tabatabai. } 1979 .\end{array}$ \\
\hline Tungsten & $\mathrm{Na} 2 \mathrm{WO} 4$ & native soil microflora & clay loam & 8 & 3.2 & 0.1 & Arylsulfatase activity & 459.8 & 4598 & 25 & $\begin{array}{l}\text { Al-Khafaji \& } \\
\text { Tabatabai. } 1979 .\end{array}$ \\
\hline Tungsten & $\mathrm{Na} 2 \mathrm{WO} 4$ & native soil microflora & loam & 7 & 5.5 & 0.1 & $\begin{array}{l}\text { Alkaline phosphatase } \\
\text { activity }\end{array}$ & 459.8 & 4598 & 32 & $\begin{array}{l}\text { Juma \& Tabatabai. } \\
1977 .\end{array}$ \\
\hline Vanadium & V205 & native soil microflora & $\begin{array}{l}\text { soil/litter } \\
\text { microcosm }\end{array}$ & & & & Respiration & & $\begin{array}{r}23 \\
\mathrm{LCT}\end{array}$ & 21 & $\begin{array}{l}\text { Lighthart et al. } \\
1977 .\end{array}$ \\
\hline Vanadium & $\mathrm{NaVO} 3$ & native soil microflora & $\begin{array}{l}\text { Forest mor } \\
\text { (litter) }\end{array}$ & & 46 & 0.1 & $\begin{array}{l}\text { Acid phosphatase } \\
\text { activity }\end{array}$ & 30 & 50 & 40 & Tyler. 1976. \\
\hline Vanadium & VSO4 & native soil microflora & loam & 7 & 2.9 & 0.1 & Arylsulfatase activity & & $\begin{array}{r}127.3 \\
\text { LCT }\end{array}$ & 76 & $\begin{array}{l}\text { Al-Khafaji \& } \\
\text { Tabatabai. } 1979 .\end{array}$ \\
\hline Vanadium & VSO4 & native soil microflora & clay loam & 8 & 3.2 & 0.1 & Arylsulfatase activity & & $\begin{array}{r}127.3 \\
\text { LCT }\end{array}$ & 32 & $\begin{array}{l}\text { Al-Khafaji \& } \\
\text { Tabatabai. } 1979 .\end{array}$ \\
\hline Vanadium & VSO4 & native soil microflora. & loam & 6 & 2.6 & 0.1 & $\begin{array}{l}\text { Acid phosphatase } \\
\text { activity }\end{array}$ & & $\begin{array}{r}127.3 \\
\text { LCT }\end{array}$ & 30 & $\begin{array}{l}\text { Juma \& Tabatabai. } \\
1977 .\end{array}$ \\
\hline Vanadium & VSO4 & native soil microflora & clay loam & 6 & 2.7 & 0.1 & Arylsulfatase activity & & $\begin{array}{l}1273 \\
\text { LCT }\end{array}$ & 87 & $\begin{array}{l}\text { Al-Khafaji \& } \\
\text { Tabatabai. } 1979 .\end{array}$ \\
\hline
\end{tabular}


Table B.1 (continued)

\begin{tabular}{|c|c|c|c|c|c|c|c|c|c|c|c|}
\hline CHEMICAL & $\begin{array}{c}\text { CHEMICAL } \\
\text { FORM } \\
\end{array}$ & ORGANISMS & $\begin{array}{l}\text { GROWTH } \\
\text { MEDIUM } \\
\end{array}$ & $\mathrm{pH}$ & $\% O C$ & $\begin{array}{l}\exp \\
\text { (D) }\end{array}$ & $\begin{array}{c}\text { RESPONSE } \\
\text { PARAMETER } \\
\end{array}$ & NOEC & LOEC & $\begin{array}{c}\% \\
\text { DEC }\end{array}$ & REFERENCE \\
\hline Vanadium & vSO4 & native soil microflora & loam & 7 & 5.3 & 0.1 & Arylsulfatase activity & & $\begin{array}{l}1273 \\
\text { LCT }\end{array}$ & 85 & $\begin{array}{l}\text { Al-Khafaji \& } \\
\text { Tabatabai. } 1979 .\end{array}$ \\
\hline Vanadium & VSO4 & native soil microflora & clay loam & 8 & 3.7 & 0.1 & $\begin{array}{l}\text { Alkaline \& } \\
\text { acid phosphatase } \\
\text { activities }\end{array}$ & & $\begin{array}{l}1273 \\
\text { LCT }\end{array}$ & $\begin{array}{r}61 \\
45\end{array}$ & $\begin{array}{l}\text { Juma \& Tabatabai. } \\
\text { 1977. }\end{array}$ \\
\hline Vanadium & VSO4 & native soil microflora & loam & 7 & 5.5 & 0.1 & $\begin{array}{l}\text { Acid phosphatase } \\
\text { activity }\end{array}$ & & $\begin{array}{l}1273 \\
\mathrm{LCT}\end{array}$ & 55 & $\begin{array}{l}\text { Juma \& Tabatabai. } \\
1977 .\end{array}$ \\
\hline Vanadium & VSO4 & native soil microflora & loam & 7 & 5.5 & 0.1 & $\begin{array}{l}\text { Alkaline phosphatase } \\
\text { activity }\end{array}$ & 127.3 & 1273 & 60 & $\begin{array}{l}\text { Juma \& Tabatabai. } \\
1977 .\end{array}$ \\
\hline Zinc & $\mathrm{Zn}(\mathrm{NO} 3) 2$ & Pseudomonas sp. & silt loam & 7 & & 4 & Denitrification & 10 & 50 & 29 & $\begin{array}{l}\text { Bollag \& Barabasz. } \\
1979 .\end{array}$ \\
\hline Zinc & $\mathrm{ZnCl} 2$ & native soil microflora & sandy peat & 4 & 6.5 & 548 & Urease activity & & $\begin{array}{r}70 \\
\text { ED50 }\end{array}$ & 50 & $\begin{array}{l}\text { Doelman \& } \\
\text { Haanstra. } 1986 .\end{array}$ \\
\hline Zinc & $\mathrm{ZnCl} 2$ & native soil microflora & clay & 8 & 1.5 & 548 & Urease activity & & $\begin{array}{r}90 \\
\text { ED50 }\end{array}$ & 50 & $\begin{array}{l}\text { Doelman \& } \\
\text { Haanstra. } 1986 .\end{array}$ \\
\hline Zinc & $\mathrm{ZnSO4}$ & native soil microflora & $\begin{array}{l}\text { sandy } \\
\text { loam }\end{array}$ & 7 & 2 & 21 & Nitrification & & $\begin{array}{r}100 \\
\text { LCT }\end{array}$ & 57 & $\begin{array}{l}\text { Premi \& Cornfield. } \\
1969 .\end{array}$ \\
\hline Zinc & $\mathrm{ZnSO} 4$ & native soil microflora & $\begin{array}{l}\text { sandy } \\
\text { loam }\end{array}$ & 8 & 2 & 56 & Nitrification & & $\begin{array}{r}100 \\
\text { LCT }\end{array}$ & 43 & $\begin{array}{l}\text { Premi \& Cornfield. } \\
1969 / 1970 .\end{array}$ \\
\hline Zinc & $\mathrm{ZnCl} 2$ & native soil microflora & $\begin{array}{l}\text { sandy } \\
\text { loam }\end{array}$ & 6 & 3 & 548 & Urease activity & & $\begin{array}{r}110 \\
\text { ED50 }\end{array}$ & 50 & $\begin{array}{l}\text { Doelman \& } \\
\text { Haanstra. } 1986 .\end{array}$ \\
\hline Zinc & $\mathrm{ZnCl} 2$ & native soil microflora & sandy soil & 7 & 1 & 548 & Phosphatase activity & & $\begin{array}{r}170 \\
\text { ED50 }\end{array}$ & 50 & $\begin{array}{l}\text { Doelman \& } \\
\text { Haanstra. } 1989 .\end{array}$ \\
\hline
\end{tabular}


Table B.1 (continued)

\begin{tabular}{|c|c|c|c|c|c|c|c|c|c|c|c|}
\hline CHEMICAL & $\begin{array}{c}\text { CHEMICAL } \\
\text { FORM } \\
\end{array}$ & ORGANISMS & $\begin{array}{l}\text { GROWTH } \\
\text { MEDIUM } \\
\end{array}$ & $\mathrm{pH}$ & $\mathscr{H O C}$ & $\begin{array}{l}\text { EXP } \\
(D) \\
\end{array}$ & $\begin{array}{c}\text { RESPONSE } \\
\text { PARAMETER }\end{array}$ & NOEC & LOEC & $\begin{array}{c}\% \\
\text { DEC } \\
\end{array}$ & REFERENCE \\
\hline Zinc & $\mathrm{ZnCl2}$ & native soil microflora & sandy soil & 7 & 1 & 42 & Phosphatase activity & & $\begin{array}{r}220 \\
\text { ED50 }\end{array}$ & 50 & $\begin{array}{l}\text { Doelman \& } \\
\text { Haanstra. } 1989 .\end{array}$ \\
\hline Zinc & $\mathrm{Zn}(\mathrm{NO}) 2$ & native soil microflora & silt loam & 7 & & 21 & Denitrification & 100 & 250 & 31 & $\begin{array}{l}\text { Bollag \& Barabasz. } \\
1979 .\end{array}$ \\
\hline Zinc & $\mathrm{Zn}(\mathrm{NO}) 2$ & $\begin{array}{l}\text { Pseudomonas } \\
\text { denitrificans }\end{array}$ & silt loam & 7 & . & 4 & Denitrification & 100 & 250 & 22 & $\begin{array}{l}\text { Bollag \& Barabasz. } \\
1979 .\end{array}$ \\
\hline Zinc & $\mathrm{Zn}(\mathrm{NO}) 2$ & $\begin{array}{l}\text { Pseudomonas } \\
\text { aeruginosa }\end{array}$ & silt loam & 7 & & 4 & Denitrification & 100 & 250 & 35 & $\begin{array}{l}\text { Bollag \& Barabasz. } \\
1979 .\end{array}$ \\
\hline Zinc & $\mathrm{ZnCl} 2$ & native soil microflora & sandy soil & 7 & 1 & 548 & Urease activity & & $\begin{array}{r}290 \\
\text { ED50 }\end{array}$ & 50 & $\begin{array}{l}\text { Doelman \& } \\
\text { Haanstra. } 1986 .\end{array}$ \\
\hline Zinc & $\mathrm{ZnSO4}$ & native soil microflora & $\begin{array}{l}\text { surface } \\
\text { soil }\end{array}$ & & 1.3 & 1 & Dehydrogenase activity & 150 & 300 & 30 & Rogers \& Li. 1985. \\
\hline Zinc & $\mathrm{ZnCl} 2$ & native soil microflora & sandy soil & 7 & 1 & 548 & Arylsulfatase activity & & $\begin{array}{r}375 \\
\text { ED50 }\end{array}$ & 50 & $\begin{array}{l}\text { Haanstra \& } \\
\text { Doelman. } 1991 .\end{array}$ \\
\hline Zinc & $\mathrm{ZnCl2}$ & native soil microflora & sandy soil & 7 & 1 & 42 & Urease activity & & $\begin{array}{r}420 \\
\text { ED50 }\end{array}$ & 50 & $\begin{array}{l}\text { Doelman \& } \\
\text { Haanstra. } 1986 .\end{array}$ \\
\hline Zinc & $\mathrm{ZnCl} 2$ & native soil microflora & $\begin{array}{l}\text { soil/litter } \\
\text { microcosm }\end{array}$ & & & 23 & Respiration & 47 & 479 & 21 & Chaney et al. 1978. \\
\hline Zinc & $\mathrm{ZnCl} 2$ & native soil microflora & $\begin{array}{l}\text { sandy } \\
\text { loam }\end{array}$ & 6 & 3 & 42 & Urease activity & & $\begin{array}{r}480 \\
\text { ED50 }\end{array}$ & 50 & $\begin{array}{l}\text { Doelman \& } \\
\text { Haanstra. } 1986 .\end{array}$ \\
\hline Zinc & $\mathrm{Zn}(\mathrm{SO} 4) 2$ & native soil microflora & $\begin{array}{l}\text { surface } \\
\text { soil }\end{array}$ & 6 & 2 & 56 & Biomass & & $\begin{array}{r}600 \\
\text { LCT }\end{array}$ & 31 & Leita et al.1995 \\
\hline Zinc & $\mathrm{ZnCl} 2$ & native soil microflora & sandy soil & 7 & 1 & 42 & Arylsulfatase activity & & $\begin{array}{r}909 \\
\text { ED50 }\end{array}$ & 50 & $\begin{array}{l}\text { Haanstra \& } \\
\text { Doelman. } 1991 .\end{array}$ \\
\hline
\end{tabular}


Table B.1 (continued)

\begin{tabular}{|c|c|c|c|c|c|c|c|c|c|c|c|}
\hline CHEMICAL & $\begin{array}{c}\text { CHEMICAL } \\
\text { FORM } \\
\end{array}$ & ORGANISMS & $\begin{array}{l}\text { GROWTH } \\
\text { MEDIUM } \\
\end{array}$ & $\mathrm{pH}$ & $\% O C$ & $\begin{array}{l}\text { EXP } \\
(D)\end{array}$ & $\begin{array}{c}\text { RESPONSE } \\
\text { PARAMETER } \\
\end{array}$ & NOEC & LOEC & $\begin{array}{c}\% \\
\text { DEC } \\
\end{array}$ & REFERENCE \\
\hline Zinc & $\mathrm{ZnCl} 2$ & native soil microflora & $\begin{array}{l}\text { sandy } \\
\text { loam }\end{array}$ & 6 & 3 & 548 & Arylsulfatase activity & & $\begin{array}{r}948 \\
\text { ED50 }\end{array}$ & 50 & $\begin{array}{l}\text { Haanstra \& } \\
\text { Doelman. } 1991 .\end{array}$ \\
\hline Zinc & $\mathrm{ZnO}$ & native soil microflora & sandy soil & 7 & & 84 & $\begin{array}{l}N \text { mineralization \& } \\
\text { nitrification }\end{array}$ & & $\begin{array}{l}1000 \\
\text { LCT }\end{array}$ & $\begin{array}{r}28 \\
31\end{array}$ & $\begin{array}{l}\text { Bhuiya \& } \\
\text { Cornfield. } 1976 .\end{array}$ \\
\hline Zinc & Zno & native soil microflora & sandy soil & 8 & & 42 & $\mathrm{~N}$ mineralization & & $\begin{array}{l}1000 \\
\text { LCT }\end{array}$ & 32 & $\begin{array}{l}\text { Bhuiya \& } \\
\text { Cornfield. } 1974 .\end{array}$ \\
\hline Zinc & $\mathrm{ZnCl} 2$ & native soil microflora & $\begin{array}{l}\text { Forest mor } \\
\text { (litter) }\end{array}$ & 4 & & 30 & Respiration & 200 & 1000 & 26 & $\begin{array}{l}\text { Laskowski et al. } \\
1994 .\end{array}$ \\
\hline Zinc & $\mathrm{ZnSO4}$ & native soil microflora & clay loam & 6 & 1.2 & 49 & Nitrification & 100 & 1000 & 99 & Wilson. 1977. \\
\hline Zinc & ZnSO4 & native soil microflora & $\begin{array}{l}\text { sandy } \\
\text { loam }\end{array}$ & 6 & 0.8 & 49 & Nitrification & 100 & 1000 & 98 & Wilson. 1977. \\
\hline Zinc & ZnSO4 & native soil microflora & $\begin{array}{l}\text { loamy } \\
\text { sand }\end{array}$ & 5 & 0.6 & 49 & Nitrification & 100 & 1000 & 100 & Wilson. 1977. \\
\hline Zinc & $\mathrm{ZnCl} 2$ & native soil microflora & silty loam & 8 & 1 & 42 & Urease activity & & $\begin{array}{r}1030 \\
\text { ED50 }\end{array}$ & 50 & $\begin{array}{l}\text { Doelman \& } \\
\text { Haanstra. } 1986 .\end{array}$ \\
\hline Zinc & $\mathrm{ZnCl} 2$ & native soil microflora & silty loam & 8 & 1 & 42 & Arylsulfatase activity & & $\begin{array}{r}1295 \\
\text { ED50 }\end{array}$ & 50 & $\begin{array}{l}\text { Haanstra \& } \\
\text { Doelman. } 1991 .\end{array}$ \\
\hline Zinc & $\mathrm{ZnSO} 4$ & native soil microflora & clay loam & 8 & 3.7 & 0.1 & $\begin{array}{l}\text { Alkaline \& } \\
\text { acid phosphatase } \\
\text { activities }\end{array}$ & . & $\begin{array}{l}1635 \\
\text { LCT }\end{array}$ & $\begin{array}{r}59 \\
32\end{array}$ & $\begin{array}{l}\text { Juma \& Tabatabai. } \\
1977 .\end{array}$ \\
\hline Zinc & $\mathrm{ZnSO4}$ & native soil microflora & loam & 7 & 5.5 & 0.1 & $\begin{array}{l}\text { Acid phosphatase } \\
\text { activity }\end{array}$ & & $\begin{array}{l}1635 \\
\text { LCT }\end{array}$ & 33 & $\begin{array}{l}\text { Juma \& Tabatabai. } \\
1977 .\end{array}$ \\
\hline Zinc & $\mathrm{ZnCl} 2$ & native soil microflora & loam & 7 & 2.9 & 0.1 & Arylsulfatase activity & 163.5 & 1635 & 33 & $\begin{array}{l}\text { Al-Khafaji \& } \\
\text { Tabatabai. } 1979 .\end{array}$ \\
\hline
\end{tabular}


Table B.1 (continued)

\begin{tabular}{|c|c|c|c|c|c|c|c|c|c|c|c|}
\hline CHEMICAL & $\begin{array}{c}\text { CHEMICAL } \\
\text { FORM }\end{array}$ & ORGANISMS & $\begin{array}{l}\text { GROWTH } \\
\text { MEDIUM } \\
\end{array}$ & pH & $\% O C$ & $\begin{array}{l}\text { EXP } \\
\text { (D) }\end{array}$ & $\begin{array}{c}\text { RESPONSE } \\
\text { PARAMETER } \\
\end{array}$ & NOEC & LOEC & $\begin{array}{c}\% \\
\text { DEC }\end{array}$ & REFERENCE \\
\hline Zinc & $\mathrm{ZnCl} 2$ & native soil microflora & clay loam & 8 & 3.2 & 0.1 & Arylsulfatase activity & 163.5 & 1635 & 36 & $\begin{array}{l}\text { Al-Khafaji \& } \\
\text { Tabatabai. } 1979 .\end{array}$ \\
\hline Zinc & $\mathrm{ZnSO4}$ & native soil microflora & loam & 6 & 2.6 & 0.1 & $\begin{array}{l}\text { Acid phosphatase } \\
\text { activity }\end{array}$ & 163.6 & 1635 & 30 & $\begin{array}{l}\text { Juma \& Tabatabai. } \\
1977 .\end{array}$ \\
\hline Zinc & $\mathrm{ZnSO} 4$ & native soil microflora & loam & 7 & 5.5 & 0.1 & $\begin{array}{l}\text { Alkaline phosphatase } \\
\text { activity }\end{array}$ & 163.5 & 1635 & 28 & $\begin{array}{l}\text { Juma \& Tabatabai. } \\
\text { 1977. }\end{array}$ \\
\hline Zinc & $\mathrm{ZnCl} 2$ & native soil microflora & clay & 8 & 1.5 & 42 & Urease activity & & $\begin{array}{r}1780 \\
\text { ED50 }\end{array}$ & 50 & $\begin{array}{l}\text { Doelman \& } \\
\text { Haanstra. } 1986 .\end{array}$ \\
\hline Zinc & $\mathrm{ZnCl} 2$ & native soil microflora & $\begin{array}{l}\text { sandy } \\
\text { loam }\end{array}$ & 6 & 3 & 42 & Arylsulfatase activity & & $\begin{array}{r}2184 \\
\text { ED50 }\end{array}$ & 50 & $\begin{array}{l}\text { Haanstra \& } \\
\text { Doelman. } 1991 .\end{array}$ \\
\hline Zinc & $\mathrm{ZnCl} 2$ & native soil microflora & clay & 8 & 1.5 & 548 & Arylsulfatase activity & & $\begin{array}{r}2838 \\
\text { ED50 }\end{array}$ & 50 & $\begin{array}{l}\text { Haanstra \& } \\
\text { Doelman. } 1991 .\end{array}$ \\
\hline Zine & $\mathrm{ZnCl} 2$ & native soil microflora & clay & 8 & 1.5 & 548 & Phosphatase activity & & $\begin{array}{r}2845 \\
\text { ED50 }\end{array}$ & 50 & $\begin{array}{l}\text { Doelman \& } \\
\text { Haanstra. } 1989 .\end{array}$ \\
\hline Zinc & $\mathrm{ZnCl} 2$ & native soil microflora & silty loam & 8 & 1 & 42 & Phosphatase activity & & $\begin{array}{r}2963 \\
\text { ED50 }\end{array}$ & 50 & $\begin{array}{l}\text { Doelman \& } \\
\text { Haanstra. } 1989 .\end{array}$ \\
\hline Zinc & $\mathrm{ZnCl} 2$ & native soil microflora & $\begin{array}{l}\text { sandy } \\
\text { loam }\end{array}$ & 6 & 3 & 548 & Phosphatase activity & & $\begin{array}{r}2969 \\
\text { ED50 }\end{array}$ & 50 & $\begin{array}{l}\text { Doelman \& } \\
\text { Haanstra. } 1989 .\end{array}$ \\
\hline Zinc & $\mathrm{ZnCl} 2$ & native soil microflora & $\begin{array}{l}\text { sandy } \\
\text { loam }\end{array}$ & 6 & 3 & 42 & Phosphatase activity & & $\begin{array}{r}3342 \\
\text { ED50 }\end{array}$ & 50 & $\begin{array}{l}\text { Doelman \& } \\
\text { Haanstra. } 1989 .\end{array}$ \\
\hline Zinc & $\mathrm{ZnCl} 2$ & native soil microflora & $\begin{array}{l}\text { soil/litter } \\
\text { microcosm }\end{array}$ & & & & Respiration & & $\begin{array}{l}3600 \\
\text { LCT }\end{array}$ & 66 & $\begin{array}{l}\text { Lighthart et al. } \\
1977 .\end{array}$ \\
\hline Zinc & $\mathrm{ZnCl} 2$ & native soil microflora & clay & 8 & 1.5 & 42 & Phosphatase activity & & $\begin{array}{r}3623 \\
\text { ED50 }\end{array}$ & 50 & $\begin{array}{l}\text { Doelman \& } \\
\text { Haanstra. } 1989 .\end{array}$ \\
\hline
\end{tabular}


Table B.1 (continued)

\begin{tabular}{|c|c|c|c|c|c|c|c|c|c|c|c|}
\hline CHEMICAL & $\begin{array}{c}\text { CHEMICAL } \\
\text { FORM } \\
\end{array}$ & ORGANISMS & $\begin{array}{l}\text { GROWTH } \\
\text { MEDIUM }\end{array}$ & $\mathrm{pH}$ & $\% \mathrm{OC}$ & $\begin{array}{l}\text { EXP } \\
\text { (D) }\end{array}$ & $\begin{array}{c}\text { RESPONSE } \\
\text { PARAMETER } \\
\end{array}$ & NOEC & LOEC & $\begin{array}{c}\% \\
\text { DEC }\end{array}$ & REFERENCE \\
\hline Zinc & $\mathrm{ZnCl} 2$ & native soil microflora & silty loam & 8 & 1 & 548 & Arylsulfatase activity & & $\begin{array}{r}4349 \\
\text { ED50 }\end{array}$ & 50 & $\begin{array}{l}\text { Haanstra \& } \\
\text { Doelman. } 1991 .\end{array}$ \\
\hline Zinc & $\mathrm{ZnCl} 2$ & native soil microflora & silty loam & 8 & 1 & 548 & Phosphatase activity & & $\begin{array}{r}4872 \\
\text { ED50 }\end{array}$ & 50 & $\begin{array}{l}\text { Doelman \& } \\
\text { Haanstra. } 1989 .\end{array}$ \\
\hline Zinc & $\mathrm{ZnCl} 2$ & native soil microflora & clay & 8 & 1.5 & 42 & Arylsulfatase activity & & $\begin{array}{r}5559 \\
\text { ED50 }\end{array}$ & 50 & $\begin{array}{l}\text { Haanstra \& } \\
\text { Doelman. } 1991 .\end{array}$ \\
\hline Zinc & $\mathrm{ZnCl2}$ & native soil microflora & sandy peat & 4 & 6.5 & 548 & Arylsulfatase activity & & $\begin{array}{r}9679 \\
\text { ED50 }\end{array}$ & 50 & $\begin{array}{l}\text { Haanstra \& } \\
\text { Doelman. } 1991 .\end{array}$ \\
\hline \multicolumn{2}{|l|}{ acrylonitrile } & native soil microflora & silt loam & 5 & 1.5 & 4 & Respiration & & $\begin{array}{l}1000 \\
\text { LCT }\end{array}$ & 41 & Walton et al. 1989. \\
\hline acrylonitrile & & native soil microflora & $\begin{array}{l}\text { sandy } \\
\text { loam }\end{array}$ & 5 & 0.7 & 4 & Respiration & & $\begin{array}{l}1000 \\
\text { LCT }\end{array}$ & 59 & Walton et al. 1989. \\
\hline \multicolumn{2}{|c|}{ carbon tetrachloride } & native soil microflora & $\begin{array}{l}\text { sandy } \\
\text { loam }\end{array}$ & 5 & 0.7 & 4 & Respiration & & $\begin{array}{l}1000 \\
\text { LCT }\end{array}$ & 21 & Walton et al. 1989. \\
\hline \multicolumn{2}{|c|}{$\begin{array}{l}\text { cis-1,4-dichloro- } \\
\text { 2-butene }\end{array}$} & native soil microflora & silt loam & 5 & 1.5 & 4 & Respiration & & $\begin{array}{l}1000 \\
\text { LCT }\end{array}$ & 44 & Walton et al. 1989. \\
\hline \multicolumn{2}{|c|}{$\begin{array}{l}\text { cis-1,4-dichloro- } \\
\text { 2-butene }\end{array}$} & native soil microflora & $\begin{array}{l}\text { sandy } \\
\text { loam }\end{array}$ & 5 & 0.7 & 4 & Respiration & & $\begin{array}{l}1000 \\
\text { LCT }\end{array}$ & 48 & Walton et al. 1989. \\
\hline
\end{tabular}


Table B.1 (continued)

\begin{tabular}{|c|c|c|c|c|c|c|c|c|c|c|c|}
\hline CHEMICAL & $\begin{array}{c}\text { CHEMICAL } \\
\text { FORM }\end{array}$ & ORGANISMS & $\begin{array}{l}\text { GROWTH } \\
\text { MEDIUM }\end{array}$ & $\mathrm{pH}$ & $\% 0 \mathrm{C}$ & $\begin{array}{l}\text { EXP } \\
(D) \\
\end{array}$ & $\begin{array}{c}\text { RESPONSE } \\
\text { PARAMETER }\end{array}$ & NOEC & LOEC & $\begin{array}{c}\% \\
\text { DEC }\end{array}$ & REFERENCE \\
\hline hexachlorobenze & & native soil microflora & silt loam & 5 & 1.5 & 4 & Respiration & & $\begin{array}{l}1000 \\
\text { LCT }\end{array}$ & 37 & Walton et al. 1989. \\
\hline nitrobenzene & & native soil microflora & silt loam & 5 & 1.5 & 4 & Respiration & & $\begin{array}{l}1000 \\
\text { LCT }\end{array}$ & 22 & Walton et al. 1989. \\
\hline nitrobenzene & & native soil microflora & $\begin{array}{l}\text { sandy } \\
\text { loam }\end{array}$ & 5 & 0.7 & 4 & Respiration & & $\begin{array}{l}1000 \\
\text { LCT }\end{array}$ & 61 & Walton et al. 1989. \\
\hline pentachlorophen & & native soil microflora & $\begin{array}{l}\text { surface } \\
\text { soil }\end{array}$ & 5 & 5.2 & 1.8 & Respiration & & $\begin{array}{r}460 \\
\text { EC50 }\end{array}$ & 50 & $\begin{array}{l}\text { vanBeelen\&Fleurin- } \\
\text { Kemila.1993 }\end{array}$ \\
\hline pentachlorophen & & native soil microflora & dune sand & 4 & 0.6 & 3 & Respiration & & $\begin{array}{r}800 \\
\text { EC50 }\end{array}$ & 50 & $\begin{array}{l}\text { vanBeelen\&Fleurin- } \\
\text { Kemila.1993. }\end{array}$ \\
\hline pentachlorophen & & native soil microflora & polder soil & 8 & 0.6 & & Respiration & & $\begin{array}{r}57 \\
\text { EC50 }\end{array}$ & 50 & $\begin{array}{l}\text { vanBeelen } \\
\text { et al.1994. }\end{array}$ \\
\hline pentachlorophen & & native soil microflora & $\begin{array}{l}\text { surface } \\
\text { soil }\end{array}$ & 4 & 2.6 & & Respiration & & $\begin{array}{r}1207 \\
\text { EC50 }\end{array}$ & 50 & $\begin{array}{l}\text { vanBeelen } \\
\text { et al.1994. }\end{array}$ \\
\hline phenol & & native soil microflora & silt loam & 5 & & & Nitrification & & 100 & $>20$ & $\begin{array}{l}\text { Suter and Sharples. } \\
1984 .\end{array}$ \\
\hline $\begin{array}{l}\text { trans-1,4-dichlor } \\
\text { 2-butene }\end{array}$ & & native soil microflora & silt loam & 5 & 1.5 & 4 & Respiration & & $\begin{array}{l}1000 \\
\text { LCT }\end{array}$ & 58 & Walton et al. 1989. \\
\hline
\end{tabular}


Table B.1 (continued)

\begin{tabular}{|c|c|c|c|c|c|c|c|c|c|c|c|}
\hline CHEMICAL & $\begin{array}{c}\text { CHEMICAL } \\
\text { FORM }\end{array}$ & ORGANISMS & $\begin{array}{l}\text { GROWTH } \\
\text { MEDIUM } \\
\end{array}$ & $\mathrm{pH}$ & $\% O C$ & $\begin{array}{l}\text { EXP } \\
\text { (D) }\end{array}$ & $\begin{array}{c}\text { RESPONSE } \\
\text { PARAMETER } \\
\end{array}$ & NOEC & LOEC & $\begin{array}{c}\% \\
\text { DEC }\end{array}$ & REFERENCE \\
\hline $\begin{array}{l}\text { trans-1,4-dichlo } \\
\text { 2-butene }\end{array}$ & & native soil microflora & $\begin{array}{l}\text { sandy } \\
\text { loam }\end{array}$ & 5 & 0.7 & 4 & Respiration & & $\begin{array}{l}1000 \\
\text { LCT }\end{array}$ & 44 & Walton et al. 1989. \\
\hline
\end{tabular}




\section{Appendix C}

\section{TOXICITY DATA FOR OTHER SOIL AND}

LITTER INVERTEBRATES 
Chemical concentrations are $\mathrm{mg}$ of element $/ \mathrm{kg}$ of food or substrate

EXP (D) - exposure duration in days

LCT - lowest concentration tested

LC50 - concentration causing $50 \%$ mortality

\% DEC - \% decrease in measured parameter at LOEC as compared to controls.

\begin{tabular}{|c|c|c|c|c|c|c|c|c|c|}
\hline CHEMICAL & FORM & SPECIES & FOOD & $\begin{array}{l}\text { EXP } \\
\text { (D) }\end{array}$ & RESPONSE & $\begin{array}{c}\text { NOEC } \\
\text { APPLIED } \\
\end{array}$ & $\begin{array}{c}\text { LOEC } \\
\text { APPLIED } \\
\end{array}$ & $\%$ DEC & REFERENCE \\
\hline Cadmium & $\mathrm{CdCl} 2$ & Diplogasteritus spp. & solution & 3 & survival LC50 & & 3.3 & 50 & Kammenga et al. 1994. \\
\hline Cadmium & $\mathrm{CdCl} 2$ & Caenorhabditis elegans & solution & 7 & reproduction & 1.1 & 3.6 & 36 & van Kessel et al. 1989. \\
\hline Cadmium & $\mathrm{CdCl} 2$ & Cephalobus persegnis & solution & 3 & survival LC50 & & 9.3 & 50 & Kammenga et al. 1994. \\
\hline Cadmium & $\mathrm{CdCl} 2$ & Rhabditis species & solution & 3 & survival LC50 & & 14.1 & 50 & Kammenga et al. 1994. \\
\hline Cadmium & $\mathrm{CdCl} 2$ & Caenorhabditis elegans & solution & 3 & survival LC50 & & 14.7 & 50 & Kammenga et al. 1994. \\
\hline Cadmium & $\mathrm{CdCl} 2$ & Acrobeloides buetschlii & solution & 3 & survival LC50 & & 59.3 & 50 & Kammenga et al. 1994. \\
\hline Cadmium & CdNO3 & Porcellio scaber-juv. & maple leaves & 360 & number of offspring & & 10LCT & 47 & $\begin{array}{l}\text { Hopkin and Hames. } \\
1994 .\end{array}$ \\
\hline Cadmium & $\mathrm{CdSO} 4$ & Orchesella cincta & green algae & 61 & $\begin{array}{l}\text { population growth } \\
\text { rate }\end{array}$ & 4.7 & 15 & 56 & $\begin{array}{l}\text { van Straalen et al. } \\
1989 .\end{array}$ \\
\hline Cadmium & $\mathrm{CdCl} 2$ & Folsomia candida & Baker's yeast & 42 & number of offspring & 148 & 326 & 21 & $\begin{array}{l}\text { Crommentuijn et al. } \\
1993 .\end{array}$ \\
\hline Cadmium & $\mathrm{CdSO} 4$ & Platynothrus peltifer & green algae & 61 & $\begin{array}{l}\text { population growth } \\
\text { rate }\end{array}$ & 3 & 9 & 23 & $\begin{array}{l}\text { van Straalen et al. } \\
1989 .\end{array}$ \\
\hline
\end{tabular}


Table C.1 (continued)

\begin{tabular}{|c|c|c|c|c|c|c|c|c|c|}
\hline CHEMICAL & FORM & SPECIES & FOOD & $\begin{array}{l}\text { EXP } \\
(D) \\
\end{array}$ & RESPONSE & $\begin{array}{c}\text { NOEC } \\
\text { APPLIED } \\
\end{array}$ & $\begin{array}{c}\text { LOEC } \\
\text { APPLIED } \\
\end{array}$ & $\% \mathrm{DEC}$ & REFERENCE \\
\hline Cadmium & $\mathrm{CdCl} 2$ & Helix aspersa & Lab Chow & 30 & reproductive behavior & 10 & 25 & 28 & Russell et al. 1981. \\
\hline Copper & $\mathrm{CuSO} 4$ & $\begin{array}{l}\text { nema-omnivore/ } \\
\text { predator }\end{array}$ & soil OM & 7 & survival & & 72 LCT & 85 & Parmalee et al. 1993. \\
\hline Copper & $\mathrm{CuCl} 2$ & Caenorhabditis elegans & solution & 1 & survival LC50 & & 105 & 50 & $\begin{array}{l}\text { Donkin and Dusenbery. } \\
1993 .\end{array}$ \\
\hline Copper & CuSO4 & nematode-fungivores & soil OM & 7 & survival & 185 & 400 & 65 & Parmalee et al. 1993. \\
\hline Copper & $\mathrm{CuSO} 4$ & nematode-bacterivores & soil OM & 7 & survival & 185 & 400 & 80 & Parmalee et al. 1993. \\
\hline Copper & $\mathrm{CuSO} 4$ & nematode-herbivores & soil $\mathrm{OM}$ & 7 & survival & 185 & 400 & 57 & Parmalee et al. 1993. \\
\hline Copper & $\mathrm{CuSO} 4$ & nematode-hatchlings & soil OM & 7 & survival & 185 & 400 & 75 & Parmalee et al. 1993. \\
\hline Copper & $\mathrm{CuCl} 2$ & Caenorhabditis elegans & soil $O M$ & 1 & survival LC50 & & 413 & 50 & $\begin{array}{l}\text { Donkin and Dusenbery. } \\
1993 .\end{array}$ \\
\hline Copper & $\mathrm{CuCl} 2$ & Caenorhabditis elegans & soil OM & 1 & survival LC50 & & 534 & 50 & $\begin{array}{l}\text { Donkin and Dusenbery. } \\
1993 .\end{array}$ \\
\hline Copper & $\mathrm{CuCl} 2$ & Caenorhabditis elegans & soil OM & 1 & survival LC50 & & 629 & 50 & $\begin{array}{l}\text { Donkin and Dusenbery. } \\
1993 .\end{array}$ \\
\hline Copper & $\mathrm{CuCl} 2$ & Caenorhabditis elegans & soil OM & 1 & survival LC50 & & 1061 & 50 & $\begin{array}{l}\text { Donkin and Dusenbery. } \\
1993 .\end{array}$ \\
\hline Copper & CuNO3 & Porcellio scaber-juv. & maple leaves & 360 & number of offspring & 20 & 50 & 53 & $\begin{array}{l}\text { Hopkin and Hames. } \\
1994 .\end{array}$ \\
\hline
\end{tabular}


Table C.1 (continued)

\begin{tabular}{|c|c|c|c|c|c|c|c|c|c|}
\hline CHEMICAL & FORM & SPECIES & FOOD & $\begin{array}{l}\operatorname{EXP} \\
\text { (D) }\end{array}$ & RESPONSE & $\begin{array}{c}\text { NOEC } \\
\text { APPLIED } \\
\end{array}$ & $\begin{array}{c}\text { LOEC } \\
\text { APPLIED } \\
\end{array}$ & $\% \mathrm{DEC}$ & REFERENCE \\
\hline Copper & CuSO4 & Mesostigmata & soil OM & 7 & survival & & 72 LCT & & Parmalee et al. 1993. \\
\hline Copper & $\mathrm{CuSO} 4$ & Oribatida & soil OM & 7 & survival & & 72 LCT & 48 & Parmalee et al. 1993. \\
\hline Copper & CuSO4 & Prostigmata & soil OM & 7 & survival & 185 & 400 & 37 & Parmalee et al. 1993. \\
\hline Copper & CuSO4 & other microarthropods & soil OM & 7 & survival & 185 & 400 & 60 & Parmalee et al. 1993. \\
\hline Copper & $\mathrm{CuSO} 4$ & Arion ater & fruit \& veg & 27 & percent growth & 300 & 1000 & 55 & Marigomez et al. 1986. \\
\hline Iron & $\mathrm{FeSO} 4$ & Orchesella cincta & green algae & 21 & percent growth & 3515 & 7533 & 42 & Nottrot et al. 1987. \\
\hline Lead & $\mathrm{PbO}$ & Porcellio scaber & $01+02$ litter & 448 & $\begin{array}{l}\text { gen } 1 \text { survival \& } \\
\text { repro; gen } 2 \text { survival }\end{array}$ & 6400 & 12800 & 27,6884 & $\begin{array}{l}\text { Beyer and Anderson. } \\
1985 .\end{array}$ \\
\hline Lead & $\mathrm{PbNO} 3$ & Porcellio scaber-juv. & maple leaves & 360 & $\begin{array}{l}\text { survival; } \\
\text { number of offspring }\end{array}$ & 1000 & 2000 & $\begin{array}{l}100 \\
100\end{array}$ & $\begin{array}{l}\text { Hopkin and Hames. } \\
1994 .\end{array}$ \\
\hline Lead & & Onychiurus armatus & fungus & 125 & growth rate & & 3089 LCT & 25 & Bengtsson et al. 1983. \\
\hline Lead & $\mathrm{PbNO} 3$ & Arion ater & fruit \& veg & 27 & percent growth & 300 & 1000 & 51 & Marigomez et al. 1986. \\
\hline Mercury & $\mathrm{HgCl} 2$ & Arion ater & fruit \& veg & 27 & percent growth & 300 & 1000 & 26 & Marigomez et al. 1986. \\
\hline
\end{tabular}


Table C.1 (continued)

\begin{tabular}{|c|c|c|c|c|c|c|c|c|c|}
\hline CHEMICAL & FORM & SPECIES & FOOD & $\begin{array}{l}\text { EXP } \\
\text { (D) }\end{array}$ & RESPONSE & $\begin{array}{c}\text { NOEC } \\
\text { APPLIED } \\
\end{array}$ & $\begin{array}{r}\text { LOEC } \\
\text { APPLIED } \\
\end{array}$ & $\% \mathrm{DEC}$ & REFERENCE \\
\hline Zinc & $\mathrm{ZnNO} 3$ & Porcellio scaber-juv. & maple leaves & 360 & survival; & 500 & 1000 & 100 & $\begin{array}{l}\text { Hopkin and Hames. } \\
1994 .\end{array}$ \\
\hline Zinc & $\mathrm{ZnO}$ & Porcellio scaber & $01+02$ litter & 448 & $\begin{array}{l}\text { gen } 2 \text { population size; } \\
\text { generation } 2 \text { survival }\end{array}$ & 800 & 1600 & 22,27 & $\begin{array}{l}\text { Beyer and Anderson. } \\
1985 .\end{array}$ \\
\hline Zinc & $\mathrm{ZnO}$ & Porcellio scaber & 02 litter & 56 & survival & & $5000 \mathrm{LCT}$ & 26 & Beyer et al. 1984. \\
\hline Zinc & $\mathrm{ZnCl2}$ & Arion ater & fruit \& veg & 27 & percent growth & & $10 \mathrm{LCT}$ & 38 & Marigomez et al. 1986. \\
\hline benzo[a]pyrene & & Porcellio scaber & leaf\&dog food & 63 & change in dry weight & 31.6 & 100 & 30 & $\begin{array}{l}\text { vanBrummelen } \\
\text { \&Stuijfzand.1993 }\end{array}$ \\
\hline benzo[a]pyrene & & Porcellio scaber & poplar leaves & 28 & \% growth efficiency & 25 & 125 & 82 & $\begin{array}{l}\text { van Straalen and } \\
\text { Verweij. } 1991\end{array}$ \\
\hline benzo[a]pyrene & & Oniscus asellus & leaf\&dog food & 63 & $\begin{array}{l}\text { change in dry weight } \\
\text { and length }\end{array}$ & 100 & 316 & 58,48 & $\begin{array}{l}\text { vanBrummelen } \\
\text { \&Stuijfzand. } 1993\end{array}$ \\
\hline p-nitrophenol & & nematode-bacterivores & soil OM & 7 & survival & & $20 \mathrm{LCT}$ & 40 & Parmalee et al. 1993. \\
\hline p-nitrophenol & & nematode-fungivores & soil OM & 7 & survival & 20 & 40 & 55 & Parmalee et al. 1993. \\
\hline p-nitrophenol & & nematode-herbivores & soil OM & 7 & survival & 20 & 40 & 51 & Parmalee et al. 1993. \\
\hline p-nitrophenol & & $\begin{array}{l}\text { nema-omnivore/ } \\
\text { predator }\end{array}$ & soil OM & 7 & survival & 20 & 40 & & Parmalee et al. 1993. \\
\hline
\end{tabular}


Table C.1 (continued)

\begin{tabular}{|c|c|c|c|c|c|c|c|c|c|}
\hline CHEMICAL & FORM & SPECIES & FOOD & $\begin{array}{l}\text { EXP } \\
\text { (D) }\end{array}$ & RESPONSE & $\begin{array}{c}\text { NOEC } \\
\text { APPLIED } \\
\end{array}$ & $\begin{array}{c}\text { LOEC } \\
\text { APPLIED } \\
\end{array}$ & $\% \mathrm{DEC}$ & REFERENCE \\
\hline p-nitrophenol & & nematode-hatchlings & soil OM & 7 & survival & 20 & 40 & 61 & Parmalee et al. 1993. \\
\hline p-nitrophenol & & nematode-total & soil OM & 7 & survival & 20 & 40 & 56 & Parmalee et al. 1993. \\
\hline p-nitrophenol & & Prostigmata & soil $\mathrm{OM}$ & 7 & survival & 40 & 80 & 24 & Parmalee et al. 1993. \\
\hline p-nitrophenol & & Oribatida & soil OM & 7 & survival & 80 & 160 & 26 & Parmalee et al. 1993. \\
\hline p-nitrophenol & & total microarthropods & soil OM & 7 & survival & 80 & 160 & 35 & Parmalee et al. 1993. \\
\hline pentachlorophenol & & Tylenchus elegans & solution & 3 & survival LC50 & & 1.2 & 50 & Kammenga et al. 1994. \\
\hline pentachlorophenol & & Rhabditis species & solution & 3 & survival LC50 & & 2.4 & 50 & Kammenga et al. 1994. ? \\
\hline pentachlorophenol & & Cephalobus persegnis & solution & 3 & survival LC50 & & 2.6 & 50 & Kammenga et al. 1994. \\
\hline pentachlorophenol & & Diplogasteritus spp. & solution & 3 & survival LC50 & & 6.8 & 50 & Kammenga et al. 1994. \\
\hline trinitrotoluene & & Prostigmata & soil OM & 7 & survival & 100 & 200 & 71 & Parmalee et al. 1993. \\
\hline trinitrotoluene & & Oribatida & soil OM & 7 & survival & 100 & 200 & 58 & Parmalee et al. 1993. \\
\hline trinitrotoluene & & total & soil OM & 7 & survival & 100 & 200 & 58 & Parmalee et al. 1993. \\
\hline
\end{tabular}


C-8 


\section{DISTRIBUTION}

1. T. L. Ashwood

2. L. V. Asplund

3. R. R. Bonczek

4. M.Clauberg

5. J. R. Duncan

6. R. A. Efroymson

7. K. M. Golden

8. P. S. Hovatter

9. J. Jagoe

10. D. S. Jones

11-21. S. B. Kerr

22. J. M. Loar

23. D. M. Matteo

24. C. W. McGinn

25. G. Melendez

26. D. B. Miller

27. J. H. Moyer

28. B. D. Nourse

29. F. R. O’Donnell
30. D. M. Opresko

31-32. P. T. Owen

33. S. T. Purucker

34. A. S. Quist

35. B. E. Sample

36. J. A. Sokol

37. D. M. Steinhauff

38-40. G. W. Suter

41. S. S. Talmage

42. M. F. Tardiff

43. C. C. Travis

44. C. J. E. Welsh

45. D. C. White

46. R. K. White

47-49. M. E. Will

50. Central Research Library

51. ER Document Management Center

52. A. Temeshy, Bechtel National Inc., 151 Lafayette Dr., Oak Ridge, Tennessee 37831-0350

53. M. Leslie, CDM Federal Programs Corporation, 800 Oak Ridge Turnpike, Suite 500, Oak Ridge, Tennessee 37830

54. K. Hopper, EASI, 105 Broadway Ave., Oak Ridge, Tennessee, 37830

55. D. Gonzales, Jacobs Engineering, 125 Broadway, Oak Ridge, Tennessee 37830

56. G. Snyder, Jacobs, Engineering, 100 West 3rd St., Piketon, Ohio 45611

57. J. Tate, Jacobs, Engineering, 125 Broadway, Oak Ridge, Tennessee 37830

58. D. Wilkes, Jacobs, Engineering, 175 Freedom Blvd., Kevil, Kentucky 42053

59. P. Carter, Science Applications International Corporation, 655 Metro Place South, Suite 74S, Dublin, Ohio 43017

60. B. Kornaby, Science Applications International Corporation, P.O. Box 2501, 301, Laboratory Rd., Oak Ridge, Tennessee 37831

61. S. Pack, Science Applications International Corporation, P.O. Box 2501, 301, Laboratory Rd., Oak Ridge, Tennessee 37831

62. F. Zafran, Science Applications International Corporation, P.O. Box 1303, McLean, Virginia 22102-1303

63. B. G. Blaylock, SENES, 102 Donner Drive, Oak Ridge, TN 37831

64. G. W. Bodenstein, DOE Oak Ridge Operations Office, P.O. Box 2001, Oak Ridge, TN 378318541

65. T. W. Joseph, DOE Oak Ridge Operations Office, P.O. Box 2001, Oak Ridge, TN 37831-8541

66. T. C. Perry, DOE Oak Ridge Operations Office, P.O. Box 2001, Oak Ridge, TN 37831-8541

67-68. R. C. Sleeman, DOE Oak Ridge Operations Office, P.O. Box 2001, Oak Ridge, TN 37831-8541 

:

. • 
Please do not forward or discard this document.

If this address is not correct for the designated addressee, please return this document to the

ER Central Document Management Center Building K-1002, MS 7243

Martin Marietta Energy Systems, Inc. P.O. Box 2003

Oak Ridge, TN 37831 